\title{
THE CASSINI ION AND NEUTRAL MASS SPECTROMETER (INMS) INVESTIGATION
}

\author{
J. H. WAITE ${ }^{1, *}$, JR., W. S. LEWIS ${ }^{2}$, W. T. KASPRZAK ${ }^{3}$, V. G. ANICICH ${ }^{4}$, \\ B. P. BLOCK ${ }^{1}$, T. E. CRAVENS ${ }^{5}$, G. G. FLETCHER ${ }^{1}$, W.-H. IP ${ }^{6}$, J. G. LUHMANN ${ }^{7}$, \\ R. L. MCNUTT ${ }^{8}$, H. B. NIEMANN ${ }^{3}$, J. K. PAREJKO ${ }^{1}$, J. E. RICHARDS ${ }^{3}$, \\ R. L. THORPE ${ }^{2}$, E. M. WALTER ${ }^{1}$ and R. V. YELLE ${ }^{9}$ \\ ${ }^{1}$ University of Michigan, Ann Arbor, MI, U.S.A. \\ ${ }^{2}$ Southwest Research Institute, San Antonio, TX, U.S.A. \\ ${ }^{3}$ NASA Goddard Space Flight Center, Greenbelt, MD, U.S.A. \\ ${ }^{4}$ NASA Jet Propulsion Laboratory, Pasadena, CA, U.S.A. \\ ${ }^{5}$ University of Kansas, Lawrence, KS, U.S.A. \\ ${ }^{6}$ National Central University, Chung-Li, Taiwan \\ ${ }^{7}$ University of California, Berkeley, CA, U.S.A. \\ ${ }^{8}$ Johns Hopkins University Applied Physics Laboratory, Laurel, MD, U.S.A. \\ ${ }^{9}$ University of Arizona, Flagstaff, AZ, U.S.A. \\ (*Author for correspondence, E-mail: hunterw@umich.edu)
}

(Received 13 August 1998; Accepted in final form 17 February 2004)

\begin{abstract}
The Cassini Ion and Neutral Mass Spectrometer (INMS) investigation will determine the mass composition and number densities of neutral species and low-energy ions in key regions of the Saturn system. The primary focus of the INMS investigation is on the composition and structure of Titan's upper atmosphere and its interaction with Saturn's magnetospheric plasma. Of particular interest is the high-altitude region, between 900 and $1000 \mathrm{~km}$, where the methane and nitrogen photochemistry is initiated that leads to the creation of complex hydrocarbons and nitriles that may eventually precipitate onto the moon's surface to form hydrocarbon-nitrile lakes or oceans. The investigation is also focused on the neutral and plasma environments of Saturn's ring system and icy moons and on the identification of positive ions and neutral species in Saturn's inner magnetosphere. Measurement of material sputtered from the satellites and the rings by magnetospheric charged particle and micrometeorite bombardment is expected to provide information about the formation of the giant neutral cloud of water molecules and water products that surrounds Saturn out to a distance of $\sim 12$ planetary radii and about the genesis and evolution of the rings.

The INMS instrument consists of a closed ion source and an open ion source, various focusing lenses, an electrostatic quadrupole switching lens, a radio frequency quadrupole mass analyzer, two secondary electron multiplier detectors, and the associated supporting electronics and power supply systems. The INMS will be operated in three different modes: a closed source neutral mode, for the measurement of non-reactive neutrals such as $\mathrm{N}_{2}$ and $\mathrm{CH}_{4}$; an open source neutral mode, for reactive neutrals such as atomic nitrogen; and an open source ion mode, for positive ions with energies less than $100 \mathrm{eV}$. Instrument sensitivity is greatest in the first mode, because the ram pressure of the inflowing gas can be used to enhance the density of the sampled non-reactive neutrals in the closed source antechamber. In this mode, neutral species with concentrations on the order of $\geq 10^{4} \mathrm{~cm}^{-3}$ will be detected (compared with $\geq 10^{5} \mathrm{~cm}^{-3}$ in the open source neutral mode). For ions the detection threshold is on the order of $10^{-2} \mathrm{~cm}^{-3}$ at Titan relative velocity $\left(6 \mathrm{~km} \mathrm{sec}^{-1}\right)$. The INMS instrument has a mass range of 1-99 Daltons and a mass resolution $M / \Delta M$ of 100 at $10 \%$ of the mass peak height, which will allow detection of heavier hydrocarbon species and of possible cyclic hydrocarbons such as $\mathrm{C}_{6} \mathrm{H}_{6}$.
\end{abstract}

Space Science Reviews 114: 113-231, 2004.

(C) 2004 Kluwer Academic Publishers. Printed in the Netherlands. 
The INMS instrument was built by a team of engineers and scientists working at NASA's Goddard Space Flight Center (Planetary Atmospheres Laboratory) and the University of Michigan (Space Physics Research Laboratory). INMS development and fabrication were directed by Dr. Hasso B. Niemann (Goddard Space Flight Center). The instrument is operated by a Science Team, which is also responsible for data analysis and distribution. The INMS Science Team is led by Dr. J. Hunter Waite, Jr. (University of Michigan).

Keywords: Cassini, Titan, Saturn, Huygens, Mass Spectrometry

\section{Introduction and Scientific Background}

The Cassini spacecraft will enter Saturn orbit in July 2004. During Cassini's 4-year exploration of the Saturn system, the INMS instrument will acquire data needed to address two major scientific objectives: (1) characterize the composition, structure, and chemical behavior of Titan's upper atmosphere and its interaction with the plasma of Saturn's magnetosphere and (2) investigate the neutral and plasma environments of the rings and icy satellites and their interactions with the magnetosphere. Key mission events for the INMS investigation include Saturn Orbit Insertion (SOI), during which the spacecraft will pass at low altitude over the ring system and cross the ring plane, providing a unique opportunity for in-situ measurement of the ring environment; over 40 planned close encounters with Titan; and close flybys of the icy satellites Enceladus, Dione, and Rhea. The primary measurement objective during the icy satellite encounters will be the detection of neutral species that have been sputtered from the satellite surfaces by charged particle bombardment. Measurement of this material will provide information about the surface composition of the satellites and about the formation of the neutral water/water product cloud surrounding Saturn. Of the Titan flybys, the sixth, nearly 9 months after SOI, will be particularly important, as it will occur just 3 months after the descent of the Huygens Probe through Titan's nitrogen-methane atmosphere. INMS data acquired near 950-km altitude during this time (Flyby T5: April 16, 2005) will provide detailed composition data on the upper atmosphere, which can be compared with Probe data on the lower atmospheric composition.

\subsection{The INMS Titan Investigation}

During the Orbiter's Titan encounters, the INMS instrument will gather data on the composition, density, and temperature of Titan's upper neutral atmosphere and on the composition and density of the ionosphere. These data, together with complementary neutral atmosphere data from the Orbiter Radio Science Subsystem (RSS), UV Imaging Spectrograph (UVIS), Visible and Infrared Mapping Spectrometer (VIMS), and Composite Infrared Spectrometer (CIRS) experiments and the Probe atmospheric experiments and ionospheric data from the Cassini Plasma 
Spectrometer (CAPS), the Radio Plasma Wave Spectrometer (RPWS), and the RSS investigations, will be used (1) to characterize Titan's neutral atmosphere and ionosphere, with particular emphasis on the chemistry that initiates the formation of complex hydrocarbon and nitrile compounds present in the aerosol haze layers and perhaps in liquid and solid form on the surface; and (2) to study the interaction of Titan's upper atmosphere/ionosphere with Saturn's magnetosphere and, occasionally, the solar wind. In the following, we will review the science background for the INMS Titan investigation and outline the measurements that the INMS instrument will make to address the investigation's science objectives. Before turning to this discussion, however, we would like to note that the INMS measurements have operational as well as scientific importance. INMS data on neutral atmosphere densities acquired during the Orbiter's first pass (at a conservative altitude of 1200 $\mathrm{km}$ ) will be used to assess possible atmospheric drag effects on the spacecraft and will be factored into planning Orbiter trajectories for subsequent Titan encounters. It is hoped that the analysis of the density measurements made during the first Titan encounter will indicate that the sixth Titan flyby can take place at a lower altitude, $\sim 950 \mathrm{~km}$, allowing for measurement deeper in the atmosphere at a time when the atmosphere will not have undergone significant changes since the Probe data were taken. This would provide a valuable basis for correlative studies, based on INMS and Probe data, of the upper and lower regions of Titan's atmosphere and of the processes coupling them.

\subsubsection{Titan's Neutral Upper Atmosphere}

Our present knowledge of Titan's neutral atmosphere rests wholly on remotesensing (infrared imaging and radio and ultraviolet occultation) data acquired during the Voyagers 1 and 2 Saturn flybys and on observations with various ground-based telescopes, and, since 1997, with the European Space Agency's Infrared Space Observatory (ISO). The INMS instrument will make the first in-situ measurements of Titan's upper atmosphere and, with over 40 planned flybys of the moon, will achieve the extensive seasonal, spatial, and temporal coverage needed to understand the atmosphere's varying response to solar and magnetospheric energy inputs. The INMS data will provide altitude-dependent composition profiles both for the major atmospheric gases $\left(\mathrm{N}_{2}\right.$ and $\left.\mathrm{CH}_{4}\right)$ and for the hydrocarbons and nitriles (e.g., $\mathrm{C}_{2} \mathrm{H}_{2}$, $\mathrm{C}_{2} \mathrm{H}_{6}, \mathrm{HCN}$, etc.) created through methane and nitrogen photochemistry. The nonmethane hydrocarbons significantly influence the energetics and thermal structure of the atmosphere and are sensitive probes of upper atmospheric chemistry. Such profiles will thus be of crucial importance in elucidating the coupled chemistry and dynamics of Titan's upper atmosphere. The INMS will also measure isotope ratios $\left(\mathrm{H} / \mathrm{D}\right.$ and $\left.{ }^{14} \mathrm{~N} /{ }^{15} \mathrm{~N}\right)$ and argon (if present). These data, together with information about atmospheric escape and loss resulting from the upper atmosphere's interaction with Saturn's magnetosphere and other processes, will provide evidence about the formation and evolution of Titan's atmosphere over geologic time. Finally, as presently planned, the INMS will not sample Titan's atmosphere below $950 \mathrm{~km}$; 
however, the information that the INMS can provide-both through direct measurement of neutral densities and through measurement of ion densities from which neutral densities can in some cases be deduced —on Titan's thermosphere will be of direct relevance to questions of aerosol formation, neutral composition and chemistry, atmospheric dynamics, and radiative transfer in the lower atmosphere. INMS measurements in the upper atmosphere will thus provide a valuable and necessary complement to data on the lower atmosphere from the Probe Aerosol Collector and Pyrolysor (ACP), Huygens Atmospheric Structure Instrument (HASI), and Gas Chromatograph/Mass Spectrometer (GC/MS) and the Orbiter UV Imaging Spectrograph (UVIS), Visibile and Infrared Mapping Spectrometer (VIMS), and Composite Infrared Spectrometer (CIRS) investigations.

1.1.1.1. Composition and Photochemistry. Titan has a massive neutral atmosphere, with a surface pressure of $\sim 1.5$ bar. The major neutral constituents are nitrogen, methane, and hydrogen. Nitrogen, with a mixing ratio in the troposphere of $\geq 90 \%$, is the dominant species. Its presence in Titan's atmosphere was proposed by Lewis (1971) and Hunten (1972) on theoretical grounds and was established with the Voyager UVS instrument (Broadfoot et al., 1981), which detected extreme ultraviolet emissions from molecular and atomic nitrogen.

Methane was the first constituent to be identified in Titan's atmosphere; its detection — by Kuiper (1944) — confirmed the suggestion made over three decades earlier by Comas Solá (1908) that Titan had an atmosphere. Based on their analysis of Voyager 1 IRIS data, Samuelson et al. (1997) posit a methane-supersaturated troposphere with a methane mixing near the surface of 0.057 at the equator and of 0.02 at higher latitudes. Courtin et al. (1995) estimate the stratospheric methane mole fraction to lie between 0.026 and 0.045 . In the thermosphere, where the INMS measurements will be made, methane mixing ratios of $0.06 \pm 0.01$ and $0.20 \pm 0.02$ at altitudes of 1000 and $1400 \mathrm{~km}$, respectively, have been inferred from solar EUV occultation measurements made with the Voyager 1 UVS (Strobel et al., 1992). However, recent re-analysis of the Voyager UVS occultation results indicates lower $\mathrm{CH}_{4}$ and higher $\mathrm{N}_{2}$ densities than previously reported (Vervack, 1997; Vervack et al., 1999). The implications of these new and not yet widely disseminated findings for the chemistry and thermal structure of Titan's atmosphere are still being investigated.

The presence of molecular hydrogen in Titan's troposphere, tentatively identified by Trafton (1972) on the basis of ground-based observations, was confirmed by IRIS spectra (Samuelson et al., 1981). The most recent estimate of the tropospheric $\mathrm{H}_{2}$ mole fraction, based on a re-analysis of the IRIS data by Samuelson et al. (1997), is $\sim 0.0011$.

Although it has not been detected, argon is considered to be a possible major constituent of Titan's atmosphere, i.e., present at the few percent level. A wide range of abundances has been proposed. To account for the atmosphere's mean molecular mass of 28.6 Daltons estimated from the Voyager radio occultation and 
IRIS data, Samuelson et al. (1981) invoked the presence of argon and estimated its mole fraction at the surface to be $11.6 \%$. Based on Voyager UVS data, Broadfoot et al. (1981) estimated an upper limit of $6 \%$ for the argon mixing ratio in the thermosphere; extrapolation from this value yields a mixing ratio at Titan's surface of $30 \%$ for ${ }^{36} \mathrm{Ar}$ (Hunten et al., 1984). Lellouch et al. (1989) consider a mole fraction of $21 \%$ to be the upper limit on argon abundance at the surface. Calculations by Strobel et al. (1993), based on the Voyager UVS solar occultation data, indicate that a value of $\leq 10 \%$ represents a reasonable upper limit on the argon mixing ratio at the tropopause; and recent re-analyses of IRIS data by Courtin et al. (1995) and Samuelson et al. (1997) yield argon mole fractions in the troposphere of $<0.06$ and $0.026 \pm 0.045$, respectively. The measurement of argon is important because of its relevance to the question of the origin and evolution of Titan's atmosphere. A large argon-to-nitrogen ratio (0.01-0.1) would support the hypothesis (Owen, 1982; Strobel and Shemansky, 1982) that the $\mathrm{N}_{2}$ component of Titan's atmosphere was derived from clathrates, and was thus present from the beginning, rather than the product - accumulated over geologic time - of $\mathrm{NH}_{3}$ photodissociation (Courtin et al., 1995, and references therein).

The Voyager IRIS data confirmed the presence of several non-methane hydrocarbons $\left(\mathrm{C}_{2} \mathrm{H}_{6}, \mathrm{C}_{2} \mathrm{H}_{2}\right.$, and $\left.\mathrm{C}_{2} \mathrm{H}_{4}\right)$ that had been detected earlier with ground-based observations and revealed the presence of other hydrocarbons not previously detected $\left(\mathrm{C}_{3} \mathrm{H}_{4}\right.$ and $\left.\mathrm{C}_{3} \mathrm{H}_{8}\right)$, along with presence of the nitriles $\mathrm{HCN}, \mathrm{HC}_{3} \mathrm{~N}$, and $\mathrm{C}_{2} \mathrm{~N}_{2}$ (Hanel et al., 1981; Maguire et al., 1981; Kunde et al., 1981). (Recent estimates of the abundances of these and other species are given in Table I.) Limited information about non-methane hydrocarbons in Titan's upper atmosphere was also provided by the Voyager UVS solar occultation data, which revealed a sharp increase in the $\mathrm{C}_{2} \mathrm{H}_{2} / \mathrm{N}_{2}$ mixing ratio in the altitude range $725-825 \mathrm{~km}$ above Titan's surface from $0.1-0.3 \%$ below $725 \mathrm{~km}$ to $1-2 \%$ above $825 \mathrm{~km}$ (Smith et al., 1982); however, as in the case of $\mathrm{CH}_{4}$, the re-analysis of these data by Vervack (1997) and Vervack et al. (1999) has yielded lower $\mathrm{C}_{2} \mathrm{H}_{2}$ densities than those retrieved by Smith et al. The UVS occultation data also indicated the possible presence of a polymer layer between 675 and $1025 \mathrm{~km}$ at both the evening and morning terminators.

The oxygen-bearing compounds $\mathrm{CO}_{2}$ (Samuelson et al., 1983), $\mathrm{CO}$ (Lutz et al., 1983), and-most recently- $\mathrm{H}_{2} \mathrm{O}$ (Coustenis et al., 1998) have also been detected in Titan's atmosphere. The principal source of oxygen in Titan's atmosphere is believed to be water vapor released by sublimation from infalling icy meteoroids (Samuelson et al., 1983; Yung et al., 1984). Photolysis of the water vapor thus introduced yields $\mathrm{H}$, which is lost from the atmosphere, and the hydroxyl radical. $\mathrm{OH}$ reacts with the methyl radical $\mathrm{CH}_{3}$ (from the photodissocation of methane) to produce $\mathrm{CO}$ and molecular hydrogen. Some of the $\mathrm{CO}$ then reacts with $\mathrm{OH}$ to form $\mathrm{CO}_{2}$ and $\mathrm{H}$. Based on the data acquired with the ISO Short Wavelength Spectrometer, Coustenis et al. (1998) estimate the mole fraction of water vapor at $400 \mathrm{~km}$ to be $\sim 8 \times 10^{-9}$ and the meteoritic water influx at an altitude of $700 \mathrm{~km}$ to be $(0.8-2.8) \times 10^{6} \mathrm{~mol} \mathrm{~cm}^{-2} \mathrm{sec}^{-1}$. 
TABLE I

Abundances of atmospheric constitutents in Titan's atmosphere.

\begin{tabular}{|c|c|c|}
\hline Species & Mole fraction & Reference \\
\hline \multicolumn{3}{|c|}{ Troposphere $(z \leq 40 \mathrm{~km})$} \\
\hline $\mathrm{N}_{2}$ & $0.90-0.99$ & Gautier and Raulin (1997) \\
\hline $\mathrm{CH}_{4}$ & $\sim 0.057$ & Samuelson et al. (1997) \\
\hline $\mathrm{Ar}$ & $0.026 \pm 0.045$ & Samuelson et al. (1997) \\
\hline $\mathrm{H}_{2}$ & $\sim 0.0011$ & Samuelson et al. (1997) \\
\hline \multicolumn{3}{|c|}{ Stratosphere $(z \sim 40-325 \mathrm{~km})$} \\
\hline $\mathrm{CH}_{4}$ & $0.026-0.045$ & Courtin et al. (1995) \\
\hline $\mathrm{CO}$ & $2.9 \times 10^{-5}$ at $60 \mathrm{~km} ; 2.4 \times 10^{-5}$ at $175 \mathrm{~km}$ & Hidayat et al. (1998) \\
\hline $\mathrm{C}_{2} \mathrm{H}_{6}$ & $9.4 \times 10^{-6}$ at $z \sim 120-350 \mathrm{~km}$ & Kostiuk et al. (1997) \\
\hline $\mathrm{C}_{2} \mathrm{H}_{2}$ & $2.2 \times 10^{-6}$ at $130 \mathrm{~km}$ & Coustenis et al. (1989) \\
\hline $\mathrm{C}_{3} \mathrm{H}_{8}$ & $7.0 \times 10^{-7}$ & Coustenis et al. (1989) \\
\hline $\mathrm{HCN}$ & $\begin{array}{l}3.5 \times 10^{-7} \text { at } z \geq 200 \mathrm{~km} \text {, decreasing } \\
\text { below } 200 \mathrm{~km} \text { to } \sim 10^{-8} \text { at the } \\
\text { condensation level }(\sim 80 \mathrm{~km})\end{array}$ & Hidayat et al. (1997) \\
\hline $\mathrm{C}_{2} \mathrm{H}_{4}$ & $9.0 \times 10^{-8}$ at $125 \mathrm{~km}$ & Coustenis et al. (1989) \\
\hline $\mathrm{CO}_{2}$ & $1.4 \times 10^{-8}$ at $110 \mathrm{~km}$ & Coustenis et al. (1989) \\
\hline $\mathrm{C}_{3} \mathrm{H}_{4}$ & $4.4 \times 10^{-9}$ at $105 \mathrm{~km}$ & Coustenis et al. (1989) \\
\hline $\mathrm{C}_{4} \mathrm{H}_{2}$ & $1.4 \times 10^{-9}$ at $110 \mathrm{~km}$ & Coustenis et al. (1989) \\
\hline $\mathrm{HC}_{3} \mathrm{~N}$ & $\leq 1.5 \times 10^{-9}$ at $105 \mathrm{~km}$ & Coustenis et al. (1989) \\
\hline $\mathrm{C}_{2} \mathrm{~N}_{2}$ & $\leq 1.5 \times 10^{-9}$ at $105 \mathrm{~km}$ & Coustenis et al. (1989) \\
\hline \multicolumn{3}{|c|}{ Mesosphere $(z \sim 325-600 \mathrm{~km})$} \\
\hline $\mathrm{CO}$ & $4.8 \times 10^{-6}$ at $350 \mathrm{~km}$ & Hidayat et al. (1998) \\
\hline $\mathrm{H}_{2} \mathrm{O}$ & $8 \times 10^{-9}$ at $400 \mathrm{~km}$ & Coustenis et al. (1998) \\
\hline \multicolumn{3}{|c|}{ Thermosphere $(z \sim 600 \mathrm{~km})$} \\
\hline $\mathrm{CH}_{4}$ & $0.06 \pm 0.01$ at $1000 \mathrm{~km} ; 0.20 \pm 0.02$ at $1400 \mathrm{~km}$ & Strobel et al. (1992) \\
\hline $\mathrm{C}_{2} \mathrm{H}_{2}$ & $0.001-003$ at $\geq 725 \mathrm{~km} ; 0.01-0.02$ at $\geq 825 \mathrm{~km}$ & Smith et al. (1982) \\
\hline
\end{tabular}

Note: Except for argon, which has not been detected but is postulated to be present, the values listed above are observation-derived estimates of the abundances of species that have been identified in Titan's atmosphere. For details of the models used to derive specific abundances from the data, and for uncertainties and differences from values reported in earlier studies, the reader should consult the references cited. The altitude ranges for the different atmospheric layers are based on the thermal structure model of Yelle et al. (1997). The mixing ratios given by Smith et al. (1982) for acetylene in the thermosphere are based on the $\mathrm{N}_{2}$ density rather than the total atmospheric density. This table is a modified and updated version of Table I of Toublanc et al. (1995).

The interpretation of Voyager IRIS data has yielded some limited information about variations with latitude and altitude in the distribution of certain atmospheric constituents. Coustenis et al. (1991) find that the abundances of the hydrocarbons $\mathrm{C}_{2} \mathrm{H}_{2}, \mathrm{C}_{4} \mathrm{H}_{2}$, and $\mathrm{C}_{3} \mathrm{H}_{4}$ and of the nitriles $\mathrm{HC}_{3} \mathrm{~N}$ and $\mathrm{C}_{2} \mathrm{~N}_{2}$ (and to a lesser degree of 
$\mathrm{HCN}$ ) are greater in Titan's north polar stratosphere than at the equator. (Coustenis et al., speculate that the cold temperature of the polar stratosphere, compared to that of the equatorial stratosphere, may be attributable to increased IR cooling resulting from the enhanced hydrocarbon abundance.) No significant latitudinal differences were seen in the mixing ratios of the three most abundant hydrocarbons (ethane, acetylene, and propane), while the abundance of $\mathrm{CO}_{2}$ was a factor of two lower at the pole than at the equator. The reason for these variations is not known but may have to do with seasonal and latitudinal variability in the solar ultraviolet flux at Titan and with differences in the photodissociation rates of the various species. Analysis of the north polar data (vertical distribution information cannot be derived from the equatorial data) also reveals an increase in the mixing ratio with altitude for the nitriles and some of the hydrocarbons. As Coustenis et al., point out, the positive gradient in mole fraction with increasing altitude is explicable in terms of the photochemical production of these species in Titan's thermosphere.

The non-methane hydrocarbons and nitriles identified in the stratosphere by Voyager are created by complex photochemical reactions occurring among the products of $\mathrm{CH}_{4}$ and $\mathrm{N}_{2}$ dissociation (Strobel and Shemansky, 1982; Yung et al., 1984; Yung, 1987; Toublanc et al., 1995; Lara et al., 1996; Wilson, 2002). In Titan's thermosphere and mesosphere, $\mathrm{CH}_{4}$ is photolyzed directly by solar extreme ultraviolet photons. The principal products of direct methane photolysis at high altitudes are $\mathrm{C}_{2} \mathrm{H}_{2}$ (the most abundant non-methane hydrocarbon in Titan's atmosphere) and $\mathrm{C}_{2} \mathrm{H}_{4}$. In the stratosphere, where the bulk of the $\mathrm{CH}_{4}$ destruction takes place, $\mathrm{CH}_{4}$ dissociation occurs catalytically, in conjunction with the photodissociation of acetylene (transported downward from its production region in the upper atmosphere); the main products of methane photochemistry in the stratosphere are ethane and propane. The hydrogen produced by methane dissociation and in other reactions escapes from Titan's atmosphere to space and contributes to a cloud of neutral molecular and atomic hydrogen that extends from $\sim 25 \mathrm{R}_{\mathrm{S}}$ inward to the top of Saturn's atmosphere (Shemansky and Hall, 1992). (Hydrogen escape makes possible the irreversible destruction of methane and its conversion to heavier hydrocarbons.) The principal loss process for the hydrocarbons produced by methane photolysis is condensation at the tropopause and precipitation onto Titan's surface, possibly resulting in the formation, over the age of the solar system, of a hydrocarbon ocean (Lunine et al., 1983; Lunine, 1993, 1994).

$\mathrm{N}_{2}$ is dissociated in Titan's upper atmosphere both photolytically, by EUV photons $(\lambda<80 \mathrm{~nm})$, and by the impact of energetic electrons from Saturn's magnetosphere. (Prior to the re-analysis by Strobel et al. $(1991,1992)$ of Titan's EUV airglow emissions, electron impact was held to be the dominant mechanism for nitrogen dissociation. Recent calculations (Toublanc et al., 1995, Table II and associated discussion) indicate that the dissociation rate for EUV photolysis is about five times that for electron impact). Nitrogen is also dissociated, in the stratosphere, by cosmic ray absorption (Capone et al., 1983; Lara et al., 1996). Nitrogen atoms produced by the dissociation of $\mathrm{N}_{2}$ react with methyl and methylene radicals 
produced by methane photolysis to form the most abundant nitrile, hydrogen cyanide (Yung et al., 1984; Yung, 1987). HCN then participates in photochemical reactions that, together with reactions between dissociated nitrogen atoms and acetylene, lead to the formation of the nitriles $\mathrm{HC}_{3} \mathrm{~N}, \mathrm{C}_{2} \mathrm{~N}_{2}, \mathrm{C}_{4} \mathrm{~N}_{2}$, and $\mathrm{CH}_{3} \mathrm{CN}$. Like the non-methane hydrocarbons, the nitriles are lost through condensation at the tropopause.

In addition to the creation of the lighter hydrocarbons, $\mathrm{CH}_{4}$ and $\mathrm{N}_{2}$ photochemistry is expected to lead to the synthesis, at altitudes above $500 \mathrm{~km}$, of heavier, more complex molecules that may play an important role in aerosol formation. For example, polyacetylenes $\left(\mathrm{C}_{2 \mathrm{n}} \mathrm{H}_{2}\right)$, created through insertion reactions involving ethynyl $\left(\mathrm{C}_{2} \mathrm{H}\right)$ and butadiynyl $\left(\mathrm{C}_{4} \mathrm{H}\right)$ radicals (from the photolysis of $\mathrm{C}_{2} \mathrm{H}_{2}$ and $\mathrm{C}_{4} \mathrm{H}_{2}$, respectively), have been proposed as one source of the aerosols that constitute Titan's detached haze layer, which lies above the main layer at altitudes between 350 and $400 \mathrm{~km}$ (Chassefière and Cabane, 1995). Chassefière and Cabane also suggest that $\mathrm{C}-\mathrm{N}$ oligomers synthesized from dicyanoacetylene $\left(\mathrm{C}_{4} \mathrm{~N}_{2}\right)$ may be an additional source of aerosols for the detached haze layer comparable in importance to the polyacetylenes. Production of both $\mathrm{C}_{2 \mathrm{n}} \mathrm{H}_{2}$ and $\mathrm{C}-\mathrm{N}$ oligomers occurs at altitudes of $\sim 500-800 \mathrm{~km}$.

A further contribution to the detached haze layer may come from $\mathrm{C}-\mathrm{H}-\mathrm{N}$ polymers created at higher altitudes $(900-1000 \mathrm{~km})$ by energetic electron bombardment of Titan's upper atmosphere. According to Chassefière and Cabane's two-layer haze model, however, $\mathrm{C}-\mathrm{H}-\mathrm{N}$ polymers are primarily important for the formation of the main haze layer. This layer is distinct from the detached layer in terms of its composition, formation region, and formation mechanism and consists predominantly of aerosols created from $\mathrm{C}-\mathrm{H}-\mathrm{N}$ polymers produced by energetic-particle-initiated chemistry at altitudes between 350 and $400 \mathrm{~km}$. (Such C-H-N polymers are conventionally termed "tholins" following the usage of the researchers at Cornell who have synthesized them in the laboratory under conditions approximating those at Titan and consider them likely to be a significant source for Titan's haze (e.g., Thompson et al., 1994, and references therein.)

Photochemical models of Titan's neutral atmosphere have been developed by Yung et al. (1984), Toublanc et al. (1995), Lara et al. (1996), Wilson (2002), and, as a background atmosphere for their ionosphere model, by Fox and Yelle (1997) (cf. Figure 1). Coupled neutral-charged particle models have also been recently developed by Banaszkiewicz et al. (2000), as an extension of the Lara et al. model, and Wilson (2002). The model by Yung et al. (with updated nitrile chemistry; Yung, 1987) has until recently been the standard model for Titan photochemistry. Neutral abundances calculated with this model were in reasonable agreement with those determined from the early analyses of the data acquired during the Voyager encounters in 1980 and 1981. However, more extensive analysis of the Voyager data by Coustenis et al. (1989) indicated that, with the exception of $\mathrm{CO}_{2}$ and $\mathrm{C}_{2} \mathrm{H}_{4}$, the model predicted concentrations of minor species that were higher than the values observed in Titan's equatorial stratosphere. Coustenis et al. suggested that 
the discrepancy between model-generated and observed values could be reduced by adjustment of the eddy diffusion coefficient or through adoption of a revised rate constant for the reaction $\mathrm{H}+\mathrm{C}_{4} \mathrm{H}_{2}$ that would increase the concentration of atomic hydrogen available to suppress the formation of heavier hydrocarbons. Analysis of IRIS data for Titan's north polar stratosphere likewise showed that the model of Yung et al. overestimated the abundances of most minor species in that region (Coustenis et al., 1991).

The recently published models by Toublanc et al. (1995) and Lara et al. (1996) attempt to achieve better agreement with the Voyager data than is possible with the Yung et al. model. Toublanc et al. incorporate a new scheme in their model for methane photolysis, improved photolysis rates and radiative transfer calculations, and a revised eddy diffusion coefficient constrained to fit an $\mathrm{HCN}$ profile derived from recent ground-based observations. The Wilson (2002) model uses updated rate coefficients, cross sections, and quantum yields, with a radiative transfer scheme used in the study of Jovian atmospheres (Edgington et al., 1998), to obtain chemical abundances in a coupled ion-neutral environment. With this model, a best-fit eddy diffusion profile yields chemical abundances, with the exception of $\mathrm{C}_{2} \mathrm{H}_{4}$, that are underpredicted by no more than a factor of three compared to observational constraints, which may be misinterpreted on the high end at the given altitudes as a result of uniform mole fraction assumptions inherent in the observations, as in the case of $\mathrm{CO}_{2}$ (Coustenis et al., 1989) and $\mathrm{C}_{6} \mathrm{H}_{6}$ (Cousteinis et al., 2002).

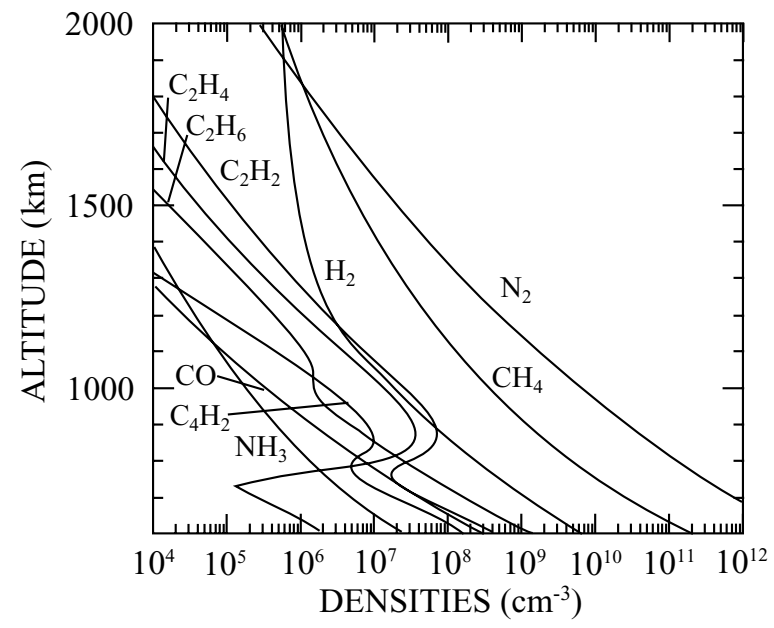

Figure 1. Neutral densities as a function of altitude in Titan's upper atmosphere (from Fox and Yelle, 1997). Hydrocarbon profiles are based on the neutral atmosphere model of Yung et al. (1984); $\mathrm{N}_{2}$ and $\mathrm{CH}_{4}$ profiles are from Strobel et al. (1992). The minimum altitude at which INMS measurements will be made is $950 \mathrm{~km}$. In closed source mode, the INMS will be able to measure neutrals with concentrations $\geq 10^{4} \mathrm{~cm}^{-3}$; in the open source, densities $\geq 10^{5} \mathrm{~cm}^{-3}$ can be measured. 
These models obtained better fits to the observations for some species than were achieved by Yung et al. Numerous differences remain, however, both between observed values and those calculated by each model and between the models themselves. These differences are attributable to insufficient observational data, the lack of accurate rate coefficients for some key reactions, and uncertainty about the eddy diffusion coefficient. Reconciling these differences and obtaining improved agreement with observational constraints is important both for our understanding of Titan's neutral atmosphere and also for the development of model ionospheres (cf. Keller et al., 1998). Thus, evaluation of existing neutral atmosphere models and development of improved models is one of the key tasks undertaken by the INMS Science Team as part of its planning for the neutral atmosphere and ion composition measurements to be made during the Orbiter's Titan flybys. (A preliminary list of target constituents, based on the present state of model development and currently available data, is shown in Table II.)

TABLE II

Expected neutral species in Titan's upper atmosphere.

\begin{tabular}{|c|c|c|}
\hline Molecular weight & Closed source & Open source neutral \\
\hline 2 & $\mathrm{H}_{2}$ & \\
\hline 3 & $\mathrm{HD}$ & \\
\hline 4 & $\mathrm{He}$ & \\
\hline 14 & & $\mathrm{~N}$ \\
\hline 15 & & $\mathrm{NH}$ \\
\hline 16 & $\mathrm{CH}_{4}$ & $\mathrm{CH}_{4}, \mathrm{O}$ \\
\hline 17 & ${ }^{13} \mathrm{CH}_{4}$ & $\mathrm{OH}$ \\
\hline 18 & $\mathrm{H}_{2} \mathrm{O}$ & $\mathrm{H}_{2} \mathrm{O}$ \\
\hline 26 & $\mathrm{C}_{2} \mathrm{H}_{2}$ & \\
\hline 27 & $\mathrm{HCN}$ & $\mathrm{HCN}$ \\
\hline 28 & $\mathrm{~N}_{2}, \mathrm{C}_{2} \mathrm{H}_{4}, \mathrm{CO}$ & $\mathrm{N}_{2}, \mathrm{C}_{2} \mathrm{H}_{4}, \mathrm{CO}$ \\
\hline 29 & ${ }^{15} \mathrm{~N}^{14} \mathrm{~N},{ }^{13} \mathrm{C}_{2} \mathrm{H}_{4}$ & \\
\hline 30 & $\mathrm{C}_{2} \mathrm{H}_{6}$ & \\
\hline 36 & $\left({ }^{36} \mathrm{Ar}\right)$ & \\
\hline 39 & & $\mathrm{CHCN}$ \\
\hline 44 & $\mathrm{CO}_{2}, \mathrm{C}_{3} \mathrm{H}_{8}$ & \\
\hline 50 & & $\mathrm{C}_{3} \mathrm{~N}$ \\
\hline 51 & $\mathrm{CH}_{3} \mathrm{CN}, \mathrm{HC}_{3} \mathrm{~N}$ & \\
\hline 52 & $\mathrm{C}_{2} \mathrm{~N}_{2}$ & \\
\hline 74 & & $\mathrm{C}_{6} \mathrm{H}_{2}$ \\
\hline 76 & $\mathrm{C}_{4} \mathrm{~N}_{2}$ & \\
\hline 78 & $\mathrm{C}_{6} \mathrm{H}_{6}$ & \\
\hline
\end{tabular}


1.1.1.2. Thermal Structure. The temperature of Titan's upper atmosphere between 1265 and $1525 \mathrm{~km}$ above the surface has been inferred from Voyager UVS measurements of $\mathrm{N}_{2}$ density variations to be $186 \pm 20 \mathrm{~K}$ (Smith et al., 1982). Below an altitude of $200 \mathrm{~km}$, the thermal profile can be derived from RSS and IRIS data, while constraints on temperatures in the region between 200 and 450 $\mathrm{km}$ are provided by IRIS measurements and stellar occultation data (cf. Lellouch et al., 1990, and references therein). Analysis of these data and modeling studies reveals an atmospheric structure characterized by negative temperature gradients in the troposphere and mesosphere and positive gradients in the stratosphere and thermosphere. The principal heat source for the stratosphere is the absorption of solar radiation by organic haze particles, while the thermosphere and exosphere are heated by the absorption of solar UV radiation by $\mathrm{CH}_{4}$ and, above $\sim 1000 \mathrm{~km}$, by nitrogen (Lellouch et al., 1990; Yelle, 1991). Magnetospheric electron precipitation is expected to contribute to thermospheric heating as well, but to a lesser and still undetermined degree (cf. Strobel et al., 1991, 1992 on thermospheric energy sources). (The relative contributions of the solar EUV and magnetospheric energy inputs to Titan aeronomy will vary with Titan's orbital position and degree of exposure to the magnetospheric electron flux, which is maximized on the wake side). The thermally active hydrocarbons $\mathrm{CH}_{4}, \mathrm{C}_{2} \mathrm{H}_{2}$, and $\mathrm{C}_{2} \mathrm{H}_{6}$ serve both as heating agents and coolants, their particular role varying with altitude. $\mathrm{HCN}$ has been shown to be an extremely important coolant.

Four models of the vertical structure of Titan's upper atmosphere have been developed to date. Friedson and Yung (1984) made the first attempt to interpret the Voyager UVS measurements of Titan's exospheric temperature by constructing an aeronomical model that included solar EUV and FUV radiation, thermal conduction, and non-LTE cooling by hydrocarbons (principally $\mathrm{C}_{2} \mathrm{H}_{2}$ ) in the mid-IR. Hydrocarbon cooling rates were estimated by assuming that the emissions were optically thin. Friedson and Yung were able to match the Voyager measurements quite well; however, the solar heating rates used in their model were later discovered to be in error (Lellouch et al., 1990). The correct solar heating rates were found to yield a temperature near the exobase of $\sim 300 \mathrm{~K}$, which is in serious disagreement with the observations. Using an aeronomical model similar to Friedson and Yung's, Lellouch et al. succeeded in producing a thermospheric temperature profile with an exospheric temperature consistent with that derived from Voyager UVS data, but only by adopting unreasonably low heating efficiencies $(0.015-0.20)$ and an unreasonably large $\mathrm{C}_{2} \mathrm{H}_{2}$ cooling rate.

The third model of the thermal structure of Titan's upper atmosphere is a sophisticated aeronomical model by Yelle (1991) that includes non-LTE radiative transfer in the mid-IR vibration-rotation bands of $\mathrm{CH}_{4}, \mathrm{C}_{2} \mathrm{H}_{2}$, and $\mathrm{C}_{2} \mathrm{H}_{6}$, a detailed treatment of vibrational chemistry, and, most importantly, cooling by rotational emissions from HCN (Figure 2). Neither HCN nor ethane was included in the models of Friedson and Yung and Lellouch et al. Yelle's model predicts that HCN rotational cooling is sufficient to balance solar UV heating of the thermosphere and 


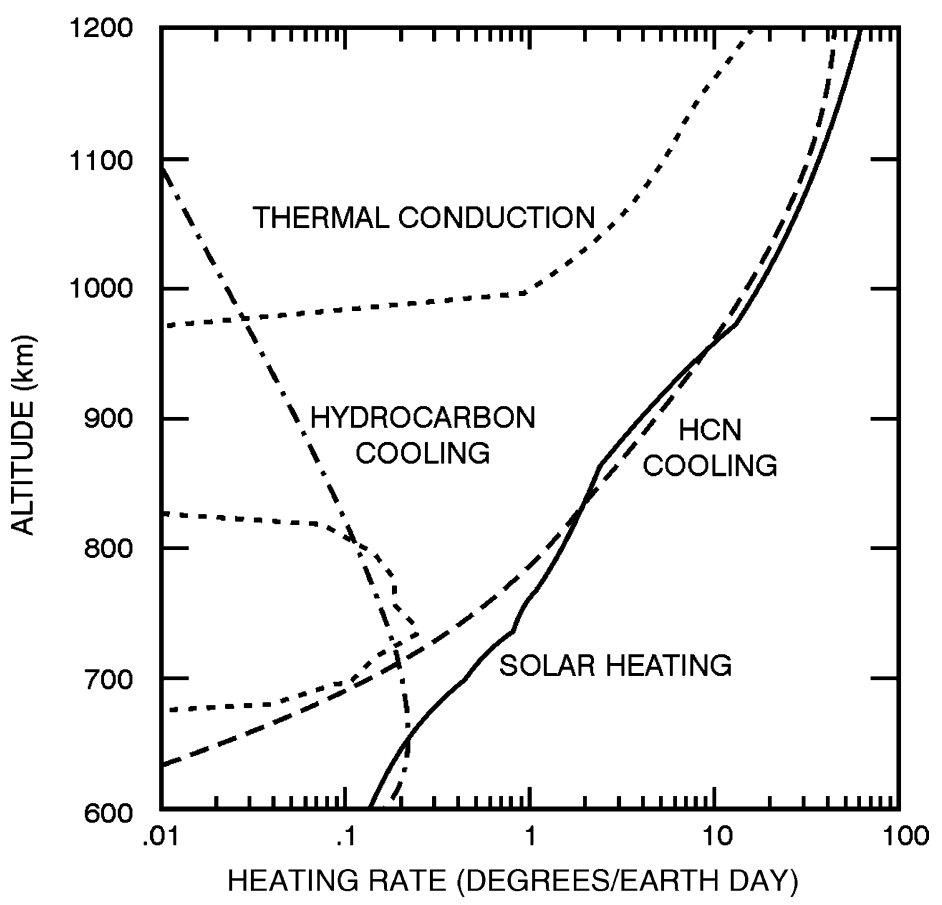

Figure 2. Plot illustrating the contributions of various heating and cooling processes to the thermal structure of Titan's atmosphere (Yelle, 1991).

to maintain the thermospheric temperature near the value derived from the Voyager UVS data $(186 \pm 20 \mathrm{~K})$ and that neither low heating efficiencies nor enhanced $\mathrm{C}_{2} \mathrm{H}_{2}$ cooling rates are required. This result suggests that Titan's thermal structure is radiatively controlled at all levels and distinguishes Titan's atmosphere from most other atmospheres, whose thermospheres are dominated by thermal conduction. The important influence of HCN cooling on Titan's thermospheric structure predicted by the Yelle model can be confirmed and characterized with INMS measurements of $\mathrm{HCN}$ abundance and its variability with time and latitude.

The fourth model is the engineering model developed by Yelle et al. (1997). It is an empirical model based on the Yelle (1991) physical model (Figure 3).

All four of the above models predict a well-developed mesopause. Friedson and Yung (1984) calculated a very cold mesopause temperature of $\sim 110 \mathrm{~K}$ at an altitude of $736 \mathrm{~km}$. As Lellouch et al. (1990) point out, however, if hydrostatic equilibrium is to be maintained, such a low mesopause temperature requires higher stratospheric temperatures than are consistent with the IRIS data. In the model of Lellouch et al., the mesopause occurs at an altitude of $\sim 800 \mathrm{~km}$ and has a temperature of $135 \mathrm{~K}$. Yelle's model predicts a comparable mesopause temperature (135-140 K) but locates the mesopause at an altitude of $\sim 600$ rather than $800 \mathrm{~km}$. The Yelle model indicates that $\mathrm{CH}_{4}$-not acetylene, as assumed by Friedson and Yung and Lellouch et al.--is the primary coolant near the mesopause and, surprisingly, that 


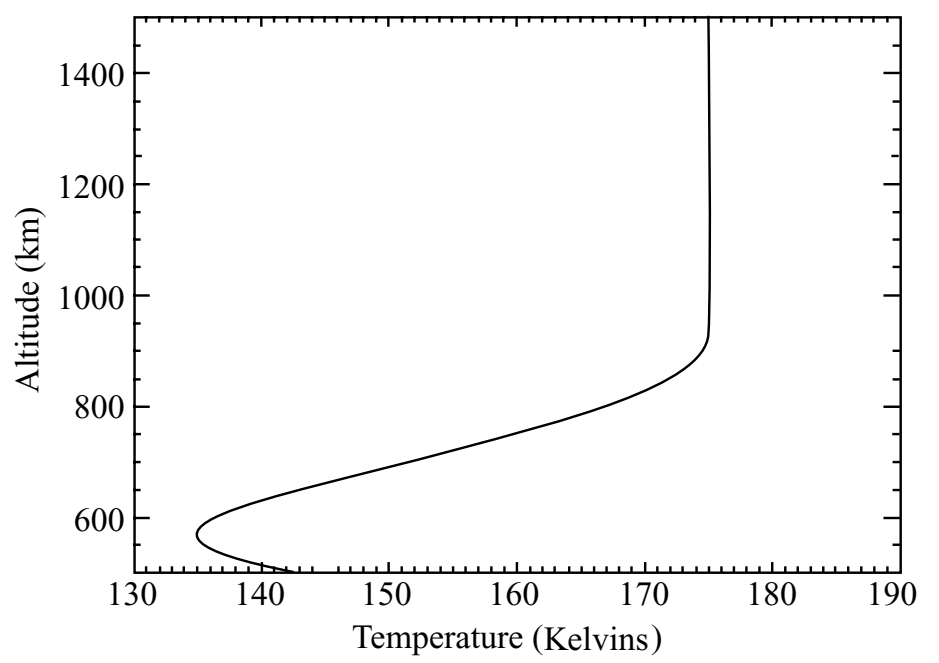

Figure 3. Temperature profile with altitude for Titan's upper atmosphere $(z>500 \mathrm{~km})$, according to the engineering model of Yelle et al. (1997). The mesopause, with a temperature of $\sim 135 \mathrm{~K}$, is located at around $570 \mathrm{~km}$. The model atmosphere above $900 \mathrm{~km}$ is isothermal; in actuality, thermospheric temperature will show both temporal and spatial variations. The engineering model uses a nominal altitude of $1040 \mathrm{~km}$ for the homopause. It should be noted, however, that there is some disagreement among the models, with some models indicating that Titan does not have a homopause. The exobase is located at an altitude of $1400 \mathrm{~km}$.

ethane-not considered by either Friedson and Yung or Lellouch et al.-is the dominant heating agent in this region.

The 1D models described above are useful for identifying important physical processes and representing a global average atmosphere, but Titan's atmosphere is three dimensional and 3D Thermospheric General Circulation Models (TGCMs) are needed to study the full complexity of the upper atmosphere. Such models have been presented by Müller-Wodarg et al. (2000) and Müller-Wodarg and Yelle (2002) while initial estimates on the importance of dynamics have been presented by Rishbeth et al. (2000). The models incorporate heating and cooling processes, dynamical processes, and simplified chemistry. The comprehensive nature of the models makes them ideal for interpretation of INMS measurements of temperature and densities across Titan's globe. They predict variations in latitude and local time that are well within the INMS measurement capability.

Müller-Wodarg et al. (2000) presented the first Titan TGCM and calculated a circulation pattern with upwelling slightly after local noon, horizontal flow from the day to night side, and subsidence at night (see Figure 4). These authors calculated day/night temperature difference of $20 \mathrm{~K}$ and a maximum wind speed of $60 \mathrm{~m} \mathrm{sec}^{-1}$, of the same order as winds in the Earth's thermosphere. Dynamics strongly affect the temperature field, greatly reducing gradients over radiative solutions; however, the predicted temperature differences of $20 \mathrm{~K}$ are easily measured by INMS. On 

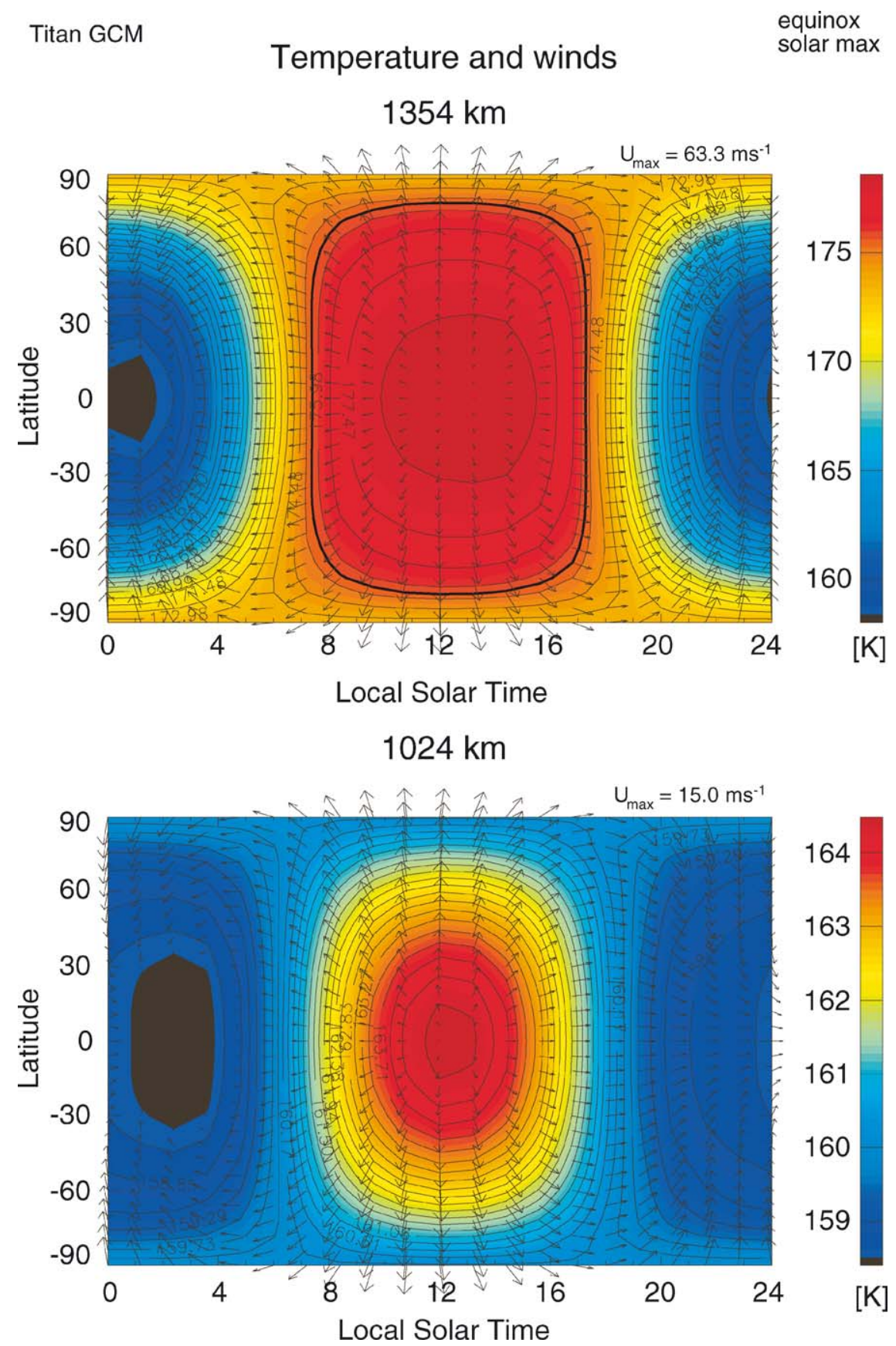

Figure 4. Simulations of temperature and wind fields at two altitudes in Titan's thermosphere. The temperatures and winds are calculated with a 3D thermospheric general circulation model that solves the continuity, momentum, and energy equations, including only solar input. 
Earth, pressure gradient forces are balanced by molecular viscosity and ion drag. On Titan, molecular viscosity is weak because of the low temperature and densities while ion drag is weak because of the weak or absent magnetic field (Rishbeth $e t$ al., 2000). Thus, despite the low solar heating rate, Titan has strong winds which will strongly affect the distribution of molecular constituents in its atmosphere.

Extension of the Titan TGCM to include composition shows that the dynamics in the upper atmosphere cause large changes in the distribution of minor constituents. Müller-Wodarg et al. (2000) show that solar driven dynamics can cause a factor of several change in the $\mathrm{CH}_{4}$ mole fraction with local time. This is caused primarily by the interaction of the wind field with diffusive flows in the upper atmosphere. Similar phenomena have been seen in the upper atmospheres of the Earth and Venus. The calculated $\mathrm{CH}_{4}$ distribution exhibits a maximum in late afternoon over the region of maximum subsidence and a minimum in early morning over the region of maximum upwelling. These variations also alter the heating rates in the upper atmosphere. Horizontal variations are likely for other species as well with species whose mean molecular weight differs substantially from $\mathrm{N}_{2}$ showing the greatest variation. Analysis of horizontal variations of long-lived constituents will provide the best means for diagnosing winds in the upper atmosphere.

Fortunately, because $\mathrm{N}_{2}$ and $\mathrm{CH}_{4}$ are nonreactive gases, the more accurate closed source INMS mode can be used to make the measurements from which the thermal structure will be derived. Closed source measurements have the further advantage of being less dependent than the open source measurements on instrument pointing direction. An exospheric temperature of $175 \mathrm{~K}$ is used for present planning purposes. This value gives an atmospheric scale height of $81 \mathrm{~km}$ near $1000 \mathrm{~km}$. The tangent path of the geometry increases the path length through the atmosphere by a factor of approximately 10 , which, with a spacecraft velocity of $6.1 \pm 0.3 \mathrm{~km} \mathrm{sec}^{-1}$, gives a time of $\sim 150 \mathrm{sec}$ for traversing one scale height near closest approach. Determination of the temperature requires a minimum of five samples over this time interval or, in other words, a sample of major constituent densities every 30 sec. This temporal/spatial resolution can be increased 1000 fold if required.

\subsubsection{Titan's Ionosphere}

The characterization of Titan's ionosphere, and of the interaction of the ionosphere and neutral upper atmosphere with Titan's plasma environment, is a major objective of the INMS investigation and the Cassini mission. To achieve this objective, the INMS instrument will measure ionospheric composition as a function of altitude at various locations on Titan (day side, night side, ram side, wake side). Most of these data will be acquired within Saturn's magnetosphere; however, measurements may also be made when Titan, at times of high solar wind dynamic pressure, lies outside the subsolar magnetopause, in Saturn's magnetosheath or the solar wind. The INMS measurements, along with CAPS/Ion Beam Spectrometer (IBS) ion velocity and temperature measurements and CAPS/Ion Mass Spectrometer composition measurements, will be the first in situ measurements of the ionosphere of an outer 
planetary body. INMS ion composition and density data, together with complementary data from other Orbiter investigations (e.g., CAPS, UVIS, MAG, RSS, RPWS, etc.), will be used to address questions relating to the composition, chemistry, structure, and dynamics of Titan's ionosphere; the interactions between the ionosphere and neutral atmosphere; the relative roles of solar EUV and magnetospheric energy inputs in ion production and in ionospheric energetics and dynamics; and the loss of atmospheric material through hydrodynamic outflow, scavenging by the magnetospheric plasma flow, and the production of fast neutrals through ionospheric photochemistry. Finally, it is possible that the densities of important but difficult-to-measure neutrals—such as $\mathrm{CH}_{3}$ — can be deduced from ion densities measured with the INMS and CAPS, allowing important chemical pathways to be distinguished by which, for example, $\mathrm{HCN}$ and polyacetylenes are formed in the upper atmosphere.

1.1.2.1. Structure and Composition. Observational data on Titan's ionosphere are limited to Voyager 1 radio occultation measurements. No definitive detection of an ionosphere was reported; however, initial analysis of these data placed an upper limit on the peak ionospheric electron density of $3 \times 10^{3} \mathrm{~cm}^{-3}$ near the evening terminator and of $5 \times 10^{3} \mathrm{~cm}^{-3}$ near the morning terminator (Lindal et al., 1983; McNutt and Richardson, 1988). Re-analysis of the Voyager ingress data by Bird et al. (1997) indicates that the Voyager measurements yield a "marginal detection" of an ionosphere with an electron density peak of $2400 \pm 1100 \mathrm{~cm}^{-3}$ at an altitude of $1180 \pm 150 \mathrm{~km}$. These values (for the evening terminator) are consistent with those computed by Keller et al. (1992) for the terminator ionosphere $\left(3030 \mathrm{~cm}^{-3}\right.$ at an altitude of $1175 \mathrm{~km}$ ). On the dayside, with an average solar zenith angle of $60^{\circ}$, the electron density maximum is predicted to be larger and the altitude of the density peak lower. For the dayside case, Keller et al. calculated a density maximum of $6150 \mathrm{~cm}^{-3}$ at $1055 \mathrm{~km}$, which compares well with the $7.5 \times 10^{3} \mathrm{~cm}^{-3}$ at 1040 $\mathrm{km}$ from the recent model by Fox and Yelle (1997).

The composition of Titan's ionosphere is determined by a complex chemistry involving neutrals, ions created by photoionization and electron impact (e.g., $\mathrm{N}_{2}^{+}$, $\mathrm{N}^{+}, \mathrm{CH}_{4}^{+}, \mathrm{CH}_{3}^{+}$, etc.), and ions formed in ion-neutral reactions. Recent modeling studies (by Fox and Yelle, 1997; Keller et al., 1998) indicate that the major ionospheric constituents are $\mathrm{N}_{2}^{+}$, hydrocarbon ions (including higher-mass ions with three or more carbon atoms), and ions containing $\mathrm{H}, \mathrm{C}$, and N. Of the nitrile ions, $\mathrm{HCNH}^{+}$is the most common and is predicted by several ionospheric models to be the dominant ion species near the ionospheric peak $(\sim 1100 \mathrm{~km})$. The dominance of $\mathrm{HCNH}^{+}$is questioned by Fox and Yelle, whose model provides for relatively rapid loss of $\mathrm{HCNH}^{+}$through ion-neutral reactions not included in earlier models and predicts an $\mathrm{HCNH}^{+}$density in the ionospheric peak region several times lower than that previously computed (e.g., Ip, 1990; Keller et al., 1992). Keller et al. (1998) incorporate similar chemistry in an updated version of their 1992 model and calculate a somewhat lower density for $\mathrm{HCNH}^{+}$as well (compared with their 
earlier calculation). However, the inclusion of the new loss channels notwithstanding, $\mathrm{HCNH}^{+}$remains the major ion near the ionospheric peak in their model, with a density three times that estimated by Fox and Yelle. As Keller et al. point out, this disagreement results from differences between the neutral background atmospheres used in the two models.

The discrepancy between the Fox/Yelle and Keller et al. models regarding the density of the important ionospheric species $\mathrm{HCNH}^{+}$illustrates the sensitivity of Titan ionosphere models to assumptions about the neutral atmosphere. Our limited knowledge of the latter is a major source of uncertainty in the former. A further source of uncertainty is the lack of laboratory data on important ion-neutral reactions (see Anicich and McEwan, 1997 for a summary of the relevant laboratory data currently available). Thus new observational data on the structure and composition of Titan's neutral atmosphere, together with new laboratory data on the relevant ion-neutral and neutral-neutral chemistry, are essential for developing more accurate models of the ionosphere. Conversely, new observational data acquired with the INMS instrument on ionospheric composition (e.g., on $\mathrm{HCNH}^{+}$density at the peak) will help constrain models of the neutral atmosphere. As in the case of the neutral atmosphere models discussed in the preceding section, assessment of existing model ionospheres and development of improved models (e.g., through the incorporation of new laboratory data on key ion-neutral reaction rates and pathways) will be an integral part of the planning of INMS operations during the Titan flybys. For initial planning purposes, both the Fox and Yelle model and the updated Keller et al. model will be used. Representative ionospheric density profiles from both models are shown in Figure 5, and a list of the most abundant species expected to be present in Titan's ionosphere is given in Table III.

1.1.2.2. Ionization Mechanisms. Titan's ionosphere is produced by both solar EUV photoionization and electron impact ionization. Magnetospheric electron impact was originally considered to be the dominant ionization mechanism (e.g., Ip, 1990). However, later modeling studies (Keller et al., 1992, 1994; Keller and Cravens, 1994) have demonstrated that solar EUV photons and photoelectrons are in many cases more important than magnetospheric electrons in ion production and that the relative roles of photoionization and magnetospheric electron impact ionization vary according to the degree of insolation and the extent to which magnetospheric electrons have access to Titan's lower ionosphere. The former depends on Titan's orbital position (Figure 6). The latter is thought to be a function of the geometry of the Saturnian field lines that drape around Titan and will be greater on the wake side than on the ram side (Keller and Cravens, 1994), as the radial orientation of the field lines in the wake region allows magnetospheric electrons to reach the lower ionosphere without significant attenuation from extended passage through the neutral atmosphere. Model calculations indicate that the rate of ion production by magnetospheric electron impact can be as much as 100 times greater on the wake side than on the ram side and is comparable to the rate of ion 


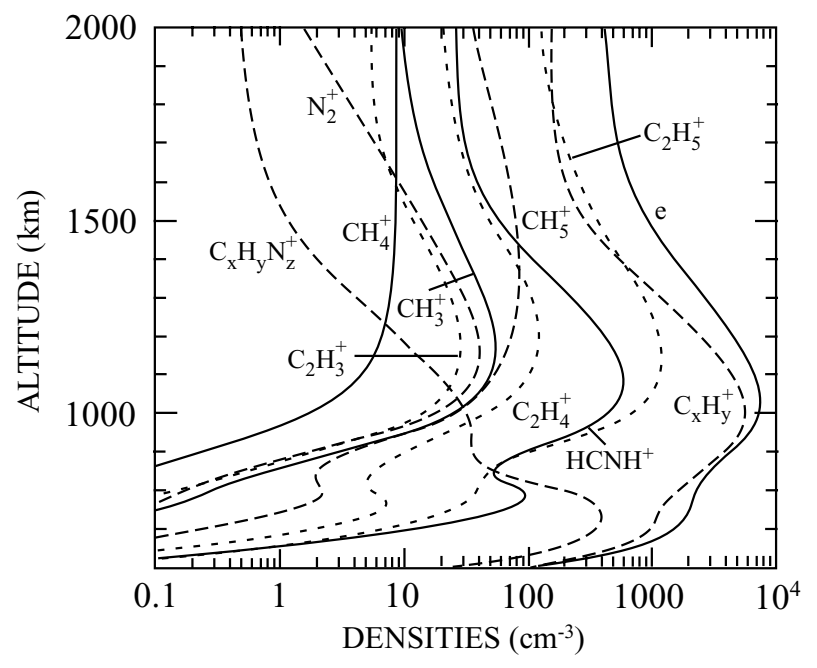

(a)

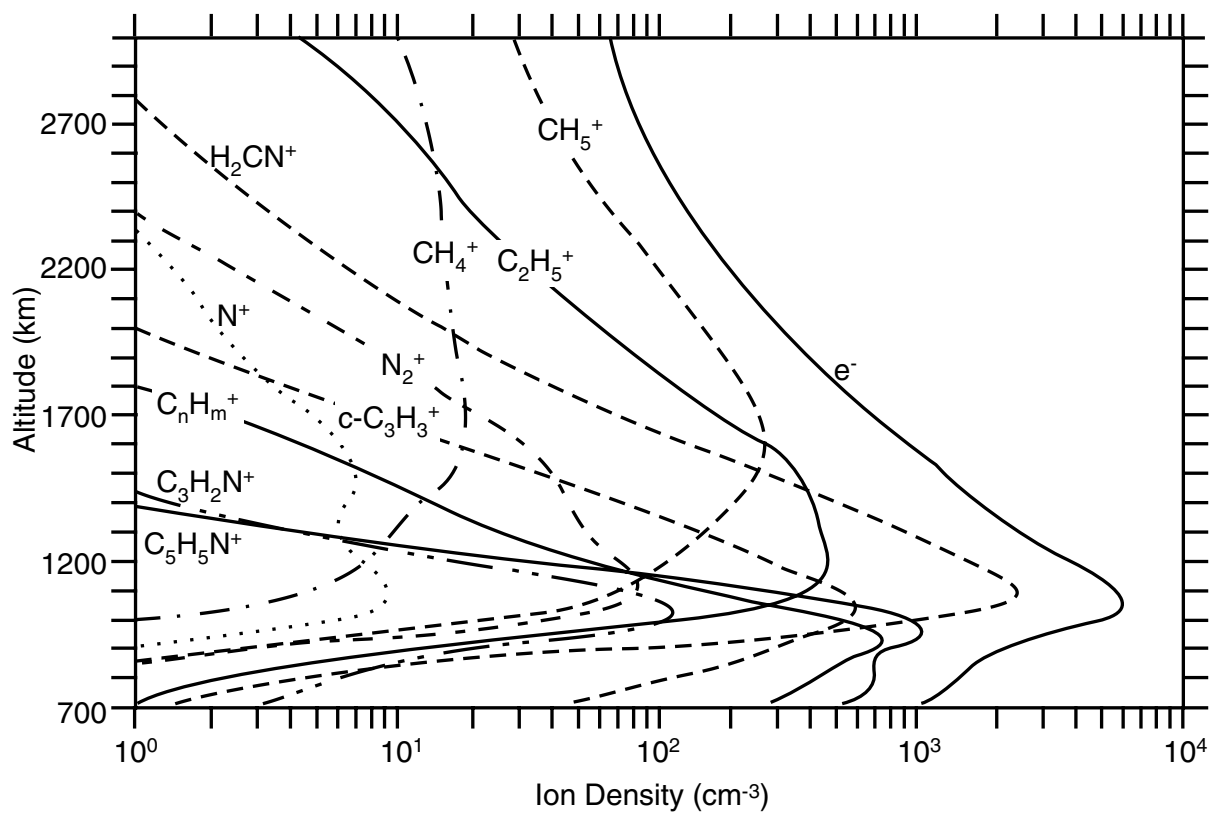

(b)

Figure 5. Density vs. altitude profiles for the major ion species in Titan's ionosphere as calculated with the models of (a) Fox and Yelle (1997) and (b) Keller et al. (1998). Both models use neutral atmospheres based on the model of Yung et al. (1984). (Keller et al. also calculate ion profiles-not shown here-using a more recent neutral atmosphere model developed by Toublanc et al., 1995). Both models predict that heavy hydrocarbons (with three or more carbon atoms) are important ionospheric species. Fox and Yelle obtain a lower value for the $\mathrm{HCNH}^{+}$density near the ionospheric peak than do Keller et al. because the background atmosphere used in their model contains three times less HCN than is contained in the neutral atmosphere used by Keller et al. 
TABLE III

Most abundant ion species in Titan's ionosphere.

\begin{tabular}{lll}
\hline Mass Group & Mass Number & Species \\
\hline Light & 1 & $\mathrm{H}^{+}$ \\
& 2 & $\mathrm{H}_{2}^{+}$ \\
Medium & 3 & $\mathrm{H}_{3}^{+}$ \\
& 14 & $\mathrm{~N}^{+}, \mathrm{CH}_{2}^{+}$ \\
& 15 & $\mathrm{CH}_{3}^{+}, \mathrm{NH}^{+}$ \\
Heavy & 16 & $\mathrm{CH}_{4}^{+}$ \\
& 17 & $\mathbf{C H}_{5}^{+}$ \\
Very heavy & 27 & $\mathrm{C}_{2} \mathrm{H}_{3}^{+}$ \\
& 28 & $\mathrm{~N}_{2}^{+}, \mathrm{C}_{2} \mathrm{H}_{4}^{+}, \mathbf{H C N H}^{+}$ \\
& 29 & $\mathrm{~N}_{2} \mathrm{H}^{+}, \mathbf{C}_{2} \mathbf{H}_{5}^{+}$ \\
& 39 & $c_{3}-\mathrm{C}_{3} \mathrm{H}_{3}^{+}$ \\
& 41 & $\mathrm{C}_{3} \mathrm{H}_{5}^{+}$ \\
& 51 & $\mathrm{C}_{4} \mathrm{H}_{4}^{+}$ \\
52 & $\mathrm{C}_{3} \mathrm{H}_{2} \mathrm{~N}^{+}$ \\
53 & $\mathbf{C}_{4} \mathbf{H}_{5}^{+}$ \\
65 & $\mathbf{C}_{5} \mathbf{H}_{5}^{+}$ \\
67 & $\mathbf{C}_{5} \mathbf{H}_{7}^{+}$ \\
69 & $\mathrm{C}_{5} \mathrm{H}_{9}^{+}$ \\
77 & $\mathrm{C}_{6} \mathrm{H}_{5}^{+}$ \\
79 & $\mathrm{C}_{6} \mathrm{H}_{7}^{+}, \mathbf{C}_{5} \mathbf{H}_{5} \mathbf{N}^{+}$ \\
& 91 & $\mathrm{C}_{7} \mathrm{H}_{7}^{+}$ \\
\hline
\end{tabular}

Note: Bold type identifies the major species. Recent modeling studies by Fox and Yelle (1997) and Keller et al. (1998) indicate that higher mass hydrocarbons are important constituents, accounting for approximately $50 \%$ of the predicted ion density.

production by EUV photoionization on the day side (Gan et al., 1992; Keller et al., 1994; Keller and Cravens, 1994; Cravens et al., 1992). Auger electron spikes in the measured (CAPS) superthermal electron fluxes can help distinguish magnetospheric electrons from solar radiation-produced photoelectrons. Auger electrons will be produced by K-shell ionization from carbon (electron energies near $280 \mathrm{eV}$ ) and nitrogen (electron energies near $400 \mathrm{eV}$ ) (Craven et al., 2004). $\mathrm{C}$ and $\mathrm{N}$ are found in the $\mathrm{CH}_{4}$, and $\mathrm{N}_{2}$ molecules, respectively.

Maximum ionization occurs when the wakeside ionosphere is in sunlight, i.e., when both magnetospheric electrons and solar EUV photons contribute comparably to ion production (Roboz and Nagy, 1994). In the case of the sunlit ramside ionosphere, on the other hand, $80 \%$ of the ionization at the ionospheric peak is due to photoionization. The remaining $20 \%$ results predominantly from photoelectron 


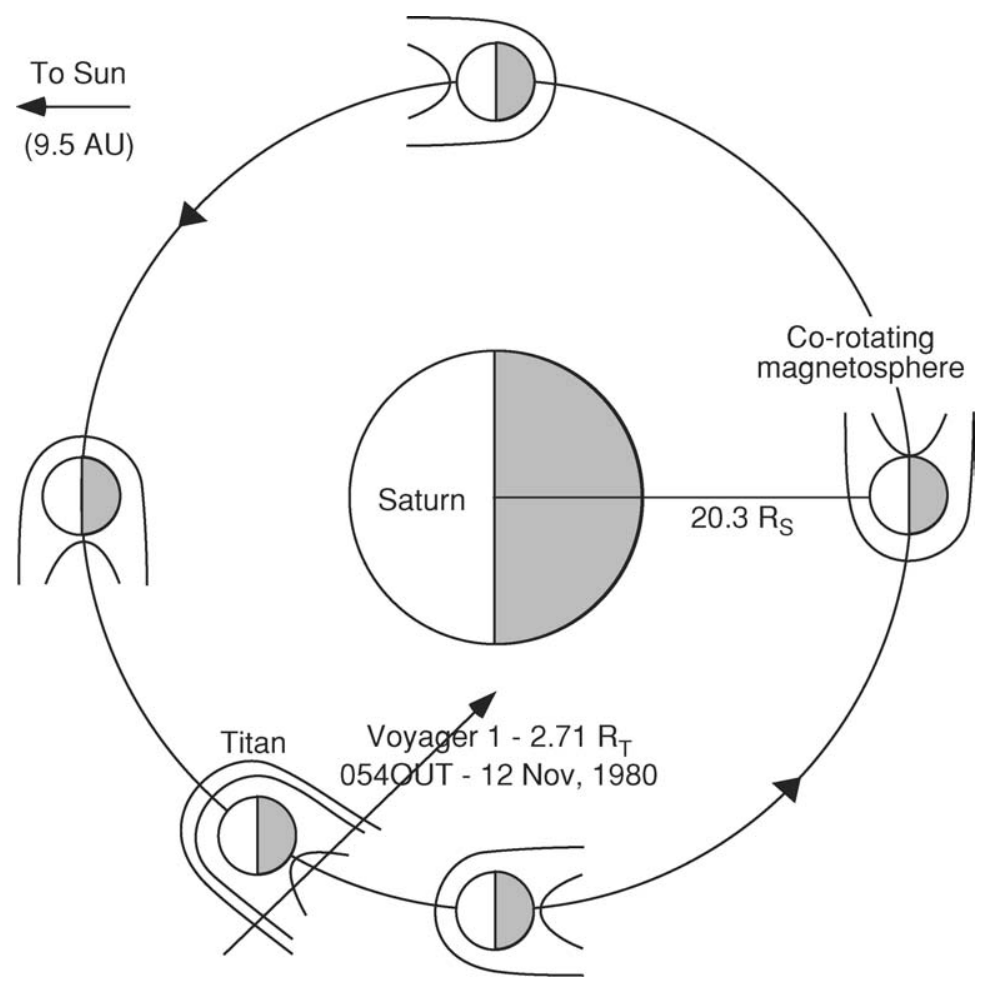

Figure 6. Solar EUV radiation and magnetospheric electron precipitation provide the energy that drives the chemistry and dynamics and determines the structure of Titan's atmosphere. Although solar EUV radiation is thought to be the dominant energy source for heating, ion production, and photochemistry, magnetospheric electrons also play an important role. The relative contributions of the two energy sources to Titan aeronomy will vary according to the intensity of the solar radiation, which is a function of latitude and Titan's orbital phase, and the degree of exposure to magnetospheric electron flux, which studies have shown to be maximized on the wake side (Keller and Cravens, 1994). The sketch above (based on Keller and Cravens, 1994) illustrates the changing geometry of solar zenith angle, ram direction, and orientation of the draped field lines (shown here rotated $90^{\circ}$ out of their actual plane for ease of illustration). Maximum ionization will occur when both solar EUV and magnetospheric electrons contribute to ion production. Magnetospheric electrons will be the sole energy source for Titan's atmosphere when Titan is in Saturn's shadow.

impact, with a small contribution (1\%) from magnetospheric electrons (Keller et al., 1992). When Titan is outside Saturn's magnetosphere (see below), the solar EUV flux is the principal ionization source; the contribution from solar wind electrons is minor. (This case has recently been modeled by Galand et al. (1999), who also consider the case where Titan is in Saturn's shadow and magnetospheric electron impact is the sole ionization source.) Changes in the intensity of the solar EUV flux (with orbital phase) and the magnetospheric electron flux (from ram side to wake 
side) and in their relative contribution to ion production will lead to variations in ionospheric densities, temperatures, and dynamics (Keller et al., 1994; Roboz and Nagy, 1994; Nagy and Cravens, 1998). To adequately characterize this variability it will be necessary to acquire INMS data at a variety of local times, latitudes, and plasma ram angles. Thus INMS measurements during a number of low-altitude Titan passes are required (cf. Section 3.3.4 and Table VII).

1.1.2.3. Titan's Interaction with Its Plasma Environment. Titan's interaction with the surrounding plasma is highly complex, and its details depend on the state of the ionosphere and the plasma environment. As discussed above, the former varies according to changing fluxes of solar EUV photons and magnetospheric electrons incident on Titan's upper atmosphere. The latter, as discussed by Wolf and Neubauer (1982), varies with Saturn local time and solar wind conditions. At its orbital distance of $\sim 20 \mathrm{R}_{\mathrm{S}}$, Titan usually remains within Saturn's outer magnetosphere and thus interacts with the partially co-rotating magnetospheric plasma. However, whenever increased solar wind ram pressure compresses Saturn's magnetosphere, Titan may be located for a portion of its orbit outside the dayside magnetopause. In this case, the interaction is with the magnetosheath or the upstream solar wind. (Under relatively undisturbed interplanetary conditions, the stagnation point is located at a nominal standoff distance of $\sim 23 R_{S}$. When conditions are disturbed, the magnetopause can move inward as far as $\sim 17 \mathrm{R}_{\mathrm{S}}$, as observed during the Pioneer 11 encounter; Schardt et al., 1984.) Even within the magnetosphere, Titan's plasma environment can be expected to vary according to the satellite's location in the magnetosphere. Estimated parameters for four representative plasma environments (solar wind, magnetosheath, outer magnetosphere, magnetotail) are given by Wolf and Neubauer (1982); however, observational data are available only for the case when Titan was located in the dayside outer magnetosphere.

Our picture of Titan's interaction with its surrounding plasma environment (Figure 7) is based on data acquired by Voyager 1 during a single pass downstream of Titan and on theoretical models of the interaction of a flowing magnetized plasma with an unmagnetized body possessing a significant atmosphere/ionosphere. During its traversal of the Saturn magnetosphere in November 1980, Voyager flew within $<3 \mathrm{R}_{\mathrm{T}}$ of Titan. The plasma science (PLS) instrument detected a wake of relatively cool, dense plasma that may have been dominated by mass 28 ions of $\mathrm{N}_{2}^{+} / \mathrm{H}_{2} \mathrm{CN}^{+}$(Hartle et al., 1982). The magnetometer revealed perturbations in the Saturnian magnetic field near Titan that have been interpreted as the signature of draped field lines that form a Venus-like bipolar induced magnetic tail; there was no clear evidence for the presence of an intrinsic magnetic field (Ness et al., 1982; Kivelson and Russell, 1983; Luhmann et al., 1991). The plasma wave (PWS) instrument observed plasma wave emissions apparently associated with the acceleration of pickup ions and the escape down the tail of plasma from Titan's ionosphere (Gurnett et al., 1981, 1982). PLS data also indicated a significant slowing of the magnetospheric plasma flow near the tail as a result of mass loading by the 


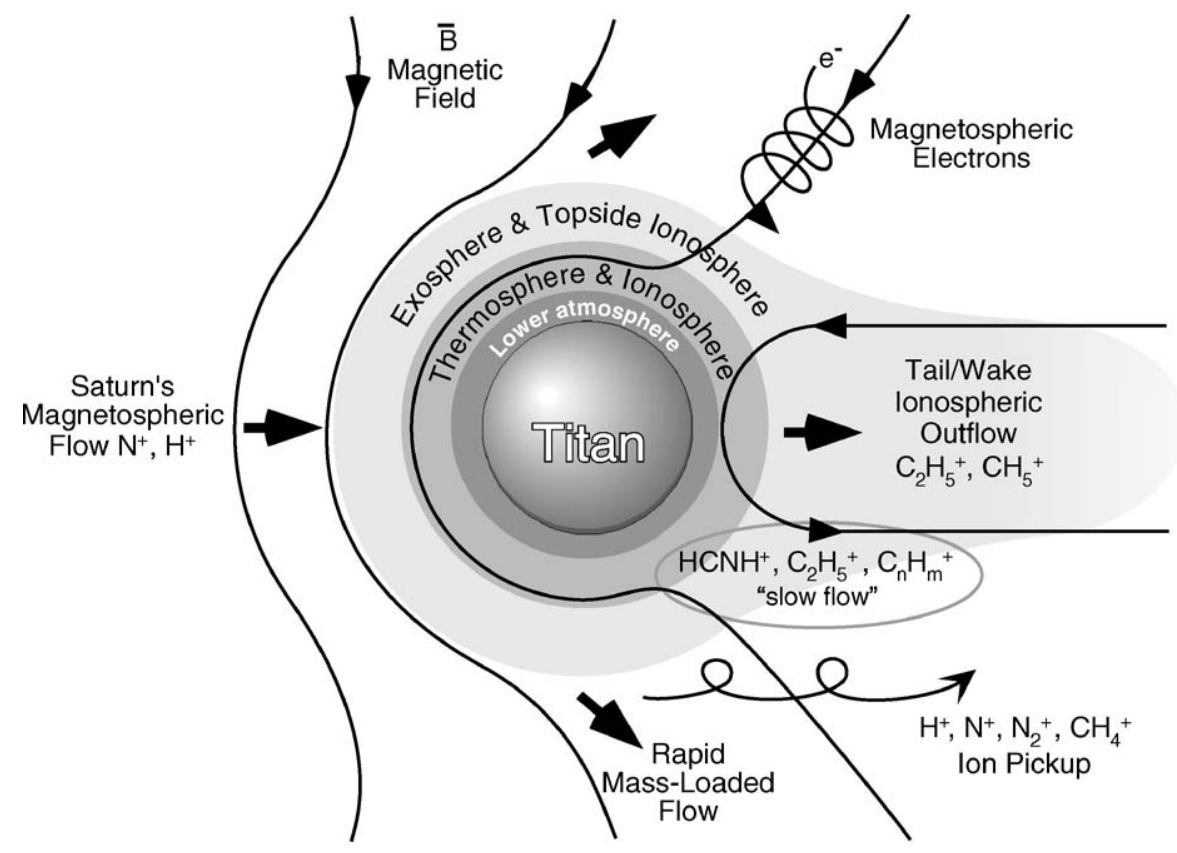

Figure 7. Sketch of Titan's interaction with Saturn's subsonic co-rotating magnetospheric plasma. Horizontal transport moves cold ionospheric plasma (principally $\mathrm{N}^{+}, \mathrm{N}_{2}^{+}$, and $\mathrm{CH}_{4}^{+}$) from altitudes above $1700 \mathrm{~km}$ toward the downstream side of Titan, where it can become entrained in the flowing plasma, while a polar wind-type hydrodynamic outflow is responsible for the escape of ionized material down the wake. $\mathrm{N}^{+}$and $\mathrm{H}^{+}$are produced by the photoionization of neutral atomic nitrogen and hydrogen in Titan's extended exosphere and picked up by the external plasma flow. At altitudes of 2500 $\mathrm{km}$ and less, ion-neutral friction and mass loading slow the external plasma flow, resulting in strong field line draping and the production of a magnetic barrier on Titan's ram side (Cravens et al., 1998).

addition of heavy ions such as $\mathrm{N}_{2}^{+}, \mathrm{HCNH}^{+}$, and/or $\mathrm{N}^{+}$. The velocity differential between the mass-loaded flow and the faster flow of the background plasma is thought to lead to the draping of Saturn's magnetic field lines, which are frozen into the background plasma, around Titan to form the induced tail. Asymmetries observed in the orientation and structure of the tail are likely due to the day-night differences in Titan's ionosphere on the ram side or to the influence of finite pickup ion gyroradii (Ness et al., 1982; Gurnett et al., 1981; Luhmann, 1996; Brecht et al., 2000). As revealed by the Voyager observations, Titan's interaction with Saturn's magnetospheric plasma is similar to the interaction of Venus with the solar wind. There are important differences, however. No bow shock forms at Titan because the co-rotating magnetospheric plasma is submagnetosonic (Ness et al., 1982), and there is little draping of the field observed in the "magnetosheath" region compared to that in the induced magnetotail.

Models developed to examine the effects of Titan's interaction with the magnetospheric plasma flow on the dynamics and structure of the ionosphere predict that the piling up of field lines forms a magnetic barrier around Titan's ramside and 
flanks from which magnetic flux convects downward into the ionosphere (Keller et al., 1994; Cravens et al., 1998). As a result, the ionosphere down to relatively low altitudes is expected to be magnetized. Under some conditions, the entire ionosphere may be magnetized, in which case magnetic flux may "leak" into the lower atmosphere and the field strength may be non-zero at Titan's surface. (It should be noted that the models of the Titan interaction with Saturn's magnetospheric plasma assume that the ionospheric magnetic fields and tail are induced by the interaction. The presence of an intrinsic magnetic field at Titan must still be considered a possibility, however, in light of the Galileo discovery of an internally generated field at Ganymede and possibly at Io; Kivelson et al., 1996; Khurana et al., 1997.)

Based on the in-situ Voyager data, the magnetospheric plasma incident on Titan's neutral atmosphere and ionosphere is thought to consist of $\mathrm{H}^{+}$and $\mathrm{N}^{+}$(in the number ratio $\sim 1: 2$ ) flowing at a velocity of $\sim 80-150 \mathrm{~km} \mathrm{sec}^{-1}$ (Hartle et al., 1982). According to a recent two-dimensional MHD modeling study of the plasma interaction (Cravens et al., 1998), at radial distances from Titan's center of $<2.5 \mathrm{R}_{\mathrm{T}}$ this flow is slowed by ion-neutral friction and mass loading to

Total Speed

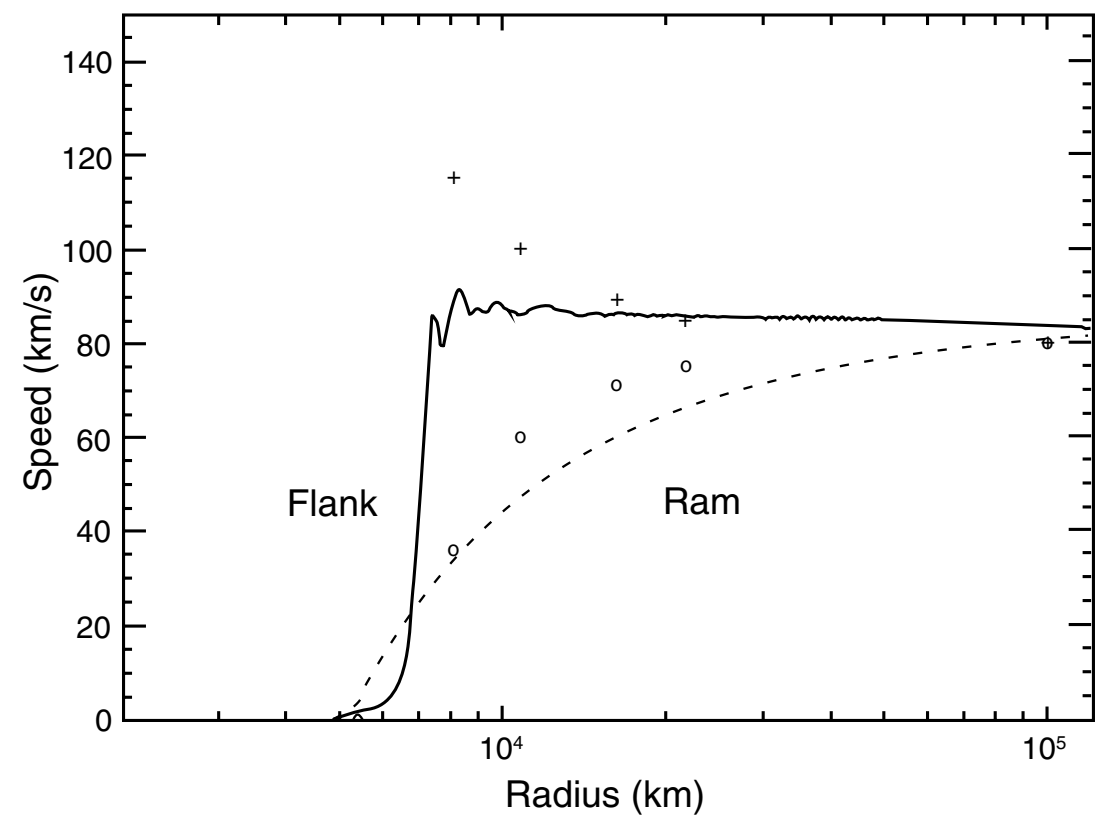

Figure 8. Predicted plasma flow speed vs. radial distance from Titan for the magnetospheric plasma ram direction (dashed curve) and the flank direction (solid line), calculated from the 2D plasma interaction model of Cravens et al. (1998). According to this model, the flow speed inside $2 \mathrm{R}_{\mathrm{T}}$ is $<1$ $\mathrm{km} \mathrm{sec}^{-1}$, so that ions should enter the INMS instrument essentially in the Orbiter ram direction (2 $\mathrm{R}_{\mathrm{T}}$ is about $5000 \mathrm{~km}$ ). At greater distances, alteration of the incoming plasma direction from the ram direction may complicate the alignment of the INMS open source look direction with the ion flow direction. 


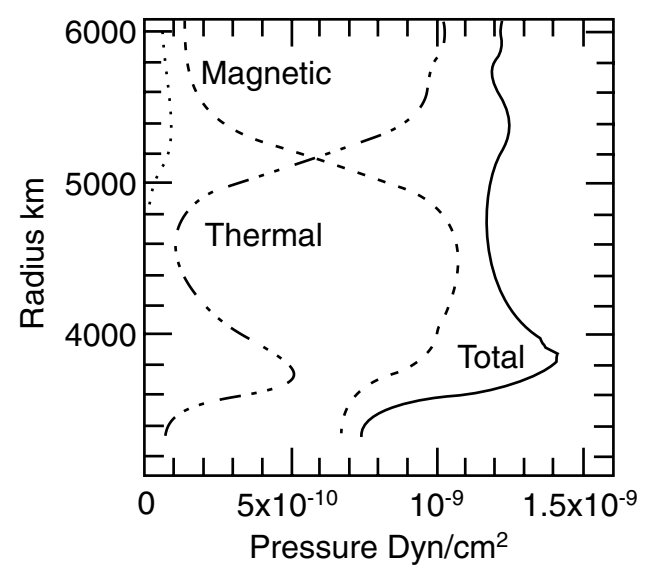

Figure 9. Comparison of the contributions of magnetic pressure and ionospheric thermal pressure to the momentum balance at Titan (from Cravens et al., 1998). At radial distances of $<2 \mathrm{R}_{\mathrm{T}}$, the magnetic field on Titan's ram side and flanks is enhanced as a result of the draping and pile up of the Saturnian magnetic field lines. As this plot indicates, within $\sim 2 \mathrm{R}_{\mathrm{T}}$ it is the enhanced magnetic field strength rather than the thermal pressure of the ionosphere that makes the greater contribution to the obstacle that Titan presents to the external plasma flow.

velocities of under $1 \mathrm{~km} \mathrm{sec}^{-1}$ (Figure 8). The slowing of the external plasma flow results in the piling up of field lines on the ram side, producing the magnetic barrier, which forms the principal obstacle to the flow (Figure 9). The induced magnetic fields are found to have little effect beyond $2 \mathrm{R}_{\mathrm{T}}$, in the fast flow region upstream of Titan, but according to three-dimensional MHD models of the plasma interaction (Ledvina and Cravens, 1998; Kabin et al., 1999), they produce effects many radii downstream. The actual length of Titan's wake is not yet known.

Within the ionosphere, below an altitude of around $2000 \pm 500 \mathrm{~km}$, plasma flow speeds are on the order of a few meters per second and the flow direction is principally vertical (Keller et al., 1994; Cravens et al., 1998). At these altitudes, horizontal transport plays a relatively unimportant role, and the chemical lifetimes of the ionospheric species are much shorter than the time scales for vertical transport. In other words, photochemistry is more important than dynamics in determining ionospheric density distributions. In the topside ionosphere, however, horizontal flows (of more than a kilometer per second) are expected to dominate over photochemistry. Ionospheric material-consisting of the primary ionization products $\left(\mathrm{N}^{+}, \mathrm{N}_{2}^{+}, \mathrm{CH}_{4}^{+}\right)$rather than ions produced at lower altitudes by photochemical processing - will be removed as a result of pick up and entrainment in the external plasma flow (Keller et al., 1994). The extent to which this is a fluid-like, as opposed to a kinetic pick-up process, remains to be determined (e.g., Luhmann et al., 1996), but new "hybrid" models of the Titan-plasma interaction that preserve the particle aspects of the ion motion are beginning to address this question (Brecht et al., 2000). 


\subsubsection{Atmospheric Loss: Titan as a Source of Material for Saturn's Magnetosphere}

Titan supplies both neutrals and plasma to Saturn's outer magnetosphere (Figure 10). Neutral hydrogen, produced by the photolytic destruction of methane, is rapidly lost from Titan's atmosphere, principally by Jeans escape. Photochemical modeling by Yung et al. (1984) predicts global escape rates for $\mathrm{H}$ and $\mathrm{H}_{2}$ of $4.6 \times$ $10^{27} \mathrm{sec}^{-1}$ and $1.2 \times 10^{28} \mathrm{sec}^{-1}$, respectively. Nonthermal removal of nitrogen and other neutrals occurs as well, through the sputtering of Titan's neutral atmosphere by magnetospheric or solar wind particles and/or pickup ions and through production of fast neutrals by ion and ion-neutral chemistry. The rate of neutral loss due to sputtering has been estimated to be $3 \times 10^{25} \mathrm{~N}$ atoms sec ${ }^{-1}$ (for sputtering by solar wind protons) and $7 \times 10^{26} \mathrm{~N}$ atoms $\mathrm{sec}^{-1}$ (for sputtering by magnetospheric $\mathrm{N}^{+}$ and protons) (Lammer and Bauer, 1993). The escape of fast neutrals produced by electron impact dissociation, dissociative recombination, and certain ion-neutral reactions within the ionosphere is predicted to lead to a global loss of $2.5 \times 10^{25}$ $\mathrm{N}$ atoms (in the form of $\mathrm{N}, \mathrm{N}_{2}, \mathrm{HCN}, \mathrm{NH}$, and $\mathrm{CN}$ ) and $1.7 \times 10^{25}$ carbon atoms

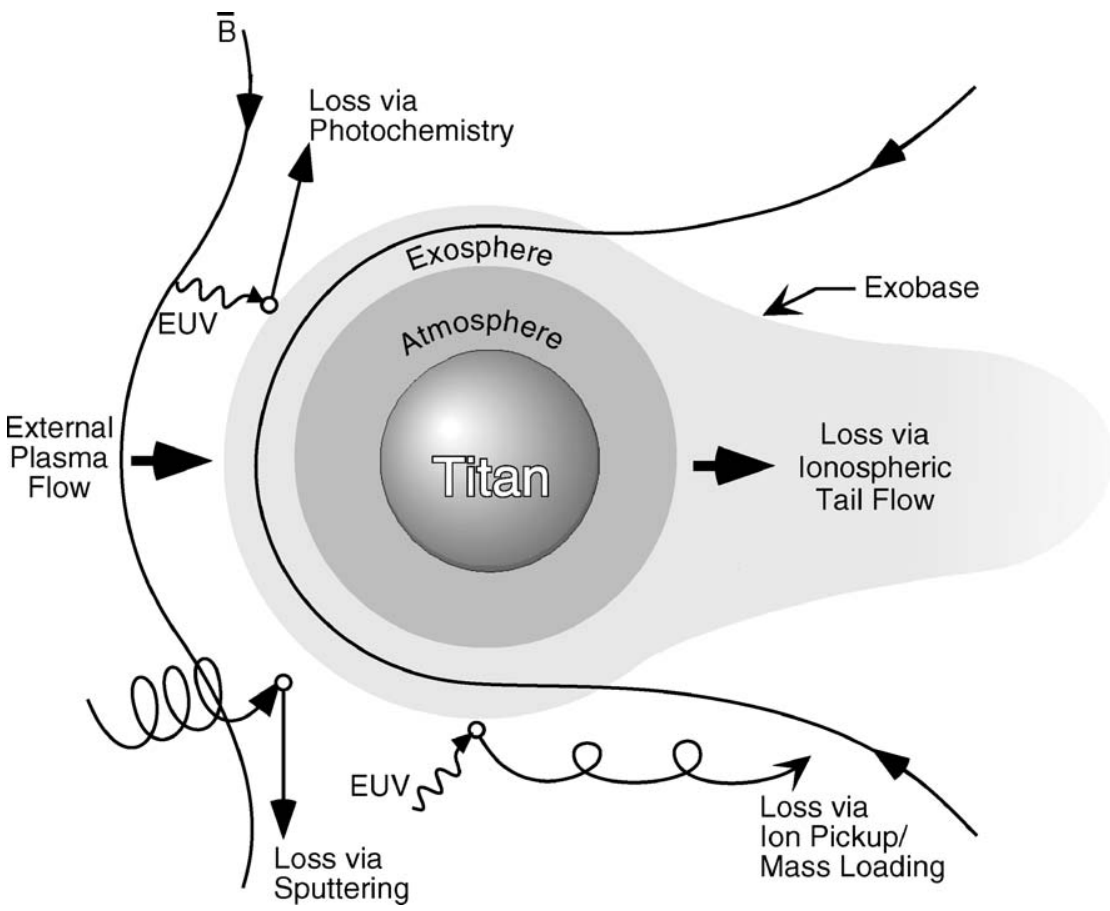

Figure 10. Sketch illustrating the principal mechanisms by which neutrals and ions are lost from Titan's atmosphere: sputtering by charged particle impact, escape of hot, non-thermal neutrals created by dissociative recombination and ion-neutral chemistry, pick-up and scavenging by the external plasma flow, and hydrodynamic escape down the tail. Determining the relative efficiency of each loss process and assessing the strength of Titan as a source of neutrals and plasma for Saturn's magnetosphere are two objectives of the INMS Titan investigation. 
(principally in the form of $\mathrm{CH}_{4}$ ) per second (Cravens et al., 1997). Additional loss occurs as a result of the photoionization of hot exospheric neutrals and their subsequent pickup and removal by the external plasma flow. Lammer and Bauer (1991) calculate a loss of $10^{24}$ heavy ions $\left(\mathrm{N}_{2}^{+}\right.$or $\left.\mathrm{H}_{2} \mathrm{CN}^{+}\right) \mathrm{s}^{-1}$ as a result of pick up by Saturn's co-rotating magnetospheric plasma and a loss of $2.5 \times 10^{22} \mathrm{~N}_{2}^{+} \mathrm{s}^{-1}$ as result of solar wind scavenging when Titan is outside Saturn's magnetosphere. (These values are upper limits.) More is said about loss due to ion pick up below.

Atomic hydrogen that has escaped from Titan's exosphere contributes to a cloud of neutral hydrogen atoms that occupies a sizeable region within Saturn's magnetosphere. Initial analysis of Voyagers 1 and 2 UVS observations of resonantly scattered H Lyman $\alpha$ appeared to indicate that the escaping hydrogen atoms form a symmetrical torus with well-defined inner and outer boundaries at 8 and $25 \mathrm{R}_{\mathrm{S}}$, respectively, a vertical thickness of $14-16 \mathrm{R}_{\mathrm{S}}$, and a density of $\sim 20 \mathrm{~cm}^{-3}$ (Broadfoot et al., 1981; Sandel et al., 1982). However, a more recent analysis using a larger UVS data set indicates that the neutral cloud is neither symmetrically toroidal nor predominantly Titanogenic. The distribution of atomic hydrogen in the neutral cloud appears instead to be highly nonuniform, with strong enhancements in the dusk and dawn sectors, and to extend inward, with increasing density, to the top of Saturn's atmosphere (Shemansky and Hall, 1992). Shemansky and Hall conclude that Saturn rather than Titan is the major source of the neutral atomic hydrogen cloud, although Titan is the dominant source at $18 \mathrm{R}_{\mathrm{S}}$ and beyond. According to a numerical simulation of the orbital behavior of hydrogen atoms originating in the Titan exosphere (Smyth and Marconi, 1993), some of the features of the neutral cloud noted by Shemansky and Hall — the dusk sector enhancement and the increasing density toward Saturn - can in part be accounted for in terms of the effect of solar radiation pressure, which deforms the torus and pushes the atomic hydrogen distribution toward the dusk side of the planet. This model predicts that a significant fraction (27\%) of the Titanogenic atomic hydrogen will be lost through collision with Saturn's duskside atmosphere rather than through ionization and charge exchange.

Escaping molecular hydrogen and atomic nitrogen are expected to form neutral tori as well (e.g., Eviatar and Podolak, 1983; Hilton and Hunten, 1988; Ip, 1992; Smyth and Marconi, 1993). Such tori have not been observed, however. It is believed that solar radiation pressure will have little effect on the spatial distribution of these species in the magnetosphere so that the corresponding tori will be approximately symmetrical, in contrast to the atomic hydrogen torus (Smyth and Marconi, 1993).

Titan supplies plasma to Saturn's magnetosphere both directly, through the removal of ions from the topside ionosphere as the result of a polar wind type hydrodynamic outflow from Titan's wakeside ionosphere (Keller and Cravens (1994) calculate a total ion loss by this process of $(6-20) \times 10^{24} \mathrm{sec}^{-1}$. This rate is consistent with earlier Voyager-based estimates of Titan's plasma source strength by Bridge et al. (1981), Gurnett et al. (1982), and Neubauer et al. (1984)), and indirectly, through the ionization of material contributed to the neutral atomic hydrogen 
cloud and in the $\mathrm{H}_{2}$ and $\mathrm{N}$ tori. As noted above, Lammer and Bauer (1991) estimate that ions created from "hot" exospheric neutrals (mass 28) are lost due to the pickup process at a rate of $10^{24} \mathrm{sec}^{-1}$, which is comparable to the estimated rate of loss by hydrodynamic outflow. Direct removal of plasma occurs through pick up by Saturn's co-rotating magnetospheric plasma flow (or by the solar wind, when Titan is outside the magnetosphere).

The contribution of ionized Titanogenic neutral cloud/torus material to Saturn's magnetospheric plasma has received relatively limited attention in the literature and has been addressed principally in two papers by Barbosa $(1987,1990)$. Assuming that ions are produced at the same rates at which the corresponding neutrals escape from Titan's atmosphere, Barbosa (1990) uses production rates of $10^{27}$ and $10^{26}$ $\sec ^{-1}$ for $\mathrm{H}^{+}$and $\mathrm{N}^{+}$, respectively, in his study of diffusive ion transport in Saturn's magnetosphere. In the earlier study, Barbosa (1987) proposes that the ions created by ionization of Titan's postulated atomic nitrogen torus "supply the bulk of the mass and energy input to the magnetosphere at a power level of $2 \times 10^{11} \mathrm{~W}$ ".

Finally, we note that assessing the efficiency of the various loss processes is important for our understanding not just of the present state of Titan's upper atmosphere but also of its evolution. Lammer and Bauer (1993) estimate, for example, that sputtering by magnetospheric charged particles may have resulted in the loss of $20 \%$ of the mass of Titan's atmosphere over the age of the solar system.

\subsubsection{Titan Science Questions and Measurement Objectives}

The reference tour selected by the Cassini Project Science Group (tour T18-5, reference trajectory 041001) provides for 44 targeted flybys of Titan. Forty-three of the Titan encounters take place at altitudes below $8000 \mathrm{~km}$; as currently planned, the altitude of closest approach for over half the passes will be $950 \mathrm{~km}$. (The actual minimum altitude will be established on the basis of the atmospheric densities determined from measurements made during the initial flyby.) It is possible that the closest approach altitude will be decreased to $850 \mathrm{~km}$ for a few of the Titan passes. Orbiter velocities during Titan flybys will range from 5.8 to $6.2 \mathrm{~km} \mathrm{sec}^{-1}$.

Three orbital sequences (cf. Sections 3.3.2-3.3.4) have been designed for INMS measurements during the Titan encounters: a Titan Exploratory Sequence for the initial two passes, a High-Altitude Sequence for flybys with closest approach altitudes above the exobase $(\sim 1465 \mathrm{~km})$, and a Low-Altitude Aeronomy Sequence for passes with a closest approach at $950 \mathrm{~km}$, below the homopause and ionospheric peak (Strobel et al., 1992; Fox and Yelle, 1997). The Titan orbital sequences provide for a combination of mass survey scans and scans of selected neutral and ion species. Neutral species with densities $\geq 10^{4} \mathrm{~cm}^{-3}$ can be measured in the INMS closed source mode, and with densities $\geq 10^{5} \mathrm{~cm}^{-3}$ in the open source neutral mode; positive ions with densities above $10^{-2} \mathrm{~cm}^{-3}$ can be measured in the open source ion mode (cf. Figures 1 and 5, which indicate predicted neutral and ion densities over the lower part of the altitude range that the Orbiter will traverse during the Titan encounters). 
When the INMS is operating in the open source ion mode, optimal sampling requires that the inflowing ions enter the instrument within $8.6^{\circ}$ of the ram direction. According to the recent modeling study of Titan's interaction with the external plasma flow cited above (Cravens et al., 1998), the plasma is expected to flow rather slowly $\left(<1 \mathrm{~km} \mathrm{sec}^{-1}\right)$ inside a radial distance of $2.5 \mathrm{R}_{\mathrm{T}}$ (altitude $=3800$ $\mathrm{km}$ ), and ions should enter the INMS instrument essentially in the Orbiter ram direction. Outside this distance, however, INMS thermal plasma measurements will be complicated by plasma flow directions that lie outside the open source acceptance angle and by ion flow speeds that exceed the instrument's upper energy limit $(100 \mathrm{eV})$. CAPS will be the more appropriate instrument for measurements in this region. Understanding Titan's interaction with the external plasma flow and the effects of this interaction on the dynamics, structure, and energetics of Titan's upper atmosphere will require a combination of INMS data from the region inside $2.5 \mathrm{R}_{\mathrm{T}}$, CAPS data on external ion flow velocities and on ion and electron temperatures, and magnetic field data from the MAG experiment. For example, both INMS and CAPS data will be needed, together with models, to calculate escape rates from both dissociative recombination of ionospheric ions and ion pickup.

Key specific science questions to be addressed by the INMS Titan investigation and measurement requirements are summarized in the following.

- What is the thermal structure of Titan's upper atmosphere? (Needed measurements: high-time-resolution INMS measurements of densities as a function of altitude for the principal neutral and ion species known or expected to be present in Titan's atmosphere; complementary UVIS and RSS data.)

- What is the bulk composition of Titan's neutral upper atmosphere and ionosphere? What are the key chemical processes determining the composition of the ionosphere and neutral upper atmosphere? How does the ionosphere affect the composition of the neutral atmosphere and vice-versa? For example, how is the ion composition determined by the densities of neutral species such as $\mathrm{C}_{2} \mathrm{H}_{2}, \mathrm{HCN}$, and nitriles? What neutrals, including complex hydrocarbon species, are produced by the ion chemistry? How does the chemistry occurring in Titan's upper atmosphere contribute to the production of aerosol hazes in the stratosphere? More specifically, how are complex hydrocarbons and nitriles generated in Titan's upper atmosphere and ionosphere, and do magnetospheric inputs affect this? (Needed measurements: detailed INMS ion and neutral composition measurements over the complete mass range (1-99 Daltons); complementary UVIS occultation measurements and VIMS and CIRS data on the composition of the lower atmosphere.)

- How do Saturn's magnetosphere (when Titan resides in it) and the solar wind (when Titan is located outside Saturn's magnetopause) interact with Titan? 
How are the structure and dynamics of Titan's ionosphere affected by this interaction? How are the energetics of the ionosphere, and upper atmosphere as a whole, affected by this interaction? Is the magnetospheric interaction or solar EUV radiation a more important energy source for Titan's ionosphere and upper atmosphere? How does this depend on location on Titan (that is, versus solar zenith angle, on the ram or wake side, etc.)? How does the plasma interaction depend on the relative angles of the subsolar and subflow points on Titan? (Needed measurements: measurements of total ion density versus altitude for a wide range of solar zenith angles and ram angles; energetic particle measurements from CAPS and MIMI, complementary MAG and PWS data, and RSS occultation measurements of the ionosphere; INMS, CAPS, MAG, PWS measurements at Titan whenever Titan is near noon Saturn time in the event that high solar wind dynamic pressure compresses magnetopause, placing Titan in the magnetosheath or solar wind.)

- Is Titan's ionosphere magnetized? And if so, by a small intrinsic field or by fields induced by the interaction with Saturn's magnetosphere? How does this field interact with the thermal plasma in the ionosphere? (The ionospheric electrical conductivity will determine whether or not an induced magnetic field can penetrate into the lower atmosphere.) (Needed measurements: INMS neutral and ion density measurements to determine ionospheric electrical conductivity as a function of altitude, local time, ram angle, etc.; complementary MAG and RSS data.)

- How is the upper boundary of the ionosphere affected by the plasma interaction? Is the scale height altered by plasma erosion on the ram side? Are there ionospheric "tail rays" in the wake as seen at comets, Venus, and Mars? (Needed measurements: global coverage of the upper ionosphere region to examine $3 D$ shape of the ionosphere boundary; CAPS data; PWS Langmuir Probe measurements and MAG measurements to understand geometry of plasma interaction-related features.)

- What are the relative contributions of various loss processes-ion scavenging, sputtering by co-rotating particles, the escape of hot, non-thermal neutrals produced by ion-neutral and dissociative recombination reactions, and the bulk flow of ionospheric plasma out the tail/wake-to the loss of material from Titan's neutral upper atmosphere and ionosphere? What are the evolutionary consequences for Titan? (Needed measurements: INMS measurements of neutral and ion densities vs. altitude and location, e.g., ram side versus wake side; CAPS measurements of flux and composition of the incident particles.)

- How many and what neutrals and ions does Titan supply to Saturn's magnetosphere and how does this Titan source affect the outer magnetosphere of Saturn? How does Titan's ionosphere contribute to the extended exosphere of that satellite as well as to the neutral torus around Saturn near Titan's orbit? (Needed measurements: same as in preceding paragraph.) 


\subsection{Saturn's Inner Magnetosphere: Rings and Icy Satellites}

A secondary focus of the INMS investigation is on the neutral and thermal plasma environment of Saturn's inner magnetosphere $(L<10)$ and its association with the rings and icy satellites. Sputtering of material from the rings and the surfaces of the moons by charged particle and micrometeorite bombardment is believed to create an extensive neutral cloud of water molecules and water dissociation products in the inner magnetosphere. Subsequent ionization of this neutral material through electron impact, EUV radiation, and charge exchange is the primary source for the thermal plasma (protons and heavy ions) observed in the inner magnetosphere by Pioneer 11 (Frank et al., 1980) and Voyagers 1 and 2 (Bridge et al., 1981, 1982; Lazarus and McNutt, 1983). The relative contributions of the neutral sources, their adequacy to account for neutral densities determined from recent HST observations, and the contributions and efficiencies of different production mechanisms (e.g., plasma sputtering, photosputtering, micrometeoroid bombardment) have been the subject of several modeling studies. Such studies, together with the HST observations and new analysis of Voyager plasma data, have added significantly to our understanding of the neutral and plasma environment of Saturn's inner magnetosphere. There remain a number of important questions, however, whose resolution must await the arrival of Cassini in the Saturn system. (For a review of the relevant observations and model results, see Richardson (1998). See also the recent studies by Jurac et al. (2001a,b).)

INMS measurements in the inner magnetosphere will be challenging because of the low neutral densities, intense radiation background, and the co-rotational energy acquired by the thermal ions. However, long accumulation periods and the co-adding of mass scans will be used to increase counting statistics, and thermal ion energies will be low enough in certain regions of interest (e.g., above and at the ring plane during Saturn Orbit Insertion, icy satellite wakes) to permit useful data to be acquired.

\subsubsection{The Neutral and Plasma Environment of the Main Ring System}

Prior to the deployment of the Hubble Space Telescope, the only direct information on the neutral gas population in the inner magnetosphere was provided by remotesensing observations of Lyman $\alpha$ radiation resonantly scattered by neutral atomic hydrogen. These observations were interpreted as evidence for the presence of a tenuous ring atmosphere with an atomic hydrogen number density of 400-600 $\mathrm{cm}^{-3}$ (Weiser et al., 1977; Judge et al., 1980; Carlson, 1980; Broadfoot et al., 1981). Such a neutral atmosphere is thought to be created and maintained by the ejection of water vapor and water products from the icy ring particles as a result principally of micrometeorite bombardment and is expected to consist of $\mathrm{H}_{2} \mathrm{O}$, $\mathrm{OH}$, and $\mathrm{O}$ in addition to atomic hydrogen (Ip, 1984, 1995; Pospieszalska and Johnson, 1991). In addition to the atomic hydrogen associated with the rings, atomic hydrogen apparently originating in Saturn's exosphere also exists within the inner magnetosphere in significant amounts and with densities as high as $100 \mathrm{~cm}^{-3}$ 
(Shemansky and Hall, 1992). As Hall et al. (1996) point out, the presence of this exospheric component and of contributions from Titan and other sources makes it difficult to distinguish an atomic hydrogen population uniquely associated with the ring system. Thus estimates of the density and properties of the ring atmosphere based on the Lyman $\alpha$ data (e.g., Broadfoot et al., 1981) should be used with caution.

The signature of an $\mathrm{OH}$ component of the ring atmosphere was detected with the HST Faint Object Spectrograph (FOS) during edge-on observations made at the time of the Earth's ring plane crossing in August 1995 (Hall et al., 1996). Five observations of UV fluorescence emissions from the $\mathrm{OH} \mathrm{A}-\mathrm{X}$ band were made close to the ring plane, at altitudes ranging from 0.28 to $0.60 \mathrm{R}_{\mathrm{S}}$ above the plane and at equatorial distances between 1.9 and $2.3 \mathrm{R}_{\mathrm{S}}$. Emission brightness was found to decrease with altitude above the ring plane and to increase with increasing equatorial distance, with the brightest emissions occurring at an altitude of $0.28 \mathrm{R}_{\mathrm{S}}$ and an equatorial distance of $2.3 \mathrm{R}_{\mathrm{S}}$. Based on the brightness of these emissions, Hall et al. estimate a scale height of $0.45 \mathrm{R}_{\mathrm{S}}$ and a number density of $150-700 \mathrm{~cm}^{-3}$ for the $\mathrm{OH}$ component of the ring atmosphere. (The larger value for the $\mathrm{OH}$ number density represents an upper limit because it may include an $\mathrm{OH}$ contribution from non-ring sources in the inner magnetosphere.) A much lower $\mathrm{OH}$ density $\left(\sim 30 \mathrm{~cm}^{-3}\right)$ near the rings has been calculated by Richardson et al. (1998), whose model is constrained by HST OH observations from three epochs (1992 and 1994 as well as 1995) and Voyager atomic hydrogen and plasma data (see their Figures 2 and 4). The higher value obtained by Hall et al. (1996) may reflect the preliminary nature of their analysis.

According to the Richardson et al. model (their Figure 8), $\mathrm{OH}$ accounts for $\sim 50 \%$ of the neutral density in the vicinity of the rings (at a radial distance of 2.3 $\mathrm{R}_{\mathrm{S}}$ ), which implies a total neutral density of $\sim 60 \mathrm{~cm}^{-3}$. This value is consistent with that given by $\mathrm{Ip}(1995)$ for the density near $2.5 \mathrm{R}_{\mathrm{S}}$ but is lower than that predicted by the ring neutral cloud model of Pospieszalska and Johnson (1991) $\left(\sim 300 \mathrm{~cm}^{-3}\right.$ at $2.3 R_{S}$ and at an altitude of $0.28 R_{S}$ above the ring plane; see their Figure 1a). The differences among the model predictions are attributable in part to uncertainties in our knowledge of the micrometeorite flux at Saturn and of the rate of gas production by hypervelocity impact.

Indirect evidence for the existence of a neutral ring atmosphere was provided by the detection of a population of cold $(10 \mathrm{eV})$, dense $\left(100 \mathrm{~cm}^{-3}\right)$ heavy ions during the Voyager 2 ring plane crossing at an equatorial distance of $\sim 2.7 \mathrm{R}_{\mathrm{S}}$, just outside the outer edge of the main rings $\left(\sim 2.3 \mathrm{R}_{\mathrm{S}}\right)$ (Bridge et al., 1982; Lazarus and McNutt, 1983; Gan-Baruch et al., 1994). It is probable that this cold dense plasma consists of water group ions $\left(\mathrm{O}^{+}, \mathrm{OH}^{+}, \mathrm{H}_{2} \mathrm{O}^{+}\right.$, and $\left.\mathrm{H}_{3} \mathrm{O}^{+}\right)$created by the ionization of the water vapor and water dissociation products that make up the neutral atmosphere of the ring system. The ring atmosphere-which one model has shown can extend well beyond the edge of the main rings- - would thus constitute the "missing" source of the thermal plasma that exists inside the orbit of Enceladus and is inadequately accounted for by other sources (Pospieszalska and Johnson, 1989, 
1991). In addition to the creation of plasma through the ionization of the sputtered neutrals, some plasma will also be produced directly by the micrometeorite impacts upon the ring material (Morfill et al., 1983).

Eviatar and Richardson $(1990,1992)$ suggest that the cold dense plasma associated with the rings and lying between the outer edge of the main rings and the orbit of Mimas $\left(\sim 3 R_{S}\right)$ should be considered the outer "ionosphere" of the ring system, a population distinct from the warmer plasma associated with the icy satellites. Voyager 2 plasma measurements in the ring plane at $2.7 \mathrm{R}_{\mathrm{S}}$ indicate that the ring ionosphere in this region is rather dense $\left(\sim 100 \mathrm{~cm}^{-3}\right)$. No observational data exist on the density of the plasma in the immediate vicinity of the main rings (i.e., between 1.2 and $2.3 \mathrm{R}_{\mathrm{S}}$ ); however, extrapolation from the Voyager data suggests a density of $\sim 30$ heavy (e.g., $\mathrm{O}^{+}, \mathrm{OH}^{+}, \mathrm{H}_{2} \mathrm{O}^{+}$, and $\mathrm{H}_{3} \mathrm{O}^{+}$) ions $\mathrm{cm}^{-3}(25-50$ Daltons) at altitudes between 0.2 and $0.4 \mathrm{R}_{\mathrm{S}}$ above the ring plane (Richardson and Sittler, 1990, Figure 9).

Because the rings are magnetically connected with Saturn's ionosphere, it is expected that plasma transport between the ionosphere and the ring system (and between the ring system and the ionosphere) will occur and that the plasma in the vicinity of the rings will thus consist of both ring-generated plasma (mainly water group ions) and ionospheric plasma (principally $\mathrm{H}^{+}$) (Wilson and Waite, 1989). Model calculations by Wilson and Waite indicate that the relative proportions of the two populations will vary according to radial distance and source strength; for example, for one set of model parameters, ionospheric $\mathrm{H}^{+}\left(\right.$densities $\left.\geq 1.0 \mathrm{~cm}^{-3}\right)$ is found to be the dominant species near the $\mathrm{C}$ ring, while the plasma environment of the $\mathrm{B}$ and $\mathrm{A}$ rings is dominated by heavy ions with densities as high as $50 \mathrm{~cm}^{-3}$. The Wilson and Waite model also demonstrates that the flux of ring-generated water group ions from the B ring into the ionosphere can be significant, $>2 \times 10^{7} \mathrm{~cm}^{-2}$ $\mathrm{sec}^{-1}$, and could contribute to the low electron densities observed in the ionosphere at latitudes magnetically connected to the B ring (cf. Connerney and Waite, 1984). Since absorption of ionospheric material by the rings can also produce such features (Luhmann and Walker, 1981), in-situ measurements are needed to determine what exchanges between the rings and ionosphere are taking place.

\subsubsection{The E Ring and Icy Satellite Environments}

Neutrals produced by micrometeorite bombardment of the main rings are likely to contribute significantly to the neutral population inside the orbit of Enceladus (Pospieszalska and Johnson, 1991). However, the principal source of neutral gas and thermal plasma in Saturn's inner magnetosphere is the sputtering of water products from the surfaces of the icy satellites and from the icy particles of the diffuse E ring (3-8 R $\mathrm{R}_{\mathrm{S}}$ ) (Shi et al., 1995; Jurac et al., 2001a). Neither Pioneer 11 nor Voyagers 1 and 2 were instrumented to make in-situ neutral measurements during their passes through the inner magnetosphere. However, the measurement of heavy ions with the Pioneer and Voyager plasma instruments near the orbits of the icy satellites implied the presence of an extended neutral cloud of water molecules and water 
dissociation products that could serve as the source for the observed ions. Using Voyager LECP particle flux data and laboratory data on the sputtering of water ice, Lanzerotti et al. (1983) demonstrated that the sputtering of the inner moons by charged particle bombardment could produce such an extended neutral source. Calculations of neutral and plasma densities surrounding the inner moons were reported by Richardson et al. (1986), and a model of neutral cloud morphology and of the inner heavy ion torus was developed by Johnson et al. (1989). In both models, charged particle bombardment was assumed to be the primary means by which water and water products are sputtered from the satellite surfaces to form the neutral cloud. Both models predicted relatively low neutral densities in the inner magnetosphere: $<7 \mathrm{~cm}^{-3}$ in the Tethys-Dione torus (Richardson et al., 1986, Table $\mathrm{Vb}$ ) and 44-60 $\mathrm{cm}^{-3}$ at the orbit of Tethys (4.88 $\mathrm{R}_{\mathrm{S}}$ ) (Johnson et al., 1989, Figure 5). In contrast, Shemansky and Hall (1992, Table V) estimated the densities of water group neutrals $\left(\mathrm{H}_{2} \mathrm{O}, \mathrm{OH}, \mathrm{O}\right)$ to be as high as $\sim 470 \mathrm{~cm}^{-3}$ at a distance of $4.5 \mathrm{R}_{\mathrm{S}}$.

The first direct observation of neutral gas associated with the inner moons was the detection with the HST FOS of a surprisingly large abundance of OH (mean density $=160 \pm 50 \mathrm{~cm}^{-3}$ ) at $4.5 \mathrm{R}_{\mathrm{S}}$-near the orbit of Tethys-by Shemansky et al. (1993). Model calculations constrained by these and subsequent HST observations (from 1994 and 1995) indicate even higher $\mathrm{OH}$ densities, $>700 \mathrm{~cm}^{-3}$ at $4.5 \mathrm{R}_{\mathrm{S}}$ and on the order of $500 \mathrm{~cm}^{-3}$ at $3 \mathrm{R}_{\mathrm{S}}$ (Richardson et al., 1998; S. Jurac, private communication, 2001). These findings confirm the prediction by Shemansky and Hall (1992) of large amounts of heavy neutrals in Saturn's inner magnetosphere and call into question the adequacy of the principal neutral source mechanismcharged particle sputtering - assumed by the earlier models of Richardson et al. (1986) and Johnson et al. (1989). By using revised yields for sputtering by $\mathrm{keV} \mathrm{O}^{+}$ and including sputtering of the icy E-ring grains as an important neutral source in the region between Enceladus and Tethys, Shi et al. (1995) were able to increase the total source rate for charged particle sputtering by a factor of two compared with that used by Johnson et al. (1989). Even so, the new production rate $(1.7 \times$ $10^{26} \mathrm{sec}^{-1}$ ) is roughly 10 times smaller than the source rate required by Shemansky et al. (1993) $\left(2 \times 10^{27} \mathrm{sec}^{-1}\right)$ and more recently by Richardson et al. (1998) (1.4 $\times 10^{27} \mathrm{sec}^{-1}$ ) to account for the HST OH observations.

The discrepancy between the neutral densities implied by the $\mathrm{OH}$ observations and those predicted by models that invoke charged particle sputtering as the major neutral source may be attributable in part to underestimates of the actual sputter yields from the icy satellites and/or of the magnitude of energetic particle fluxes between 4 and $8 \mathrm{R}_{\mathrm{S}}$ (cf. Shi et al., 1995). This discrepancy may also be partly accounted for in terms of the contribution of processes other than charged particle sputtering to the formation of the neutral cloud. For example, vapor production by micrometeorite impact is usually considered a relatively minor source of neutrals at the inner moons (as opposed to at the rings) (Johnson et al., 1989). There is great uncertainty about micrometeorite fluxes at Saturn, however, and thus Shemansky 
et al. (1993) suggest that, with sufficiently large fluxes, micrometeorite bombardment of the satellites could be a plausible additional source of neutrals for the inner magnetosphere.

Following up on a suggestion by Hamilton and Burns (1993), Ip (1997) considers as another possible source the impact of E-ring particles, in highly eccentric orbits, on Enceladus and suggests that this mechanism could contribute substantially to the neutral cloud in the vicinity of this satellite. According to Ip's model, a combination of charged particle sputtering and sputtering of Enceladus by E-ring particles (estimated source strength $=6 \times 10^{25} \mathrm{sec}^{-1}$ ) gives an $\mathrm{OH}$ density at $4.5 \mathrm{R}_{\mathrm{S}}$ of $300 \mathrm{~cm}^{-3}$ and a total heavy neutral density of $4 \times 10^{3} \mathrm{~cm}^{-3}$. In addition, Ip notes that E-ring particles in eccentric orbits could also collide with the A ring and contribute to the production of a dense ring system atmosphere (cf. the $\mathrm{OH}$ densities at $2.3 \mathrm{R}_{\mathrm{S}}$ reported by Hall et al., 1996).

Another possible solution to the problem of the discrepancy between the modeled sources and the observed $\mathrm{OH}$ densities is offered by Jurac et al. (2001a,b), who posit the existence of a population of submicron-sized ice grains distributed among the larger E ring grains near the orbit of Enceladus. According to their model, this population represents a stronger source of sputtered neutrals than either the satellites or the regular E ring grains, and the three sources together are sufficient to account for the measured $\mathrm{OH}$ densities.

Models show that neutral densities peak close to the icy moons (Johnson et al., 1989; Ip, 1997). For example, estimated densities of sputtered $\mathrm{H}_{2} \mathrm{O}$ and $\mathrm{O}_{2}$ at an altitude of $560 \mathrm{~km}$ above the surface of Dione are $\sim 7 \times 10^{4} \mathrm{~cm}^{-3}$ and $10^{4} \mathrm{~cm}^{-3}$, respectively (Johnson, 1998, Figure 9). This is approximately the altitude of closest approach during the Dione encounter as specified in the Cassini reference tour T18-5. Thus some direct sampling with the INMS of satellite neutral atmospheres may be possible during targeted (i.e., low-altitude) icy satellite encounters. Data acquired during these encounters can be used to assess the neutral source strength of a particular moon and to obtain some information about satellite surface composition. Determination of satellite surface composition from sputter products will be significantly improved by the high-sensitivity CAPS measurements of sputter-produced plasma (cf. Johnson and Sittler, 1990).

\subsubsection{INMS Inner Magnetosphere Science Objectives and Measurement Requirements}

The Cassini Orbiter is the first outer planet probe instrumented to make in-situ neutral composition measurements. It thus has the potential to provide unique data on the neutral gases that recent HST observations have shown to be abundant in Saturn's inner magnetosphere. Such data would be of extraordinary value in our efforts to characterize the neutral environments of the rings and icy satellites, to understand the interactions of these bodies with the magnetospheric plasma or, in the case of the rings, with Saturn's ionosphere, and to assess the relative contributions of the ring system and inner moons to the neutral and thermal plasma populations 
of the inner magnetosphere. INMS neutral (and thermal plasma) data would contribute as well to efforts to address planetological questions, e.g., relating to the age and evolution of the rings, the composition of the surfaces of the icy satellites, etc.

INMS measurements of neutral gases in the inner magnetosphere are expected to be challenging, however, because, as is evident from the discussion in the preceding sections, available data and modeling results indicate that neutral densities in the inner magnetosphere do not exceed a few times $10^{3} \mathrm{~cm}^{-3}$ at the most. Neutral densities are thus generally below the detection level of the INMS in both the closed source $\left(10^{4} \mathrm{~cm}^{-3}\right)$ and open source neutral $\left(10^{5} \mathrm{~cm}^{-3}\right)$ modes. These measurements are further complicated by the intense radiation background in the inner magnetosphere. To mitigate this latter problem, the INMS was modified to include a 0.23-cm-thick tantalum shield around the detectors (cf. Section 2.1). To address the problem of densities below the neutral detection threshold, long accumulation periods of up to $50 \mathrm{~min}$ will be employed to allow for the co-adding of mass scans. Five mass spectra consisting of 15-255 co-added mass scans each will be acquired during each of the four measurement cycles (at least one in each INMS operating mode) that constitute the inner magnetosphere orbital sequence (cf. Sections 3 and 3.3.6).

The INMS can also provide, under certain circumstances, valuable data on the thermal ions in the inner magnetosphere. Although thermal plasma densities in the equatorial plane near the rings and satellites (e.g., heavy ion densities of 20$25 \mathrm{~cm}^{-3}$ and proton densities of $2 \mathrm{~cm}^{-3}$ near the orbit of Dione; Richardson, 1986) lie above the detection threshold $\left(10^{-2} \mathrm{~cm}^{-3}\right)$, the co-rotational energy acquired by the ions places them at times outside the instrument's energy range $(1-100 \mathrm{eV})$ at radial distances greater than $\sim 3.5 \mathrm{R}_{\mathrm{S}}$. (Co-rotational energy is approximately given by $E \sim A R^{2} / 2 \mathrm{eV}$, where $A$ is the atomic mass unit and $R$ is radial location in Saturn radii. However, this general rule must be supplemented by information on the spacecraft's orbital velocity to set the actual limit on detection.) Following Saturn Orbit Insertion (SOI), the Orbiter will cross the ring plane through the gap between the $F$ and $G$ rings, at $\sim 2.5 R_{S}$. Prior to this, the Orbiter will fly over the ring plane at altitudes ranging from 0.5 to $0.13 \mathrm{R}_{\mathrm{S}}$ for $\sim 1.5 \mathrm{hr}$ after the main engine burn associated with SOI. The ring plane crossing and, depending on the plasma scale height, the ring overflight thus offer a key opportunity for INMS open source ion measurements of the ring plasma environment. Additional opportunities for thermal ion measurements are expected to occur during targeted flybys of the icy satellites, whenever the Orbiter is located in plasma stagnation regions in the satellite wakes.

Representative science questions to be addressed with INMS data acquired in the inner magnetosphere and measurement requirements include the following:

- What is the composition and density of the neutral atmosphere and ionosphere of the ring system? How are the rings coupled to the Saturnian ionosphere? Is 
there active water injection from the ring systems into Saturn's atmosphere? (Needed measurements: ion composition, density, and temperature and open source neutral measurements during ring overflight and at ring plane crossing; complementary ion measurements with CAPS.)

- What are the interactions between icy satellites and the magnetospheric plasma? Do Enceladus, Dione, and/or Rhea have exospheres and ionospheres? If so, how are they generated, by charged particle sputtering or micrometeorite bombardment? What can be inferred from the neutral/plasma environment of the satellites about their surface composition? Is there any current outgassing activity (cyro-volcanism) on these icy satellites (i.e., Enceladus and/or Dione)? Which satellite is most important in supplying neutral material to the magnetosphere? What is the contribution of the E ring to the neutral cloud? What are the density distribution and composition of the neutral gas cloud in the vicinity of the satellites? (Needed measurements: ram-pointed neutral density and composition measurements at closest approaches to icy satellites for possible detection of exospheres and to set limits on exosphere sizes; ion density and composition measurements at wake crossings; complementary measurements with CAPS, MAG, and plasma wave experiments; MIMI imaging of neutral tori.)

\subsection{Plasma Outflow from Saturn's High-Latitude Ionosphere}

Hamilton et al. (1983) reported the detection with the Voyager LECP instrument of $\mathrm{H}_{2}^{+}$and $\mathrm{H}_{3}^{+}$in Saturn's magnetosphere and postulated that such ionized molecular hydrogen most likely originates in Saturn's high-latitude ionosphere. Outflows of thermal ions from the Earth's high-latitude ionosphere are known to be a major source of plasma for the terrestrial magnetosphere (cf. Chappell et al., 1987), and calculations by Nagy et al. (1986) demonstrated that polar ion outflows could in principle supply substantial amounts of plasma to the Jovian magnetosphere as well. Evidence for an ionospheric plasma source at Jupiter was provided by the observation of Doppler-shifted Lyman $\alpha$ emissions from the Jovian auroral zone, which Clarke et al. (1989) attributed to fast atomic $\mathrm{H}$ produced by interactions with upflowing $10-20 \mathrm{eV}$ protons and possibly $\mathrm{H}_{2}^{+}$and $\mathrm{H}_{3}^{+}$as well. If similar outflows occur at Saturn, ion flow energies would likely be $<10$ and $<1 \mathrm{eV}$ in the case of a polar-wind-type outflow. Such energies fall within the energy range of the INMS for open source ion measurements. Thus an additional objective of the INMS investigation is to attempt to detect the postulated $\mathrm{H}_{2}^{+}$and $\mathrm{H}_{3}^{+}$outflows from Saturn's ionosphere during the Orbiter's passes through the polar magnetosphere and, if such outflows are detected, to assess the strength of the ionospheric source. INMS measurements will be coordinated with CAPS observations, which will provide information on plasma flow directions and energy distributions. 


\section{Instrument Description}

\subsection{Overview}

The INMS instrument (Kasprzak et al., 1996) is a modification of the Neutral Gas and Ion Mass Spectrometer (NGIMS) instrument designed for the Comet Rendezvous Asteroid Flyby Mission (CRAF). Its heritage includes similar sensors designed by GSFC for such missions as Atmospheric Explorer, Dynamics Explorer, Pioneer Venus, and the Galileo Probe. The Cassini instrument consists of two separate ion sources for sampling ambient neutrals and ions, an ion deflector/trap, four hot-filament electron guns, an electrostatic quadrupole switching lens that selects between the sources, various focusing lenses, a quadrupole mass analyzer, and two secondary electron multiplier (SEM) detectors. Instrument control is provided by the Flight Computer, according to the values entered in various software tables (Section 3.1). A sketch of the key INMS components is shown in Figure 11, and the primary instrument parameters are listed in Table IV.

The gas densities at Titan and other INMS targets are nearly optimal for direct sampling without ambient pressure reduction. Two separate ion sources-a closed source and an open source-rather than a single combined quasi-open ion source are used in the INMS instrument in order to optimize interpretation of the neutral species (Figure 12). In the closed source mode, the ram pressure of the inflowing gas creates a density enhancement in the source antechamber, allowing the sampled species to be measured with relatively high precision and sensitivity. This mode will be used to measure species, such as $\mathrm{N}_{2}$ and $\mathrm{CH}_{4}$, which do not react with the antechamber surfaces. The open source has the advantage that it can measure reactive neutral radicals, such as atomic nitrogen, and ions. In this mode, the ambient neutral gas density is sampled directly with no stagnation enhancement and no collisions with the surfaces of the instrument. For open source ion measurements, the INMS angular response can be increased beyond the geometric view cone $\left(8.6^{\circ}\right.$ cone half angle) by adjusting the voltages on the plates in the ion deflector/trap and the exit aperture lens (top plate lens). For neutral sampling in the open source mode, the ion trap removes incoming ions and electrons, which could cause spurious ionization of neutral species, and allows only neutrals to pass into the ionization region. In both the closed and open source modes, impacting electrons emitted from the hot-filament electron guns ionize the sampled neutrals.

Electrostatic lenses are used to focus the ambient ions and those created from ambient neutrals by electron impact into the quadrupole switching lens (Mahaffy and Lai, 1990), an electrostatic device that steers ions from either the closed or open source through a system of focusing lenses into a dual radio frequency (RF) quadrupole mass analyzer. The mass analyzer selectively filters the ions according to their mass-to-charge ratio. Two secondary electron multipliers operating in pulse-counting mode cover the dynamic range required. The INMS mass range was increased from its initial value of 1-66 to 1-99 Daltons (atomic mass units) 


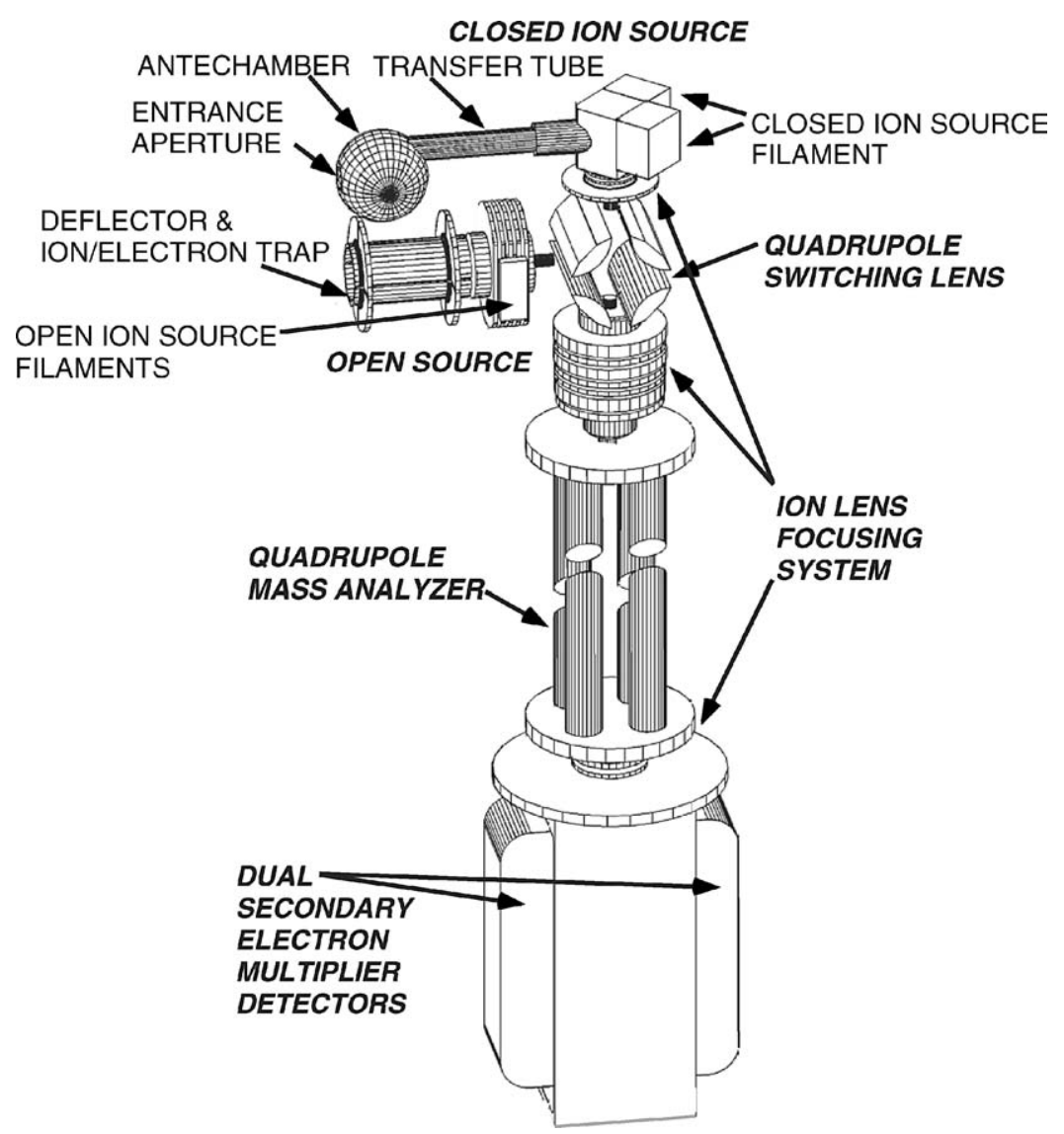

Figure 11. Schematic illustrating the principal components of the Cassini Ion and Neutral Mass Spectrometer (INMS).

to allow detection of heavier hydrocarbon species and possible pre-biotic cyclic hydrocarbons such as $\mathrm{C}_{6} \mathrm{H}_{6}$. Using two different radio frequencies and scanning the mass-to-charge ratios from 1 to 8 and then from 12 to 99 Daltons accomplish this.

The INMS instrument is mounted on the Cassini's Fields and Particles Pallet (FPP). The outward normal to both the open and closed source INMS apertures lies in the spacecraft $-\mathrm{X}$ direction. The open source geometric field of view is about $8.6^{\circ}$ cone half angle. This limits the angular response for neutrals and ions measured in the open source mode, although, as noted above and discussed in greater detail below, the angular response for the measurement of ambient ions can be improved by adjusting the voltage applied to the open source ion deflectors. In contrast, the closed source has a much wider geometric field of view of approximately $2 \pi$ steradians. The open source is vented to lower the ion source and analyzer pressures (increasing the ion mean free path) during a Titan pass when the spacecraft ram is 
TABLE IV

Cassini Ion and Neutral Mass Spectrometer (INMS) parameter summary.

\section{Neutral gas sampling systems \\ Ion sampling system \\ Sample system switching \\ Viewing angle (angle of response) \\ Neutral mode ionization sources}

Mass analyzer

Mass range

Scan modes

Resolution/crosstalk

Detector system

Sensor sensitivity

Density/flux for 1 count per integration period, no background
(1) Open source (molecular beaming) with energy discrimination; (2) closed source

Thermal and suprathermal positive ions

Electrostatic quadrupole deflector

(1) Open source $8.6^{\circ}$ cone half angle; (2) closed source $\sim 2 \pi$ steradians; (3) exhaust vent $\sim 2 \pi$ steradians

Electron impact ionization; for the primary filament Open source: 25 and $70 \mathrm{eV}$;

Closed source: 27 and $71 \mathrm{eV}$

Quadrupole mass filter, $0.5 \mathrm{~cm}$ field radius, $10 \mathrm{~cm}$ rod length

Radio frequencies: 1.64 and $3.57 \mathrm{MHz}$

1-8, 12-99 Daltons nominal; high pass filter mode

(1) Survey: scan mass range in $1 / 8$ or 1 Dalton steps; (2) adaptive mode: select mass values

$10^{-6}$ for adjacent masses

Two secondary electron multiplier detectors operating in pulse counting mode (detector noise $<1$ count per minute in laboratory)

Dynamic range of two detector system for 1 integration period sample $\sim 10^{8}$

(1) Ion flux sensitivity for nominal $3 \mathrm{eV}$ energy, entrance aperture diameter $0.864 \mathrm{~cm}$

$$
\begin{aligned}
& \mathrm{He}^{+} \sim 9 \times 10^{-4}(\text { counts } / \mathrm{sec}) /\left(\mathrm{ions} / \mathrm{cm}^{2} / \mathrm{sec}\right) \\
& \left.\mathrm{Ar}^{+} \sim 7 \times 10^{-4} \text { (counts } / \mathrm{sec}\right) /\left(\mathrm{ions} / \mathrm{cm}^{2} / \mathrm{sec}\right) \\
& \left.\mathrm{Kr}^{+} \sim 5 \times 10^{-4} \text { (counts } / \mathrm{sec}\right) /\left(\mathrm{ions} / \mathrm{cm}^{2} / \mathrm{sec}\right)
\end{aligned}
$$

(2) Neutral mode sensitivity for mass $28, \mathrm{~N}_{2}$, primary filament Closed source, detector $1 \sim 6 \times 10^{-4}$ (counts $\left./ \mathrm{sec}\right) /\left(\right.$ particle $/ \mathrm{cm}^{3}$ )

Closed source, detector $2 \sim 3.6 \times 10^{-7}$ (counts/sec)/(particle $/ \mathrm{cm}^{3}$ )

Open source, detector $1 \sim 1.9 \times 10^{-4}$ (counts $\left./ \mathrm{sec}\right) /\left(\right.$ particle $\left./ \mathrm{cm}^{3}\right)$ Open source, detector $2 \sim 1.3 \times 10^{-7}$ (counts $\left./ \mathrm{sec}\right) /\left(\right.$ particle $\left./ \mathrm{cm}^{3}\right)$

(3) Maximum energy for ion beaming mode: $54 \mathrm{eV}$; for neutral beaming mode: $103 \mathrm{eV}$.

Minimum neutral ion source density

Closed source $\sim 5 \times 10^{4}$ particles $/ \mathrm{cm}^{3}$

Open source $\sim 2 \times 10^{5}$ particles $/ \mathrm{cm}^{3}$

Maximum neutral ion source density $\sim 10^{12}$ particles $/ \mathrm{cm}^{3}$

Maximum closed source ram enhancement factor for $\mathrm{N}_{2}$ at $6 \mathrm{~km} / \mathrm{sec}=50$

Minimum ion flux and density for $3 \mathrm{eV}$ ions $\sim(7-10) \times 10^{3} \mathrm{ions} / \mathrm{cm}^{2} / \mathrm{sec}$ for nom. $3 \mathrm{eV}$ ions $\sim 10^{-3}$ particles $/ \mathrm{cm}^{3}(6 \mathrm{~km} / \mathrm{sec}$ speed $)$ 
TABLE IV

(Continued).

\begin{tabular}{ll}
\hline Data rate & Sample integration period $=31.1 \mathrm{~ms}$; total sample period $=34.0 \mathrm{~ms}$ \\
Spatial resolution & $\sim 200$ meters along spacecraft track per sample period \\
Instrument control & Microprocessor: MA31750, RAM: 64 Kbytes, IORAM: 32 Kbytes, \\
& PROM: 64 kbytes \\
Telemetry & Science data rate: $1498 \mathrm{bps}$; housekeeping data rate: $12 \mathrm{bps}$ \\
& Reduced science packet production mode implemented \\
Deployment mechanism & Metal ceramic breakoff cap, pyrotechnically activated \\
Power (current best & Neutral mode: average $23.3 \mathrm{~W}$ \\
estimate) & Ion mode: average $20.9 \mathrm{~W}$ \\
& Sleep: average $13.1 \mathrm{~W}$ \\
& Off: $4 \mathrm{~W}$ replacement heater \\
Size & Maximum envelope (cruise): height $20.3 \mathrm{~cm}(8.0$ in), length $42.2 \mathrm{~cm}$ \\
& $(16.6$ in), width $36.5 \mathrm{~cm}(14.4$ in $)$ \\
Weight (current best & $10.29 \mathrm{~kg}$ including $\sim 1.4 \mathrm{~kg}$ for tantalum radiation shield $0.23 \mathrm{~cm}$ \\
estimate) & $(0.090$ in) thick \\
\hline
\end{tabular}

approximately along the $-\mathrm{X}$ direction. Venting occurs at right angles to the $-\mathrm{X}$ axis.

The INMS sensor and supporting electronics are packaged as shown in Figures 13 and 14. The aluminum electronics box is mechanically strong and lightweight and provides electrostatic shielding for the instrument as well as protection against micrometeoroids and high-energy particles. A 0.23 -cm (0.09-in) thick tantalum shield shields the secondary electron multipliers (SEM) against magnetospheric background radiation, which could interfere with the measurement of low-density gases in the vicinity of Saturn's icy satellites. The tantalum shielding reduces the modeled background radiation flux to an acceptable level of less than $10^{-11}$ particles $\mathrm{cm}^{-2} \mathrm{sec}^{-1}$. Multilayer insulation (MLI) is used for thermal shielding and micrometeoroid protection of the sensor and electronics package, and is attached to the brackets as shown in Figure 13. A thermal radiator panel is used to dissipate internally generated heat and is not covered by the MLI. The package design is such that the entrance apertures of the sensor protrude beyond the edge of the FPP platform and MLI insulation. This configuration prevents contamination from spacecraft out gassing and provides the maximum field of view.

The INMS sensor is made of titanium and is free of organic materials. It was baked to about $280^{\circ} \mathrm{C}$ for vacuum clean up. During the launch and cruise phases, a getter pump is used to maintain the sensor interior at a low pressure; internal pressure is monitored with a miniature ion gauge and a thermistor. In this sealed configuration the INMS retains a residual gas atmosphere (composed primarily of helium, argon, methane, carbon monoxide, carbon dioxide, hydrogen, and water). 


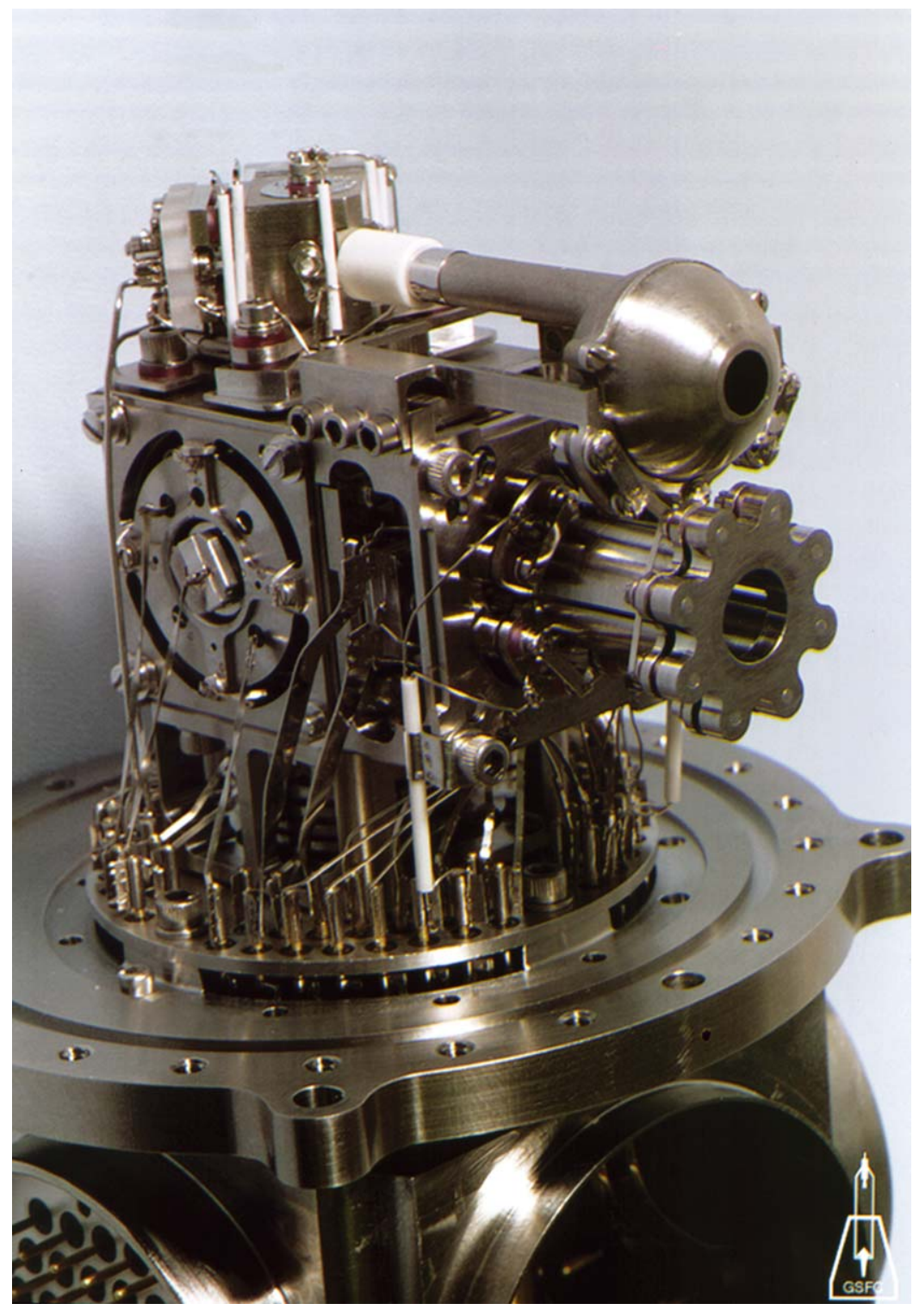

Figure 12. Photo showing the INMS closed and open ion sources.

This residual atmosphere can be used for sensor testing. The INMS will remain sealed and at near vacuum interior pressures to preserve instrument cleanliness until ambient atmosphere measurements can be made.

The INMS entrance apertures are masked by a single plate and are covered by a metal-ceramic break-off hat that can be pyrotechnically separated from the main sensor. Ejection of the break-off hat and opening of the sensor to the external 


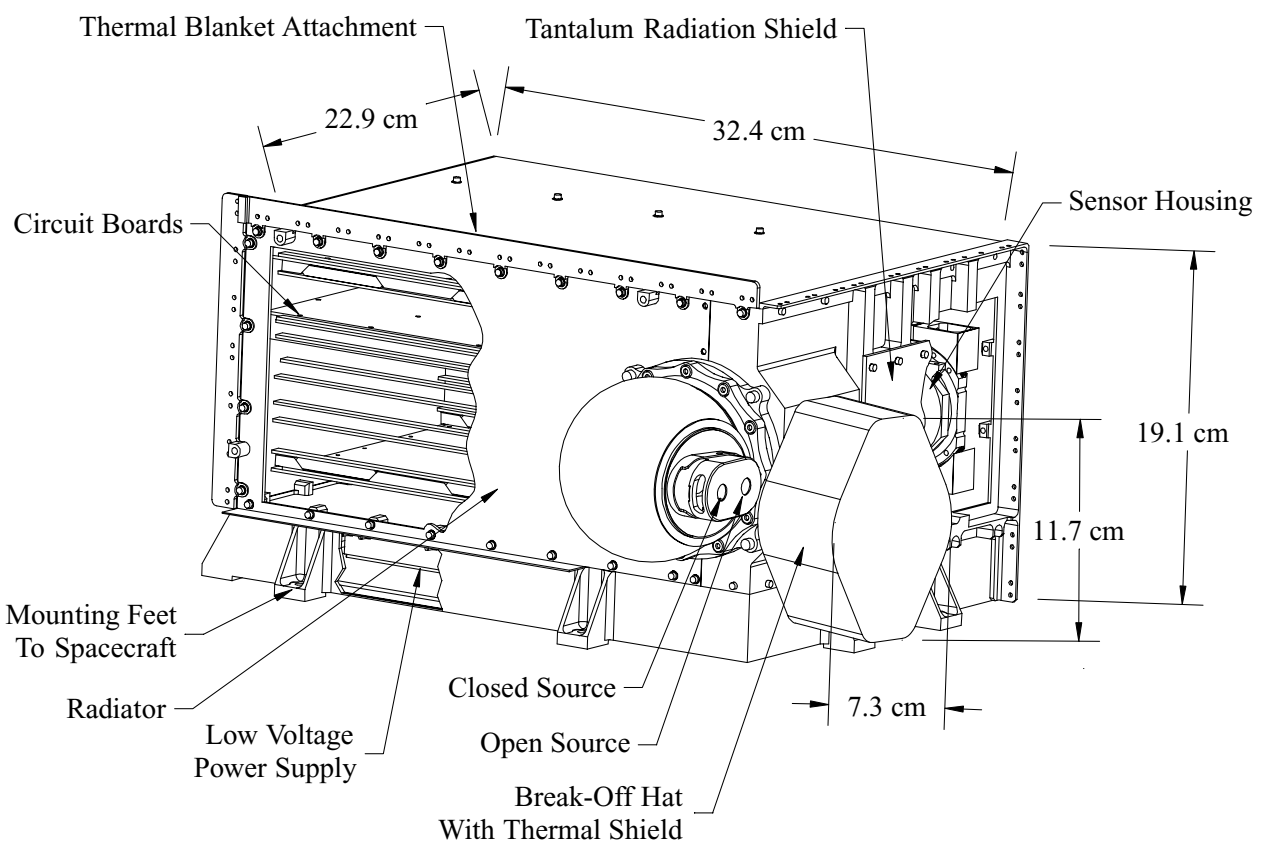

Figure 13. Schematic showing the INMS with the electronic and mechanical subsystems.

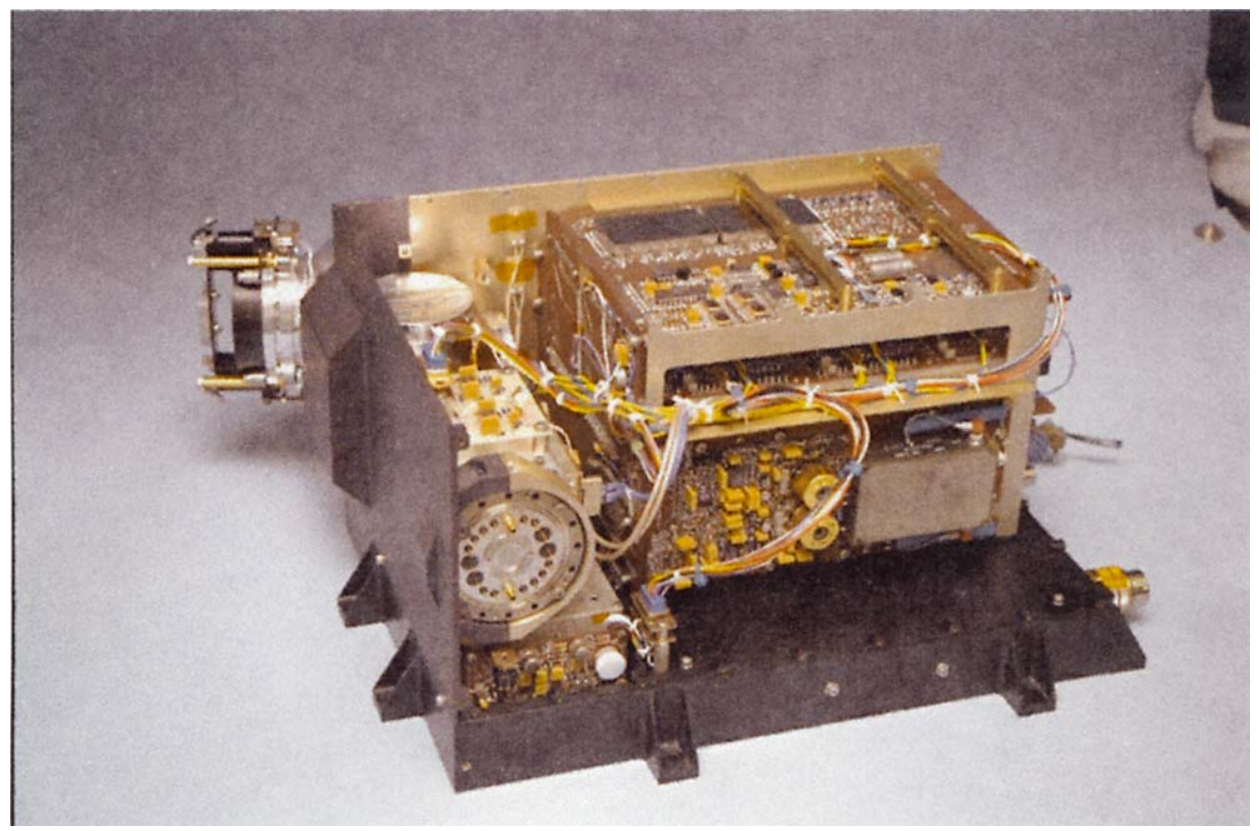

Figure 14. The INMS sensor and electronics. 
environment are planned to occur after SOI main engine burn but prior to the descending ring plane crossing. The break-off device has been used successfully on Earth-orbiting satellites as well as on the Pioneer Venus Orbiter.

\subsection{INMS COMPONENTS AND OPERATING PRINCIPLES}

As discussed above, the INMS instrument uses two ion sources, a closed source for the measurement of non-reactive neutrals and an open source for the measurement of reactive neutrals and ions. The INMS is thus operated in three basic modes: neutral closed source, open source neutral beaming, and open source ion. In this section, we describe in detail the major INMS components and the principles of operation for each of the three modes. (A fourth mode, open source thermal neutral, is possible but would only be used as a backup in the event that the closed source fails. It will not be discussed in this paper. In the following, whenever reference is made to the "open source neutral mode," the "neutral beaming mode" is meant unless otherwise specified.)

\subsubsection{Closed and Open Ion Sources}

The closed source for ionization of neutrals consists of a spherical antechamber with an entrance orifice for the ambient gas flux and a cylindrical tube that connects this antechamber to the entrance of the ionization region (Figure 15). The incoming gas makes many collisions with the antechamber surfaces and thermally accommodates to the surface temperature. A ram enhancement of the antechamber pressure above that of the ambient gas is achieved by limiting gas conductance from the antechamber into the ion source while maintaining a much higher gas conductance through the entrance aperture. Once in the ion source, an electrostatically collimated electron beam emitted from one of two redundant electron gun assemblies ionize the neutral gas. The ions thus formed are focused into the quadrupole mass analyzer by a series of cylindrical electrostatic lenses and by the quadrupole switching lens.

The entrance aperture of the open source ion (Figure 15) leads into the ion deflector/trap, a cylindrical antechamber that contains four electrodes in equally spaced segments. The four deflectors can be used to trap incoming ions and electrons during neutral measurements or to focus incoming ions into an aperture in the top plate lens (TPL). In the ion mode, the deflectors and TPL are set at ground potential as the default setting; the deflector electrode and TPL lens potentials can be programmed to vary as a function of species mass and angle of attack to improve the instrument's angular response (see Section 2.3). The open source ionization region contains two redundant opposing hot-filament electron guns that are used to ionize the neutral beam; in the open source ion mode, the electron gun filaments are switched off. Four open source lenses (designated OL1-4) focus the ion beam into the quadrupole-switching lens. OL4 serves as the entrance lens to the switching lens; its potential is set at $-5 \mathrm{~V}$ in the open source neutral mode and at $-30 \mathrm{~V}$ 


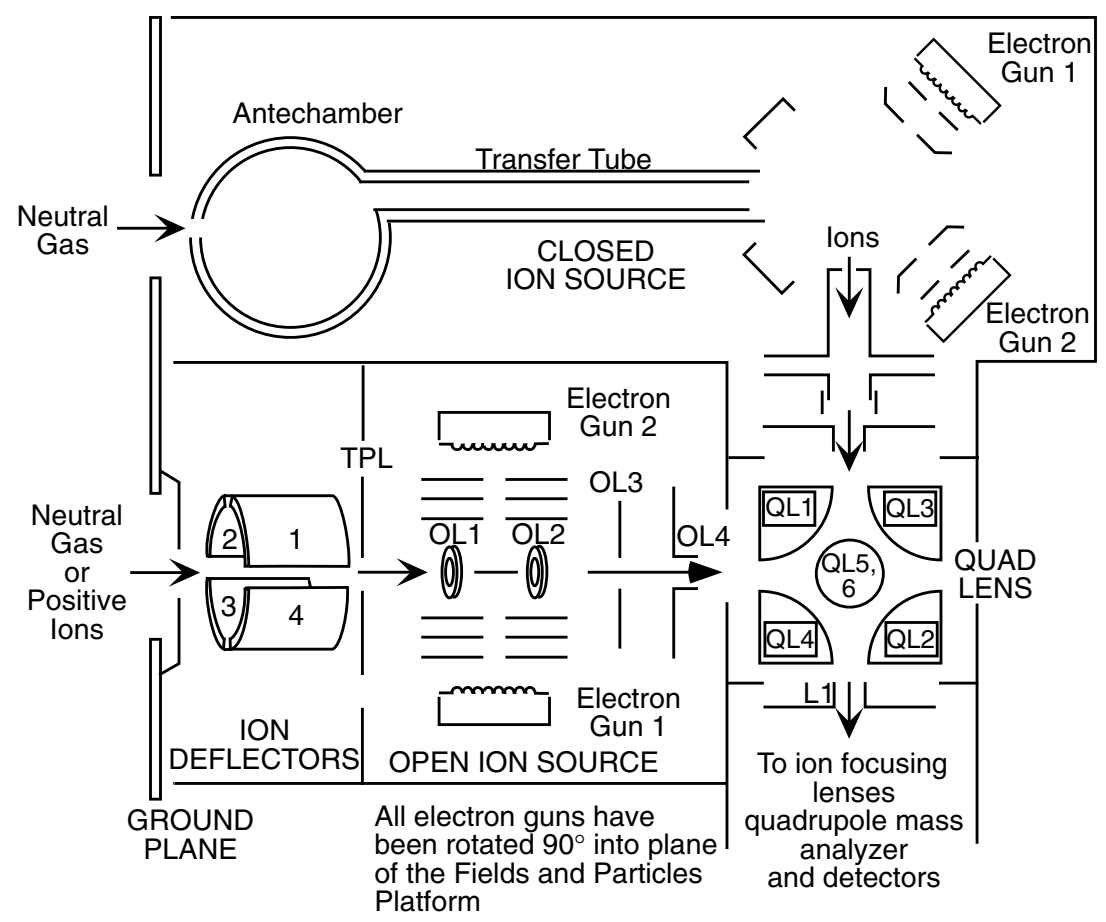

Figure 15. Schematic showing both INMS ion sources, the deflector plates in the ion trap, the open source focusing lens (OL1-4), and the switching lens electrodes (QL1-4).

in the ion mode. These settings reflect the different requirements for measuring neutrals or ions and determine the mean energy of the ions being transmitted into the switching lens.

In both the closed source and open source neutral modes, impacting electrons emitted from hot-filament electron guns ionizes sampled neutrals. Electron impact ionization offers significant efficiency for almost all neutral species and produces unique fractionation patterns that aid in the identification of molecules. In some cases, fragment ions created by the dissociative ionization of the more abundant primary species can mask the presence of trace constituents. However, this difficulty can, to a large degree, be overcome by using two ionization energies to produce different fractionation patterns that can be exploited to minimize interference. Nominal electron energies of 70 and $25 \mathrm{eV}$ have been selected for INMS operation. The electron guns have filaments made of a tungsten-rhenium alloy $(0.0076 \mathrm{~cm}$ diameter; $97 \%$ tungsten, $3 \%$ rhenium) in a coiled configuration, which are heated to emit an electron beam. The beam is collimated and focused by electrostatic lenses.

The electron guns are controlled according to information stored in the Cycle Tables (Section 3.1). These tables specify whether the filaments are on or off and indicate the ionization energy to be used. Normally the higher electron energy is used; however, sometimes the lower energy may be used to obtain simpler fractionation 
patterns. Changing ionization energies requires that the filaments be switched off while the energy is being changed and then turned back on again. This prevents the filaments from being driven to their maximum current during the transition. The process takes about $10 \mathrm{sec}$.

\subsubsection{Quadrupole Switching Lens}

The quadrupole switching lens (Mahaffy and Lai, 1990) consists of four circular rod sectors (QL1-4) mounted in a cube assembly and two end plates (OL 5/6). As commanded by the Flight Computer, the switching lens selects ions from either the closed source or the open source and directs them into the common entrance lens system of the quadrupole mass analyzer. When the INMS is operating in the closed source mode, the quad lens simply serves as part of a straight-line focusing lens system. In the open source mode, the switching lens provides a nearly hyperbolic electrostatic field that deflects by $90^{\circ}$ ions entering the mass analyzer from the open source. The switching lens rod potentials can be set to voltages ranging from -103 to $+101 \mathrm{~V}$ as commanded by the Flight Computer according to the relevant parameters in the flight software control tables (cf. Section 3.1). Because the deflection angle of the incoming ions is influenced by ion mass, spacecraft velocity, and charge, the voltages applied to the switching lens rods must be adjusted to compensate for these factors. In the open source ion mode, the switching lens can be used to provide estimates of ion energy distributions (over the energy range 1-100 eV) by varying the rod voltages while dwelling on a particular mass to selectively direct particles of varying kinetic energies into the analyzer. The energy resolution $(\Delta E / E)$ is albeit a rather coarse 0.3 (see Figure 37).

In the open source mode, the switching lens rods 1-4 are slaved such that QL1 $=\mathrm{QL} 2$ and $\mathrm{QL} 3=\mathrm{QL} 4$. Voltages on the rods are adjusted to allow transmission of an ion beam of a given energy according to the equation QL1 $=\mathrm{QL} 2=-(\mathrm{QL} 3$ $+2 K$ ), where $K$ is the absolute value of the potential applied to the entrance lens OL4 (and also to the exit lens L1), i.e., $K$ equals approximately $5 \mathrm{~V}$ in the neutral beaming mode and $30 \mathrm{~V}$ in the ion mode. The potential (in volts) applied to QL3 varies with the ion energy. In the closed source mode, switching lens voltages are set as follows: QL1 and 3 $=-88 \mathrm{~V}$; QL2 and $4=0 \mathrm{~V}$. End plate voltages are set at $0 \mathrm{~V}$ in the open source mode and at $+2.59 \mathrm{~V}$ in the closed source mode.

Laboratory studies using an ion beam (see Section 4.2) with energies ranging from several $\mathrm{eV}$ to about $20 \mathrm{eV}$ were performed to characterize switching lens operation in the open source neutral and open source ion modes (see Section 4.3), and the results were incorporated in the Switching Tables (Section 3.1).

\subsubsection{Quadrupole Mass Analyzer}

The quadrupole mass analyzer (or mass filter) allows ions transmitted through the switching lens and ion focusing lens to a limited range of mass-to-charge ratios, typically a fraction of a mass unit. It consists of four precision-ground hyperbolic rods mounted in a mechanical assembly. The rod spacing parameter, $r_{0}$, is $0.58 \mathrm{~cm}$ 
and the rod length is $10 \mathrm{~cm}$. The quadrupole rods are excited by radio frequency (RF) and direct current (DC) potentials that together create a dynamic electrostatic field within the quadrupole region that controls the transmitted mass (mass/charge ratio), the resolution, and the transmission efficiency. A mass scan is effected by varying the RF potential amplitude, $V_{\mathrm{ac}}$, to satisfy the relationship $M=0.55 \mathrm{~V}_{\mathrm{ac}} / f^{2} ; V_{\mathrm{ac}}$ is in Volts, $f$ is the RF frequency in MHz, and $M$ is mass in atomic mass units (Daltons). The nominal mass range for the INMS is 1-99 Daltons. Two separate RF frequencies are used; a high frequency $(3.57 \mathrm{MHz})$ for the mass range 1-8 Daltons and a low frequency $(1.64 \mathrm{MHz})$ for the mass range 12-99 Daltons. The control voltages $\left(V_{\mathrm{ac}}\right.$ and $V_{\mathrm{dc}}$ ) applied to the quadrupole filter rods are calculated by the flight software as a function of Daltons and the RF frequency selected. Because frequency drift can cause mass peaks to be slightly offset, RF frequency is monitored, allowing the control voltages to the rods to be corrected for drift. Resolution is controlled over each mass range by programming the $V_{\mathrm{dc}} / V_{\mathrm{ac}}$ ratio to maintain the resolving power as defined by a cross-talk criterion appropriate for that mass range. The resulting flat-topped peaks and narrow widths allow a mass scan mode in which each mass is monitored by a single step to achieve the lowest detection limit in a specified period. In addition to performing mass scans, the quadrupole analyzer also operates in "total transmission" or high-pass filter mode in which $V_{\mathrm{dc}}$ is reduced to zero and all masses above a specified Dalton/charge ratio are transmitted to the detectors.

When the INMS is operating in the open source mode, a quadrupole bias voltage, as specified in the Focus Table (Section 3.1), is added to the DC voltage applied to the RF mass analyzer rods to slow down incoming ions and increase their residence time in the analyzer's RF field. In the case of ions transmitted from the closed source, the ion energy is similar for all species because the gas has been thermalized in the antechamber. In the case of the open source, the ion energy is a function of the species mass and the relative velocity vector, and is higher than that of the closed source ions. This higher energy into the analyzer results in a wider mass peak width (Kasprzak et al., 1987). Slowing the ions down by applying a quadrupole retarding bias potential increases the mass resolution by reducing the peak width (Figure 16). In the open source neutral and ion modes, the quad bias voltage $=\mathrm{KE}-1 \mathrm{~V}$ ( $\mathrm{KE}$ is the ion energy in $\mathrm{eV}$ ); in the closed source mode, a quad-bias voltage of -1 $\mathrm{V}$ is applied.

\subsubsection{Secondary Electron Multipliers}

Ions exiting the quadrupole mass filter are detected by one of two secondary electron multipliers (continuous channel electron multipliers). They are electronically biased such that most of the ions are deflected into the primary detector with a much smaller fraction (on the order of several per thousand) being scattered into the secondary detector. This dual system is identical to that used in the GC/MS instrument on the Huygen's probe (Niemann et al., 1997) and is used to increase the overall dynamic range of signal detection by about a factor of $\sim 1500$ for INMS (see Table IV). Charge pulses at the anode of the multiplier are amplified and counted. 


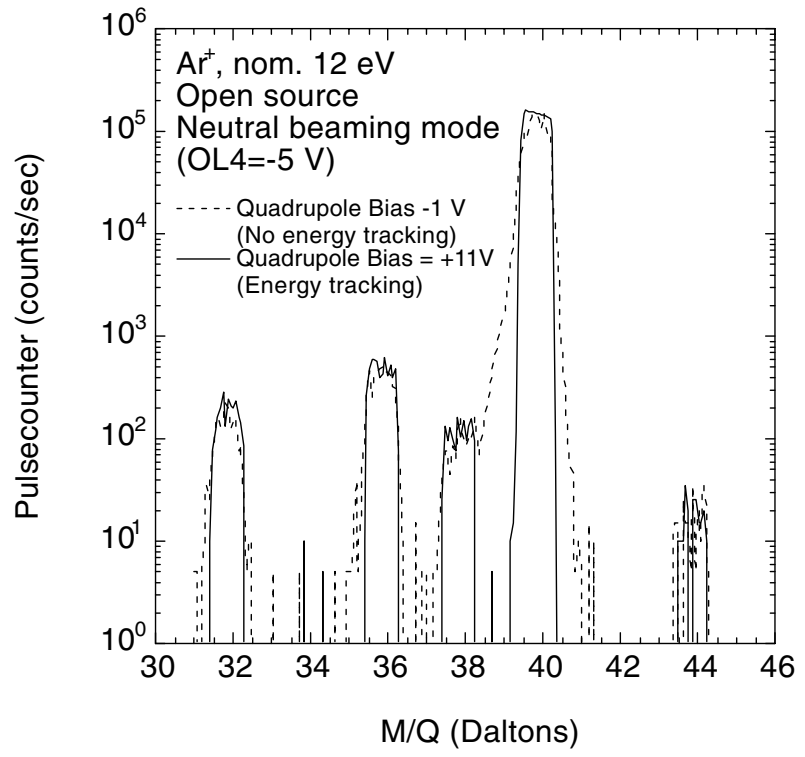

Figure 16. Spectrum showing the reduction in the width of the mass peak for $\mathrm{Ar}^{+}$that results from the application of a $+11 \mathrm{~V}$ quad bias to the mass analyzer. The quad bias compensates for the energy of the ion in the open source and equals KE (the kinetic energy of the ion) $-1 \mathrm{~V}$.

The detection threshold is determined by the background noise in the multiplier (approximately 1 count per minute in the laboratory). The upper count rate of each detector system is about $10 \mathrm{MHz}$, limited by the product of the multiplier pulse width and gain bandwidth of the pulse amplifier counter system. (There is a non-linear response that occurs in the range of $1-10 \mathrm{MHz}$ ). Ion counts above this value can be measured directly as an analog current. Multiple sample periods can be combined to lower the detection threshold to the background noise level (signal/noise ratio $=1$ ). Assuming a maximum $1 \mathrm{MHz}$ counting rate, the dynamic range of the two detector system is $\sim 10^{8}$.

\subsection{Sensor Sensitivity and Detectability Thresholds}

The sensitivity to neutral species varies with species because of the different ionization efficiencies for neutrals in the ion sources, the differential transmission of the quadrupole switching lens and mass filter, and the conversion efficiency at the secondary electron multiplier. In general, when INMS is operated in the neutral closed source mode, neutrals with densities of $\sim 5 \times 10^{4} \mathrm{~cm}^{-3}$ can be detected; in the open source neutral mode, the detection threshold is higher, $\sim 2 \times 10^{5} \mathrm{~cm}^{-3}$. In the case of ions, the instrument's sensitivity varies with ion species because of different spacecraft equivalent energies for the different masses, the differential transmission of the quadrupole switching lens and filter, and conversion efficiency 
at the secondary electron multiplier detector. Spacecraft potential will also influence INMS sensitivity to ions by modifying the incoming flux and ion trajectory directions relative to the spacecraft. At a spacecraft velocity of $6 \mathrm{~km} \mathrm{sec}^{-1}$, the minimum ion density is $\sim 10^{-2} \mathrm{~cm}^{-3}$.

In the neutral closed source mode, the background count rate due to gases adsorbed onto the surface of the source may be comparable to the minimum detectable density in certain regions of the spectrum, particularly below about 50 Daltons. For both the closed and open sources, interference at some mass numbers by other ambient gases present in high concentrations also presents a problem (cf. Section 4.2 and Figure 32). In the closed source, the calculated ambient density is lower than the ion source density because of the velocity ram enhancement. The maximum ion source density is limited by mean free path conditions in the ion source and analyzer regions.

There are several potential sources of a detector background. Section 2.1 discusses the use of an external tantalum shield around the secondary electron multiplier section of the sensor housing to reduce the effect of magnetospheric particle radiation. For high-energy electrons and ions, the physical geometry of the path from the open or closed source entrance apertures to the detectors involves a right angle bend, conducting surfaces with many constricting apertures and positive voltages that are a fraction of a $\mathrm{keV}$. The probability that a photon or a high-energy particle will make it to the detectors is extremely difficult to estimate or simulate in the laboratory, but is quite low. The net effect of either photons or highly energetic ions/electrons is that they will not be mass/charge separated in the quadrupole section of the sensor because of their high energy or uncharged condition. This will create a mass independent background in the detectors. In performing a full range mass scan (1-99 Daltons), those mass slots not occupied by ambient ions or neutrals can be used to estimate the effect of this mass-independent background, which can be subtracted off from the ambient mass peaks.

\subsection{INSTRUMENT RESPONSE}

In order for the INMS to make valid ion and neutral density measurements, the spacecraft velocity vector plus the drift velocity of any neutral or plasma flows (crosswinds) must be within the field of response of the appropriate source.

\subsubsection{Closed Source Mode}

The closed source response for several gas species and different molecular masses as a function of the angle of attack (angle between the aperture normal and the spacecraft velocity vector) is given in Figure 17. Particles entering through the aperture collide many times with the surfaces of the ion source electrodes and enclosure, and thermally accommodate to the surface temperature before leaving through the transfer tube. For angles of attack $<90^{\circ}$ this results in an enhancement of the number density in the antechamber over that in the ambient atmosphere. 


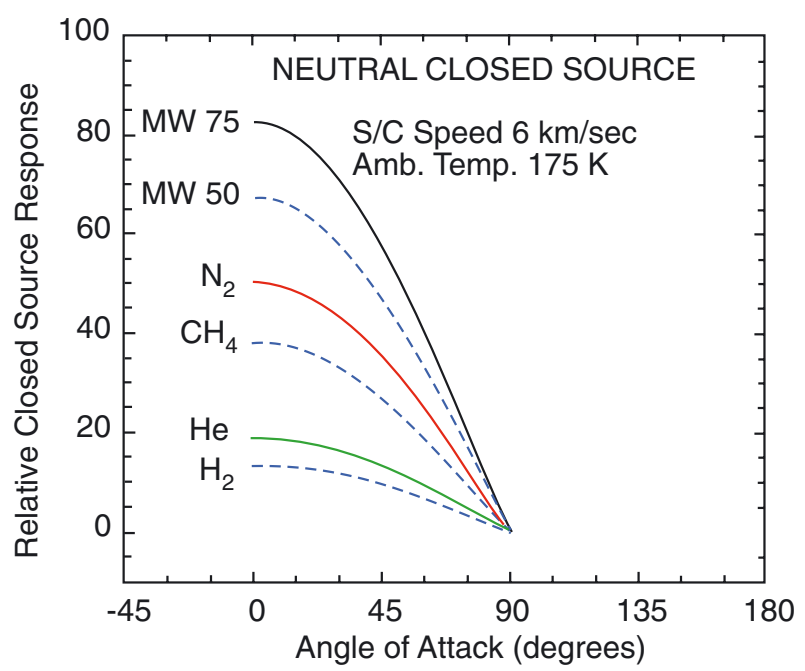

Figure 17. Plot showing the response of the INMS in the closed source mode as a function of the angle of attack. MW: molecular mass (in Dalton).

The maximum ram enhancement factor for $\mathrm{N}_{2}$ and a spacecraft velocity of $\sim 6 \mathrm{~km}$ $\mathrm{sec}^{-1}$ is 50 . The signal varies approximately with the cosine of the angle of attack, and is proportional to the product of the spacecraft speed and the square root of the ratio of the molecular weight divided by the gas temperature. A balance of the incoming number flux at the spacecraft speed and the outgoing gas flux at the antechamber wall temperature determines the number density in the antechamber. The relationship between the ion source density, incoming flux, and ambient density is predictable from kinetic theory. Non-reactive species (e.g., $\mathrm{N}_{2}$ and $\mathrm{CH}_{4}$ ) will be measured in this mode. In the closed source mode, ambient density measurements can be made at angles of attack ranging from about 0 to $90^{\circ}$, depending on the gas background.

\subsubsection{Open Source Neutral Mode}

In the open source neutral mode, the ambient particle density is measured directly. The quasi-open source geometry allows ambient gas to enter the ionization region directly and permits measurement of chemically active species. The angular response is limited by the geometric field of view. The theoretical response of the open source neutral mode as a function of angle of attack is given in Figure 2.4.2 for a view cone half angle of $8^{\circ}$. Optimum open source neutral mode measurements will occur at Titan closest approach, where the density is sufficiently large and the angle of attack is approximately within the geometric view cone. During many Titan flybys the spacecraft will provide tracking of local nadir for the Radar instrument. In this case the INMS angle of attack needed for the open source operation ranges 


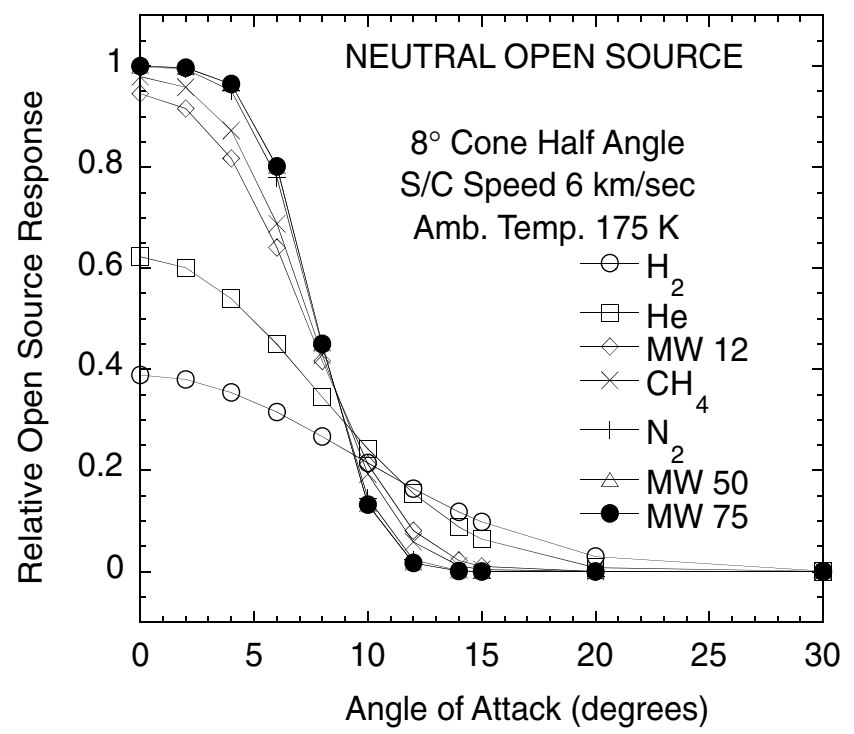

Figure 18. Plot showing the response of the INMS in the open source neutral beaming mode as a function of the angle of attack.

from 0 to $8^{\circ}$ within about 1.4 min of closest approach at a spacecraft speed of $6 \mathrm{~km}$ $\mathrm{sec}^{-1}$ (see Figure 2.4.2).

For measurements in open source neutral mode, neutrals that have been thermally accommodated to the ion source walls must be distinguished from the direct beaming component. This is achieved by (1) maximizing the gas conductance from the ionizing region into the vent region at right angles to the open source axis, which reduces the velocity ram stagnation density enhancement; (2) minimizing the ion acceleration into the switching lens; and (3) using the quadrupole switching lens transmission, which is a function of energy, to filter the ion energy.

Numerical studies (Swaminathan et al., 1996) indicate that $<2 \%$ of mass 28 ions from thermally accommodated $\mathrm{N}_{2}$ gas are transmitted through the mass analyzer. This is with the switching lens potential set to transmit a 28-Daltons ionized neutral beam at spacecraft energies (the spacecraft equivalent energy for a $6 \mathrm{~km} \mathrm{sec}^{-1}$ spacecraft velocity is $5.22 \mathrm{eV}$ compared to $0.015 \mathrm{eV}$ for a thermally accommodated gas at $300 \mathrm{~K}$ temperature). A laboratory estimate of this ratio was made using thermal gas ions and operating the switching lens in neutral beaming mode with the entrance lens potential (OL4) set to $-5 \mathrm{~V}$. The mass was set at 28 in the total mode $\left(V_{\mathrm{dc}}=0 \mathrm{~V}\right.$ and $V_{\mathrm{ac}}$ set for mass 28). Figure 20 shows the energy scans for a thermalized neutral gas, with the open source lenses OL1 and OL2 set at $0 \mathrm{~V}$, and for a simulated neutral beam $(\mathrm{OL} 1=\mathrm{OL} 2=2 \mathrm{~V})$. The contribution of the thermal ions to the more energetic $2 \mathrm{~V}$ ions at signal maximum is about $10^{-4}$ for equal signal amplitudes. Comparison of the overlap area of the two curves with the total area under the neutral beaming curve yields a similar value, $7 \times 10^{-3}$. As in 

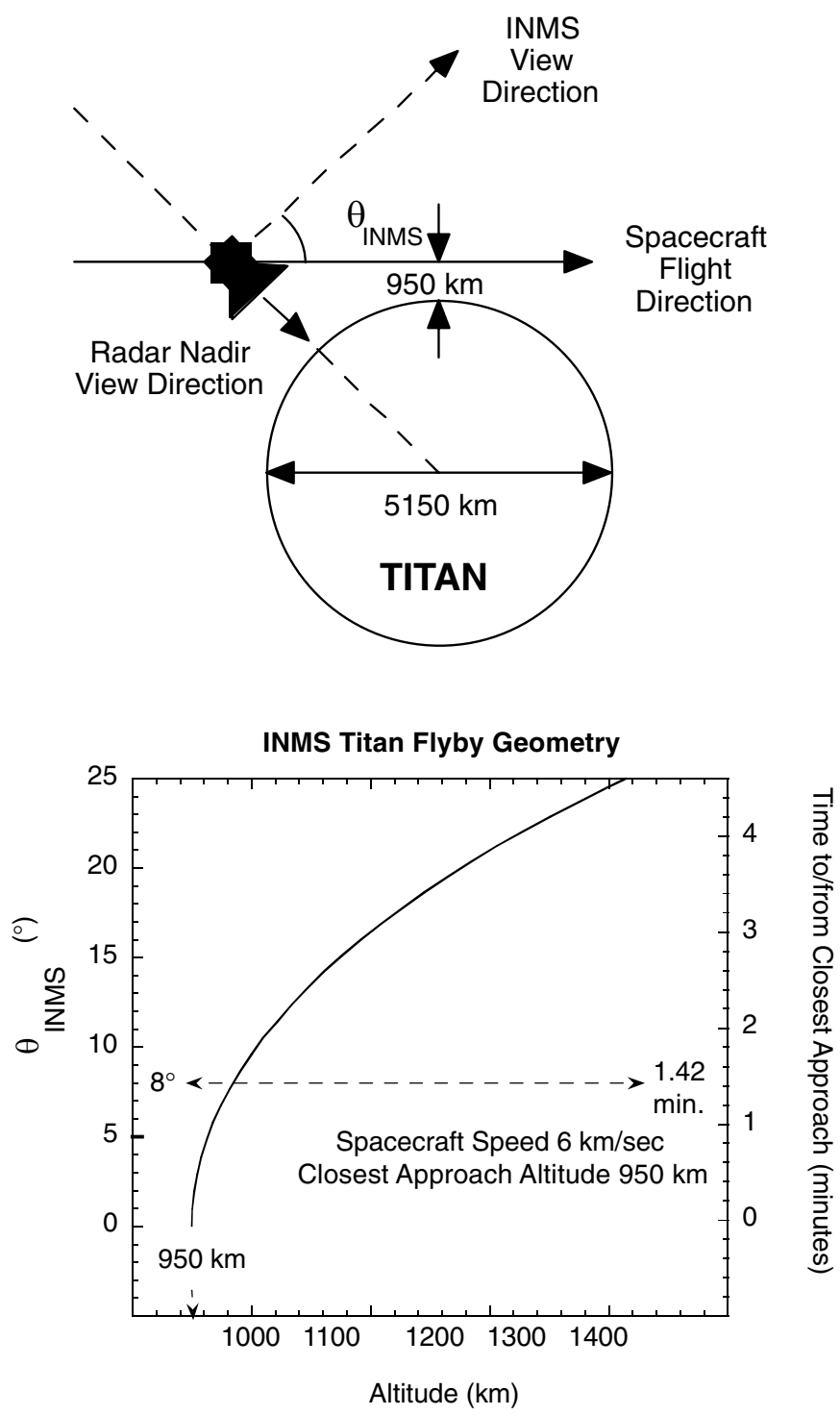

Figure 19. Titan flyby geometry and the change in INMS angle of attack as function of altitude with the Orbiter in Radar Mode.

the closed source, the thermalized gas component is formed in the open source by scattering off the walls of the ion source; little ram enhancement occurs because the gas is vented. If we assume, as an extreme case, that the density of the open source thermalized component is equivalent to the maximum ram enhancement of about 50 (for $\mathrm{N}_{2}$ at an angle of attack of $0^{\circ}$ ), the thermal contribution would be less than or equal to $50 \times 10^{-4}=5 \times 10^{-3}$, which is negligible for mass 28 . Neutral 
INMS Energy Scan, Neutral Gas, Open Source

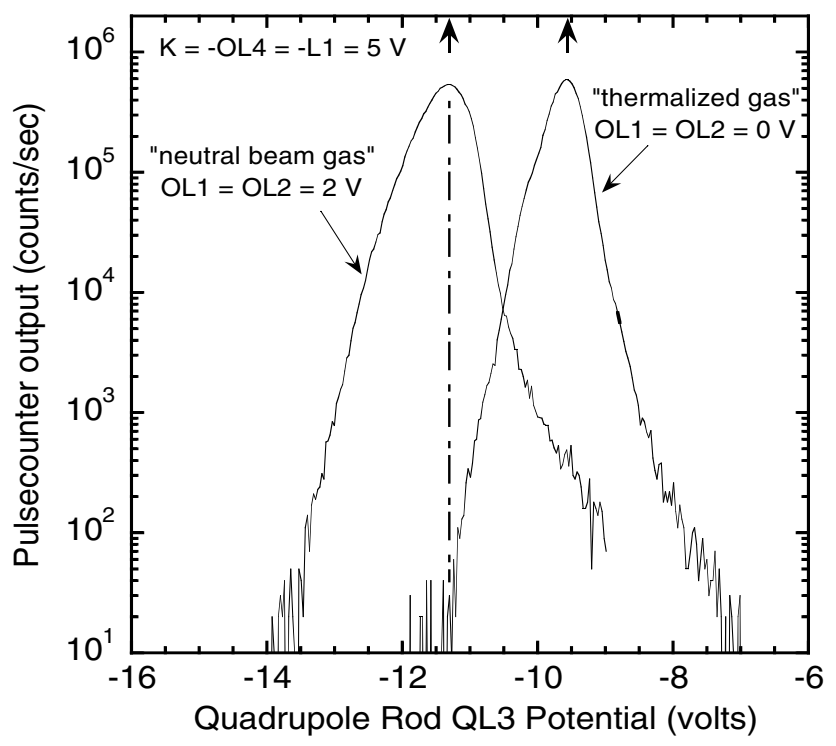

Figure 20. Results of an energy scans performed in the neutral thermal $(\mathrm{OL} 1=\mathrm{OL} 2=0 \mathrm{~V})$ and simulated neutral beaming $(\mathrm{OL} 1=\mathrm{OL} 2=2 \mathrm{~V})$ modes. The contribution of the thermalized population to the beaming population, at signal maximum (dashed line), is about $10^{-4}$.

beam tests on the engineering unit will provide more complete data for this and other species.

\subsubsection{Open Source Ion Mode}

To determine the response of the INMS in the open source ion mode, a laboratory study was performed of the angular response with the deflector electrodes 1-4, the top plate lens, OL1 and OL2 set at ground potential. Figure 21 shows the relative transmission as a function of angle for two ion masses $\left(\mathrm{Ar}^{+}\right.$and $\left.\mathrm{Kr}^{+}\right)$and two energies $(8$ and $13.9 \mathrm{eV})$ that closely correspond to a $6-\mathrm{km} \mathrm{sec}^{-1}$ spacecraft speed for these masses. The open source ion mode response has also been studied by numerical simulation using the Sarnoff BEAM 3D (Swaminathan et al., 1996) software to model the lens system from the entrance aperture to the entrance of the quadrupole mass analyzer. Results of that simulation are also shown in Figure 21. Although the conditions of the simulation and the laboratory data are not exactly identical, both sets of data show a similar decrease of transmission with increasing angle except for the $\mathrm{Ar}^{+} Z$-axis rotation (X's), which most likely reflects experimental difficulties. The INMS scale is arbitrary, while for the numerical simulation data it is the total lens system transmission.

A more advanced numerical study of the angular response (Swaminathan et al., 1996) is shown in Figure 22 (left-hand scale) for a spacecraft speed of $6 \mathrm{~km}^{-1}$ and 


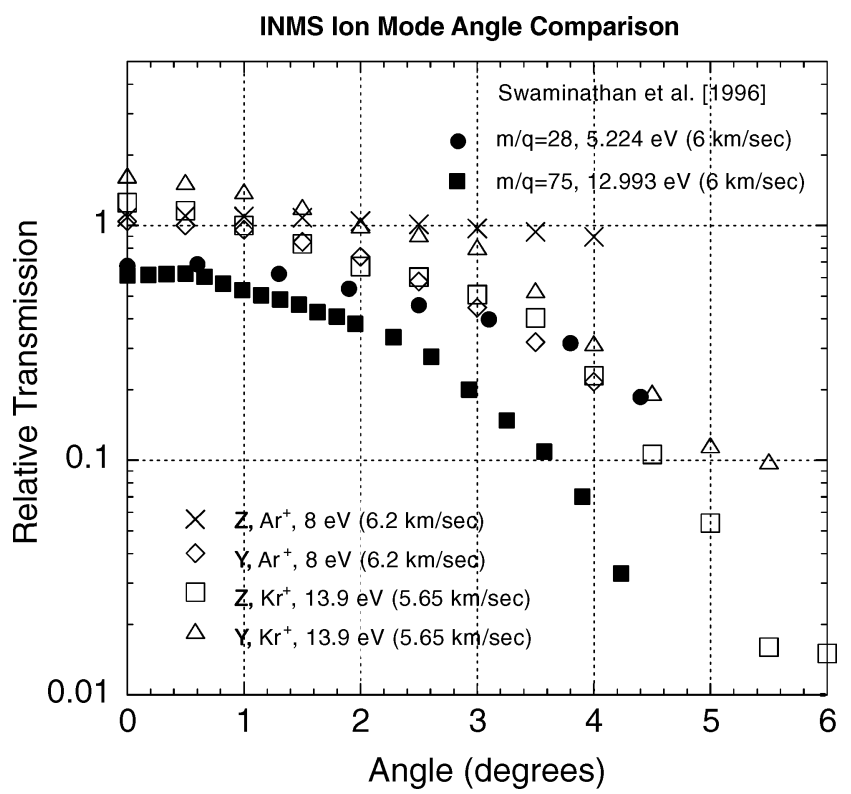

Figure 21. Laboratory data showing the relative transmission in the open source ion mode for $\mathrm{Kr}^{+}$ and $\mathrm{Ar}^{+}$corresponding to a spacecraft velocity of $6 \mathrm{~km} \mathrm{sec}^{-1}$. The laboratory data are compared with similar data from a numerical study by Swaminathan et al. (1996). The INMS $Y$ and $Z$ correspond to rotations about the space $Y$ and $Z$ axes (outward INMS source normal is $-X$ ).

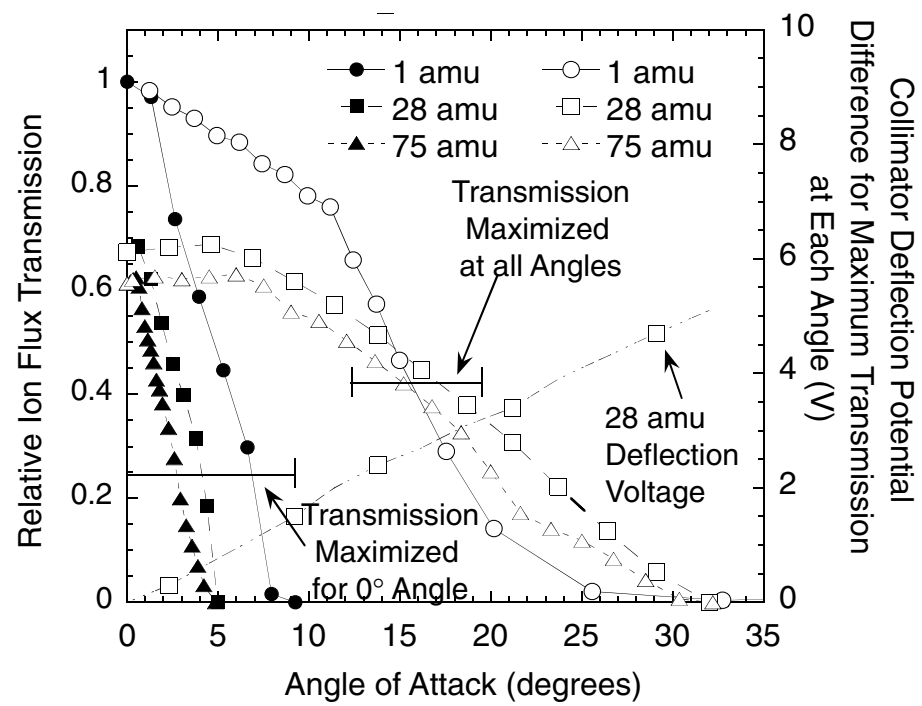

Figure 22. Results of a numerical study (Swaminathan et al., 1996) of the angular response of the open source in the ion mode. The deflector plate voltages were adjusted to optimize the transmission for various angles of attack. Adjusting the voltages on the deflector plates makes it possible to increase open source acceptance beyond the nominal $8.3^{\circ}$ half angle. Ion energies for 1, 28, and 75 Dalton were $0.187,5.224$, and $12.993 \mathrm{eV}$, respectively. 
no thermal ion energy spread. If the transmission is optimized only at $0^{\circ}$ angle of attack, then the half-width half-maximum (HWHM) point is about $3^{\circ}$ for 28 Daltons. Optimizing the transmission by adjusting the potential on paired deflectors at each angle of attack results in a HWHM of about $15^{\circ}$ for 28 Daltons. The difference in potential between opposite pairs of deflector electrodes needed to optimize the transmission is approximately linear with increasing angle of attack (Figure 22, right-hand scale). The advantage of being able to program the deflector voltages to increase the angular response beyond the geometric view cone is important for increasing the coverage in altitude of thermal ions during a Titan pass. For example, optimization of the angle coverage for $\mathrm{N}_{2}^{+}$for a $950 \mathrm{~km}$ closest approach altitude to Titan is sufficient to permit measurements over the ionospheric peak (Keller et al., 1998) up to about $1050 \mathrm{~km}$. In evaluating the use of the four-deflector electrodes to steer low-energy ions, it was found that the digital-to-analog converters (DAC) for the plates did not have adequate voltage resolution. A post-characterization change was made to introduce a non-linearity into the response (Figure 23) such that there is higher voltage resolution around $0 \mathrm{~V}$ as might be required by the Figure 22 tracking.

The INMS can also measure suprathermal ions with energies up to about $100 \mathrm{eV}$. Ion energy and direction can only be inferred by scans of the deflector electrodes and switching lens that require a substantial number of data samples. The suprathermal

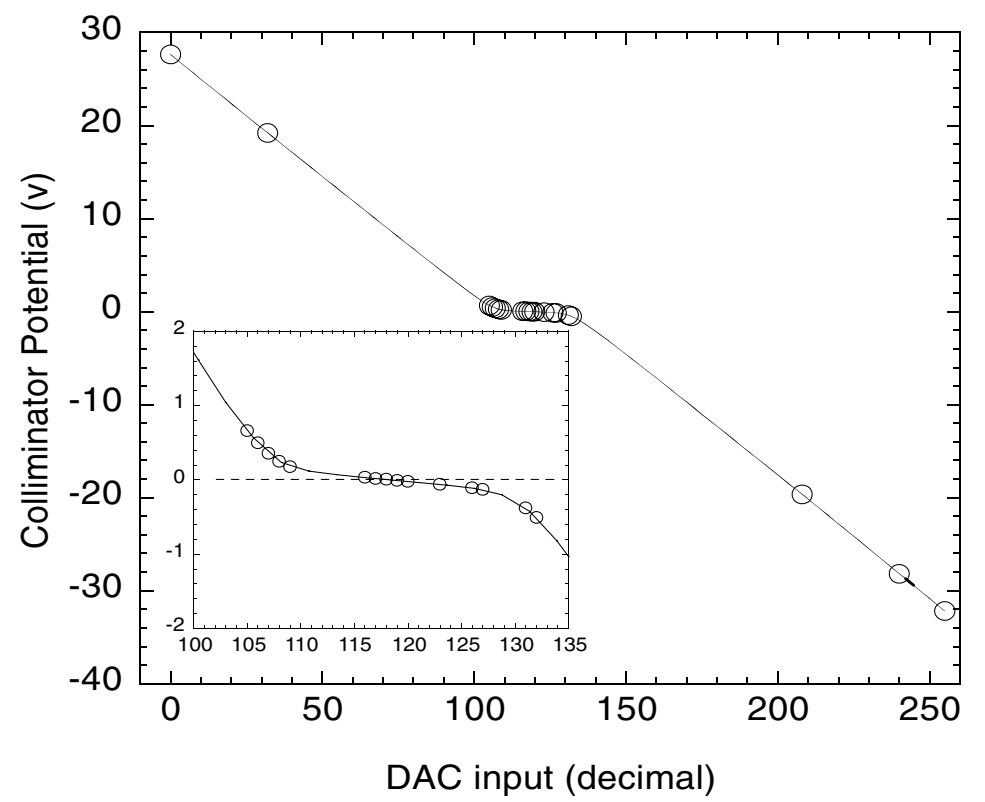

Figure 23. Deflector plate potentials as a function of the decimal values in the software table that controls digital-to-analog converters (DAC) that supply the voltage to the deflectors. (See Section 3 for a discussion of software control tables.) A nonlinearity was introduced into the response to improve the voltage resolution around $0 \mathrm{~V}$. 
ion mass-to-charge ratio can, however, be uniquely determined on a per sample basis by the quadrupole analyzer fields. Even if the particles are energetic and cause mass peak spreading, the peak center will be at the appropriate mass-per-charge value for each 34-ms sample period. This unique mass determination will complement measurements with the CAPS/IBS, which, for trans-sonic plasma regimes, will have difficulty resolving closely spaced mass groups.

\subsection{INMS ELECTRONICS}

The INMS electronics system (Figure 24) is based on designs used for the Huygen's Probe GC/MS instrument. A low-voltage (LV) power supply converts spacecraft power to well-regulated DC voltages that are supplied to the instrument electronics. A pulse-width-modulated converter allows efficient generation of multiple secondary voltages while providing secondary-to-primary isolation. A large number of voltages are required to bias the various focus electrodes as well as to supply DC voltages for the secondary electron multipliers. Analog modules are used for regulating the emission of the electron guns, for providing fixed and programmable voltages to set lens potentials, for supplying RF and DC for the quadrupole mass

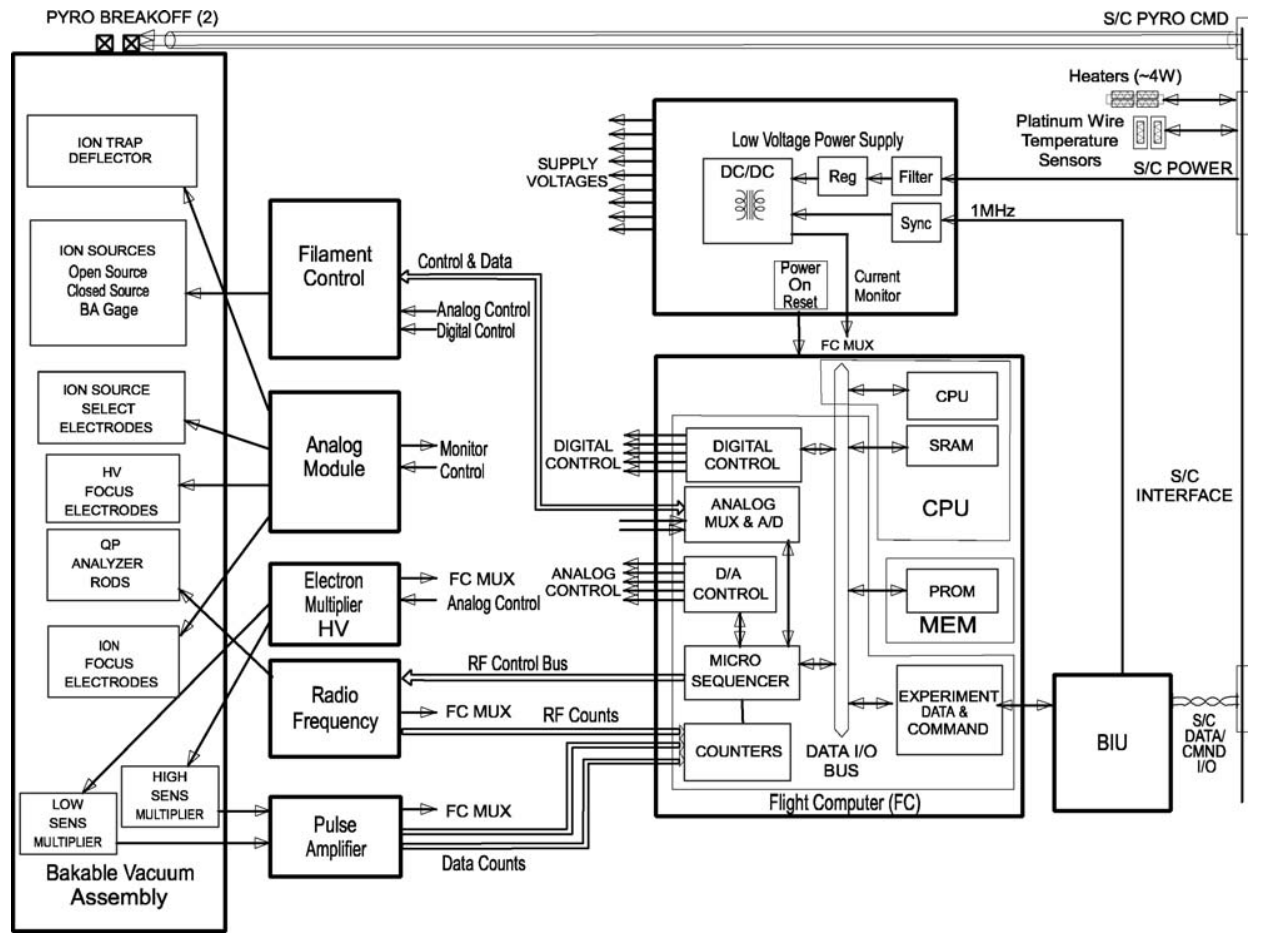

Figure 24. Schematic of the INMS electronic subsystems. 
analyzer, for supplying high voltages for the detectors, and for the pulse-counting circuits. The digital electronics includes a single microprocessor, a spacecraft bus interface circuit, and an interface between the CPU and the analog modules. Major portions of the electronics are packaged in hybrid circuits to save weight and space.

A radio frequency generator drives the quadrupole at two resonant frequencies in order to reduce the need for large amplitude potential for the required mass range (1-99 Daltons). A solid-state switched bandpass filter performs frequency selection. The DC voltage is created by high-voltage operational amplifiers and is superimposed on the RF amplitude. Digital-to-analog converters program both the RF and DC amplitudes.

Charge pulses at the anode of the electron multiplier are converted by a pulse amplifier into voltage pulses that are counted if they are above a pre-set threshold. Analog measurement of the multiplier current is used to determine the in-flight multiplier gain.

The Flight Computer uses a 16-bit Marconi MA31750 microprocessor running at $10 \mathrm{MHz}$, with $64 \mathrm{~K}$ primary RAM, $64 \mathrm{~K} \mathrm{ROM}$, and $32 \mathrm{~K}$ "extra" RAM (used only for data storage, not for execution of flight software). The computer controls the INMS measurement sequence, counts the detector pulses, provides analog-todigital conversion of the detector current, and monitors instrument housekeeping parameters. The computer is programmed in Ada as the target language with some use of assembly language to handle time-critical functions, input/output, and interrupts. The instrument ROM/RAM contains the default measurement and test sequences without requiring memory upload.

The INMS has a number of different states (Figure 2.5) which determine what information is returned from the instrument. After startup, the INMS typically waits in the Sleep_0 state for further commands. The Test and ALF states are used for configuration, memory loads, and testing. The Pressure Check is a short test to determine the pressure in the chamber while the cover is still on. Default Science is equivalent to running Science Sequence number 1 (described in Section 3.3.1). All modes except Reset return housekeeping packets, but not all modes return science packets.

Telemetry data transmitted from the INMS to the Orbiter consist of (1) housekeeping packets that contain normal analog-to-digital converter channel data or memory dump data if science packets are not being collected and (2) science packets, which contain normal science data, memory dump data, or special test data. Standard CCSDS packetization formats are used for both housekeeping and science data.

\section{Science Operations: Measurement Strategies and Sampling Methods}

INMS measurement strategies and sampling methods are determined by the investigation's science objectives and must take into account the region and species 


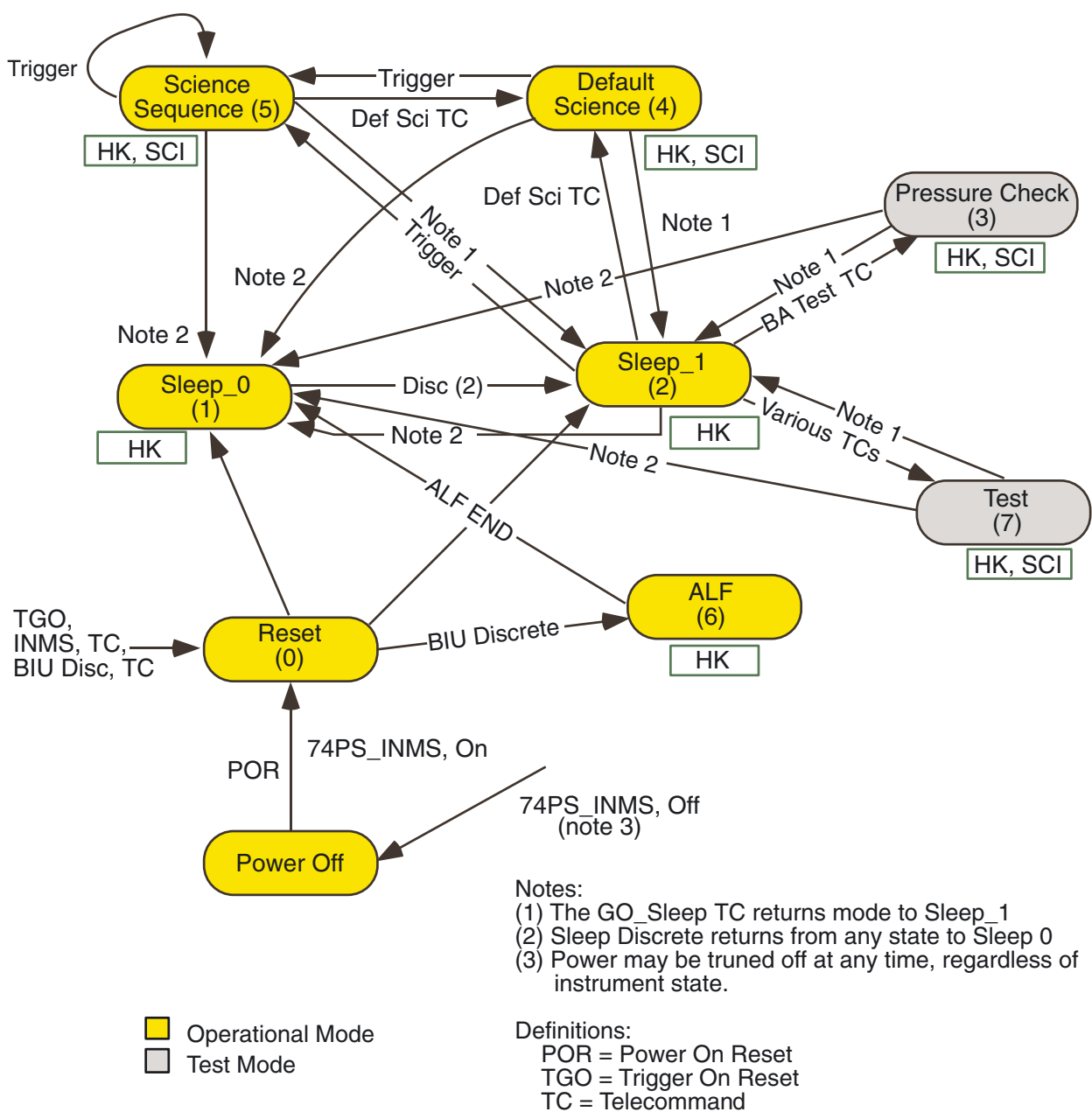

Figure 25. Diagram of the INMS instrument states. The values in parentheses correspond to the internal state number. Arrows denote allowed state changes and the commands which produce those changes, and boxes denote the types of packets that are produced.

being sampled. The basic sampling sequence is the "scan," which is a series of 68 mass/charge measurements; the mass numbers to be sampled in each scan are specified by a particular "Mass Table" (see the following section for a discussion of the INMS software tables). Each measurement period or "integration period" (IP) lasts $34 \mathrm{~ms}$ (a 31-ms counting period $+\sim 3 \mathrm{~ms}$ for set up and read out). Each scan therefore requires $2.3 \mathrm{sec}(=34 \mathrm{~ms}$ per sample $\times 68$ IPs or samples). The different types of scans and the rationale for each will be discussed below. A scan or series of scans to be repeated constitutes a "cycle." The operation of the instrument for each scan in a cycle is defined by a "Cycle Table" which indicates the Mass Table and other control tables to be used for a particular scan. One or more 
cycles make up a "science sequence." A science sequence is initiated by receipt of a time-tagged "trigger" command from the Orbiter. Trigger commands will be sent from the ground to the Orbiter and stored in the Solid State Recorder (SSR) for later execution; under some circumstances, it may be possible to command an orbital sequence from the ground in real time. The cycles to be performed during the sequence are identified in a "Sequence Table," which also specifies a velocity constant used to modify the quad lens voltages for velocity compensation in the open source mode. Several science sequences were defined prior to SOI. These are discussed in Section 3.3. Additional sequences are expected to be designed and uploaded to the INMS flight computer once exploration of the Saturn system is under way.

\subsection{INMS SOFTWARE TABLES}

The information needed by the Flight Computer to command INMS operations is contained in eight different types of software tables stored in the computer's memory. In addition to the Mass, Cycle, and Sequence tables mentioned above, the software tables include Ion Trap tables, Switching tables, Focus tables, D/A tables, and a single Velocity table. The Velocity table contains velocity constants (256 constants of which 64 are distinct velocity values) used in calculations performed to determine voltage adjustments required for velocity (energy) compensation in the open source mode. The Trap, Switching, Focus, and D/A tables are "control tables" (Table V) which contain control parameters. These values are read by the Flight Computer, which writes them to the digital-to-analog converters (DAC) that control the voltages applied to the INMS optics (or, in the case of the D/A tables, to the detectors).

Mass tables, too, are control tables. Instead of voltages, however, they specify the masses to be selected by the quadrupole mass analyzer (see Table VI) and the science mode to operate in, when velocity compensation is used. Mass Table values are used by the software to calculate the AC and DC voltages and RF oscillator frequency required to "tune" the quadrupole analyzer rods to select a particular mass. Up to 96 Mass Tables, each containing 68 records, can be stored in the Flight Computer's memory. Each one-word record contains three fields to indicate the science operating mode-open source ion (OSI), open source neutral thermal (OSNT), open source neutral beaming (OSNB) or closed source neutral (CSN) — energy scan mode, and mass number, quantized to 1/8 Daltons.

There are 64 Cycle and 64 Sequence tables. As indicated above, Sequence tables define the cycles that constitute a particular measurement sequence, and Cycle Tables define the scans to be performed during a particular cycle. A single Sequence table record contains 1-31 cycles, and each cycle contains the number of scans to perform per cycle, the velocity value to use for velocity compensation calculations, and the Cycle Table number to execute in that cycle. Each Cycle table 
TABLE V

INMS control tables.

\begin{tabular}{|c|c|c|c|c|c|}
\hline $\begin{array}{l}\text { Table } \\
\text { Type }\end{array}$ & $\begin{array}{l}\text { No. of } \\
\text { Table }\end{array}$ & $\begin{array}{l}\text { Records/ } \\
\text { Table }\end{array}$ & $\begin{array}{l}\text { Words/ } \\
\text { Record }\end{array}$ & $\begin{array}{l}\text { No. of } \\
\text { Words }\end{array}$ & Function \\
\hline Sequence & 64 & $31 / 1^{\mathrm{a}}$ & $2 / 1$ & 4032 & $\begin{array}{l}\text { Controls execution of all tables through the } \\
\text { Cycle Tables (see Figure 3.1) }\end{array}$ \\
\hline Cycle & 64 & $31 / 1^{\mathrm{a}}$ & $3 / 1$ & 6016 & $\begin{array}{l}\text { Controls execution of trap, switching, } \\
\text { mass, focus and D/A tables (see } \\
\text { Figure } 3.1 \text { ) }\end{array}$ \\
\hline Mass & 64 & 68 & 1 & 4352 & Controls mass selection \\
\hline Trap & 32 & 68 & 3 & 6528 & $\begin{array}{l}\text { Controls collimator/deflector, TPL, and } \\
\text { OL4 voltages }\end{array}$ \\
\hline Switching & 32 & 68 & 3 & 6528 & Controls quad lens rod voltages \\
\hline Focus & 32 & 68 & 3 & 6528 & $\begin{array}{l}\text { Controls OL } 1-3 \text {, end plate, ion lenses and } \\
\text { quad bias voltages }\end{array}$ \\
\hline $\mathrm{D} / \mathrm{A}$ & 16 & 1 & 3 & 48 & $\begin{array}{l}\text { Controls electron multiplier, detector } \\
\text { threshold settings }\end{array}$ \\
\hline Velocity & 1 & 256 & 1 & 256 & $\begin{array}{l}\text { Used in voltage calculations for velocity } \\
\text { compensation in open source mode }\end{array}$ \\
\hline
\end{tabular}

${ }^{a}$ Sequence and Cycle Tables have one header record per table.

contains 1-31 scans, and each scan is a record with the numbers of the Mass, Switching, Trap, Focus, and D/A tables to be used during the scan. Additional fields in the record indicate whether the open and/or closed source electron gun filaments are to be on during the scan and specify the electron energy to be used. The relationships among the various software tables are illustrated schematically in Figure 26.

\subsection{MASS SCANS}

The basic INMS sampling sequence is a scan consisting of 68 mass/charge measurements as specified in a Mass Table. Masses to be measured during a scan are entered into the Mass Table for that scan either as integers from 1 to 8 and from 12 to 99 Daltons or, in 12 tables, as fractional values, in increments of 1/8 Dalton, from 0.5 to 8.5 and 11.5 to 99.5. The Mass Tables include, in addition to the mass numbers for the primary species, mass numbers for isotopic species as well as those for possible cracking products. (A summary of currently defined Mass Tables is presented in Table VI. References to a particular Mass Table in this and the following section and in Table VII refer to this table.) During one 68-step scan, the INMS can either (i) sequentially sweep or survey, in increments of 1 or $1 / 8$ Dalton, the entire mass range covered by the instrument or a portion of that range, or (ii) sample selected masses. The first type of scan is known as a "survey" scan and can 


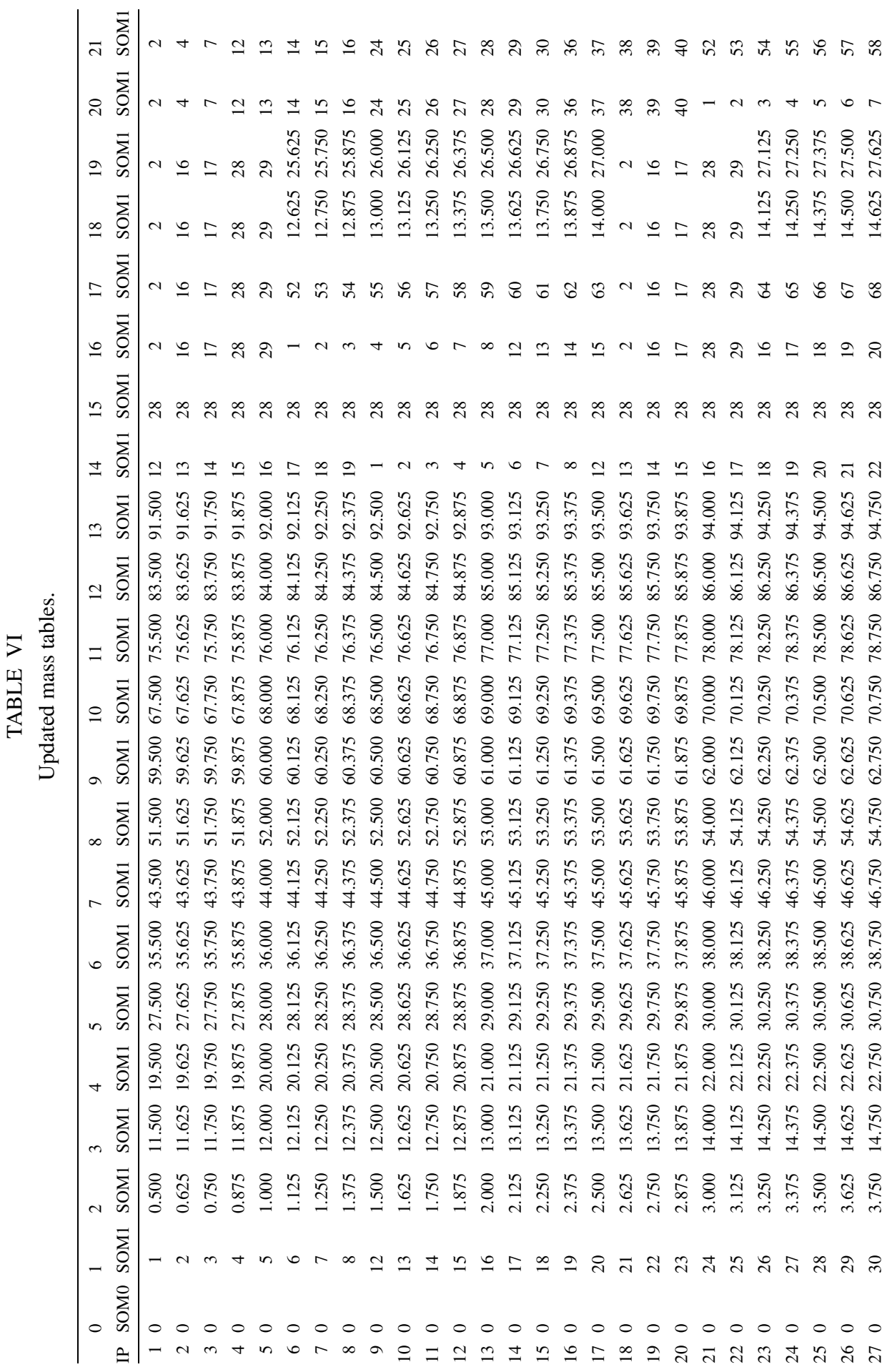




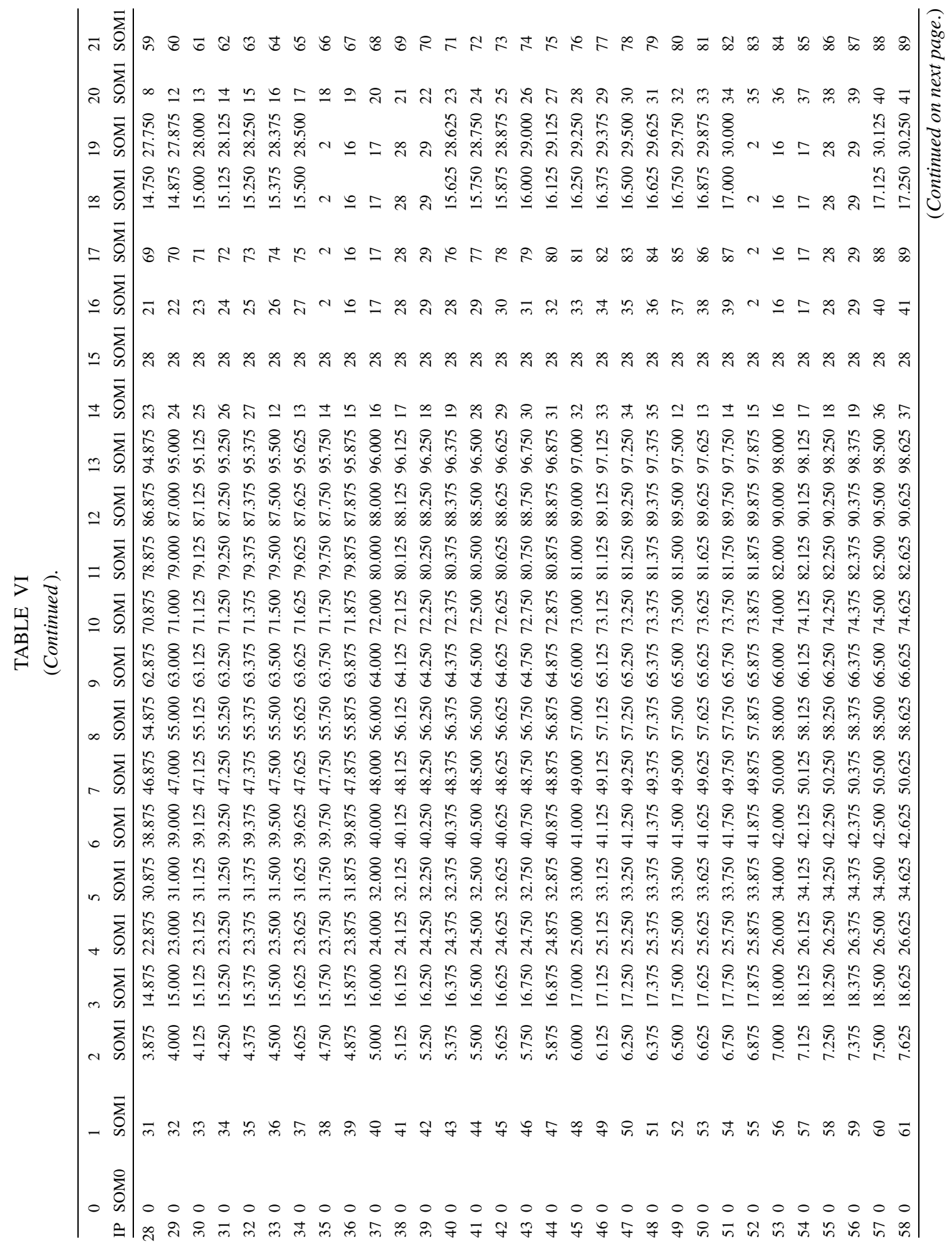




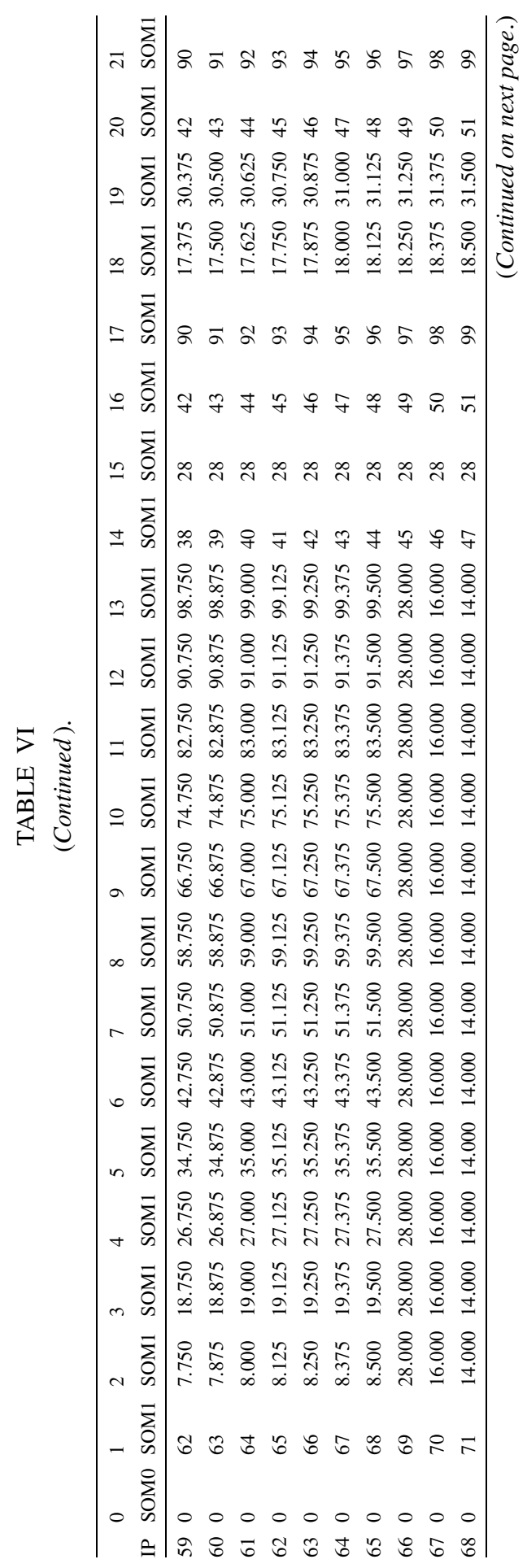




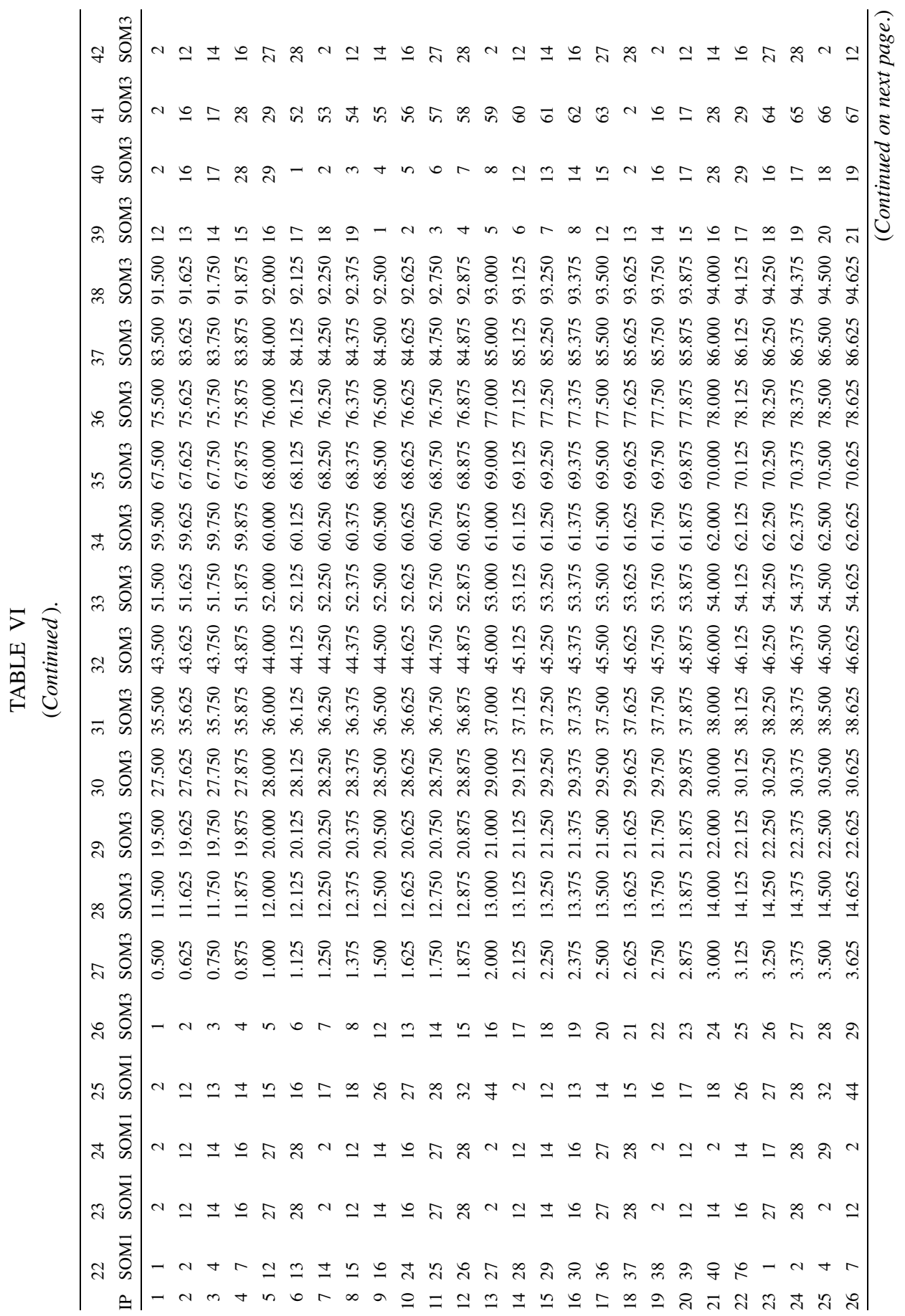




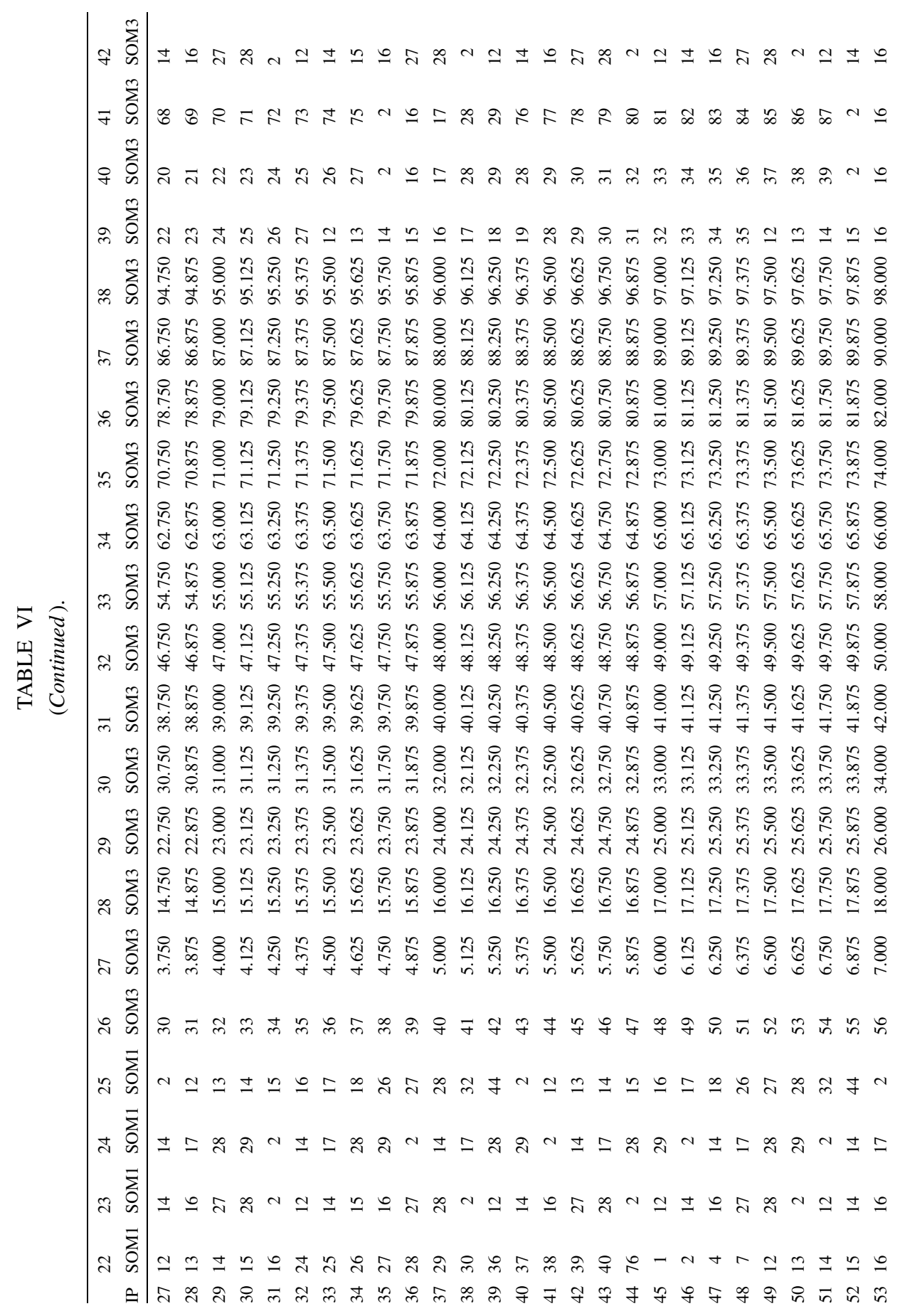




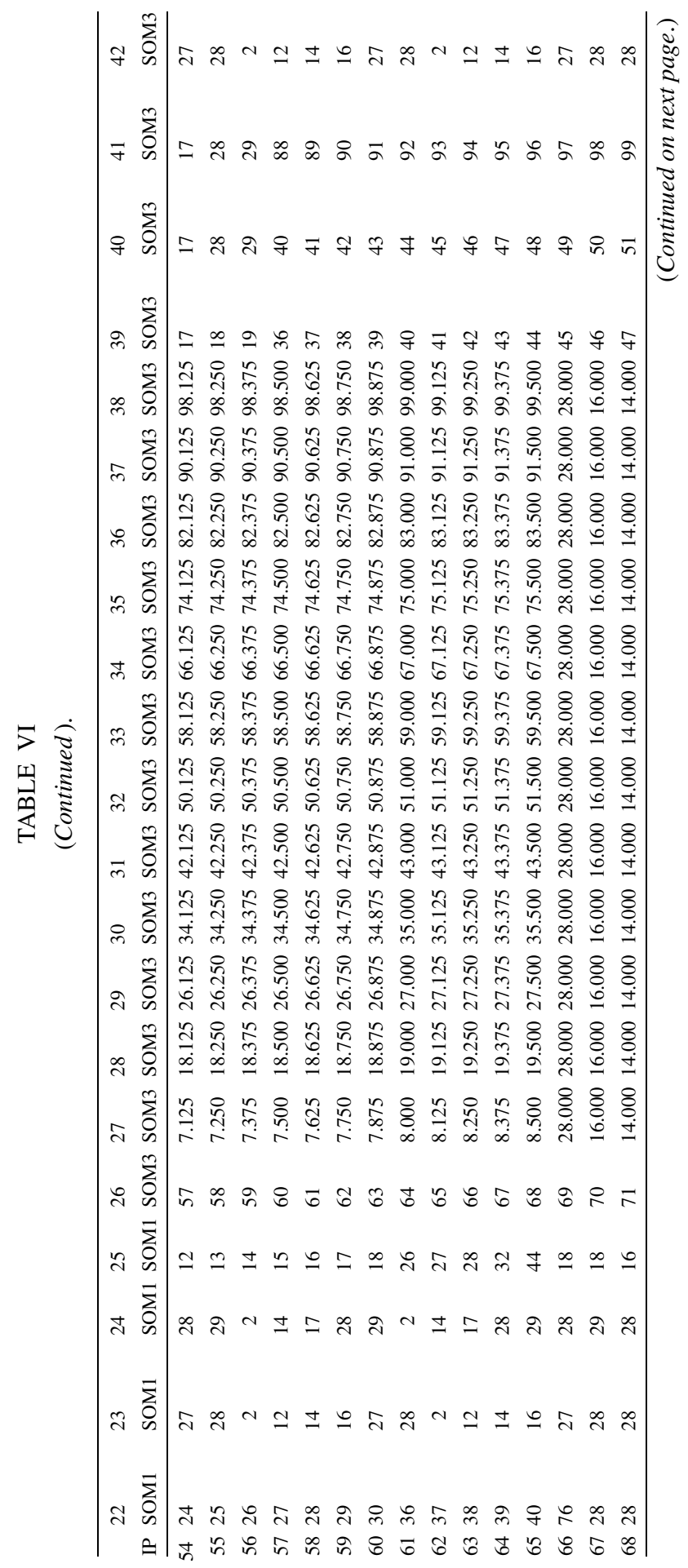




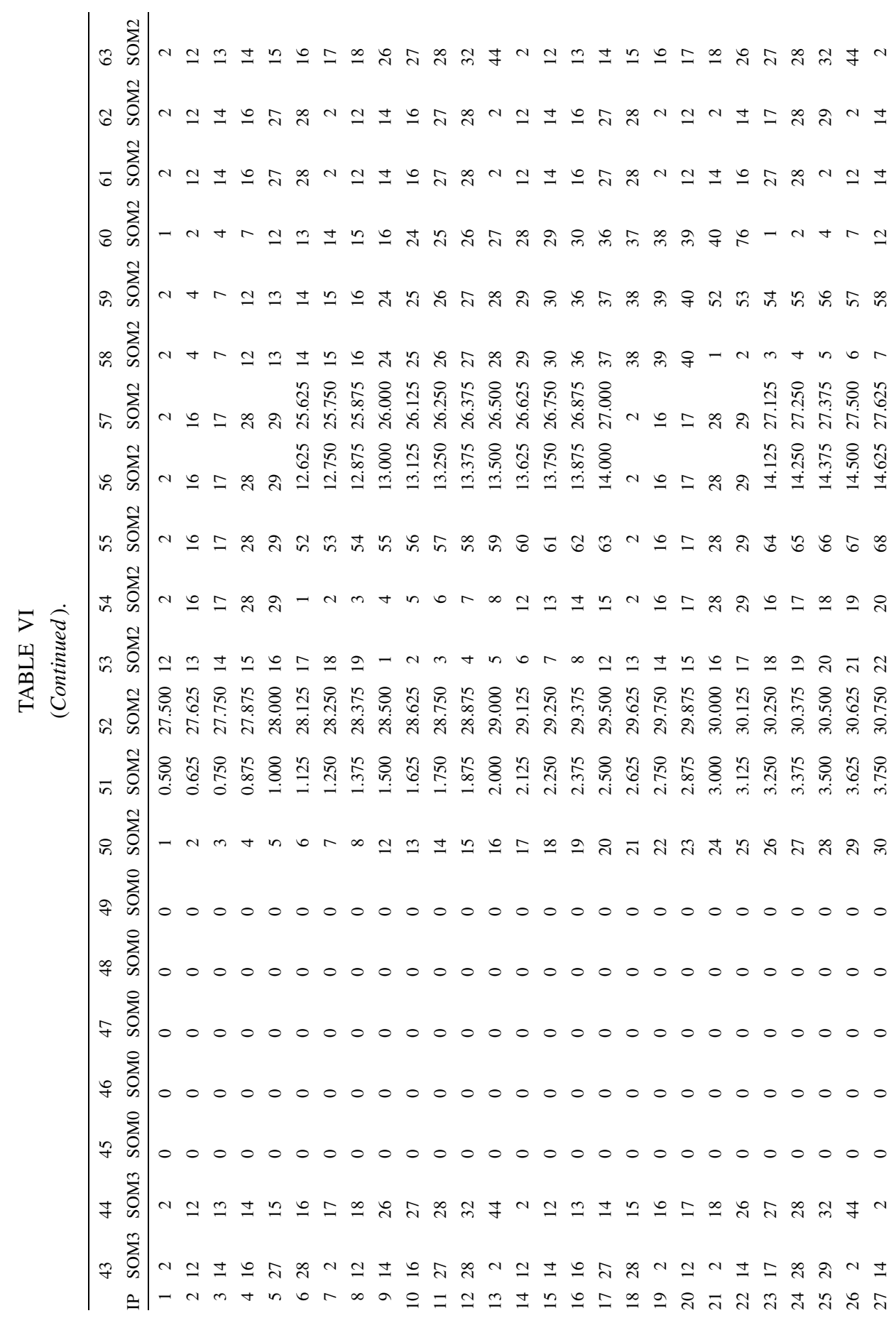




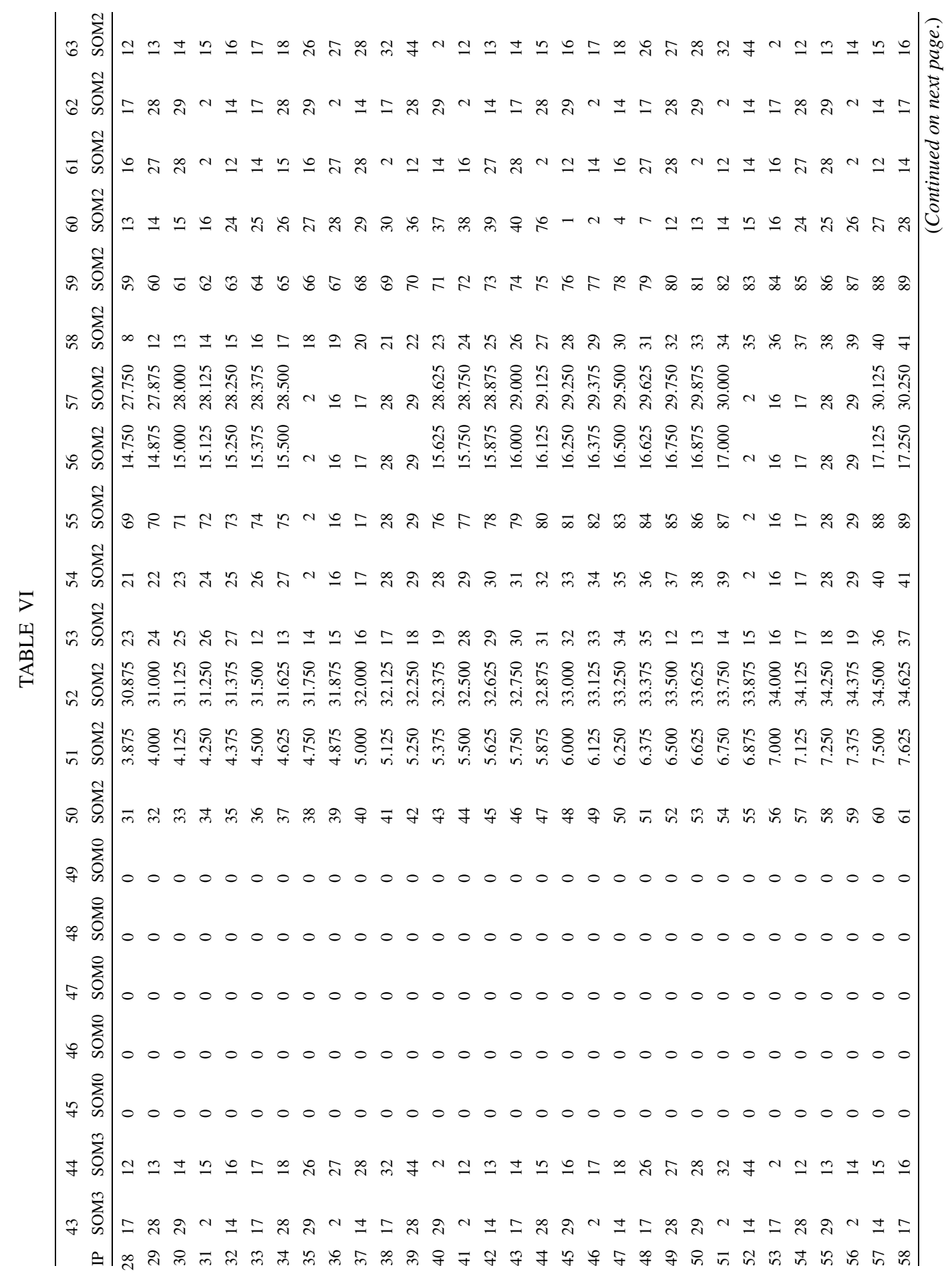




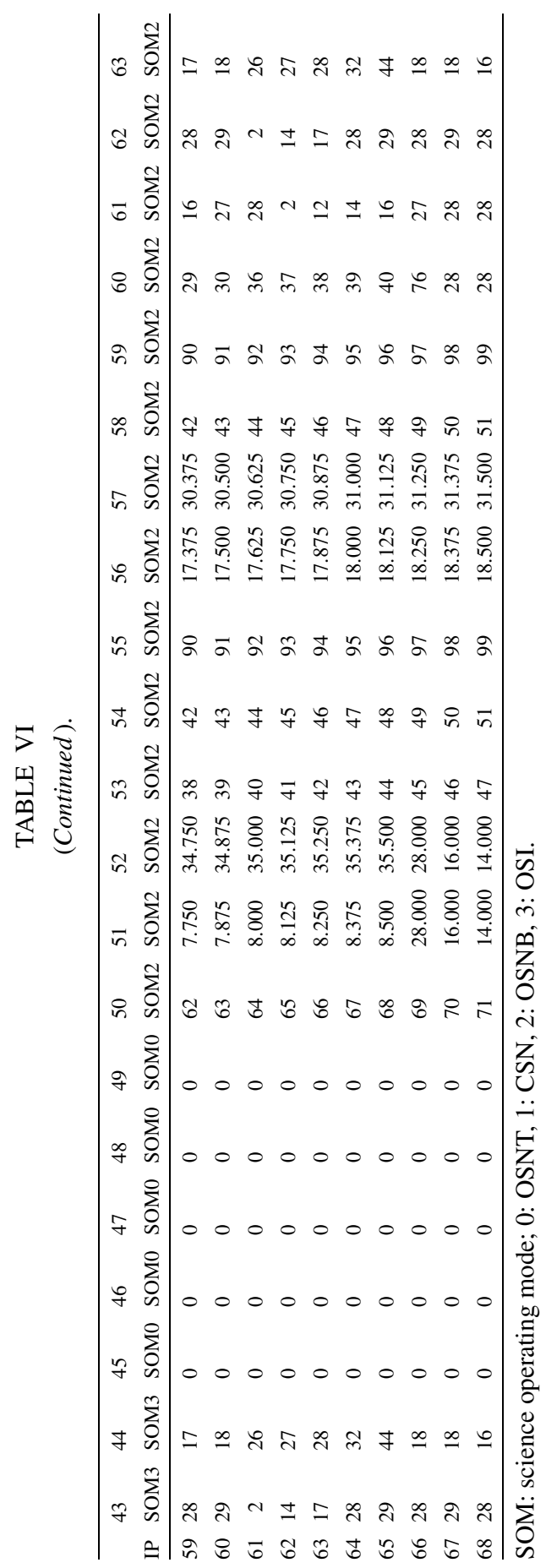



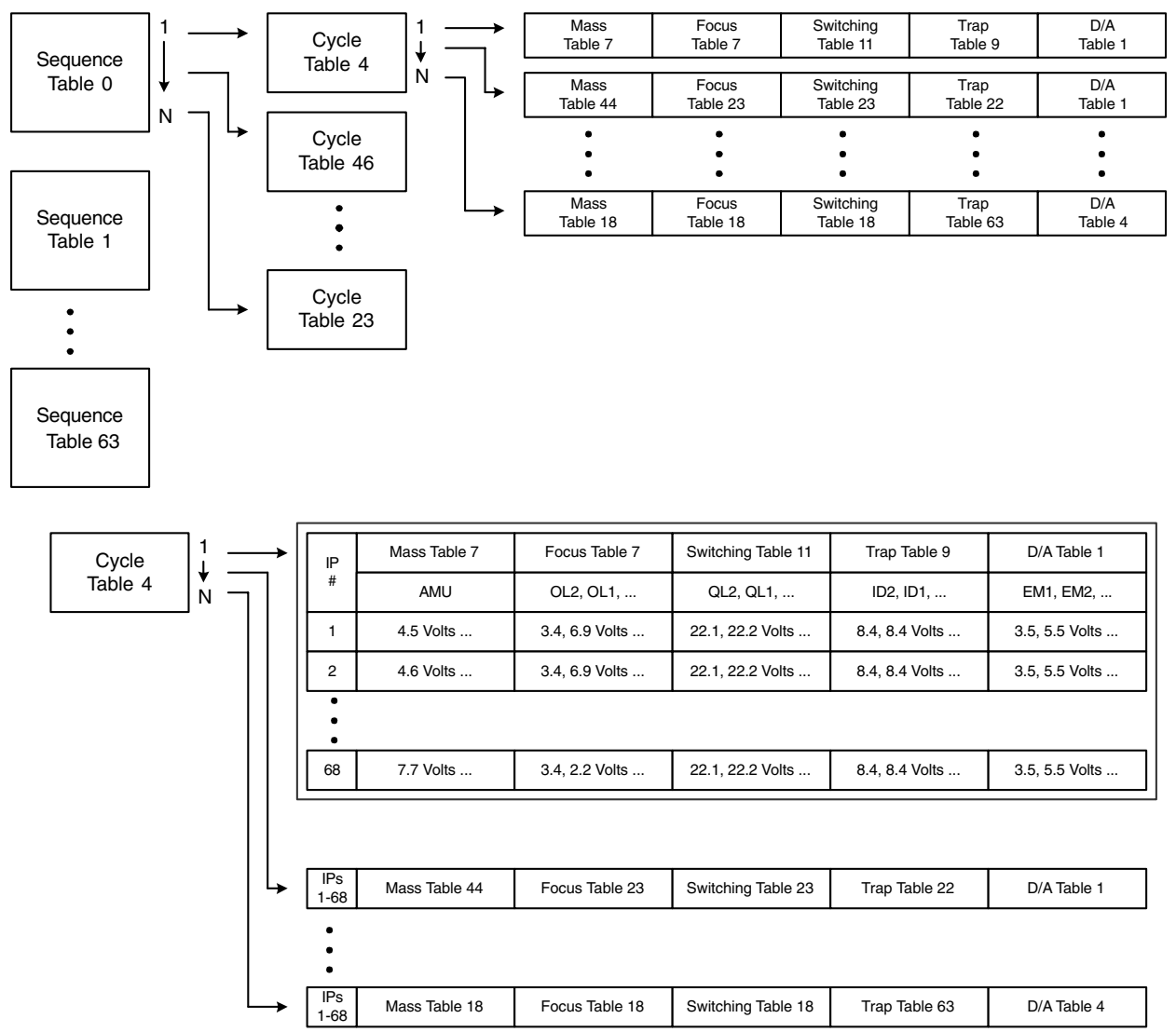

Figure 26. Schematic illustrating the relationships of various INMS software tables.

take the form of either a unit or 1/8-Dalton scan. Survey scans will allow detection of species not predicted by models to be present (or expected to be present only at subdetectable levels) in Titan's upper atmosphere or Saturn's magnetosphere. One-eighth-Dalton surveys are principally engineering scans performed to check instrument tuning and resolution; however, they also help provide ground-truth verification of mass peaks identified in the INMS data. The second type of scan is known as an "adaptive" scan and will be used for high-time-resolution sampling of species known to be present in a particular region of interest. Adaptive scan data will allow scale heights to be established with a spatial resolution of $\sim 3 \mathrm{~km}$ or less and will thus be especially important for studies of Titan's atmospheric structure. In an adaptive scan, either a set of selected masses (e.g., Mass Table 25: "Outer Magnetosphere CSN") or just one mass (e.g., Mass Table 15: "Only Mass 28 CSN") will be repeatedly sampled throughout the entire 2.3 -sec scan. The INMS may also perform adaptive scans in which the measurement of a given set of selected masses alternates with sweeps in 1-Dalton increments during the same 
TABLE VII

INMS science sequences.

\begin{tabular}{|c|c|c|c|c|c|c|}
\hline Cycle & $\begin{array}{l}\text { Cycle Table: } \\
\text { Description }\end{array}$ & Mode & $\begin{array}{l}\text { Velocity } \\
(\mathrm{km} / \mathrm{sec})\end{array}$ & $\begin{array}{l}\text { Total } \\
\text { Scans }\end{array}$ & $\begin{array}{l}\text { Mass } \\
\text { Table }\end{array}$ & Comments \\
\hline \multicolumn{7}{|c|}{ 1: Default Science—1498 bps } \\
\hline \multirow[t]{2}{*}{1} & \multirow[t]{2}{*}{$\begin{array}{l}\text { 1: Unitary } \\
\text { survey-CS and } \\
\text { OSI }\end{array}$} & CS & \multirow[t]{2}{*}{0.000} & \multirow[t]{2}{*}{778} & 1 & \multirow[t]{2}{*}{$\begin{array}{l}\text { Default Science, scaled to } 6 \text { bps. } \\
\text { Note that this sequence takes } \\
\sim 5 \mathrm{hr} \text { to run once through. The } \\
\text { co-added result will be } 5 \\
\text { Unitary scans followed by one } \\
\text { of each } 1 / 8 \text {-Dalton survey scan } \\
\text { in CS then in OSI. }\end{array}$} \\
\hline & & OSI & & & 26 & \\
\hline \multirow[t]{24}{*}{2} & \multirow{24}{*}{$\begin{array}{l}\text { 2: } 1 / 8 \text {-Dalton } \\
\text { survey-OSI and } \\
\text { CS }\end{array}$} & OSI & \multirow[t]{24}{*}{0.000} & \multirow[t]{24}{*}{24} & 27 & \multirow{24}{*}{$\begin{array}{l}\text { This should be used with a co-add } \\
\text { rate of } 240 \text { scans }=554 \mathrm{sec} \text {. }\end{array}$} \\
\hline & & OSI & & & 28 & \\
\hline & & OSI & & & 29 & \\
\hline & & OSI & & & 30 & \\
\hline & & OSI & & & 31 & \\
\hline & & OSI & & & 32 & \\
\hline & & OSI & & & 33 & \\
\hline & & OSI & & & 34 & \\
\hline & & OSI & & & 35 & \\
\hline & & OSI & & & 36 & \\
\hline & & OSI & & & 37 & \\
\hline & & OSI & & & 38 & \\
\hline & & $\mathrm{CS}$ & & & 2 & \\
\hline & & $\mathrm{CS}$ & & & 3 & \\
\hline & & CS & & & 4 & \\
\hline & & $\mathrm{CS}$ & & & 5 & \\
\hline & & $\mathrm{CS}$ & & & 6 & \\
\hline & & CS & & & 7 & \\
\hline & & $\mathrm{CS}$ & & & 8 & \\
\hline & & $\mathrm{CS}$ & & & 9 & \\
\hline & & $\mathrm{CS}$ & & & 10 & \\
\hline & & $\mathrm{CS}$ & & & 11 & \\
\hline & & $\mathrm{CS}$ & & & 12 & \\
\hline & & $\mathrm{CS}$ & & & 13 & \\
\hline \multicolumn{7}{|c|}{ 4: Default Science-100 bps } \\
\hline 1 & $\begin{array}{l}\text { 21: Unitary } \\
\text { survey-CS }\end{array}$ & $\mathrm{CS}$ & 0.000 & 300 & 1 & $\begin{array}{l}\text { Default Science, scaled to } 100 \mathrm{bps} \text {. } \\
\text { Note that this sequence takes } \\
\sim 35 \text { min to run once through. }\end{array}$ \\
\hline
\end{tabular}


TABLE VII

(Continued).

\begin{tabular}{|c|c|c|c|c|c|c|}
\hline Cycle & $\begin{array}{l}\text { Cycle Table: } \\
\text { Description }\end{array}$ & Mode & $\begin{array}{l}\text { Velocity } \\
(\mathrm{km} / \mathrm{sec})\end{array}$ & $\begin{array}{l}\text { Total } \\
\text { Scans }\end{array}$ & $\begin{array}{l}\text { Mass } \\
\text { Table }\end{array}$ & Comments \\
\hline & & & & & & $\begin{array}{l}\text { The co-added result will be } 20 \\
\text { Unitary scans followed by one } \\
\text { of each } 1 / 8 \text {-Dalton survey scan } \\
\text { in CS then in OSI. }\end{array}$ \\
\hline 2 & $\begin{array}{l}\text { 35: } 1 / 8 \text {-Dalton survey } \\
\text { CS }(1 \text { of } 12)\end{array}$ & $\mathrm{CS}$ & 0.000 & 15 & 2 & \\
\hline 3 & $\begin{array}{l}\text { 36: } 1 / 8 \text {-Dalton survey } \\
\text { CS }(2 \text { of } 12)\end{array}$ & $\mathrm{CS}$ & 0.000 & 15 & 3 & $\begin{array}{l}\text { This should be used with a co-add } \\
\text { rate of } 15 \text { scans }=34 \text { sec. }\end{array}$ \\
\hline 4 & $\begin{array}{l}\text { 37: } 1 / 8 \text {-Dalton survey } \\
\text { CS }(3 \text { of } 12)\end{array}$ & $\mathrm{CS}$ & 0.000 & 15 & 4 & \\
\hline 5 & $\begin{array}{l}\text { 38: 1/8-Dalton survey } \\
\text { CS }(4 \text { of } 12)\end{array}$ & CS & 0.000 & 15 & 5 & \\
\hline 6 & $\begin{array}{l}\text { 39: } 1 / 8 \text {-Dalton survey } \\
\text { CS }(5 \text { of } 12)\end{array}$ & CS & 0.000 & 15 & 6 & \\
\hline 7 & $\begin{array}{l}\text { 40: } 1 / 8 \text {-Dalton survey } \\
\text { CS }(6 \text { of } 12)\end{array}$ & $\mathrm{CS}$ & 0.000 & 15 & 7 & \\
\hline 8 & $\begin{array}{l}\text { 41: 1/8-Dalton survey } \\
\text { CS (7 of } 12)\end{array}$ & $\mathrm{CS}$ & 0.000 & 15 & 8 & \\
\hline 9 & $\begin{array}{l}\text { 42: 1/8-Dalton survey } \\
\text { CS (8 of } 12)\end{array}$ & $\mathrm{CS}$ & 0.000 & 15 & 9 & \\
\hline 10 & $\begin{array}{l}\text { 43: 1/8-Dalton survey } \\
\text { CS (9 of } 12)\end{array}$ & $\mathrm{CS}$ & 0.000 & 15 & 10 & \\
\hline 11 & $\begin{array}{l}\text { 44: 1/8-Dalton survey } \\
\text { CS }(10 \text { of } 12)\end{array}$ & $\mathrm{CS}$ & 0.000 & 15 & 11 & \\
\hline 12 & $\begin{array}{l}\text { 45: 1/8-Dalton survey } \\
\text { CS }(11 \text { of } 12)\end{array}$ & $\mathrm{CS}$ & 0.000 & 15 & 12 & \\
\hline 13 & $\begin{array}{l}\text { 46: 1/8-Dalton survey } \\
\text { CS }(12 \text { of } 12)\end{array}$ & $\mathrm{CS}$ & 0.000 & 15 & 13 & \\
\hline 14 & $\begin{array}{l}\text { 22: Unitary } \\
\text { survey-OSI }\end{array}$ & OSI & 0.000 & 300 & 26 & \\
\hline 15 & $\begin{array}{l}\text { 23: 1/8-Dalton survey } \\
\text { OSI ( } 1 \text { of } 12)\end{array}$ & OSI & 0.000 & 15 & 27 & \\
\hline 16 & $\begin{array}{l}\text { 24: } 1 / 8 \text {-Dalton survey } \\
\text { OSI ( } 2 \text { of } 12)\end{array}$ & OSI & 0.000 & 15 & 28 & \\
\hline 17 & $\begin{array}{l}\text { 25: 1/8-Dalton survey } \\
\text { OSI ( } 3 \text { of } 12)\end{array}$ & OSI & 0.000 & 15 & 29 & \\
\hline 18 & $\begin{array}{l}\text { 26: 1/8-Dalton survey } \\
\text { OSI ( } 4 \text { of } 12)\end{array}$ & OSI & 0.000 & 15 & 30 & \\
\hline 19 & $\begin{array}{l}\text { 27: } 1 / 8 \text {-Dalton survey } \\
\text { OSI (5 of } 12)\end{array}$ & OSI & 0.000 & 15 & 31 & \\
\hline
\end{tabular}


TABLE VII

(Continued).

\begin{tabular}{|c|c|c|c|c|c|c|}
\hline Cycle & $\begin{array}{l}\text { Cycle Table: } \\
\text { Description }\end{array}$ & Mode & $\begin{array}{l}\text { Velocity } \\
(\mathrm{km} / \mathrm{sec})\end{array}$ & $\begin{array}{l}\text { Total } \\
\text { Scans }\end{array}$ & $\begin{array}{l}\text { Mass } \\
\text { Table }\end{array}$ & Comments \\
\hline 20 & $\begin{array}{l}\text { 28: } 1 / 8 \text {-Dalton survey } \\
\text { OSI ( } 6 \text { of } 12)\end{array}$ & OSI & 0.000 & 15 & 32 & \\
\hline 21 & $\begin{array}{l}\text { 29: } 1 / 8 \text {-Dalton survey } \\
\text { OSI ( } 7 \text { of } 12)\end{array}$ & OSI & 0.000 & 15 & 33 & \\
\hline 22 & $\begin{array}{l}\text { 30: } 1 / 8 \text {-Dalton survey } \\
\text { OSI ( } 8 \text { of } 12)\end{array}$ & OSI & 0.000 & 15 & 34 & \\
\hline 23 & $\begin{array}{l}\text { 31: } 1 / 8 \text {-Dalton survey } \\
\text { OSI ( } 9 \text { of } 12)\end{array}$ & OSI & 0.000 & 15 & 35 & \\
\hline 24 & $\begin{array}{l}\text { 32: } 1 / 8 \text {-Dalton survey } \\
\text { OSI (10 of 12) }\end{array}$ & OSI & 0.000 & 15 & 36 & \\
\hline 25 & $\begin{array}{l}\text { 33: } 1 / 8 \text {-Dalton survey } \\
\text { OSI (11 of } 12)\end{array}$ & OSI & 0.000 & 15 & 37 & \\
\hline 26 & $\begin{array}{l}\text { 34: } 1 / 8 \text {-Dalton survey } \\
\text { OSI (12 of } 12)\end{array}$ & OSI & 0.000 & 15 & 38 & \\
\hline \multicolumn{7}{|c|}{ 6: Default Science -50 bps } \\
\hline 1 & $\begin{array}{l}\text { 21: Unitary } \\
\text { survey-CS }\end{array}$ & $\mathrm{CS}$ & 0.000 & 600 & 1 & $\begin{array}{l}\text { Default Science, scaled to } 50 \text { bps. } \\
\text { Note that this sequence takes } \\
\sim 70 \text { min to run once through. } \\
\text { The co-added result will be } 20 \\
\text { Unitary scans followed by one } \\
\text { of each } 1 / 8 \text {-Dalton Survey scan } \\
\text { in CS then in OSI. }\end{array}$ \\
\hline 2 & $\begin{array}{l}\text { 35: } 1 / 8 \text {-Dalton survey } \\
\text { CS }(1 \text { of } 12)\end{array}$ & $\mathrm{CS}$ & 0.000 & 30 & 2 & \\
\hline 3 & $\begin{array}{l}\text { 36: } 1 / 8 \text {-Dalton survey } \\
\text { CS }(2 \text { of } 12)\end{array}$ & $\mathrm{CS}$ & 0.000 & 30 & 3 & $\begin{array}{l}\text { This should be used with a co-add } \\
\text { rate of } 30 \text { scans }=69 \mathrm{sec} \text {. }\end{array}$ \\
\hline 4 & $\begin{array}{l}\text { 37: } 1 / 8 \text {-Dalton survey } \\
\text { CS ( } 3 \text { of } 12)\end{array}$ & CS & 0.000 & 30 & 4 & \\
\hline 5 & $\begin{array}{l}\text { 38: } 1 / 8 \text {-Dalton survey } \\
\text { CS }(4 \text { of } 12)\end{array}$ & CS & 0.000 & 30 & 5 & \\
\hline 6 & $\begin{array}{l}\text { 39: } 1 / 8 \text {-Dalton survey } \\
\text { CS (5 of 12) }\end{array}$ & CS & 0.000 & 30 & 6 & \\
\hline 7 & $\begin{array}{l}\text { 40: } 1 / 8 \text {-Dalton survey } \\
\text { CS }(6 \text { of } 12)\end{array}$ & CS & 0.000 & 30 & 7 & \\
\hline 8 & $\begin{array}{l}\text { 41: } 1 / 8 \text {-Dalton survey } \\
\text { CS (7 of } 12)\end{array}$ & CS & 0.000 & 30 & 8 & \\
\hline 9 & $\begin{array}{l}\text { 42: } 1 / 8 \text {-Dalton survey } \\
\text { CS }(8 \text { of } 12)\end{array}$ & CS & 0.000 & 30 & 9 & \\
\hline 10 & $\begin{array}{l}\text { 43: } 1 / 8 \text {-Dalton survey } \\
\text { CS }(9 \text { of } 12)\end{array}$ & CS & 0.000 & 30 & 10 & \\
\hline
\end{tabular}


TABLE VII

(Continued).

\begin{tabular}{|c|c|c|c|c|c|c|}
\hline Cycle & $\begin{array}{l}\text { Cycle Table: } \\
\text { Description }\end{array}$ & Mode & $\begin{array}{l}\text { Velocity } \\
(\mathrm{km} / \mathrm{sec})\end{array}$ & $\begin{array}{l}\text { Total } \\
\text { Scans }\end{array}$ & $\begin{array}{l}\text { Mass } \\
\text { Table }\end{array}$ & Comments \\
\hline 11 & $\begin{array}{l}\text { 44: 1/8-Dalton survey } \\
\text { CS }(10 \text { of } 12)\end{array}$ & $\mathrm{CS}$ & 0.000 & 30 & 11 & \\
\hline 12 & $\begin{array}{l}\text { 45: 1/8-Dalton survey } \\
\text { CS }(11 \text { of } 12)\end{array}$ & CS & 0.000 & 30 & 12 & \\
\hline 13 & $\begin{array}{l}\text { 46: 1/8-Dalton survey } \\
\text { CS }(12 \text { of } 12)\end{array}$ & $\mathrm{CS}$ & 0.000 & 30 & 13 & \\
\hline 14 & $\begin{array}{l}\text { 22: Unitary } \\
\text { survey_OSI }\end{array}$ & OSI & 0.000 & 600 & 26 & \\
\hline 15 & $\begin{array}{l}\text { 23: } 1 / 8 \text {-Dalton survey } \\
\text { OSI ( } 1 \text { of } 12)\end{array}$ & OSI & 0.000 & 30 & 27 & \\
\hline 16 & $\begin{array}{l}\text { 24: } 1 / 8 \text {-Dalton survey } \\
\text { OSI ( } 2 \text { of } 12)\end{array}$ & OSI & 0.000 & 30 & 28 & \\
\hline 17 & $\begin{array}{l}\text { 25: } 1 / 8 \text {-Dalton survey } \\
\text { OSI ( } 3 \text { of } 12 \text { ) }\end{array}$ & OSI & 0.000 & 30 & 29 & \\
\hline 18 & $\begin{array}{l}\text { 26: 1/8-Dalton survey } \\
\text { OSI ( } 4 \text { of } 12)\end{array}$ & OSI & 0.000 & 30 & 30 & \\
\hline 19 & $\begin{array}{l}\text { 27: 1/8-Dalton survey } \\
\text { OSI ( } 5 \text { of } 12)\end{array}$ & OSI & 0.000 & 30 & 31 & \\
\hline 20 & $\begin{array}{l}\text { 28: 1/8-Dalton survey } \\
\text { OSI ( } 6 \text { of } 12)\end{array}$ & OSI & 0.000 & 30 & 32 & \\
\hline 21 & $\begin{array}{l}\text { 29: 1/8-Dalton survey } \\
\text { OSI ( } 7 \text { of } 12 \text { ) }\end{array}$ & OSI & 0.000 & 30 & 33 & \\
\hline 22 & $\begin{array}{l}\text { 30: 1/8-Dalton survey } \\
\text { OSI ( } 8 \text { of } 12)\end{array}$ & OSI & 0.000 & 30 & 34 & \\
\hline 23 & $\begin{array}{l}\text { 31: 1/8-Dalton survey } \\
\text { OSI ( } 9 \text { of } 12)\end{array}$ & OSI & 0.000 & 30 & 35 & \\
\hline 24 & $\begin{array}{l}\text { 32: 1/8-Dalton survey } \\
\text { OSI (10 of } 12)\end{array}$ & OSI & 0.000 & 30 & 36 & \\
\hline 25 & $\begin{array}{l}\text { 33: } 1 / 8 \text {-Dalton survey } \\
\text { OSI (11 of } 12)\end{array}$ & OSI & 0.000 & 30 & 37 & \\
\hline 26 & $\begin{array}{l}\text { 34: 1/8-Dalton survey } \\
\text { OSI (12 of } 12)\end{array}$ & OSI & 0.000 & 30 & 38 & \\
\hline \multicolumn{7}{|c|}{ 9: Default Science-6.2 bps } \\
\hline 1 & $\begin{array}{l}\text { 21: Unitary } \\
\text { survey—CS }\end{array}$ & $\mathrm{CS}$ & 0.000 & 1200 & 1 & $\begin{array}{l}\text { Default Science, scaled to } 6 \text { bps. } \\
\text { Note that this sequence takes } \\
\sim 5 \text { hr to run once through. The } \\
\text { co-added result will be } 5 \\
\text { Unitary scans followed by one } \\
\text { of each } 1 / 8 \text {-Dalton Survey scan } \\
\text { in CS then in OSI. }\end{array}$ \\
\hline
\end{tabular}


TABLE VII

(Continued).

\begin{tabular}{|c|c|c|c|c|c|c|}
\hline Cycle & $\begin{array}{l}\text { Cycle Table: } \\
\text { Description }\end{array}$ & Mode & $\begin{array}{l}\text { Velocity } \\
(\mathrm{km} / \mathrm{sec})\end{array}$ & $\begin{array}{l}\text { Total } \\
\text { Scans }\end{array}$ & $\begin{array}{l}\text { Mass } \\
\text { Table }\end{array}$ & Comments \\
\hline 2 & $\begin{array}{l}\text { 35: 1/8-Dalton survey } \\
\text { CS }(1 \text { of } 12)\end{array}$ & $\mathrm{CS}$ & 0.000 & 240 & 2 & \\
\hline 3 & $\begin{array}{l}\text { 36: 1/8-Dalton survey } \\
\text { CS }(2 \text { of } 12)\end{array}$ & $\mathrm{CS}$ & 0.000 & 240 & 3 & $\begin{array}{l}\text { This should be used with a co-add } \\
\text { rate of } 240 \text { scans }=554 \mathrm{sec} \text {. }\end{array}$ \\
\hline 4 & $\begin{array}{l}\text { 37: } 1 / 8 \text {-Dalton survey } \\
\text { CS ( } 3 \text { of } 12)\end{array}$ & $\mathrm{CS}$ & 0.000 & 240 & 4 & \\
\hline 5 & $\begin{array}{l}\text { 38: } 1 / 8 \text {-Dalton survey } \\
\text { CS }(4 \text { of } 12)\end{array}$ & $\mathrm{CS}$ & 0.000 & 240 & 5 & \\
\hline 6 & $\begin{array}{l}\text { 39: } 1 / 8 \text {-Dalton survey } \\
\text { CS }(5 \text { of } 12)\end{array}$ & $\mathrm{CS}$ & 0.000 & 240 & 6 & \\
\hline 7 & $\begin{array}{l}\text { 40: } 1 / 8 \text {-Dalton survey } \\
\text { CS }(6 \text { of } 12)\end{array}$ & $\mathrm{CS}$ & 0.000 & 240 & 7 & \\
\hline 8 & $\begin{array}{l}\text { 41: } 1 / 8 \text {-Dalton survey } \\
\text { CS }(7 \text { of } 12)\end{array}$ & $\mathrm{CS}$ & 0.000 & 240 & 8 & \\
\hline 9 & $\begin{array}{l}\text { 42: } 1 / 8 \text {-Dalton survey } \\
\text { CS }(8 \text { of } 12)\end{array}$ & $\mathrm{CS}$ & 0.000 & 240 & 9 & \\
\hline 10 & $\begin{array}{l}\text { 43: 1/8-Dalton survey } \\
\text { CS }(9 \text { of } 12)\end{array}$ & CS & 0.000 & 240 & 10 & \\
\hline 11 & $\begin{array}{l}\text { 44: 1/8-Dalton survey } \\
\text { CS }(10 \text { of } 12)\end{array}$ & CS & 0.000 & 240 & 11 & \\
\hline 12 & $\begin{array}{l}\text { 45: 1/8-Dalton survey } \\
\text { CS }(11 \text { of } 12)\end{array}$ & $\mathrm{CS}$ & 0.000 & 240 & 12 & \\
\hline 13 & $\begin{array}{l}\text { 46: 1/8-Dalton survey } \\
\text { CS }(12 \text { of } 12)\end{array}$ & $\mathrm{CS}$ & 0.000 & 240 & 13 & \\
\hline 14 & $\begin{array}{l}\text { 22: Unitary } \\
\text { survey_OSI }\end{array}$ & OSI & 0.000 & 1200 & 26 & \\
\hline 15 & $\begin{array}{l}\text { 23: } 1 / 8 \text {-Dalton survey } \\
\text { OSI ( } 1 \text { of } 12)\end{array}$ & OSI & 0.000 & 240 & 27 & \\
\hline 16 & $\begin{array}{l}\text { 24: } 1 / 8 \text {-Dalton survey } \\
\text { OSI ( } 2 \text { of } 12)\end{array}$ & OSI & 0.000 & 240 & 28 & \\
\hline 17 & $\begin{array}{l}\text { 25: } 1 / 8 \text {-Dalton survey } \\
\text { OSI ( } 3 \text { of } 12)\end{array}$ & OSI & 0.000 & 240 & 29 & \\
\hline 18 & $\begin{array}{l}\text { 26: 1/8-Dalton survey } \\
\text { OSI ( } 4 \text { of } 12)\end{array}$ & OSI & 0.000 & 240 & 30 & \\
\hline 19 & $\begin{array}{l}\text { 27: } 1 / 8 \text {-Dalton survey } \\
\text { OSI ( } 5 \text { of } 12)\end{array}$ & OSI & 0.000 & 240 & 31 & \\
\hline 20 & $\begin{array}{l}\text { 28: } 1 / 8 \text {-Dalton survey } \\
\text { OSI ( } 6 \text { of } 12)\end{array}$ & OSI & 0.000 & 240 & 32 & \\
\hline 21 & $\begin{array}{l}\text { 29: } 1 / 8 \text {-Dalton survey } \\
\text { OSI ( } 7 \text { of } 12)\end{array}$ & OSI & 0.000 & 240 & 33 & \\
\hline
\end{tabular}


TABLE VII

(Continued).

\begin{tabular}{|c|c|c|c|c|c|c|}
\hline Cycle & $\begin{array}{l}\text { Cycle Table: } \\
\text { Description }\end{array}$ & Mode & $\begin{array}{l}\text { Velocity } \\
(\mathrm{km} / \mathrm{sec})\end{array}$ & $\begin{array}{l}\text { Total } \\
\text { Scans }\end{array}$ & $\begin{array}{l}\text { Mass } \\
\text { Table }\end{array}$ & Comments \\
\hline 22 & $\begin{array}{l}\text { 30: } 1 / 8 \text {-Dalton survey } \\
\text { OSI ( } 8 \text { of } 12)\end{array}$ & OSI & 0.000 & 240 & 34 & \\
\hline 23 & $\begin{array}{l}\text { 31: } 1 / 8 \text {-Dalton survey } \\
\text { OSI ( } 9 \text { of } 12)\end{array}$ & OSI & 0.000 & 240 & 35 & \\
\hline 24 & $\begin{array}{l}\text { 32: } 1 / 8 \text {-Dalton survey } \\
\text { OSI (10 of } 12)\end{array}$ & OSI & 0.000 & 240 & 36 & \\
\hline 25 & $\begin{array}{l}\text { 33: } 1 / 8 \text {-Dalton survey } \\
\text { OSI (11 of } 12)\end{array}$ & OSI & 0.000 & 240 & 37 & \\
\hline 26 & $\begin{array}{l}\text { 34: } 1 / 8 \text {-Dalton survey } \\
\text { OSI (12 of } 12)\end{array}$ & OSI & 0.000 & 240 & 38 & \\
\hline \multicolumn{7}{|c|}{ 10: Titan Exploratory_TA Sequence_-1498 bps } \\
\hline \multirow[t]{4}{*}{1} & $\begin{array}{l}\text { 47: Adaptive } \\
\text { survey - CS and } \\
\text { OSNB for TA }\end{array}$ & CS & 5.625 & 620 & 16 & $\begin{array}{l}\text { This is the sequence that will be } \\
\text { used during TA. It should be } \\
\text { started at } 1611 \mathrm{sec} \text { before CA } \\
(10,000 \mathrm{~km}) \text { : start } \\
\text { 2004-300T15:03:51 and end } \\
\text { 2004-300T15:56:55 based on } \\
\text { current trajectory information. } \\
\text { 1498 bps data rate required. }\end{array}$ \\
\hline & & $\mathrm{CS}$ & & & 17 & \\
\hline & & OSNB & & & 54 & $\begin{array}{l}\text { It performs a combined adaptive } \\
\text { and 1-99 scan between CS and } \\
\text { OSNB until } \sim 18 \mathrm{sec} \text { before } \\
\text { closest approach, then follows a } \\
\text { more complicated sequence } \\
\text { (see Cycle Table } 4 \text { ) for } \sim 30 \mathrm{sec} \text {, } \\
\text { then switches back to the first } \\
\text { cycle. }\end{array}$ \\
\hline & & OSNB & & & 55 & \\
\hline \multirow[t]{4}{*}{2} & $\begin{array}{l}\text { 47: Adaptive } \\
\text { survey-CS and } \\
\text { OSNB for TA }\end{array}$ & $\mathrm{CS}$ & 5.875 & 68 & 16 & $\begin{array}{l}\text { The velocities are selected to } \\
\text { attempt to match the radial } \\
\text { velocity over different parts of } \\
\text { the period, while keeping } \\
\text { velocity compensation constant } \\
\text { through the expected location of } \\
\text { the magnetosphere/thermal } \\
\text { crossing. }\end{array}$ \\
\hline & & CS & & & 17 & \\
\hline & & OSNB & & & 54 & \\
\hline & & OSNB & & & 55 & \\
\hline
\end{tabular}

(Continued on next page.) 
TABLE VII

(Continued).

\begin{tabular}{|c|c|c|c|c|c|c|}
\hline Cycle & $\begin{array}{l}\text { Cycle Table: } \\
\text { Description }\end{array}$ & Mode & $\begin{array}{l}\text { Velocity } \\
(\mathrm{km} / \mathrm{sec})\end{array}$ & $\begin{array}{l}\text { Total } \\
\text { Scans }\end{array}$ & $\begin{array}{l}\text { Mass } \\
\text { Table }\end{array}$ & Comments \\
\hline \multirow[t]{8}{*}{3} & \multirow{8}{*}{$\begin{array}{l}\text { 4: } 1 / 8 \text { Adaptive-CS } \\
\text { and OSNB-TA }\end{array}$} & CS & \multirow[t]{8}{*}{6.000} & \multirow[t]{8}{*}{16} & 18 & \\
\hline & & CS & & & 16 & \\
\hline & & OSNB & & & 56 & \\
\hline & & $\mathrm{CS}$ & & & 17 & \\
\hline & & CS & & & 19 & \\
\hline & & $\mathrm{CS}$ & & & 16 & \\
\hline & & OSNB & & & 57 & \\
\hline & & $\mathrm{CS}$ & & & 17 & \\
\hline \multirow[t]{4}{*}{4} & \multirow{4}{*}{$\begin{array}{l}\text { 47: Adaptive } \\
\text { survey-CS and } \\
\text { OSNB for TA }\end{array}$} & CS & \multirow[t]{4}{*}{5.875} & \multirow[t]{4}{*}{68} & 16 & \\
\hline & & CS & & & 17 & \\
\hline & & OSNB & & & 54 & \\
\hline & & OSNB & & & 55 & \\
\hline \multirow[t]{4}{*}{5} & \multirow{4}{*}{$\begin{array}{l}\text { 47: Adaptive } \\
\text { survey-CS and } \\
\text { OSNB for TA }\end{array}$} & $\mathrm{CS}$ & \multirow[t]{4}{*}{5.625} & \multirow[t]{4}{*}{620} & 16 & \\
\hline & & $\mathrm{CS}$ & & & 17 & \\
\hline & & OSNB & & & 54 & \\
\hline & & OSNB & & & 55 & \\
\hline \multicolumn{7}{|c|}{ 11: Titan High-Altitude Ionosphere Flyby_-1498 bps } \\
\hline \multirow[t]{4}{*}{1} & \multirow[t]{4}{*}{$\begin{array}{l}\text { 3: Adaptive } \\
\text { survey-CS and } \\
\text { OSI-Titan high } \\
\text { altitude }\end{array}$} & $\mathrm{CS}$ & \multirow[t]{4}{*}{5.875} & \multirow[t]{4}{*}{4} & 16 & $\begin{array}{l}\text { This is a very simple sequence, } \\
\text { to be repeated over the } \\
\text { course of all high-altitude } \\
\text { flybys }(>1500 \mathrm{~km}) \text {. It } \\
\text { contains a combined } \\
\text { adaptive and } 1-99 \text { scan. } \\
1498 \text { bps data rate required. }\end{array}$ \\
\hline & & CS & & & 17 & \\
\hline & & OSI & & & 40 & $\begin{array}{l}\text { The currently selected velocity } \\
\text { is } 5.875 \mathrm{~km} / \mathrm{sec} \text {, which is } \\
\text { ideal for T4. }\end{array}$ \\
\hline & & OSI & & & 41 & \\
\hline \multicolumn{7}{|c|}{ 12: Titan Low-Altitude 006TI_T5_1498 bps } \\
\hline 1 & $\begin{array}{l}\text { 5: OSI for outer } \\
\text { magnetosphere and } \\
\text { low altitude Titan }\end{array}$ & OSI & 5.500 & 778 & 44 & $\begin{array}{l}\text { This sequence has been worked } \\
\text { to match the timing of the } \\
\text { 006TI_T5 Titan pass. It } \\
\text { should be started } 1 \mathrm{hr} \text { before } \\
\text { closest approach: } \\
\text { 2005-106T18:05:57 by the } \\
\text { current ephemeris } \\
\text { information. } 1498 \text { bps data } \\
\text { rate required. }\end{array}$ \\
\hline
\end{tabular}

(Continued on next page.) 
TABLE VII

(Continued).

\begin{tabular}{|c|c|c|c|c|c|c|}
\hline Cycle & $\begin{array}{l}\text { Cycle Table: } \\
\text { Description }\end{array}$ & Mode & $\begin{array}{l}\text { Velocity } \\
(\mathrm{km} / \mathrm{sec})\end{array}$ & $\begin{array}{l}\text { Total } \\
\text { Scans }\end{array}$ & $\begin{array}{l}\text { Mass } \\
\text { Table }\end{array}$ & Comments \\
\hline \multirow[t]{4}{*}{2} & \multirow{4}{*}{$\begin{array}{l}\text { 48: Unitary } \\
\text { survey-CS and } \\
\text { OSNB for T5 }\end{array}$} & $\mathrm{CS}$ & \multirow[t]{4}{*}{5.750} & \multirow[t]{4}{*}{520} & 1 & \\
\hline & & OSNB & & & 50 & $\begin{array}{l}\text { (Times are before closest } \\
\text { approach, altitudes given in } \\
\text { height from surface) }\end{array}$ \\
\hline & & OSNB & & & 62 & $\begin{array}{l}\text { Cycle } 1: 1 \mathrm{hr}(18449 \mathrm{~km}) \rightarrow 30 \\
\quad \min (8439 \mathrm{~km})\end{array}$ \\
\hline & & $\mathrm{CS}$ & & & 24 & $\begin{array}{l}\text { Cycle 2: } 30 \min (8439 \mathrm{~km}) \rightarrow 10 \\
\min (2400 \mathrm{~km})\end{array}$ \\
\hline \multirow[t]{4}{*}{3} & \multirow{4}{*}{$\begin{array}{l}\text { 7: Unitary and } \\
\text { adaptive-CS and } \\
\text { OSNB for T5 }\end{array}$} & $\mathrm{CS}$ & \multirow[t]{4}{*}{5.875} & \multirow[t]{4}{*}{144} & 1 & $\begin{array}{l}\text { Cycle } 3: 10 \min (2400 \mathrm{~km}) \rightarrow 263 \\
\quad \sec (1260 \mathrm{~km})\end{array}$ \\
\hline & & OSNB & & & 50 & $\begin{array}{l}\text { Cycle 4: } 263 \mathrm{sec}(1260 \mathrm{~km}) \rightarrow \\
52.5 \mathrm{sec}(962 \mathrm{~km})\end{array}$ \\
\hline & & $\mathrm{CS}$ & & & 23 & $\begin{array}{l}\text { Cycle 5: } 52.5 \mathrm{sec}(962 \mathrm{~km}) \rightarrow 34 \\
\quad \sec (950.5)\end{array}$ \\
\hline & & OSNB & & & 62 & Cycle 6: $34 \mathrm{sec}(950.5) \rightarrow \mathrm{CA}$ \\
\hline \multirow[t]{6}{*}{4} & \multirow{6}{*}{$\begin{array}{l}\text { 8: Adaptive and } \\
1-99-\text { CS and } \\
\text { OSNB for T5 }\end{array}$} & $\mathrm{CS}$ & \multirow[t]{6}{*}{6.000} & \multirow[t]{6}{*}{90} & 20 & \\
\hline & & $\mathrm{CS}$ & & & 21 & $\begin{array}{l}\text { Going out is exactly the reverse, } \\
\text { except that Cycle Table } 6 \\
\text { (switching to CSN/OSI) starts } \\
\text { at CA }+492 \mathrm{sec}(\sim 2000 \mathrm{~km}) \\
\text { and the later timings are shifted } \\
\text { accordingly. }\end{array}$ \\
\hline & & OSNB & & & 54 & \\
\hline & & OSNB & & & 55 & $\begin{array}{l}\text { The selected velocities are for T5 } \\
\text { specifically, to match the } \\
\text { changing radial velocity. }\end{array}$ \\
\hline & & $\mathrm{CS}$ & & & 22 & \\
\hline & & OSNB & & & 60 & \\
\hline \multirow[t]{4}{*}{5} & \multirow{4}{*}{$\begin{array}{l}\text { 9: Adaptive-CS and } \\
\text { OSNB for T5 } \\
\text { pre-CA }\end{array}$} & $\mathrm{CS}$ & \multirow{4}{*}{6.000} & \multirow[t]{4}{*}{8} & 20 & \\
\hline & & OSNB & & & 58 & \\
\hline & & $\mathrm{CS}$ & & & 21 & \\
\hline & & OSNB & & & 59 & \\
\hline \multirow[t]{7}{*}{6} & \multirow{7}{*}{$\begin{array}{l}\text { 10: Adaptive large } \\
\text { and } 1 / 8 \\
\text { Dalton-CS and } \\
\text { OSNB }\end{array}$} & $\mathrm{CS}$ & \multirow[t]{7}{*}{6.000} & \multirow[t]{7}{*}{32} & 2 & \\
\hline & & $\mathrm{CS}$ & & & 22 & \\
\hline & & OSNB & & & 51 & \\
\hline & & OSNB & & & 60 & \\
\hline & & $\mathrm{CS}$ & & & 5 & \\
\hline & & $\mathrm{CS}$ & & & 22 & \\
\hline & & OSNB & & & 52 & \\
\hline
\end{tabular}

(Continued on next page.) 
TABLE VII

(Continued).

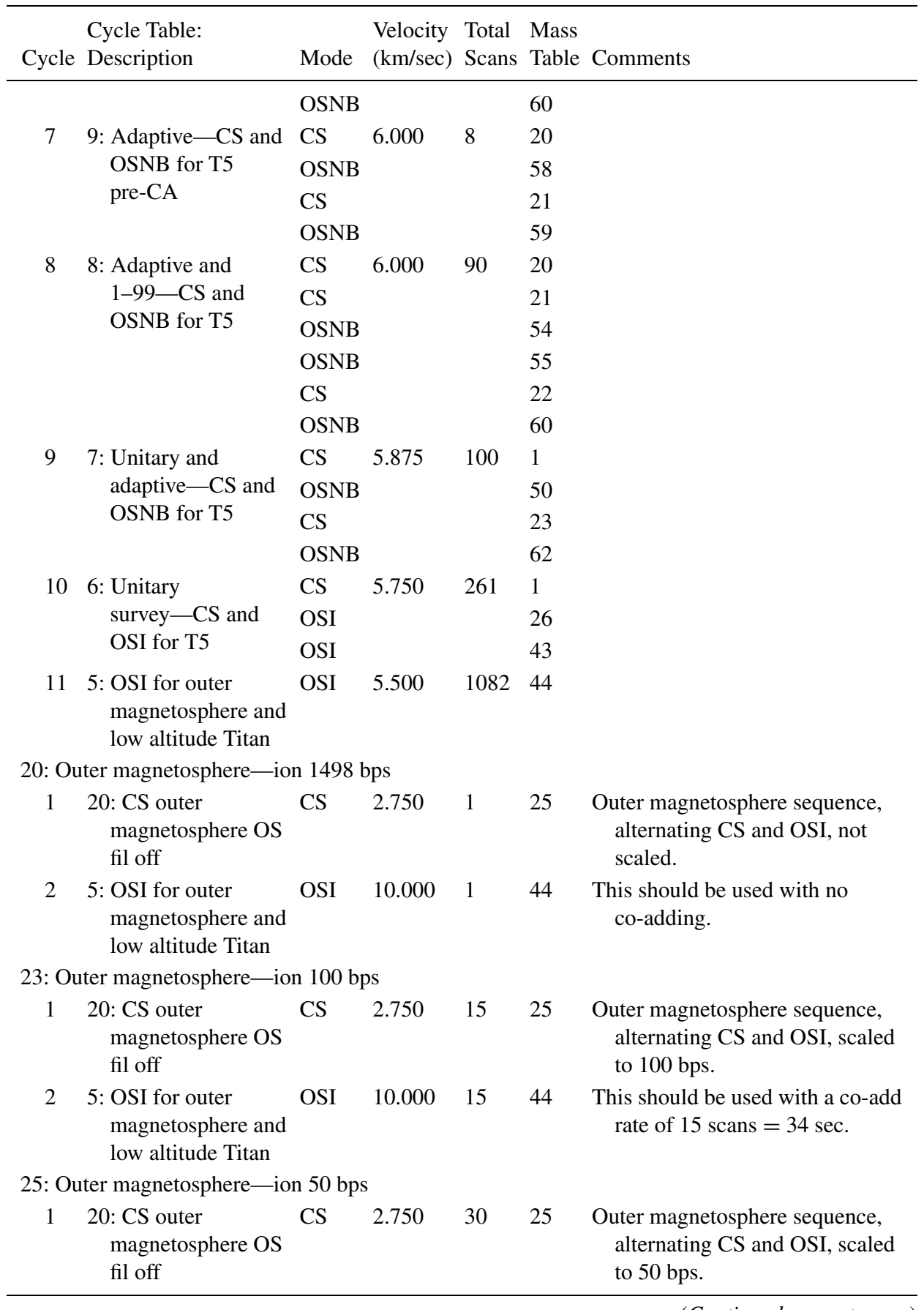

(Continued on next page.) 
TABLE VII

(Continued).

\begin{tabular}{|c|c|c|c|c|c|c|}
\hline Cycle & $\begin{array}{l}\text { Cycle Table: } \\
\text { Description }\end{array}$ & Mode & $\begin{array}{l}\text { Velocity } \\
(\mathrm{km} / \mathrm{sec})\end{array}$ & $\begin{array}{l}\text { Total } \\
\text { Scans }\end{array}$ & $\begin{array}{l}\text { Mass } \\
\text { Table }\end{array}$ & Comments \\
\hline 2 & $\begin{array}{l}\text { 5: OSI for outer } \\
\text { magnetosphere } \\
\text { and low } \\
\text { altitudeTitan }\end{array}$ & OSI & 10.000 & 30 & 44 & $\begin{array}{l}\text { This should be used with a co-add } \\
\text { rate of } 30 \text { scans }=69 \text { secs. }\end{array}$ \\
\hline \multicolumn{7}{|c|}{ 28: Outer magnetosphere—ion 6.2 bps } \\
\hline 1 & $\begin{array}{l}\text { 20: CS outer } \\
\text { magnetosphere } \\
\text { OS fil off }\end{array}$ & $\mathrm{CS}$ & 2.750 & 240 & 25 & $\begin{array}{l}\text { Outer magnetosphere sequence, } \\
\text { alternating CS and OSI, scaled } \\
\text { to } 6 \text { bps. }\end{array}$ \\
\hline 2 & $\begin{array}{l}\text { 5: OSI for outer } \\
\text { magnetosphere } \\
\text { and low altitude } \\
\text { Titan }\end{array}$ & OSI & 10.000 & 240 & 44 & $\begin{array}{l}\text { This should be used with a co-add } \\
\text { rate of } 240 \text { scans }=554 \mathrm{sec} \text {. }\end{array}$ \\
\hline \multicolumn{7}{|c|}{ 30: Outer magnetosphere—neutral 1498 bps } \\
\hline 1 & $\begin{array}{l}\text { 11: CS outer } \\
\text { magnetosphere } \\
\text { OS fil on }\end{array}$ & $\mathrm{CS}$ & 2.750 & 1 & 25 & $\begin{array}{l}\text { Outer magnetosphere sequence, } \\
\text { alternating CS and OSNB, not } \\
\text { scaled. }\end{array}$ \\
\hline 2 & $\begin{array}{l}\text { 12: OSNB outer } \\
\text { magnetosphere }\end{array}$ & OSNB & 2.750 & 1 & 63 & $\begin{array}{l}\text { This should be used with no } \\
\text { co-adding. }\end{array}$ \\
\hline \multicolumn{7}{|c|}{ 33: Outer magnetosphere-neutral 100 bps } \\
\hline 1 & $\begin{array}{l}\text { 11: CS outer } \\
\text { magnetosphere } \\
\text { OS fil on }\end{array}$ & $\mathrm{CS}$ & 2.750 & 15 & 25 & $\begin{array}{l}\text { Outer magnetosphere sequence, } \\
\text { alternating CS and OSNB, } \\
\text { scaled to } 100 \mathrm{bps} \text {. }\end{array}$ \\
\hline 2 & $\begin{array}{l}\text { 12: OSNB outer } \\
\text { magnetosphere }\end{array}$ & OSNB & 2.750 & 15 & 63 & $\begin{array}{l}\text { This should be used with a co-add } \\
\text { rate of } 15 \text { scans }=34 \text { sec. }\end{array}$ \\
\hline \multicolumn{7}{|c|}{ 35: Outer magnetosphere-neutral 50 bps } \\
\hline 1 & $\begin{array}{l}\text { 11: CS outer } \\
\text { magnetosphere } \\
\text { OS fil on }\end{array}$ & $\mathrm{CS}$ & 2.750 & 30 & 25 & $\begin{array}{l}\text { Outer magnetosphere sequence, } \\
\text { alternating CS and OSNB, } \\
\text { scaled to } 50 \mathrm{bps} \text {. }\end{array}$ \\
\hline 2 & $\begin{array}{l}\text { 12: OSNB outer } \\
\text { magnetosphere }\end{array}$ & OSNB & 2.750 & 30 & 63 & $\begin{array}{l}\text { This should be used with a co-add } \\
\text { rate of } 30 \text { scans }=69 \mathrm{sec} \text {. }\end{array}$ \\
\hline \multicolumn{7}{|c|}{ 38: Outer magnetosphere-neutral $6.2 \mathrm{bps}$} \\
\hline 1 & $\begin{array}{l}\text { 11: CS outer } \\
\text { magnetosphere } \\
\text { OS fil on }\end{array}$ & $\mathrm{CS}$ & 2.750 & 240 & 25 & $\begin{array}{l}\text { Outer magnetosphere sequence, } \\
\text { alternating CS and OSNB, } \\
\text { scaled to } 6 \mathrm{bps} \text {. }\end{array}$ \\
\hline 2 & $\begin{array}{l}\text { 12: OSNB outer } \\
\text { magnetosphere }\end{array}$ & OSNB & 2.750 & 240 & 63 & $\begin{array}{l}\text { This should be used with a co-add } \\
\text { rate of } 240 \text { scans }=554 \mathrm{sec} \text {. }\end{array}$ \\
\hline \multicolumn{7}{|c|}{ 40: Inner magnetosphere-ion 1498 bps } \\
\hline 1 & $\begin{array}{l}\text { 18: CS inner } \\
\text { magnetosphere } \\
\text { OS fil off }\end{array}$ & $\mathrm{CS}$ & 4.000 & 1 & 14 & $\begin{array}{l}\text { Inner magnetosphere sequence, } \\
\text { alternating CS and OSI, not } \\
\text { scaled. }\end{array}$ \\
\hline
\end{tabular}


TABLE VII

(Continued).

\begin{tabular}{|c|c|c|c|c|c|c|}
\hline Cycle & $\begin{array}{l}\text { Cycle Table: } \\
\text { Description }\end{array}$ & Mode & $\begin{array}{l}\text { Velocity } \\
(\mathrm{km} / \mathrm{sec})\end{array}$ & $\begin{array}{l}\text { Total } \\
\text { Scans }\end{array}$ & $\begin{array}{l}\text { Mass } \\
\text { Table }\end{array}$ & Comments \\
\hline 2 & $\begin{array}{l}\text { 19: OSI inner } \\
\text { magnetosphere }\end{array}$ & OSI & 10.000 & 1 & 39 & $\begin{array}{l}\text { This should be used with no } \\
\text { co-adding. }\end{array}$ \\
\hline \multicolumn{7}{|c|}{ 43: Inner magnetosphere-ion $100 \mathrm{bps}$} \\
\hline 1 & $\begin{array}{l}\text { 18: CS inner } \\
\text { magnetosphere } \\
\text { OS fil off }\end{array}$ & $\mathrm{CS}$ & 4.000 & 15 & 14 & $\begin{array}{l}\text { Inner magnetosphere sequence, } \\
\text { alternating CS and OSI scaled } \\
\text { to } 100 \mathrm{bps} \text {. }\end{array}$ \\
\hline 2 & $\begin{array}{l}\text { 19: OSI inner } \\
\text { magnetosphere }\end{array}$ & OSI & 10.000 & 15 & 39 & $\begin{array}{l}\text { This should be used with a co-add } \\
\text { rate of } 15 \text { scans }=34 \mathrm{sec} \text {. }\end{array}$ \\
\hline \multicolumn{7}{|c|}{ 45: Inner magnetosphere-ion $50 \mathrm{bps}$} \\
\hline 1 & $\begin{array}{l}\text { 18: CS inner } \\
\text { magnetosphere } \\
\text { OS fil off }\end{array}$ & $\mathrm{CS}$ & 4.000 & 30 & 14 & $\begin{array}{l}\text { Inner magnetosphere sequence, } \\
\text { alternating CS and OSI, scaled } \\
\text { to } 50 \mathrm{bps} \text {. }\end{array}$ \\
\hline 2 & $\begin{array}{l}\text { 19: OSI inner } \\
\text { magnetosphere }\end{array}$ & OSI & 10.000 & 30 & 39 & $\begin{array}{l}\text { This should be used with a co-add } \\
\text { rate of } 30 \text { scans }=69 \mathrm{sec} \text {. }\end{array}$ \\
\hline \multicolumn{7}{|c|}{ 48: Inner magnetosphere-ion $6.2 \mathrm{bps}$} \\
\hline 1 & $\begin{array}{l}\text { 18: CS inner } \\
\text { magnetosphere } \\
\text { OS fil off }\end{array}$ & $\mathrm{CS}$ & 4.000 & 240 & 14 & $\begin{array}{l}\text { Inner magnetosphere sequence, } \\
\text { alternating CS and OSI, scaled } \\
\text { to } 6 \text { bps. }\end{array}$ \\
\hline 2 & $\begin{array}{l}\text { 19: OSI inner } \\
\text { magnetosphere }\end{array}$ & OSI & 10.000 & 240 & 39 & $\begin{array}{l}\text { This should be used with a co-add } \\
\text { rate of } 240 \text { scans }=554 \mathrm{sec} .\end{array}$ \\
\hline \multicolumn{7}{|c|}{ 50: Inner magnetosphere-neutral 1498 bps } \\
\hline 1 & $\begin{array}{l}\text { 14: CS inner } \\
\text { magnetosphere } \\
\text { OS fil on }\end{array}$ & $\mathrm{CS}$ & 4.000 & 1 & 14 & $\begin{array}{l}\text { Inner magnetosphere sequence, } \\
\text { alternating CS and OSNB, not } \\
\text { scaled. }\end{array}$ \\
\hline 2 & $\begin{array}{l}\text { 13: OSNB inner } \\
\text { magnetosphere }\end{array}$ & OSNB & 4.000 & 1 & 53 & $\begin{array}{l}\text { This should be used with no } \\
\text { co-adding. }\end{array}$ \\
\hline \multicolumn{7}{|c|}{ 53: Inner magnetosphere-neutral $100 \mathrm{bps}$} \\
\hline 1 & $\begin{array}{l}\text { 14: CS inner } \\
\text { magnetosphere } \\
\text { OS fil on }\end{array}$ & $\mathrm{CS}$ & 4.000 & 15 & 14 & $\begin{array}{l}\text { Inner magnetosphere sequence, } \\
\text { alternating CS and OSNB, } \\
\text { scaled to } 100 \mathrm{bps} \text {. }\end{array}$ \\
\hline 2 & $\begin{array}{l}\text { 13: OSNB inner } \\
\text { magnetosphere }\end{array}$ & OSNB & 4.000 & 15 & 53 & $\begin{array}{l}\text { This should be used with a co-add } \\
\text { rate of } 15 \text { scans }=34 \mathrm{sec} \text {. }\end{array}$ \\
\hline \multicolumn{7}{|c|}{ 55: Inner magnetosphere-neutral $50 \mathrm{bps}$} \\
\hline 1 & $\begin{array}{l}\text { 14: CS inner } \\
\text { magnetosphere } \\
\text { OS fil on }\end{array}$ & $\mathrm{CS}$ & 4.000 & 30 & 14 & $\begin{array}{l}\text { Inner magnetosphere sequence, } \\
\text { alternating CS and OSNB, } \\
\text { scaled to } 50 \mathrm{bps} \text {. }\end{array}$ \\
\hline 2 & $\begin{array}{l}\text { 13: OSNB } \\
\text { inner } \\
\text { magnetosphere }\end{array}$ & OSNB & 4.000 & 30 & 53 & $\begin{array}{l}\text { This should be used with a co-add } \\
\text { rate of } 30 \text { scans }=69 \mathrm{sec} \text {. }\end{array}$ \\
\hline
\end{tabular}


TABLE VII

(Continued).

\begin{tabular}{|c|c|c|c|c|c|c|}
\hline Cycle & $\begin{array}{l}\text { Cycle Table: } \\
\text { Description }\end{array}$ & Mode & $\begin{array}{l}\text { Velocity } \\
(\mathrm{km} / \mathrm{sec})\end{array}$ & $\begin{array}{l}\text { Total } \\
\text { Scans }\end{array}$ & $\begin{array}{l}\text { Mass } \\
\text { Table }\end{array}$ & Comments \\
\hline \multicolumn{7}{|c|}{ 58: Inner magnetosphere-neutral 6.2 bps } \\
\hline 1 & $\begin{array}{l}\text { 14: CS inner } \\
\text { magnetosphere } \\
\text { OS fil on }\end{array}$ & $\mathrm{CS}$ & 4.000 & 240 & 14 & $\begin{array}{l}\text { Inner magnetosphere sequence, } \\
\text { alternating CS and OSNB, } \\
\text { scaled to } 6 \mathrm{bps} \text {. }\end{array}$ \\
\hline 2 & $\begin{array}{l}\text { 13: OSNB inner } \\
\text { magnetosphere }\end{array}$ & OSNB & 4.000 & 240 & 53 & $\begin{array}{l}\text { This should be used with a } \\
\text { co-add rate of } 240 \text { scans }= \\
554 \text { sec. }\end{array}$ \\
\hline \multicolumn{7}{|c|}{ 60: Ring Overflight for SOI-1498 bps } \\
\hline \multirow[t]{2}{*}{1} & \multirow{2}{*}{$\begin{array}{l}\text { 17: SOI: magnetic } \\
\text { field } \\
\text { particles-CS } \\
\text { and OSI }\end{array}$} & $\mathrm{CS}$ & 20.000 & 156 & 14 & $\begin{array}{l}\text { To be started at } \\
\text { 2004-183T03:54:30 and } \\
\text { ended at } 04: 14: 15 \text {. }\end{array}$ \\
\hline & & OSI & & & 39 & $\begin{array}{l}\text { This sequence is designed to } \\
\text { have } 705 \mathrm{sec} \text { of B-field } \\
\text { pointing (neutrals and ions) } \\
\text { followed by } 480 \mathrm{sec} \text { of neutral } \\
\text { ram pointing (only neutrals). } \\
\text { 1498-bps data rate required. }\end{array}$ \\
\hline \multirow[t]{2}{*}{2} & \multirow{2}{*}{$\begin{array}{l}\text { 17: SOI: magnetic } \\
\text { field } \\
\text { particles-CS } \\
\text { and OSI }\end{array}$} & $\mathrm{CS}$ & \multirow[t]{2}{*}{15.000} & \multirow[t]{2}{*}{150} & 14 & \\
\hline & & OSI & & & 39 & $\begin{array}{l}\text { This mode may not be correct } \\
\text { for the entire SOI period. It is } \\
\text { correct for the SOI INMS } \\
\text { prime period pointing. For } \\
\text { time outside that region, } \\
\text { careful use of the inner } \\
\text { magnetosphere scans should } \\
\text { suffice. Also note that the OS } \\
\text { filament should be on } \\
\text { (warmed up) prior to this } \\
\text { observation, because it is on } \\
\text { for the second cycle, which is } \\
\text { after }>12 \text { min of being off. }\end{array}$ \\
\hline \multirow[t]{2}{*}{3} & \multirow{2}{*}{$\begin{array}{l}\text { 16: SOI: corotation/ } \\
\text { RAM-OSNB } \\
\text { and CS }\end{array}$} & $\mathrm{CS}$ & \multirow[t]{2}{*}{5.000} & \multirow[t]{2}{*}{108} & 14 & \\
\hline & & OSNB & & & 53 & $\begin{array}{l}\text { The velocities selected are } \\
\text { designed to attempt to catch a } \\
\text { range of particles, moving } \\
\text { relative to the spacecraft. }\end{array}$ \\
\hline \multirow[t]{2}{*}{4} & \multirow[t]{2}{*}{$\begin{array}{l}\text { 16: SOI: corotation/ } \\
\text { RAM-OSNB } \\
\text { and CS }\end{array}$} & $\mathrm{CS}$ & 6.000 & 100 & 14 & \\
\hline & & OSNB & & & 53 & \\
\hline
\end{tabular}

CS: closed source (neutral); OSI: open source ion; OSN: open source neutral; CA: closest approach. A velocity of 0 represents the use of lens values precomputed at $6.0 \mathrm{~km} / \mathrm{sec}$. 
scan (e.g., Mass Tables 16: "Titan low/high altitude part 1-CSN" and 17: "Titan low/high altitude part 2-CSN"). Finally, a third type of scan is the "high-pass" scan, in which the total signal above a given mass number (mass-to-charge ratio) is measured using the total transmission operation of the quadrupole analyzer. As noted in Section 2.2.3 above, for high-pass scans the DC mass filter voltage is set to zero. High-pass scans are used to extend the mass range of the INMS instrument.

In the case of regions where densities are expected to be very low, long accumulation periods will be required and mass scans will be co-added. The INMS software allows co-adding of up to 255 mass scans. The actual number of scans that can be co-added is determined by the count rate. That is, if the count rate is high, then fewer scans will be co-added. Otherwise, the capacity of the counter (32 bits) will be exceeded and data will be lost. However, count rates in the regions where co-adding of mass scans will be employed (e.g., the inner magnetosphere) will likely be sufficiently low that the maximum allowable number of scans can be co-added without risk of exceeding counter capacity.

\subsection{Science Sequences and Cycles}

Twenty-four science sequences have been defined. These sequences and their constituent cycles are discussed in the following and summarized in Table VII. Because of the exploratory nature of the Cassini mission, it is expected that new science sequences will be defined in response to discoveries made during the orbital tour phase. In this case, the appropriate Sequence and Cycle tables will be uploaded.

\subsubsection{Default Science Sequence}

The "Default Science-1498 bps" Sequence is the basic sequence executed by the INMS unless another orbital sequence has been commanded. This sequence comprises two cycles. In Cycle 1, the instrument performs two unitary survey scans from 1 to 8 and 12 to 70 Daltons (Mass Table I for CSN and 26 for OSI), the first in the closed source mode and the second in the open source ion mode. Cycle 1 is performed in $4.6 \mathrm{sec}$ and repeated for $\sim 30 \mathrm{~min}$ ( 389 scans in each mode). Cycle 2 consists of alternating survey scans in the open source ion mode and in the closed source mode. Mass Tables 2-13 for CSN and 27-38 for OSI, covering the mass ranges 0.5-8.5 and 11.5-99.5, are used for both surveys in Cycle 2. Cycle 2 takes $55.2 \mathrm{sec}$ to execute. The sequence is looped until a different sequence is commanded.

There are three other Default Science Sequences, each tailored to a specific data rate: 100,50 and 6.2 bits per second (bps). These rates are designed to make use of the co-adding function of the INMS, while keeping a very similar measurement order and timing to the full rate Default Science mode. The 100 and 50-bps modes are co-added 15 and 30 times, respectively, and each will return 20 packets each containing one unitary scan, followed by a complete 1/8-Dalton scan before changing to the other scan mode. The data rates most commonly assigned to the INMS 
during the mission are 100 and 50 bps. The 6.2-bps mode is co-added 240 times and will return five packets, each containing one unitary scan, before performing a complete 1/8-Dalton scan. This data rate was selected to allow bursting to full rate when the data volume allocated to the INMS is small.

\subsubsection{Titan Exploratory-TA Sequence}

The "Titan Exploratory-TA" Sequence will be executed during the Orbiter's first two flybys of Titan (Ta: October 2004, Tb: December 2004) and will occur at an altitude of approximately $1250 \mathrm{~km}$. The initial flybys will take place prior to the descent of the Hugyens Probe (Tc: January 2005). Execution of this sequence will initiate the INMS investigation of Titan's thermosphere and ionosphere, which is the primary science objective of the INMS experiment. As noted earlier (Section 1.1), INMS measurements of atmospheric density made during the initial flybys will be operationally as well as scientifically important because they will allow assessment of atmospheric drag effects on the Orbiter during subsequent flybys at lower altitudes. Initial INMS measurements at relatively high altitudes $(1250 \mathrm{~km})$ will determine densities and temperatures at and above this altitude. This information will be used to extrapolate densities to lower altitudes, which will be verified on subsequent flybys. If the extrapolated densities are found to be too high or too low, the orbital tour will need to be re-designed to protect the spacecraft while at the same time ensuring adequate science return. (Based on current atmospheric models, a minimum operational altitude of $950 \mathrm{~km}$ has been assumed for planning purposes.) A preliminary run of this extrapolation process has been completed using simulated INMS data from an atmospheric model. The results were satisfactory: density and temperature values extrapolated using two different methods agreed with the simulated density to within 15\%. A more detailed run is planned for March.

The Titan Exploratory Sequence is composed of five cycles and is designed to characterize the major neutral species in Titan's upper atmosphere. The INMS will execute Cycle 1 from an altitude of $\sim 10,000 \mathrm{~km}$ until $\sim 180 \mathrm{sec}$ before Titan closest approach. Two scans will be performed in sequence, first in the closed source mode (using Mass Tables 16 and 17) and then in the open source neutral mode (using Mass Tables 54 and 55). As specified by these two tables, the INMS will alternate sampling of masses 2, 16, 17, 28, and 29 with mass surveys in 1-Dalton increments until the entire mass range of 1-99 Daltons (excluding 9-11 Daltons) has been covered. Repeated measurement of masses 2, 16, 17, 28, and 29 during the two scans will provide high-temporal-resolution data on the density profiles of the principal neutral and ion species known or expected to be present in Titan's atmosphere: $\mathrm{H}_{2}$ (2), $\mathrm{CH}_{4}$ (16), $\mathrm{N}_{2}$ (28), $\mathrm{H}_{2} \mathrm{CN}^{+}$(28), $\mathrm{CH}_{5}^{+}$(17), and $\mathrm{C}_{2} \mathrm{H}_{5}^{+}$(29). With these data, scale heights can be calculated with a resolution of $\leq 3 \mathrm{~km}$, thus allowing the detailed structure of Titan's upper atmosphere to be determined. After $\sim 1435 \mathrm{sec}$, Cycle 2 will start, performing the same mass scans as Cycle 1 but with a slightly different velocity compensation value to reflect the changing Titan-relative radial velocity of Cassini. Cycle 3 will start $\sim 18 \mathrm{sec}$ before closest approach. In 
Cycle 3 the INMS will perform an alternating sequence of adaptive/unitary scans (Mass Tables 16 and 17 for CSN) and adaptive/fractional scans (Mass Tables 18/19 for CSN and 56/57 for OSNB). Throughout all of these scans, masses 2, 16, 17, 28, and 29 will be sampled at the same rate, to keep a consistent measurement of the primary constituents of Titan's atmosphere. At $\sim 18 \mathrm{sec}$ after closest approach the INMS will perform Cycle 2 followed by Cycle $1 \sim 160 \mathrm{sec}$ later in an exact mirror of the beginning of the sequence.

\subsubsection{Titan High-Altitude Ionosphere Flyby}

The "Titan High-Altitude Ionosphere Flyby" Sequence will be used during Titan flybys at altitudes above $1500 \mathrm{~km}$, i.e., above the exobase $(\sim 1425 \mathrm{~km})$. This sequence consists of a single repeated cycle identical to Cycle 1 in the "Titan ExploratoryTA" Sequence with OSI replacing OSNB mode. It will thus provide both the survey data needed to characterize the composition of Titan's exosphere and ionosphere and the high-temporal-resolution data on the expected major constituents (masses $2,16,17,28$, and 29) needed to establish the structure of the upper atmosphere. The neutral composition measurements will complement Probe in situ data and Orbiter remote-sensing data on atmospheric composition at lower altitudes. The ion measurements will yield insights into the photochemical and energetic-particleinduced processes occurring in Titan's upper atmosphere. Because Titan's upper atmosphere, and especially the ionosphere, are expected to exhibit day/night, plasma $\mathrm{ram} /$ wake, and latitude/longitude asymmetries, high-altitude flybys of Titan at several points in its orbit about Saturn will be required to obtain the coverage needed to adequately characterize Titan's upper atmosphere and understand its variability.

The region in which the INMS will invoke this orbital sequence is the site of the interaction between Titan's upper atmosphere (cf. Section 1.1.2) and the external plasma environment, as well as the region from which atmospheric escape occurs as the result of several different loss processes, including sputtering, scavenging by the external plasma flow, and photochemical loss by ion-neutral reactions (cf. Section 1.1.3). INMS data acquired during the Orbiter's high-altitude passes will thus be particularly important for characterizing Titan's interaction with its external plasma environment, establishing the relative importance of different atmospheric loss mechanisms, and assessing Titan's role as a source of neutrals and plasma for the Saturnian magnetosphere. Moreover, knowledge of atmospheric escape processes and rates acquired through the analysis of high-altitude INMS data, as well as from other Cassini investigations, will be of significant value in our efforts to understand the origin and evolution of Titan's atmosphere.

\subsubsection{Titan Low-Altitude 006TI_T5}

The "Titan Low-Altitude 006TI_T5" Sequence is designed for composition measurements at altitudes as low as is consistent with Orbiter safety (this version is specifically tailored to the 5th Titan Pass). As explained above, minimum safe altitudes will be determined on the basis of INMS density and temperature data obtained 
during the initial Titan flybys. Several such low-altitude passes, with spacecraft orientation optimized to point the open source aperture into the spacecraft ram direction, are required for successful completion of the INMS science investigation. A minimum flyby altitude of $950 \mathrm{~km}$ has been selected for these passes, based on densities predicted by theoretical models. Flybys at this altitude will allow for data acquisition well below the ionospheric peak and the homopause-both of which are predicted to occur at $\sim 1050 \mathrm{~km}$ (Strobel et al., 1992; Fox and Yelle, 1997; Keller et al., 1998) - and well into the region where the photochemical production of complex hydrocarbons and nitriles is initiated. At this altitude, the INMS will be able to measure with maximum sensitivity minor species, including short-lived chemically active neutral and ion species that play an important role in Titan's photochemistry and ion-neutral chemistry.

A minimum of 18 low-altitude aeronomy passes are needed to fully achieve INMS Titan science objectives. Low-altitude flyby scenarios proposed by the INMS Science Team provide for sampling of the atmosphere and ionosphere at noon, midnight, dusk, and dawn and at varying latitudes on both the ram side and the wake side (see Table VIII). Detailed ion and neutral composition measurements under these different conditions will yield a comprehensive picture of variability

TABLE VIIIA

INMS combined latitude coverage-open source ion measurements.

\begin{tabular}{|c|c|c|c|c|}
\hline & Day & Dusk & Dawn & Night \\
\hline \multirow[t]{2}{*}{ Ram } & & T26out & & T5out \\
\hline & & T32out & & T21out \\
\hline \multirow[t]{5}{*}{ Flank } & T18out & & & \\
\hline & T36out & & & \\
\hline & T39out & & & \\
\hline & T40out & & & \\
\hline & T42out & & & \\
\hline \multirow[t]{2}{*}{ Wake } & T17 out & & T40in & \\
\hline & T37out & & & \\
\hline
\end{tabular}

TABLE VIIIB

INMS combined ram/wake coverage—open source neutral measurements.

\begin{tabular}{lllll}
\hline & Day & Dusk & Dawn & Night \\
\hline North & & T18in & T5in & T32in \\
South & T39in & & T36in & \\
& T42in & & & \\
Equatorial & & T17in & T37in & T26in \\
\hline
\end{tabular}


in the composition and structure of Titan's upper atmosphere, including possible seasonal effects, and will help elucidate the relative roles of solar EUV radiation and magnetospheric electron precipitation in neutral chemistry and ion production.

The INMS science team has determined that, as a minimum set, INMS must have control of primary spacecraft axis pointing on nine low-altitude passes (nine half passes each for neutral and ions). This plan relies on INMS having secondary axis pointing on many of the other low-altitude flybys to complete its science objectives. The nine passes are a revised minimum established by the INMS science team to cover season and latitude, as well as extremes of solar and magnetospheric production of ions and radicals that lead to the complex chemistry seen in the lower atmosphere. The flybys currently allocated to INMS comprise four separate phases of the mission: investigation validation (flyby 5), northern latitude survey (flybys $17,18,21$ ), terminator study (flybys 26,32 ) and southern latitude survey (flybys 36, 37, 39, 40, 42) (see Figure 27).

One of the major issues identified to date through the Titan Orbiter Science Team (TOST) process is the pointing conflict between INMS and RADAR. The INMS closed source field of view is such that in some cases it may be possible to take measurements during the same encounter, most likely within $\pm 8 \mathrm{~min}$ of closest approach. In this case the angle of attack of the closed source sensor would be changing throughout the measurement period. The INMS team is performing a study to determine the angular dependency of the closed source. The results of this study will determine in part the extent of INMS Closed Source/RADAR compatibility.

The INMS open source geometrical field of view cone half-angle is $8.6^{\circ}$. An assessment of the geometry of an INMS/RADAR pass suggests that INMS is in a preferred pointing direction only for \pm 1 min near closest approach (out of a required $\pm 12 \mathrm{~min}$ ) if RADAR is optimally pointed. Furthermore, mutually and maximally compromised pointing of both INMS and RADAR increases that window to only $\pm 2 \mathrm{~min}$. Therefore, geometrically there is no way to satisfy the open source pointing requirements of INMS and RADAR at the same time. Two remaining possibilities are "dithering" from an INMS-optimum to a RADAR-optimum pointing continuously through a pass or using the electrostatic deflection built into the open source to obtain the ion portion of the data set. However, both of these options will require extensive calibration and simulation by both teams to demonstrate feasibility.

There has been extensive discussion within the MAPS, atmospheres, and INMS working groups to examine the INMS ionospheric and neutral atmospheric requirements. The current list of flybys includes: 5 (INMS inbound, ride with RADAR outbound), 17 outbound, 18 (full), 21 (outbound), 26 (full), 32 (outbound), 36 (full, although INMS may lose this flyby to atmospheres), 37 (starting -7 min through outbound), 39 (outbound), 40 (full) and 42 (still under discussion as to which leg will be INMS). Below is an attempt to demonstrate the importance of each of 


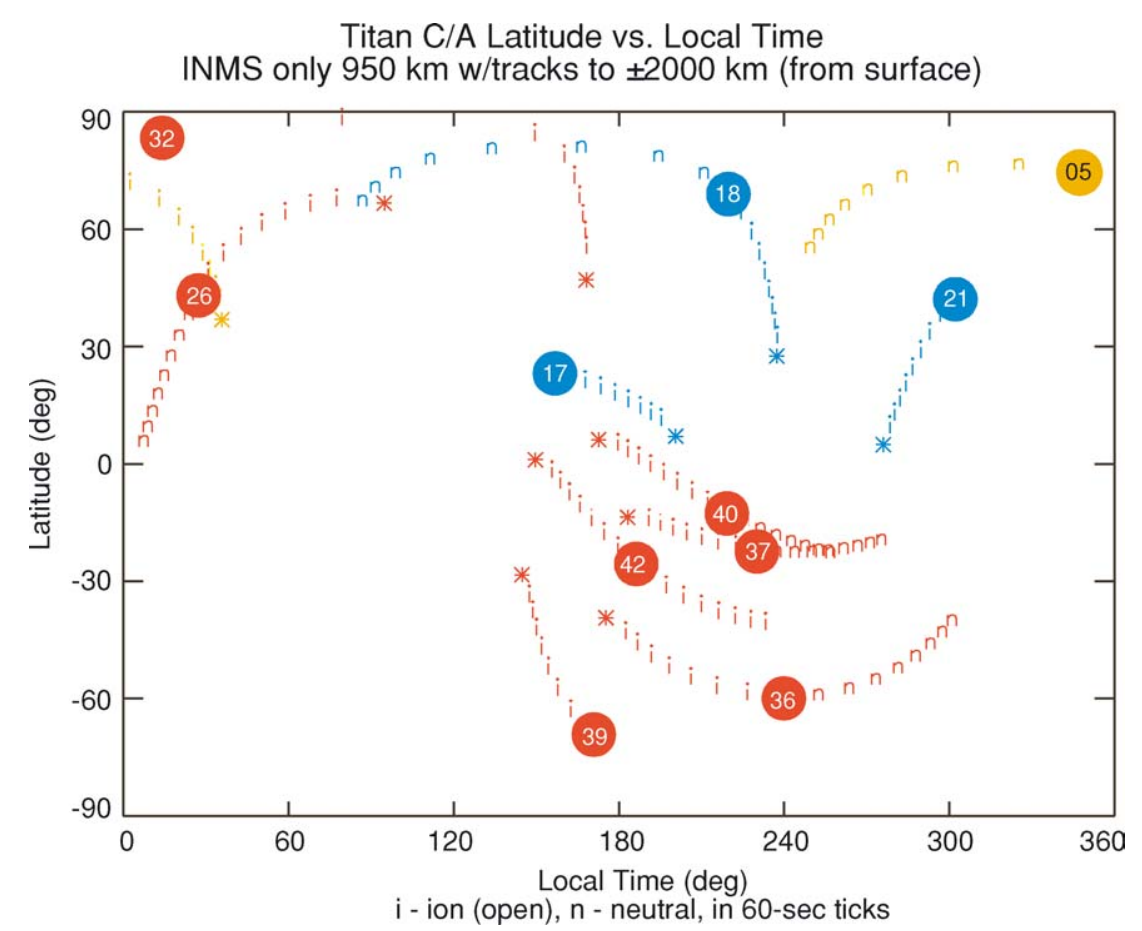

Figure 27. This figure shows latitude versus local time (Titan sub-spacecraft longitude relative to the Titan sub-sun longitude) of the Cassini spacecraft for all Titan encounters. The local time ( $X$-axis of the plot), is expressed in degrees. The circular points indicate where closest approach occurs. The number within the circle indicates which Titan encounter it represents. The Cassini orbit track is shown for periods when the spacecraft is $2000 \mathrm{~km}$ or less from Titan's surface. The '*' indicates which is the outbound leg.

these orbits on a per flyby basis, throughout the discussion reference is made to the color-coded figure of Titan's orbital phases.

1. Investigation validation phase-Pass 5 . Pass 5 is the first low-altitude pass in the tour that is available for INMS operations. Therefore, it is extremely important for determining the minor neutral and ion densities. Pass 5 is also important as a first step in sampling the global composition of the thermosphere and ionosphere and the thermal structure as a function of local time and latitude under varying conditions of magnetospheric input. It occurs during the "yellow" (a) segment of Titan's orbit (see Figure 28), which is of primary importance for studying magnetic induction in subsurface layers. From a magnetospheric point of view, it is a good flux tube crossing (see Table VIII and Figure 29). The team thought that it was imperative from both a technical and a scientific point of view to 


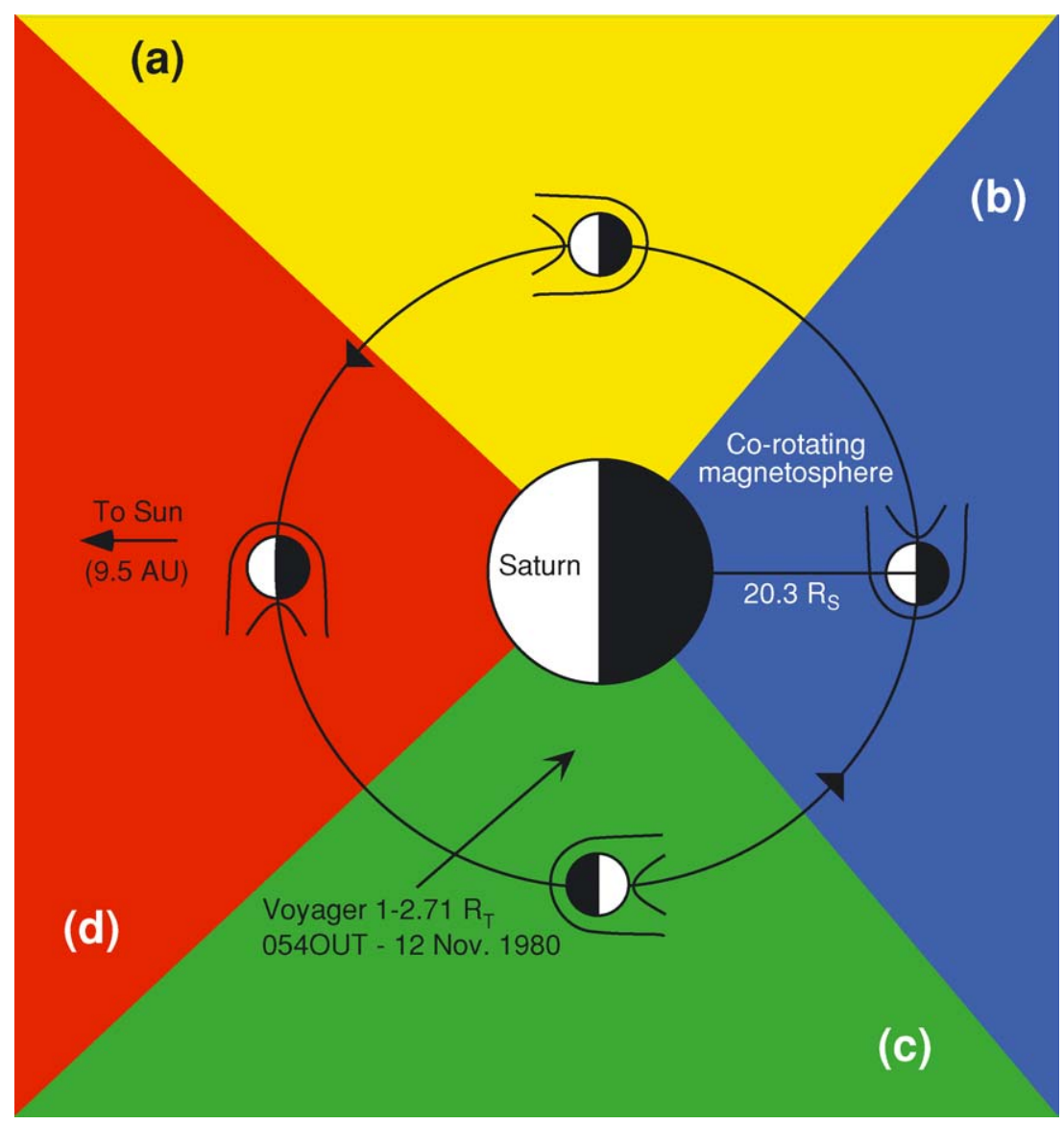

Figure 28. Shows four quadrants of Saturn's magnetosphere in sun-fixed coordinates.

have a full pass early in the mission to perform both open ion and open neutral measurements in a similar environment. This approach will best determine the performance of the instrument and will also make possible the study of the complex chemical coupling between the atmosphere and ionosphere needed to optimize the instrument performance for the rest of the mission.

2. Northern latitude survey-Passes 17, 18, and 1/2 of 21. Passes 17 and 18 are both passes within several hours of noon local time that provide coverage of the northern latitude under the same conditions of magnetospheric interaction (see Figures 27 and 29). They are both representative of the "blue" (b) orbital phase (see Figure 28). They occur near local noon and provide an excellent sampling of the flank of the magnetospheric interaction region where local ion pickup is thought to maximize, which will provide significant loss to the ionosphere and modification of the ion neutral chemistry (see Figure 29 and Table VIII). Pass 21 

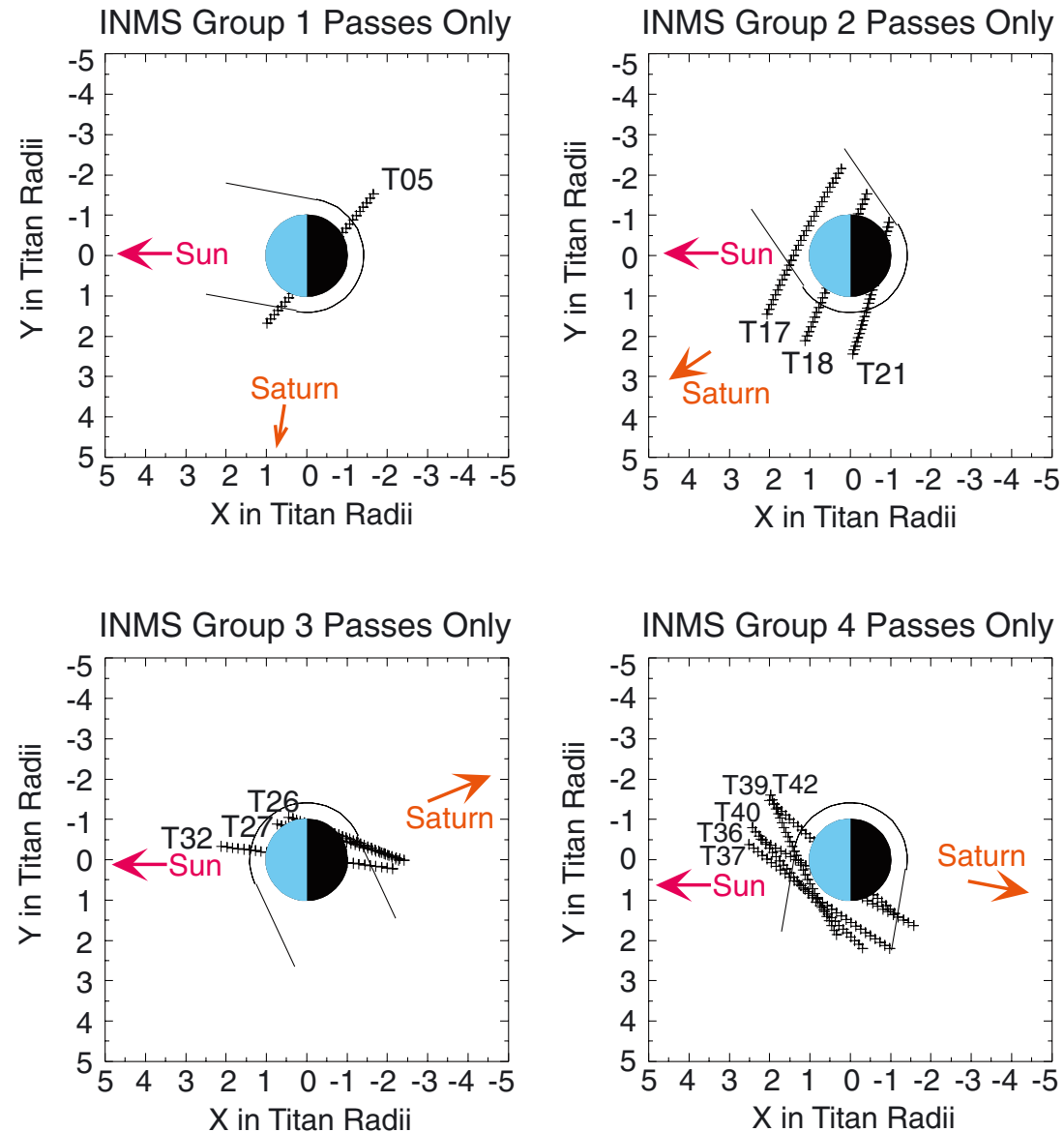

Figure 29. The position of Cassini and where it crosses the magnetospheric boundaries relative to Titan (in Titan-centered coordinates) broken up into four groups based on Titan's local time relative to Saturn.

fills in the latitude sampling, but more importantly, samples the ramside and flux tube of the magnetospheric interaction region at a local time near dusk and thus provides important measurements of the production and loss of ions and radicals that drive the ion neutral chemistry (see Table VIII and Figure 29). This subset will provide a fairly complete assessment of the factors affecting the northern latitude thermosphere and ionosphere.

3. Terminator study-Passes 26, and 1/2 of Pass 32. These passes are a twoorbit survey of the mid- to high-latitude terminator. Pass 26 takes place near $40^{\circ}$ latitude and pass 32 occurs near $75^{\circ}$ latitude (see Figure 27). They are both from the "red" (d) orbital phase (see Figure 28) and sample the flux tube where electron precipitation may have strong effects on the 
heating and chemistry of the thermosphere and ionosphere (see Table VIII and Figure 29).

4. Southern latitude survey -Passes 36, 37, 1/2 of 39, 40, and 42. The set of passes $36,37,39$, and 42 provides an adequate sampling of the southern latitudes for the "red" (d) orbital segment (see Figure 28) in both the open ion and open neutral modes (see Figure 27). They occur again all within an hour or two of local noon and thus sample the flank of the magnetospheric interaction region (see Figure 29), where energetic ion precipitation will have maximum effect on the thermosphere and ionosphere. Here pickup and energetic ion precipitation will be very different owing to the asymmetry produced by finite gyro radius effects of the magnetospheric ion interaction. Pass 40 is also important because it provides sampling of the low-latitude southern hemisphere (see Figure 27), which will provide continuity between the northern and southern latitude surveys. Pass 36 is unique in that it is the only pass selected for INMS that provides sampling of the important magnetospheric wake region where ion loss and electron influx will strongly affect the topside ionosphere and thermosphere (see Figure 29).

The Aeronomy Sequence used in these low-altitude flybys is the most complex of the INMS science sequences. It consists of seven cycles (1-11), each for a different altitude region through which the Orbiter will pass on its approach to Titan. The cycles are presented in Table VII in the order in which they will be executed during the entire flyby. Note that the inbound and outbound legs are not symmetric. The cycles prescribe a combination of unitary survey scans (for bulk composition measurement) and adaptive scans (for high-temporal-resolution measurement of key neutral and ion species expected to be present within a given altitude range). The target species for the adaptive scans to be performed during this sequence are summarized in Table IX.

\subsubsection{Outer Magnetosphere Sequence}

The INMS instrument will provide compositional information on neutral and ionized species in Saturn's outer magnetosphere. Of particular interest is the region near the orbit of Titan, as data acquired here will be used to assess Titan's contribution of neutrals and plasma to the outer magnetosphere (cf. Section 1.1.3). Because densities are expected to be low, long accumulation periods will be used and the mass scans co-added to improve counting statistics. Mass Tables 25 (CSN) and 44 (OSNB) are used for exclusively neutral measurements and 25 (CSN) and 63 (OSI) are used to sample ions; masses of particular interest are $14\left(\mathrm{~N}, \mathrm{~N}^{+}\right), 16\left(\mathrm{O}, \mathrm{O}^{+}\right)$, $17\left(\mathrm{OH}, \mathrm{OH}^{+}\right), 18\left(\mathrm{H}_{2} \mathrm{O}, \mathrm{H}_{2} \mathrm{O}^{+}\right)$, and $28\left(\mathrm{~N}_{2} / \mathrm{H}_{2} \mathrm{CN}, \mathrm{N}_{2}^{+} / \mathrm{H}_{2} \mathrm{CN}^{+}\right)$.

There are two different versions of the Outer Magnetosphere Sequence, one for purely neutral measurements (used during the inbound leg of the orbit) and one for ion and neutral measurements (used during the outbound leg of the orbit). Each of these measures the same mass values in the same order, but uses OSNB or OSI mode, 
TABLE IX

This table lists the Dalton range, and in some case the species sampled, for scans executed during the various INMS orbital sequences detailed in Table VII.

\begin{tabular}{|c|c|c|}
\hline Mass Table(s) & Scan Type & Description (source listed where applicable) \\
\hline $1,26,50$ & Unitary & $1-8$ and $12-70$ Daltons \\
\hline $2-13,27-38$ & Survey & $\begin{array}{l}\text { Closed source/open source ion: } 1 / 8 \text {-Dalton } \\
\text { surveys covering the mass range } 0.5 \text { to } 99.5\end{array}$ \\
\hline $\begin{array}{l}14,39,53 \text { (inner } \\
\text { magnetosphere) }\end{array}$ & Adaptive & $\begin{array}{l}\text { Four water fragmentation product scans from } \\
12 \text { to } 19 \text { Daltons embedded in a unitary } \\
\text { scan from } 1 \text { to } 48 \text { Daltons }\end{array}$ \\
\hline $\begin{array}{l}\text { 16/17, 40/41, 54/55 (Titan } \\
\text { low/high altitude parts } 1 \\
\text { and 2) }\end{array}$ & Adaptive & $\begin{array}{l}\text { Eight scans of } \mathrm{N}_{2}, \mathrm{CH}_{4} \text { and } \mathrm{H}_{2} \text { embedded in } \\
\text { unitary scans from } 1 \text { to } 8 \text { and } 12 \text { to } 99 \\
\text { Daltons }\end{array}$ \\
\hline $\begin{array}{l}18 / 19,56 / 57 \text { (TA adaptive } \\
\quad \text { and } 1 / 8)\end{array}$ & Adaptive/Survey & $\begin{array}{l}\text { Closed source/open source neutral: eight scans } \\
\text { of } \mathrm{N}_{2}, \mathrm{CH}_{4} \text { and } \mathrm{H}_{2} \text { embedded in } 1 / 8 \text { Dalton } \\
\text { scans from } 12.625 \text { to } 18.500 \text { and } 25.625 \text { to } \\
30.500 \text {. Used in TA to check the mass peak } \\
\text { selection accuracy }\end{array}$ \\
\hline $\begin{array}{l}\text { 20/21, 58/59 (Titan low } \\
\text { altitude parts } 1 \text { and } 2 \text { ) }\end{array}$ & Adaptive/Unitary & $\begin{array}{l}\text { Closed source: } \mathrm{H}_{2}, \mathrm{He}, \mathrm{CH}_{4}, \mathrm{C}_{2} \mathrm{H}_{2}, \mathrm{HCN}, \\
\mathrm{N}_{2} / \mathrm{C}_{2} \mathrm{H}_{4} / \mathrm{H}_{2} \mathrm{CN} /(\mathrm{CO}),{ }^{15} \mathrm{~N}^{14} \mathrm{~N} /{ }^{13} \mathrm{C}_{2} \mathrm{H}_{4}, \\
\mathrm{C}_{2} \mathrm{H}_{6},{ }^{36} \mathrm{Ar}, \mathrm{C}_{4} \mathrm{~N}_{2}, \text { cracking products } \\
(12-15,24-25,37-40 \text { Daltons); sweep of } \\
\text { 1-51 and 52-99 Daltons } \\
\text { Open source neutral: same species as are } \\
\text { measured in closed source mode plus } \mathrm{N}, \\
\mathrm{NH}, \mathrm{O}, \mathrm{CHCN} \text {; sweep of 1-51 and 52-99 } \\
\text { Daltons }\end{array}$ \\
\hline $\begin{array}{l}25,44,63 \text { (outer } \\
\text { magnetosphere) }\end{array}$ & Adaptive & $\begin{array}{l}\text { Open source ion: } \mathrm{H}_{2}^{+}, \mathrm{C}^{+}, \mathrm{CH}^{+}, \mathrm{N}^{+} / \mathrm{CH}_{2}^{+} \text {, } \\
\mathrm{CH}_{3}^{+}, \mathrm{CH}_{4}^{+} / \mathrm{O}^{+}, \mathrm{CH}_{5}^{+} / \mathrm{OH}^{+}, \mathrm{H}_{2} \mathrm{O}^{+}, \\
\mathrm{C}_{2} \mathrm{H}_{2}^{+} / \mathrm{CN}^{+}, \mathrm{HCN}^{+} / \mathrm{C}_{2} \mathrm{H}_{3}^{+}, \\
\mathrm{N}_{2}^{+} / \mathrm{H}_{2} \mathrm{CN}^{+} / \mathrm{C}_{2} \mathrm{H}_{4}^{+} /\left(\mathrm{CO}^{+}\right), \mathrm{C}_{3} \mathrm{H}_{8}^{+} /\left(\mathrm{CO}_{2}^{+}\right) \\
\text {Closed source/open source neutral: same } \\
\text { species as above, but neutrals }\end{array}$ \\
\hline $\begin{array}{l}\text { 22, } 60 \text { (Titan low altitude } \\
\text { adaptive large) }\end{array}$ & Adaptive & $\begin{array}{l}\text { Closed source: } \mathrm{H}_{2}, \mathrm{He}, \mathrm{CH}_{4}, \mathrm{C}_{2} \mathrm{H}_{2}, \mathrm{HCN} \text {, } \\
\mathrm{N}_{2} / \mathrm{C}_{2} \mathrm{H}_{4} / \mathrm{H}_{2} \mathrm{CN} /(\mathrm{CO}),{ }^{15} \mathrm{~N}^{14} \mathrm{~N} /{ }^{13} \mathrm{C}_{2} \mathrm{H}_{4}, \\
\mathrm{C}_{2} \mathrm{H}_{6},{ }^{36} \mathrm{Ar}, \mathrm{C}_{4} \mathrm{~N}_{2} \text {, cracking products } \\
(12-15,24-25,37-40 \text { Daltons }) \\
\text { Open source neutral: same species as are } \\
\text { measured in closed source mode plus } \mathrm{N} \text {, } \\
\mathrm{NH}, \mathrm{O}, \mathrm{CHCN}\end{array}$ \\
\hline $\begin{array}{l}23,42,61 \text { (Titan low } \\
\text { altitude adaptive } 1)\end{array}$ & Adaptive & $\begin{array}{l}\text { Closed source/open source neutral: } \mathrm{H}_{2}, \mathrm{CH}_{4} \text {, } \\
\mathrm{HCN}, \mathrm{N}_{2} / \mathrm{C}_{2} \mathrm{H}_{4} / \mathrm{H}_{2} \mathrm{CN} /(\mathrm{CO}) \text {, cracking } \\
\text { products (12 and } 14 \text { Daltons) } \\
\text { Open source ion: same species as above, but } \\
\text { neutrals. }\end{array}$ \\
\hline
\end{tabular}


TABLE IX

(Continued).

\begin{tabular}{|c|c|c|}
\hline Mass Table(s) & Scan Type & Description (source listed where applicable) \\
\hline \multirow[t]{2}{*}{$\begin{array}{l}24,43,62 \text { (Titan low altitude } \\
\quad \text { adaptive } 2 \text { ) }\end{array}$} & Adaptive & $\begin{array}{l}\text { Open source ion: } \mathrm{H}_{2}^{+}, \mathrm{C}^{+}, \mathrm{N}^{+} / \mathrm{CH}_{2}^{+}, \mathrm{CH}_{4}^{+} / \mathrm{O}^{+} \text {, } \\
\mathrm{CH}_{5}^{+} / \mathrm{OH}^{+}, \mathrm{HCN}^{+} / \mathrm{C}_{2} \mathrm{H}_{3}^{+}, \\
\mathrm{N}_{2}^{+} / \mathrm{H}_{2} \mathrm{CN}^{+} / \mathrm{C}_{2} \mathrm{H}_{4}^{+} /\left(\mathrm{CO}^{+}\right) \\
\mathrm{C}_{2} \mathrm{H}_{5}^{+} / \mathrm{N}_{2} \mathrm{H}^{+} /\left(\mathrm{HCO}^{+}\right)\end{array}$ \\
\hline & & $\begin{array}{l}\text { Closed source/open source neutral: } \mathrm{H}_{2}, \mathrm{~N} \text {, } \\
\mathrm{CH}_{4} / \mathrm{O}, \mathrm{OH} /{ }^{13} \mathrm{CH}_{4}, \mathrm{HCN}, \mathrm{N}_{2} / \mathrm{C}_{2} \mathrm{H}_{4} /(\mathrm{CO}) \\
{ }^{15} \mathrm{~N}^{14} \mathrm{~N},{ }^{13} \mathrm{C}_{2} \mathrm{H}_{4}\end{array}$ \\
\hline
\end{tabular}

Parentheses indicate species whose presence is possible but unlikely.

respectively, for the second set of measurements. Velocity compensation values were selected to account for expected spacecraft-relative velocities of particles in Keplarian, corotating or magnetic-field-aligned orbits. There are also four different data rate modes currently available, just as there are for Default Science: 1498, 100, 50 , and 6.2 bps, with $1,15,30$, and 240 co-added scans, respectively.

\subsubsection{Inner Magnetosphere}

While Cassini will spend most of its time in the outer magnetosphere of Saturn, the higher densities in the inner magnetosphere will be much more conducive to INMS measurements. As discussed in Section 1.2, the inner magnetosphere is characterized by the presence of water group neutrals and ions associated with the rings and icy satellites and believed to be produced from these bodies by charged particle sputtering and micrometeorite bombardment. With predicted densities as high as $4 \times 10^{3} \mathrm{~cm}^{-3}$ near the orbit of Enceladus (Ip, 1997), this material, through the complex plasma-gas-dust interactions in which it participates, is thought to play an extremely important role in the chemistry, dynamics, and structure of the inner magnetosphere. The Mass Tables used-14 for CSN, 39 for OSI and 53 for OSNBinvolve repeated measurement of masses 12-19 interleaved with measurements of the mass ranges $1-8,20-27,28-35$, and 26-47 Daltons. This provides for the repeated sampling during each scan of the water group neutrals $\mathrm{O}(16), \mathrm{OH}(17)$, and $\mathrm{H}_{2} \mathrm{O}(18)$, and ions $\mathrm{O}^{+}(16), \mathrm{OH}^{+}(17), \mathrm{H}_{2} \mathrm{O}^{+}(18)$, and $\mathrm{H}_{3} \mathrm{O}^{+}$. Although the densities of these species are expected to be at a maximum near the predicted source regions, they will still be at the lower end of the INMS sensitivity.

The organization of these sequences is very similar to that of the "Outer Magnetosphere" sequences: a single mass range sampled alternately in CSN and OSNB or CSN and OSI modes. The choice of neutral or ion and neutral is the same as described above-neutral for inbound and ion and neutral for outbound-and the four data rates are organized in the same way. Neutral particles in Keplerian orbits closer to Saturn will move faster, and the velocity compensation values were increased accordingly. 


\subsubsection{Ring Overflight for SOI}

The "Ring Overflight for SOI" Sequence is designed to sample the neutral and plasma environments of the rings and icy satellites in Saturn's inner magnetosphere and will be executed during the overflight of the rings following SOI. A modified version of this sequence could also be used during the planned flybys of Iapatus, Enceladus, Dione, and Rhea. Because the INMS team has primary spacecraft axis control during a period after SOI, a specific sequence was designed to cover this period. The Mass Tables used are the same as those used in the "Inner Magnetosphere" sequences, but the timing is different. The first $\sim 700 \mathrm{sec}$ of the measurement period centers on magnetic-field-aligned and corotating ions, while the next $\sim 480 \mathrm{sec}$ will measure neutrals corotating and in Keplerian orbits. Velocity compensation values were chosen to match the Cassini-relative velocities of particles in each type of orbit at that time period, based on estimated particle masses and energies.

\section{Flight Unit Characterization}

\subsection{General}

The characterization of the INMS flight unit was performed at Goddard Space Flight Center using a high-vacuum test station with both thermal neutral and ion sources (Figure 30). A neutral beam system was not available at the time of the INMS

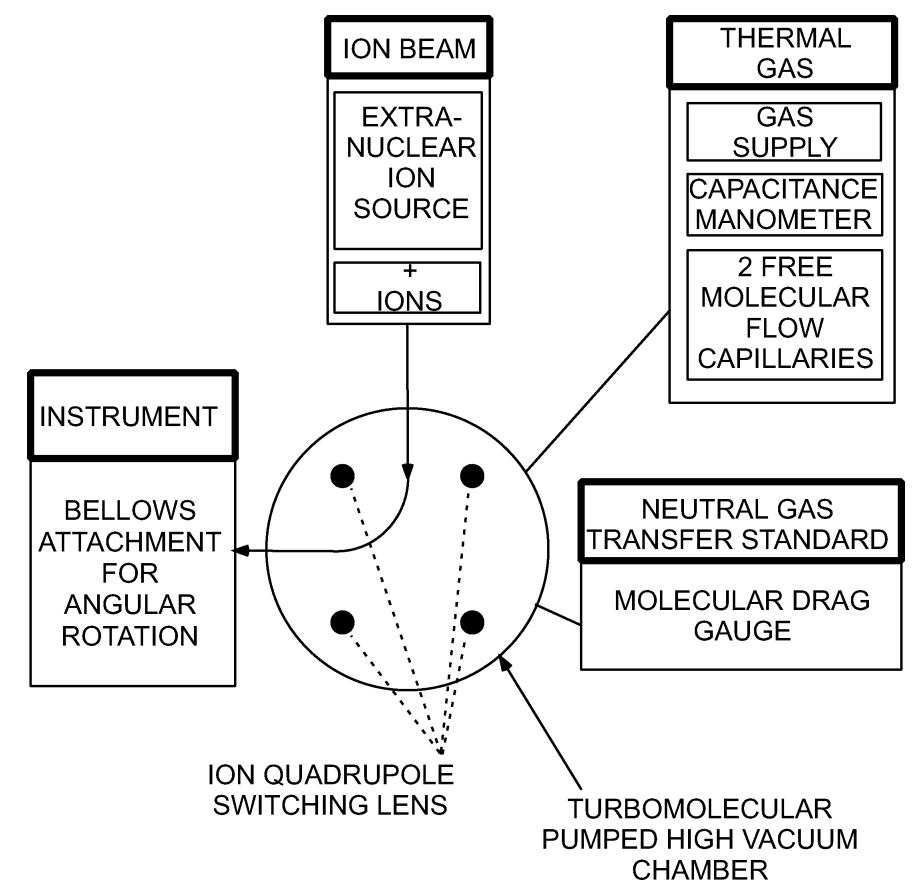

Figure 30. Schematic of the high-vacuum test station used for INMS characterization. 
testing. Thus the ion beam was also used to characterize instrument performance in the open source neutral mode; for these tests, however, the INMS entrance lens (OL4) potential was set at $-5 \mathrm{~V}$, as required for the neutral beaming mode (cf. Section 2.2.1). The test station was designed so that all the INMS operational modes could be characterized without breaking the vacuum and thus necessitating re-baking the sensor. Neutral gases and ions used for characterization testing were introduced into the main vacuum chamber, to which the INMS was attached by a flexible bellows with two degrees of rotational freedom for angles up to about $5^{\circ}$. The instrument could be translated to allow appropriate positioning of the source being tested (i.e., of the open source with respect to the ion beam). Pressures inside the main vacuum chamber were kept below $\sim 10^{-6} \mathrm{hPa}$ in order to prevent possible damage to the secondary electron multipliers. Thus the operation of the instrument at higher pressures, i.e., up to mid $-10^{-5} \mathrm{hPa}$, the estimated ram pressure at Titan closest approach, was not tested. Laboratory support electronics were used for early testing; flight electronics were used for the final characterization. The characterization of INMS performance will continue during the post-launch period with testing of the engineering unit.

\subsection{Neutral Mode Characterization}

INMS performance in the closed source and open source neutral thermal modes was characterized using the principal nonreactive species expected to be encountered at Titan: $\mathrm{H}_{2}, \mathrm{He}, \mathrm{N}_{2}, \mathrm{CH}_{4}, \mathrm{C}_{2} \mathrm{H}_{2}, \mathrm{C}_{2} \mathrm{H}_{4}$, and Ar. Tests were performed with both individual target gases and gas mixtures. Pure $\mathrm{Kr}$ was used as a high-mass reference gas, and a noble gas mixture was used to check instrument tuning. Because the geometries and efficiencies of the primary and secondary filaments in the ionization region are slightly different, test runs were conducted for both sets of filaments. Tests were also performed at both high and low electron energies. In each test run, the first measurements-both unit and 1/8-Dalton survey scans-were made at main chamber gas background pressure with no inflow of gas from the thermal gas source. Following acquisition of these background data, both survey (unit and 1/8-Dalton) scans and programmed mass scans were performed for various gas samples at different pressure levels up to $10^{-6} \mathrm{hPa}$. Representative results from thermal gas characterization tests are presented in Figures $31-36$ and are discussed in the following paragraphs.

The INMS mass range is from 1 to 8 and 12 to 99 Daltons. The capability of the INMS to measure high-mass species is important because of the expected presence of long-chain hydrocarbons (e.g., polyacetylenes) in Titan's upper atmosphere. To investigate the instrument's performance up to mass numbers near 100, data were acquired using the closed source for a sample consisting of $\mathrm{Ne}(10 \%), \mathrm{Ar}(10 \%), \mathrm{Kr}$ $(10 \%), \mathrm{Xe}(10 \%)$, and $\mathrm{He}(60 \%)$. The resulting spectrum, with clearly defined mass peaks for $\mathrm{He}^{+}$and singly and doubly charged $\mathrm{Ar}$ and $\mathrm{Kr}$, is shown in Figure 31 . $\mathrm{Xe}$ is not measured at the parent peak near mass 132, but is observed as a doubly 


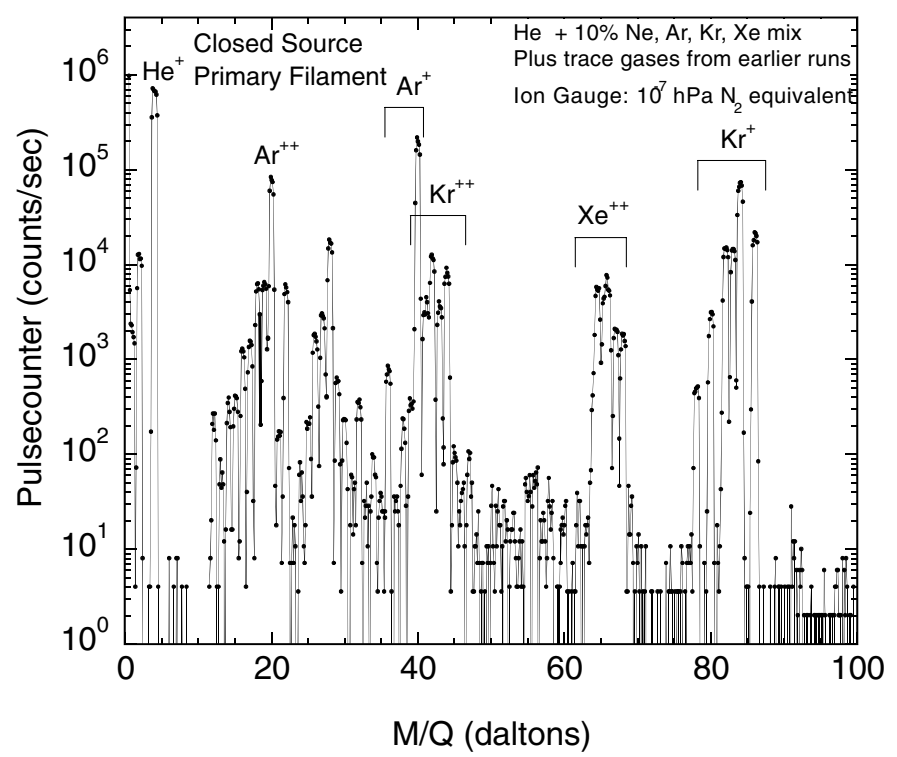

Figure 31. Mass spectrum for a mixture of noble gases illustrating the INMS performance at high mass numbers. Data were acquired in the closed source mode.

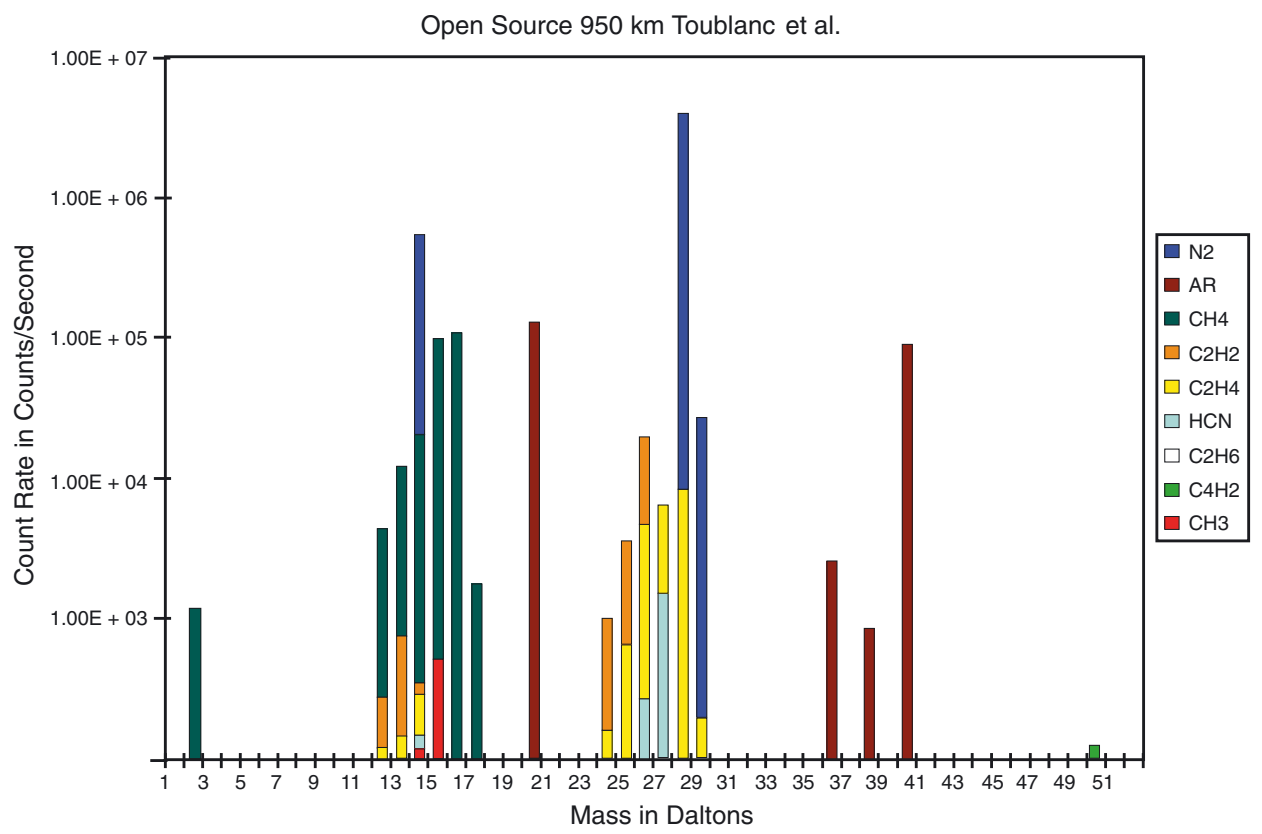

Figure 32. Simulated open source spectrum illustrating the masking of parent species and cracking products by other more abundant species with the same mass numbers. Concentrations are based on densities at Titan closest approach according to the neutral atmosphere model of Toublanc et al. (1995). 


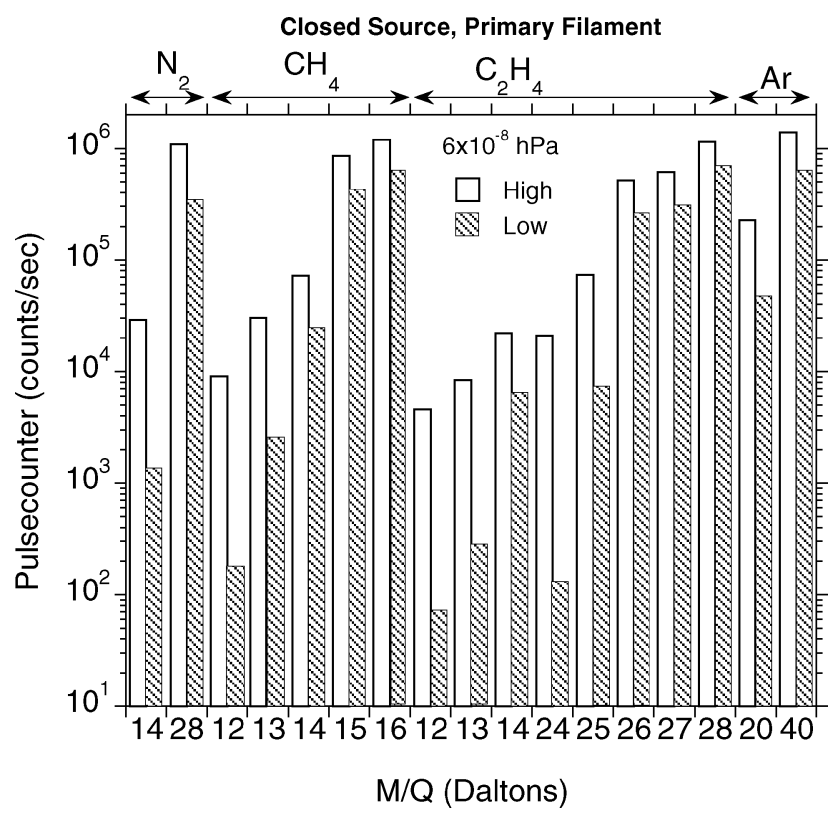

Figure 33. Counts obtained with the INMS closed source using both high and low electron energies for $\mathrm{N}_{2}, \mathrm{CH}_{4}, \mathrm{C}_{2} \mathrm{H}_{4}$, and $\mathrm{Ar}$ at a nominal pressure of $6 \times 10^{-8} \mathrm{hPa}$. Low electron energy reduces the signal amplitude and changes the relative pattern of the various mass peaks. The ionization cross sections at low electron energy change more rapidly than at higher electron energy. The ionizing electron beam energy has an energy spread of several eV, so using low electron energy does not create a sharp cutoff of some mass peaks that might be expected otherwise.

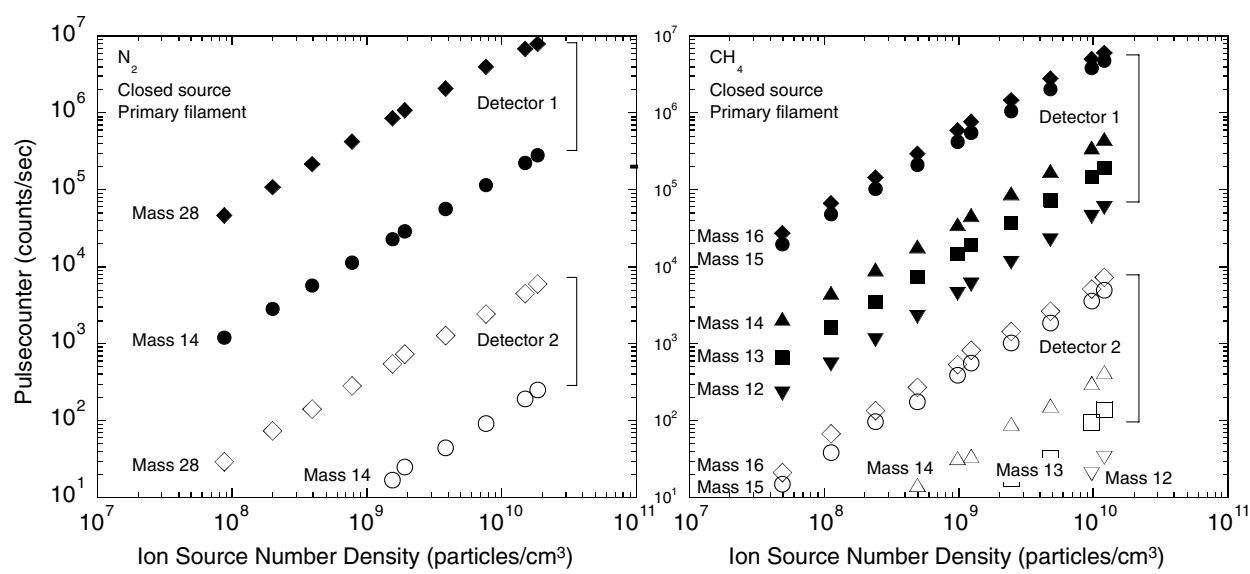

Figure 34. Pulse counter output for Detectors 1 and 2 as a function of ion source density (=main chamber density). Mass peaks for $\mathrm{N}_{2}$ and $\mathrm{CH}_{4}$ (both parent species and fragments) are shown. 

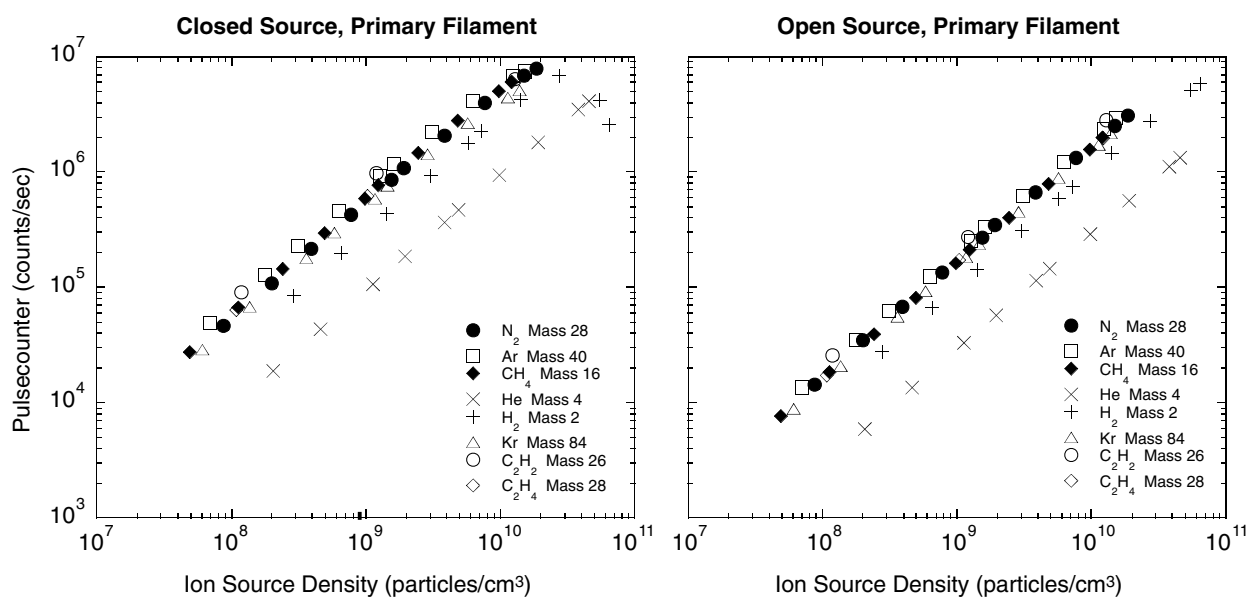

Figure 35. Summary of the pulse counter output as a function of ion source density (=main chamber density) for the parent species of all gases used in the characterization of the INMS closed source and open source neutral thermal mode. The data points for $\mathrm{CH}_{4}$ and $\mathrm{C}_{2} \mathrm{H}_{4}$, which have about the same sensitivity, overlap. Only three data points were obtained for $\mathrm{C}_{2} \mathrm{H}_{2}$ and $\mathrm{C}_{2} \mathrm{H}_{4}$ because of time limitations.

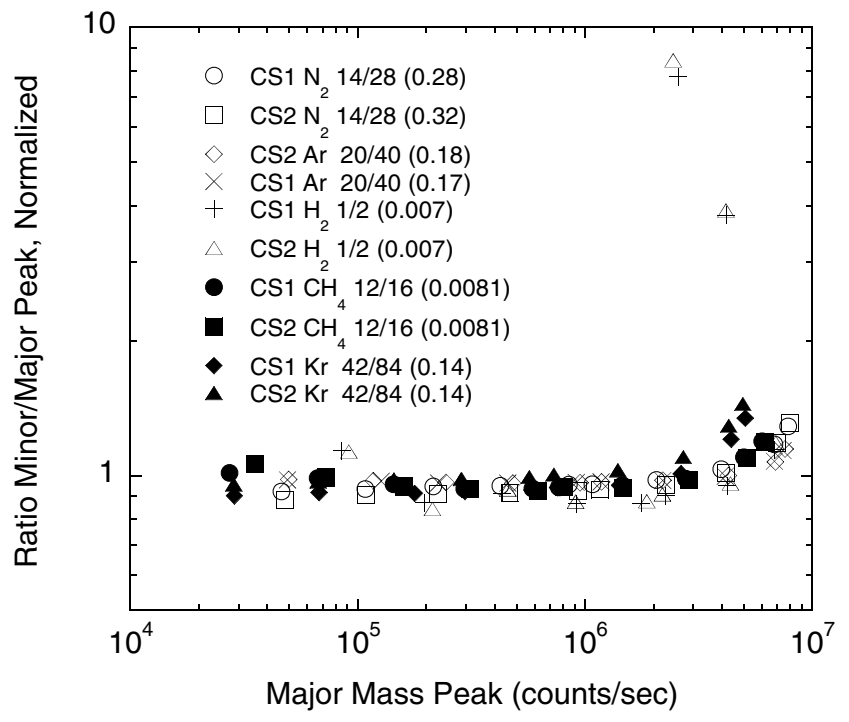

Figure 36. Minor peak to major peak ratios for several species plotted as a function of the parent peak count rate. Data were taken in the closed source (CS) mode using both the primary (CS1) and secondary (CS2) filaments. The ratios have been divided by the numbers in parentheses. The increase in the ratio evident above a count rate of $1-2 \mathrm{MHz}$ reflects a loss of counts at high count rates (the "pile up" effect). 
ionized smear around mass 65. In addition, peaks for some residual gases from earlier runs are evident near mass 28.

Distinguishing between species-whether parent species or cracking productswith the same molecular mass poses a challenging problem for the INMS investigation. This difficulty is illustrated by the simulated mass spectrum shown in Figure 32 , which shows the spectral position and concentration of the primary species and the various cracking products resulting from ionization in the open source (concentrations based on densities at $950 \mathrm{~km}$ derived from the model of Toublanc et al., 1995). $\mathrm{N}_{2}$ is present at higher concentrations than $\mathrm{C}_{2} \mathrm{H}_{4}$ (both mass 28 ) and masks the latter, for example, while a cracking product of $\mathrm{C}_{2} \mathrm{H}_{4}\left(\mathrm{C}_{2} \mathrm{H}_{3}\right)$ masks $\mathrm{HCN}$ at mass 27. As noted above (Section 2.2.1), however, the masking problem can be addressed by using two different electron energies ( 70 and $25 \mathrm{eV}$ ) in the INMS ion sources. Because of the energy dependence of the efficiencies and cross-sections for dissociative ionization, different electron energies yield different spectra, with different peak heights and different fractionation patterns, for the same gas sample, as can be seen in Figure 33, a spectrum based on closed source calibration data for both high and low electron energies. Comparative analysis of such laboratory calibration data and of the mass spectra acquired in the Saturn system can be performed using standard techniques (Kiser, 1965) to deconvolve the contributions of the various species to the mass spectra.

Figures 34 and 35 illustrate the differences in sensitivity between the two detectors and between the closed and open ion sources. Figure 34 shows a plot of the pulse counter output from detectors 1 and 2 as a function of ion source density (=main chamber number density) for $\mathrm{N}_{2}$ and $\mathrm{CH}_{4}$, the major neutral gases in the upper atmosphere of Titan. Data presented in this figure were acquired in the closed source mode using the primary filament. In the left-hand panel $\left(\mathrm{N}_{2}\right)$, mass 28 is the parent peak; in the right-hand panel $\left(\mathrm{CH}_{4}\right)$, mass 16 is the parent peak, and the remaining peaks are those of the cracking products. As noted above (Section 2.2.4), the use of two detectors that differ in signal detection level by about a factor of 1500 yields the needed dynamic range of $\sim 10^{8}$.

Count rates as a function of ion source density for each of the neutral gas species used in the characterization of the closed and open sources (using the primary filaments) are shown in Figure 35. Only the counts for the parent species are given. The higher sensitivity of the closed source is evident from a comparison of the two panels. (The lower sensitivity of the open source is due to the geometry of the open source ionization region and the complexity of the ion optics.) With the exception of $\mathrm{H}_{2}$ and $\mathrm{He}$, most species have about the same sensitivity in a given source. The lower count rates for $\mathrm{H}_{2}$ and $\mathrm{He}$ result from the lower ionization cross sections for these gases. Note: only three data points instead of the usual 10 were acquired per run for $\mathrm{C}_{2} \mathrm{H}_{2}$ and $\mathrm{C}_{2} \mathrm{H}_{4}$ because of time constraints.

As can be seen in Figures 34 and 35, the count rate as a function of ion density

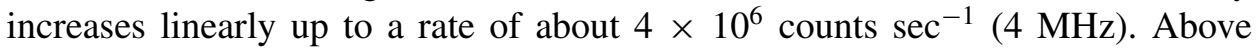


this value, however, the secondary electron multiplier pulses begin to "pile up" and several ion pulses are counted as a single pulse by the pulse counter and discriminator circuits. This loss of counts at the higher count rates changes the slope of the mass 28, 16 and 15 peak data in Figure 34 and, most noticeably, in the closed source data for $\mathrm{H}_{2}$ in Figure 35. The pile up effect is also evident in Figure 36 , which shows the normalized ratio of a minor peak to the parent peak for several gases in the closed source (both filaments) plotted as a function of the count rate of the major peak. Above a count rate of $1-2 \mathrm{MHz}$, this ratio, which should be a constant based on the ratio of the ionization cross sections, increases. The increase occurs because there is a loss of counts in the major peak and very little, if any, in the minor peaks. The pile up effect-i.e., the loss of counts at high count rates-can, in principle, be mitigated by using the output from the second detector once the count rate from the primary detector is larger than 1-2 MHz. A secondary detector count rate of $10^{3}$ counts $\mathrm{sec}^{-1}$ is equivalent to 31 counts per sample period and the statistical error is $(31)^{1 / 2} / 31$ or $\sim 0.2$. Outputs from both detectors are put into the telemetry packet so that the ratio of the output of the primary detector to that of the secondary detector can be tracked over a Titan pass and that ratio used to predict the primary value based on the secondary detector output.

\subsection{Open Source Ion/Neutral Beaming Mode Characterization}

An ion beam system was used to characterize the performance of the INMS in the open source ion mode and, in the absence of a neutral beam, in the open source neutral beaming mode as well. An extranuclear ion source in a separately pumped chamber supplied the ions, which were created from $\mathrm{He}$ (mass 4), Ar (mass 40), and $\mathrm{Kr}$ (mass 84). These particular gases were selected because ion transmission over the INMS mass range (1-99 Daltons) was of primary interest. The ions were focused electrostatically and transmitted from the extranuclear source into the main vacuum chamber, where they were deflected through a quadrupole switching lens into the INMS open source (cf. Figure 30). No magnetic field was used to separate massto-charge ratios; so all ions generated in the extranuclear source from a particular gas were present, including fragmentation ions and background gas ions. During the characterization runs, considerable difficulty was encountered with drift effects in both energy and angle for low-energy ions. These most likely resulted from charging effects in the ion source and at the main chamber quadrupole deflector electrodes.

During initial characterization using laboratory electronics, data were taken on the operation of the INMS switching lens in the open source ion mode, with the entrance lens (OL4) set at $-30 \mathrm{~V}$, and in the open source neutral beaming mode, with OL4 set at $-5 \mathrm{~V}$. Ten ion energies (nominally $2,3,4,6,8,10,12,14,17$ and $20 \mathrm{eV}$ ) plus " $0 \mathrm{eV}$ " (thermal gas in the ion source) were used for the initial tests. The ion beam was centered in the INMS aperture by moving the carriage on 
which the INMS was mounted. The ion flux into the aperture was determined by measuring the current on the top plane lens (TPL). Energy scans were performed by varying the potential on QL3 and setting the other switching lens voltages to $\mathrm{QL} 4=\mathrm{QL} 3$ and $\mathrm{QL} 1=\mathrm{QL} 2=-(\mathrm{QL} 3+2 K)$, where $K$ is the absolute value of the voltage applied to the entrance lens. QL3 was set to the voltage corresponding to the maximum count rate in the energy scan, and the quad bias voltage was set at $-1 \mathrm{~V}$. The ion energy was determined by scanning the quad-bias voltage and determining the voltage value (mean energy value) for which the signal dropped by half its value (the "pseudo-RPA cutoff curve"). (Plots of the results of the energy scans and quad bias scans are shown in Figure 37.) The energy scan was repeated with the quad bias set at $-0.5 \mathrm{~V}$ below the half-amplitude point as determined by the quad bias scan. Only $\mathrm{Ar}^{+}$was used for the initial characterization tests. Spectra were obtained with 1/8-Dalton survey scans.

Characterization tests with the flight electronics were performed using only three energies (3, 8, and $14 \mathrm{eV}$ for $\mathrm{Ar}^{+}$and $\mathrm{Kr}^{+}$and $3 \mathrm{eV}$ for $\left.\mathrm{He}^{+}\right)$at three different flux levels. In addition to test runs with the ion beam centered in the instrument aperture, angle scans around an axis in the horizontal direction and the vertical direction were performed in $0.5^{\circ}$ steps out to the maximum range $\left( \pm 5^{\circ}\right)$ of the carriage system on which the INMS was mounted. For each ion flux and energy level, the switching lens was scanned, and the value for QL3 obtained. The switching lens was frequently re-set if the maximum signal did not occur at the anticipated point as determined from earlier laboratory studies. Quad-bias scans were performed, and, if needed, the voltage was re-set at $-1 \mathrm{~V}$ below the half-amplitude value. Once the correct voltages had been set and verified, normal mass scan and dwell data were taken. A representative spectrum from a 1/8-Dalton mass scan is shown in Figure 38.

During the laboratory characterization tests, the INMS switching lens and quad bias voltages were set to transmit ions of known, fixed energy. For actual measurements at Titan and elsewhere in the Saturn system, however, the energy of the ions (both ambient and those created from neutrals in the open source ionization region) will vary as a function of mass and spacecraft velocity. (The latter will be the same for all masses.) The switching lens and quad bias settings will thus have to vary with ion energy. The switching lens voltages for a given ion energy can be determined from the relationship, established during instrument characterization, between the QL3 voltage corresponding to the maximum signal obtained in an energy scan and the quad bias scan half-amplitude point. As shown by the plot in Figure 39, the QL3 voltage at signal maximum is a linear function of the voltage at the half-amplitude point of the quad bias scans. In Figure 39, the solid and dashed lines represent a linear fit to the data points (circles and squares). The lines are used to predict the appropriate switching lens potential QL3 needed to track the incoming species' kinetic energy as represented by the quad bias half amplitude voltage. For the neutral beaming mode QL3 $=(-9.8754-0.90428 \times \mathrm{KE})$ volts. For the ion mode QL3 $=(-54.296-0.90646 \times \mathrm{KE})$ volts. KE is the species' 

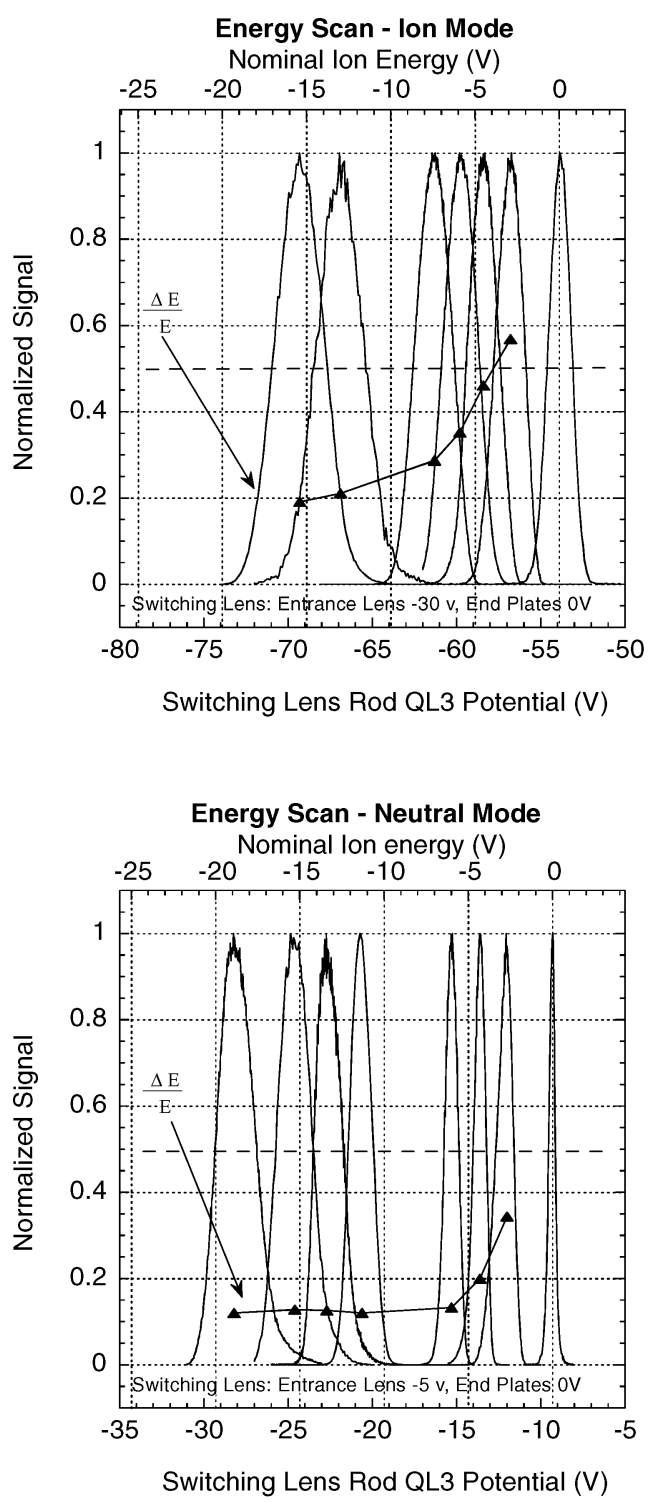

RF Quadrupole Bias Scan - Ion Mode

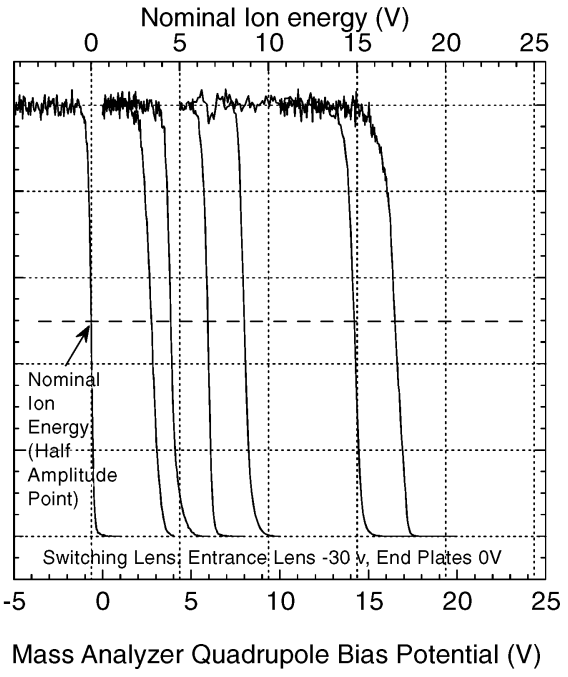

RF Quadrupole Bias Scan - Neutral Mode

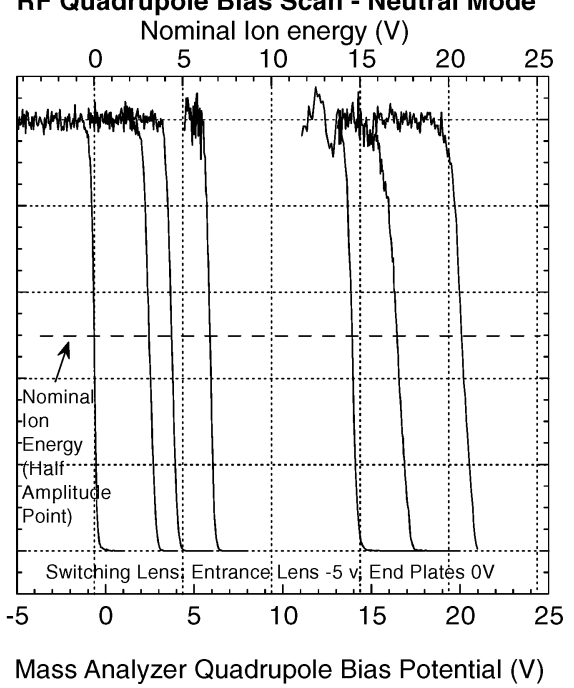

Figure 37. Energy and quadrupole bias scans for various ion energies with INMS operating in the open source ion mode (top) and neutral beaming mode (bottom). The energy scans are obtained by varying the voltage on QL3 and determining the potentials on the other switching lens rods according to the following equations: QL4 $=\mathrm{QL3}$ and QL1 $=\mathrm{QL2}=-(\mathrm{QL} 3+2 K)$, where $K$ is the absolute value of the OL4 (and exit lens L1) voltage (i.e., either 5 or $30 \mathrm{~V}$ ). The halfamplitude value obtained in the quad bias scans is used to establish mean ion energy. The end plate $(\mathrm{OL5} / 6)$ potentials are set at $0 \mathrm{~V}$ rather than at the mean ion energy (=OL4) as in Mahaffy and Li (1990). The INMS $\Delta E / E$ values shown are not constant but decrease with higher ion energy. 

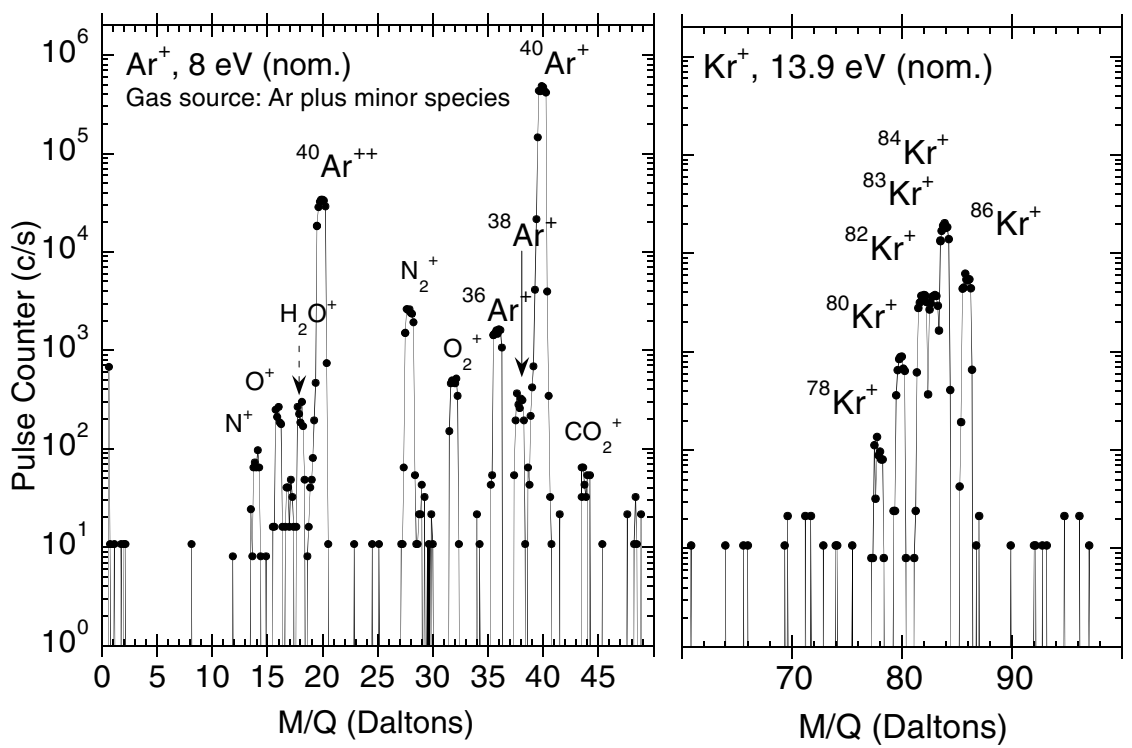

Figure 38. Spectra for $\mathrm{Ar}^{+}$and $\mathrm{Kr}^{+}$from a 1/8-amu scan in the open source ion mode. Peaks for minor species can be seen in the $\mathrm{Ar}^{+}$spectrum and for isotopes in both spectra. A quadrupole bias voltage was applied to retard the mass-analyzed ions and reduce the peak widths (cf. Section 2.2.3).

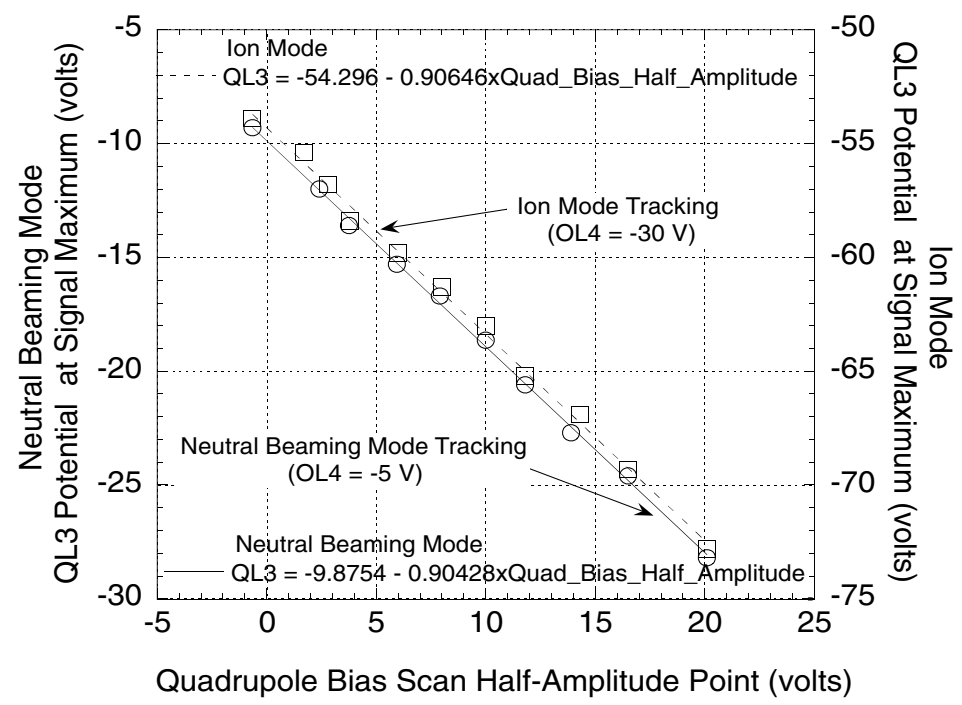

Figure 39. QL3 voltage corresponding to the maximum count rate obtained in energy scans in both the open source ion and neutral beaming modes plotted as a function of the voltage of the quadrupole bias half-amplitude point (=mean ion energy). Data used in generating this plot were taken from Figure 37. 


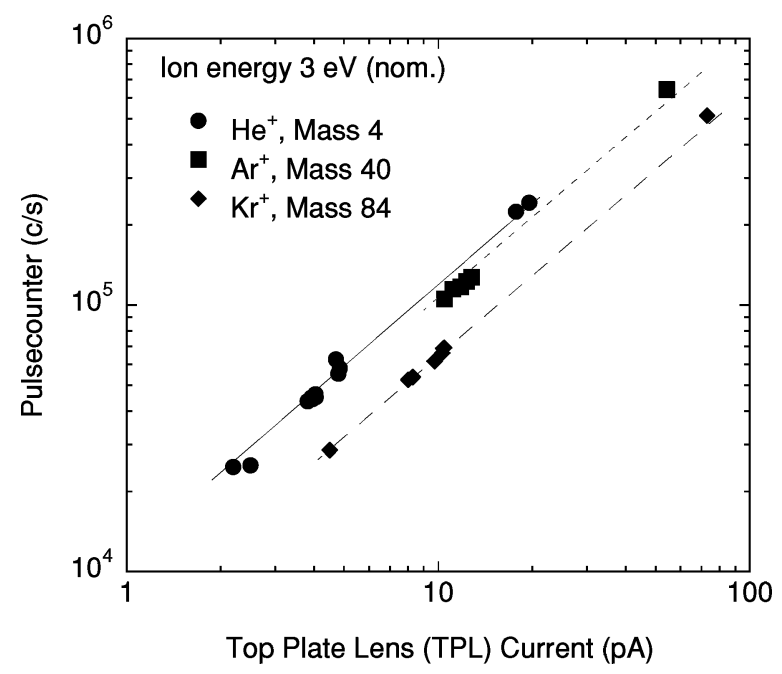

Figure 40. Counts for $\mathrm{He}^{+}, \mathrm{Ar}^{+}$, and $\mathrm{Kr}^{+}$as a function of the top plate lens current, which serves as a proxy for the ion flux into the instrument. Kr data have been corrected to remove isotopic contributions; only the mass 84 contribution is shown. The slope of the lines shown is 1 ; however, the fits of the data imply slopes ranging from 1.03 to 1.1 . It is believed that this discrepancy is due to yet unknown experimental difficulties.

kinetic energy in electron volts as observed in the spacecraft reference frame. For a Titan flyby, with a nominal spacecraft speed of $6 \mathrm{~km} / \mathrm{sec}, \mathrm{KE}=(0.191 \mathrm{eV} / \mathrm{Dalton})$ $\times$ (species' mass in Daltons). The previous equations are suitable for singly ionized species. In the case of double ionized species, the tracking voltages need to be set to a KE value equivalent to half the species' mass.

The ion flux into the INMS was determined by measuring the TPL plate current at $0^{\circ}$ angle. Figure 40 is a plot of the count rates for the three ion species as a function of TPL current. The current to the deflectors was not measured during characterization because earlier measurements had shown them to be negligible for small beam angles.

The rejection of ions by the ion deflector/trap was tested during ion mode characterization. No ion counts were detected for a $20-\mathrm{eV}$ ion beam with the switching lens set to transmit $20 \mathrm{eV}$ ions $(\mathrm{OL} 4=-30 \mathrm{~V}, \mathrm{OL} 1=\mathrm{OL} 2=0 \mathrm{~V})$ and the deflectors set at $\mathrm{D} 1=\mathrm{D} 4=+30 \mathrm{~V}$ and $\mathrm{D} 2=\mathrm{D} 3=-30 \mathrm{~V}$ or $\mathrm{D} 2=\mathrm{D} 3=0 \mathrm{~V}$. Lowering the voltage to $\mathrm{D} 1=\mathrm{D} 4=+5 \mathrm{~V}$ and $\mathrm{D} 2=\mathrm{D} 3=-5 \mathrm{~V}$ yielded about 1 count per integration period. With $\mathrm{D} 1=\mathrm{D} 4=+1 \mathrm{~V}$ and $\mathrm{D} 2=\mathrm{D} 3=-1 \mathrm{~V}$ about 530 counts

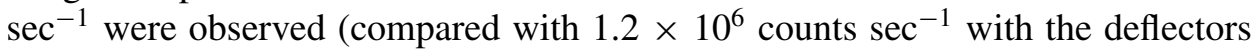
and TPL set at ground). With $\pm 30 \mathrm{~V}$ on the deflectors, only the thermal gas peak was present when the switching lens was set for open source neutral thermal mode; no ion beam ions were transmitted. For neutral beam conditions (OL1 $=-1 \mathrm{~V}$, $\mathrm{OL} 2=+1 \mathrm{~V}$ ) and a $20 \mathrm{eV}$ ion beam, no signal was detected. Tests (at ion beam 
energies of $2.8 \mathrm{eV}$ ) indicated that secondary ions were not being created on the deflectors and contributing to the signal.

\subsection{Secondary Electron Multiplier Characterization}

During characterization, tests using both ion sources were performed usually once a day at a nominal $\mathrm{N}_{2}$ chamber pressure of $10^{-7} \mathrm{hPa}$ to track possible changes in secondary electron multiplier (SEM) sensitivity. Pulse-height distributions were obtained at reasonably low count rates using low electron energy. A pseudo-secondary electron multiplier gain (SEM) was computed from measurements of the multiplier analog current, and the corresponding count rate using the open source. Three SEM high-voltage levels were used: (1) low, used during the characterization period; (2) medium, corresponding to a SEM voltage that would be needed following pulseheight distribution changes in thermal vacuum and vibration qualification testing; and (3) high, corresponding to possible future changes in the pulse-height distribution during the orbital tour. For the primary detector, the SEM voltages are 2500, 2700, and $2900 \mathrm{~V}$, while for detector 2 they are 2800, 2900, and $3000 \mathrm{~V}$. There are 16 discriminator levels; level 4 is used as the nominal setting. Figure 41 shows the mass-28 peak sensitivity referenced relative to an ion gauge on the main chamber for both the open and closed sources (filament 1), and the computed

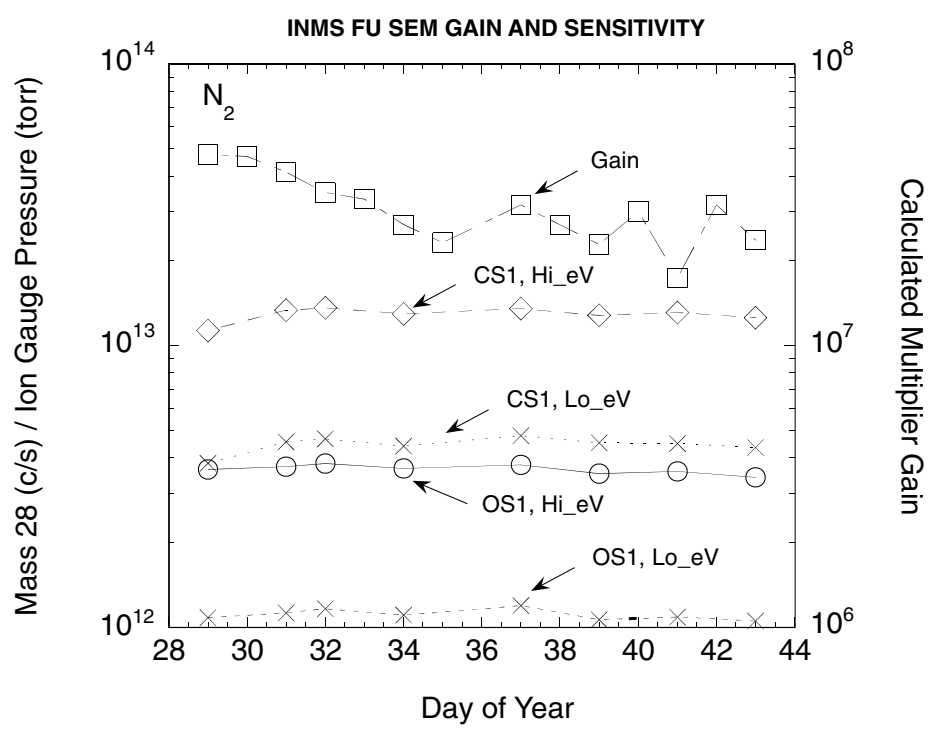

Figure 41. The mass-28 sensitivity relative to reference ion gauge for $\mathrm{N}_{2}$ at nominally $10^{-7} \mathrm{hPa}$. OS1: open source, filament 1; CS1: closed source, filament 1; Hi_eV: high electron energy; Lo_eV: low electron energy. Day of year refers to 1997. Multiplier gain is computed from the accumulated SEM counts and the analog current. 


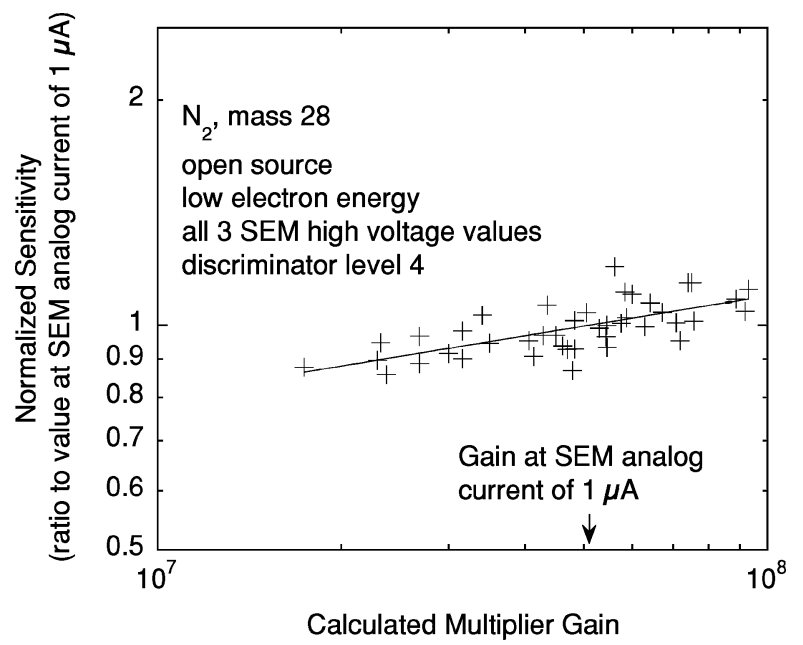

Figure 42. The relative change in sensitivity for a change in multiplier gain.

SEM gain for the low high-voltage setting and discriminator level 4. Figure 42 shows the relative sensitivity change for all three SEM high-voltage levels at discriminator level 4 . A factor of 5 change in gain results in about $20 \%$ change in sensitivity.

Figure 4.4 shows a plot the integrated pulse-height distributions measured during characterization, after vibration and thermal vacuum testing, and during one of the last spacecraft baseline tests for the three SEM high-voltage settings. Data were taken for each of the discriminator levels except for level 0 . As noted above, discriminator level 4 is the normal level used; it was originally chosen to discriminate against the noise counts (upturn in the curve below discriminator level 3 for day 970130), while not severely curtailing the real ion counts above this level. After characterization, SEM voltage was raised to the medium level for the instrument environmental tests. It can be seen from the plot that the slope of the curves above discriminator level 4 changed with time, with the maximum change occurring for the SEM low high-voltage level and the least change for SEM high high-voltage level. It is anticipated that the high high-voltage level will be used for the orbital tour at Saturn. The computed SEM gain during characterization, environmental testing, and baseline testing on the spacecraft is plotted in Figure 44. During characterization, gain values were computed using mass $28\left(\mathrm{~N}_{2}\right)$ data; afterwards, once the sensor was sealed and the getter was activated, gain was computed using mass 40 and mass 20 from Ar. No independent absolute pressure data were available after characterization to reference a possible sensitivity change.

The computed SEM gain can be used as a proxy for estimating the change in ion source sensitivity when a detailed pulse height distribution is not available. 


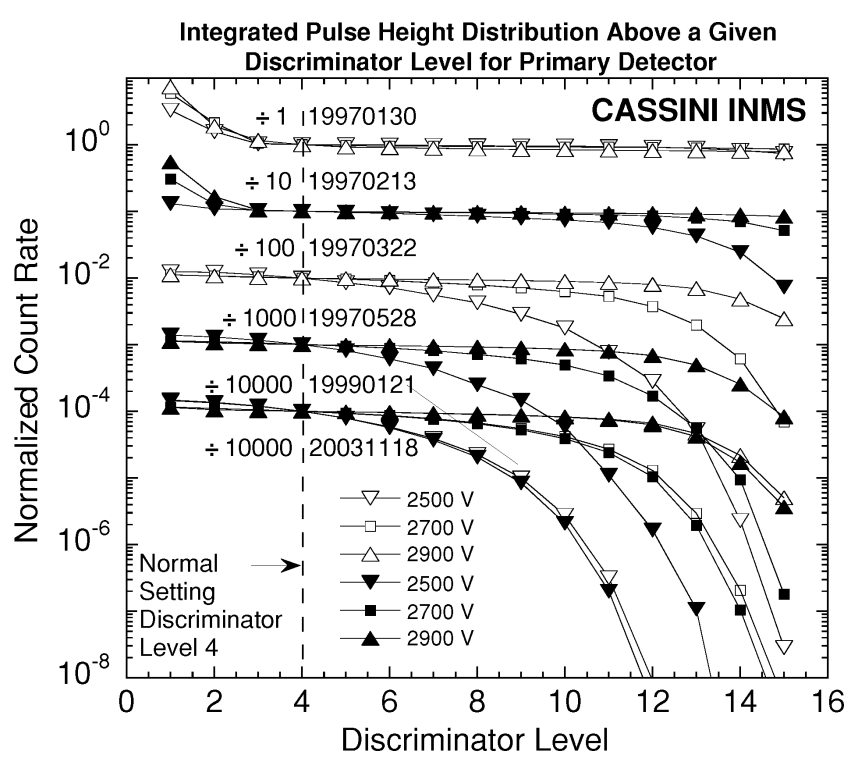

Figure 43. Plot of the integrated pulse-height distributions for the three SEM high-voltage levels (low, medium, high) obtained on four different dates: 970130 (beginning of the characterization period); 970213 (end of the characterization period); 970322 (after environmental testing); and 970528 (testing on the spacecraft). Discriminator level 4 is the normal setting used. Data taken at the beginning and end of the characterization period are for $\mathrm{N}_{2}$ (mass 28); data taken following environmental testing and on the spacecraft are for $\operatorname{Ar}$ (mass 40). The curves have been normalized to discriminator level 4 , and the three sets of data for each date have been divided by the values shown just below the curves, to the left of the dashed line. Test dates are given in YYMMDD format. Data are for the primary detector only. Open and filled symbols are used to distinguish data points for alternating dates when the curves overlap.

\subsection{Engineering Model and Post-Launch Characterization}

The prototype of the Flight Model (FM) instrument, the Engineering Model (EM), was refurbished to more closely emulate the finalized FM unit. This will allow the EM to be used for further laboratory testing, extending the amount of information available for interpretation of the FM results. The EM can also be used to test command sequences and flight computer software changes to be uploaded to the FM. Characterization of the EM in thermal gas mode was done with the same gases used for the $\mathrm{FM}$ (see Section 4.2) plus $\mathrm{C}_{6} \mathrm{H}_{6}, \mathrm{CO}_{2}, \mathrm{CO}, \mathrm{C}_{2} \mathrm{H}_{6}, \mathrm{C}_{3} \mathrm{H}_{4}$ (propyne), $\mathrm{C}_{3} \mathrm{H}_{4}$ (allene), $\mathrm{Ne}, \mathrm{O}_{2}$ and $\mathrm{C}_{3} \mathrm{H}_{8}$. The vacuum test station was modified to provide an ion source that dropped down in the middle of the main chamber. This eliminated the previous ion source and large quadrupole-switching lens shown in Figure 30. Ion energies similar to those used for the FM were used to compare the flux sensitivity and angular response of the EM to the FM. The open source neutral beaming mode was tested with a low-energy neutral beam. It revealed that lens QL3, which was 


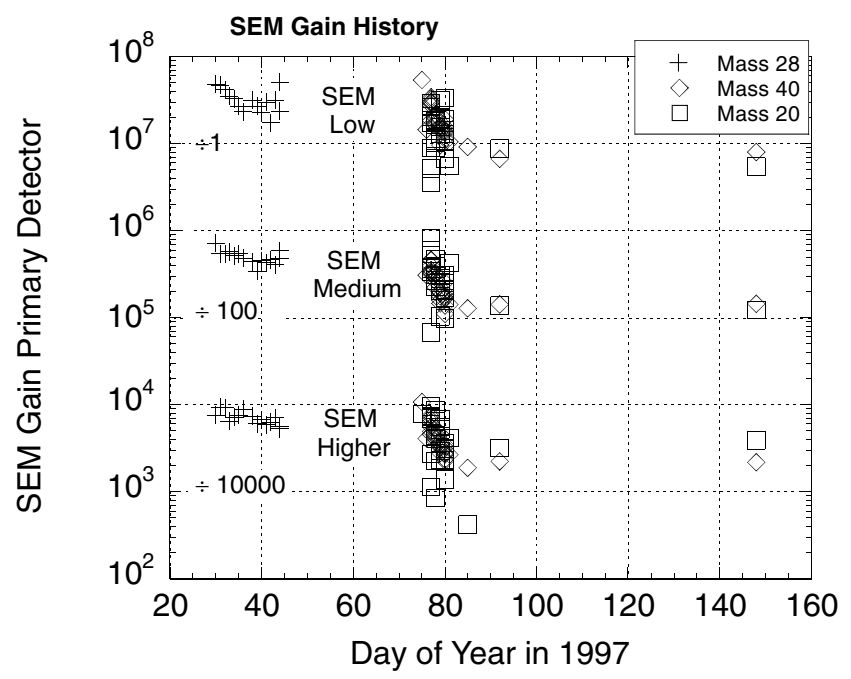

Figure 44. Multiplier gain for the three SEM high-voltage levels, as measured during characterization, after environmental testing, and on the spacecraft. Gain curves have been divided by the values shown immediately beneath the curves. During characterization, gain values were computed using mass 28 $\left(\mathrm{N}_{2}\right)$ data; afterwards, with the instrument sealed and the getter activated, the values were computed using mass 40 and mass 20 from Ar.

initially set to be $-5 \mathrm{~V}$, needed to be closer to $-17 \mathrm{~V}$ based on the angular response in that mode when compared to the angular response in the ion mode. Continued laboratory testing with the EM in thermal gas mode, ion mode and neutral beaming mode will be required to provide better operational parameters for the FM as well as to interpret the data collected.

\section{INMS Operations Network (ION)}

\subsection{ION OVERVIEW}

ION is the ground support system (GSS) that provides complete downlink, uplink, and analysis capabilities for INMS. Most of ION can be accessed through any web browser using a standard point and click hyperlink-based interface. The architecture of ION consists of four primary components-a web server and authentication component, an application component, a database access component and a database component. The main functions of ION are divided into several different components, most of which are web-based applications accessed through the ION web interface, but a few of which are stand-alone applications. Additionally, ION is being developed in three phases that will support downlink, uplink and analysis functions in versions 1.0, 2.0 and 3.0, respectively. 


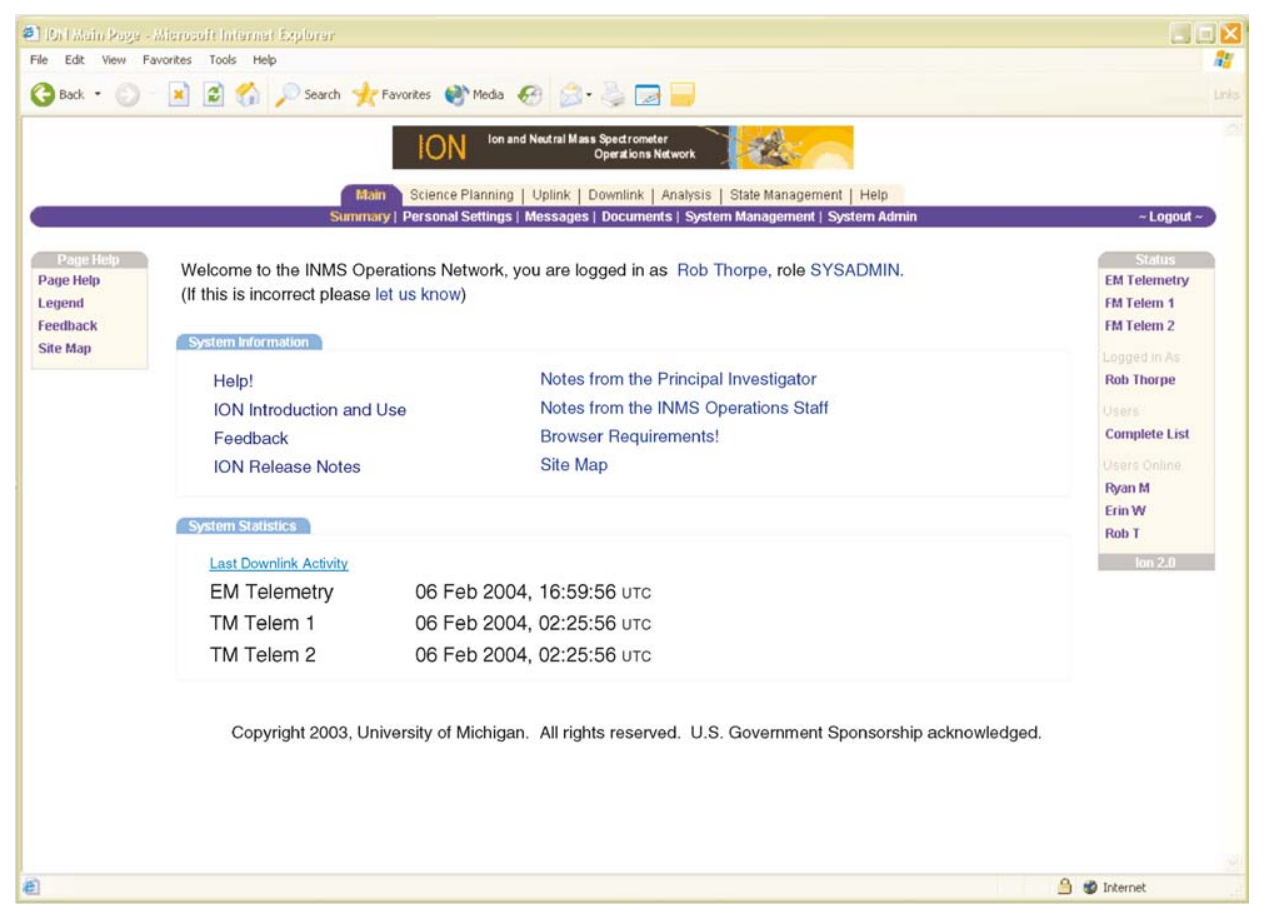

Figure 45. INMS Operations Network screen shot.

ION is accessed through a standard web browser. There is a simple hierarchical menu system for navigation that provides an easy way to access various functions of the system (see Figure 45). While web pages are carefully laid out to provide the right amount of information and color balancing, they are also kept closely aligned to basic HTML standards so many different types of browsers can access the system. This adherence to standards is an essential tenet of ION, supporting the goal of web-based platform-independent access to the INMS ground support system by virtually any web browser.

Architecturally, ION is divided into four components. The Web Server and Authentication Component authenticates a user to the system and provides most of the graphical user interface (GUI) for ION by delivering and processing ION web pages. The Application Components are integrated into the web part of ION and consist of Java Server Pages (JSPs), Java servlets and Java classes. A few applications are part of ION and are not Java-based, and interact with ION through files or direct database connections to the INMS database. The Database Access Component (commonly referred to as the Java Access Layer) consists of a series of Java classes used by all the application components and provides standardized access to the INMS database. Finally, the Database Component is a high-end relational database that stores all INMS GSS data. It is composed of a series of tables, sequences, indices and other data structures that form a 
performance-oriented and relational series of data sets for INMS operations and analysis.

Functionally, ION is divided into 14 components, which support a combination of uplink, downlink and analysis operations (see Figure 46). Most of these components are web-based and are part of the ION web interface. The Thermal Model, Table Software, and Spacecraft Simulator are stand-alone applications that were produced prior to the ION development effort, or by different organizations. Some of the Analysis Software are also stand-alone applications but may be incorporated into the web-based part of ION.

ION is being developed in three major releases. The first release is focused on downlink capabilities, and will support the storing of INMS housekeeping and science data in the INMS database, real-time and historical telemetry display and review, science operations analysis capabilities, system management capabilities, a help system, a data dictionary, and a messaging system. The second release is focused on uplink capabilities and will contain sequence generation, operations table management, Spacecraft Activity Sequence File (SASF) management, state management and memory management functions. The final release focuses on analysis capabilities, supporting the analysis of science data, health and safety analysis, online charting, data download capabilities for Co-Investigators, extended help capabilities, and other functions as necessary.

\subsection{UPLinK Operations}

INMS orbital sequences are designed using the INMS Operations Table Software and then uploaded to ION. The Sequence Generation functions in ION are then used to create the SASF, which is a combination of INMS commands, INMS memory loads (including INMS Science Sequences) and other spacecraft commands and formats that allow INMS commands to be loaded into spacecraft memory. The Sequence Generation function in ION also accesses an INMS instrument command library to produce the commands appropriate to manage INMS and trigger science sequences. The result of the Sequence Generation function in ION is an SASF file that is stored in the Sequence Library in the INMS Database.

In the case of the INMS Flight Model, this SASF file is sent to the appropriate JPL Cassini office for integration with other SASF command files from other instruments, and ultimately uploaded to Cassini through the Deep Space Network. In the case of the INMS Engineering Model, the SASF file is transferred to the spacecraft simulator, which commands the EM through the RTIU/1553 interface.

The Sequence Library is also a resource for the ION Memory Comparison, State Prediction and State Comparison functions. Memory Comparison functions are used to validate INMS memory prior to proceeding with orbital sequences. The State Prediction and State Comparison functions are used to verify that planned orbital sequences will not violate INMS health and safety operational limits, and 


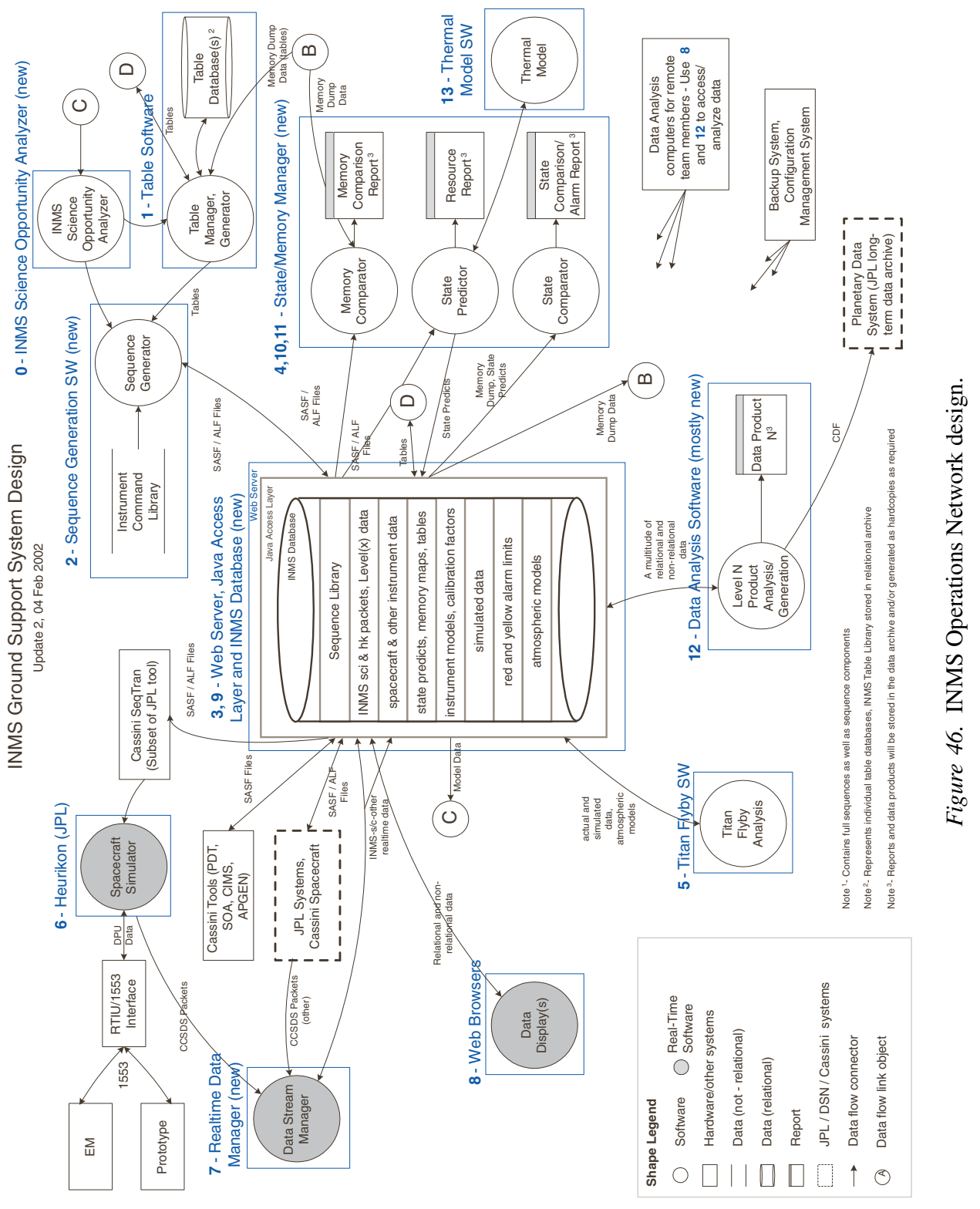


to analyze the ongoing operational performance of the instrument. The Sequence Library is also a resource for Cassini modeling and planning tools such as the Cassini Information Management System (CIMS), the Science Opportunity Analyzer (SOA), the Pointing Design Tool (PDT), and others.

\subsection{DOWnLink Operations}

INMS science and housekeeping data will be downlinked from the Solid State Recorder (SSR) in the Orbiter's Command and Data Subsystem (CDS) to the Deep Space Network and then transmitted to the Jet Propulsion Laboratory, where they will be stored in the Telemetry Delivery System (TDS). The data is also transferred by the TDS via a Virtual Private Network (VPN) to the INMS Science and Operations Center (ISOC) at the University of Michigan. The data will be received at the ISOC by the Science Operations and Planning Computer (SOPC), a secure communications computer, and then forwarded to the ION data manager, which will store the raw data packets in the ION database. An automatic procedure in the database converts and scales the raw packets (level 0 data) into engineering data (level 1 data) that can be viewed in ION (real-time or historical) via any web browser. Analysis functions in ION will convert the engineering data to science-adjusted data.

In addition to INMS science and housekeeping data, ancillary data (e.g., spacecraft ephemeris, attitude, etc.) will also come into the ISOC via the SOPC and be stored in the ION database. Queries will be designed to cross-reference the spacecraft data with the engineering and analysis data. All appropriate data sets will undergo real-time analysis for health and safety purposes as well as science analysis.

Alternately, science and housekeeping data generated from the INMS engineering model, during calibration and operational testing activities, will be sent directly to the ION data manager and stored in the INMS database. This data will go through the same automatic conversion process and be available for review and analysis by all INMS Team Members using all the functions in ION available for flight model data.

\subsection{Data Analysis and Archiving}

Data products will be produced from the INMS database using tools in ION under the oversight of the Science Team Leader and Team Members. Some data products will be dynamically available using database queries and others will be stored in the INMS database. Any range and type of data sets will also be available for download by INMS Team Members and other appropriate personnel via the Internet. Level 1 data products will be delivered to the Planetary Data System (PDS) for archiving. The INMS Team Leader will be responsible for validating the science content of the Level 1 products before release to the PDS. Higher-level data products will be 
developed as specified by the Science Team Members. The appropriate analysis and display tools will be created in ION (and, as appropriate, as remote applications for Co-Investigators) by the Data Analysis Team in consultation with the Science Team. Higher-level products will be stored in the INMS database and, as appropriate, will be archived in the PDS as well.

Exploitation of the data from the INMS investigation will involve both data analysis and modeling studies of the neutral and ionized atmospheres of Titan and of the neutral and plasma environments of the rings and icy satellites.

Analysis of data acquired during the Titan passes will include the computation of neutral and ion densities as a function of altitude and the subsequent computation of the scale height and temperatures. Direct comparison of the INMS thermal ion measurements with CAPS ion and RPWS electron measurements as well as iterative use of the three data sets in the analysis process will be a standard part of the data reduction process. The flyby data sets will also be combined with UVIS measurements to provide information on latitudinal, local time, and possible temporal changes in Titan atmospheric parameters. Of particular importance to the mission's investigation of Titan's atmosphere will be the correlative analysis of INMS high-altitude data and low-altitude Probe data. Analysis of data acquired in the inner magnetosphere-during the ring overflight and ring plane crossing following Saturn Orbit Insertion and during targeted encounters with the inner moons Enceladus, Dione, and Rhea — will yield species densities as a function of Orbiter position. Iterative reduction with CAPS data will be required to determine ion densities and flows.

Extensive use will be made of models in the INMS investigation, both in operations planning and in the interpretation of INMS data. Models of Titan's upper atmosphere will, for example, provide a global context for data acquired at particular local times or locations. In turn, data acquired during the tour-e.g., ion and neutral altitude profiles at Titan at different local times, latitudes, and ram anglescan be used to refine existing models and to develop three-dimensional models of the Titan upper atmosphere. Such three-dimensional models can then be incorporated in global MHD modeling studies of Titan's interaction with the external plasma flow (such as will be conducted as part of the Cassini interdisciplinary science investigation of plasma environment of Saturn's magnetosphere). Models to be used during the INMS investigation will be based on models already developed (or under development) by the INMS Science Team Members and others. These models are listed in Table X.

INMS data analysis will be coordinated with the analysis of complementary data from other Cassini experiments to ensure the maximum scientific yield from the investigation (cf. Sections 1.1.4 and 1.2.3). Data sets from other Cassini experiments relevant to the INMS investigation include: (1) reduced RSS radio occultation profiles of Titan and Saturn; (2) digitized cut-off frequencies of the Saturn Electrostatic Discharges from the RPWS investigation; (3) ion and electron distribution function data from CAPS in the ring ionosphere, from the Titan interaction region, from 
TABLE X

Models available for use in the INMS investigation.

\begin{tabular}{|c|c|}
\hline Model & Reference \\
\hline Titan neutral atmosphere & $\begin{array}{l}\text { Yung et al. (1984), Yung (1987), Toublanc et al. (1995), Lara } \\
\text { et al. (1996) }\end{array}$ \\
\hline Titan thermal structure & Yelle (1990) \\
\hline Titan ionosphere & Fox and Yelle (1997), Cravens et al. (1997), Keller et al. (1998) \\
\hline Titan ionospheric dynamics & Cravens et al. (1998), Ledvina and Cravens (1998) \\
\hline Titan TGCM & Müller-Wodarg et al. (2001) \\
\hline Ring atmosphere/ionosphere & Wilson and Waite (1989)*, Ip (1984; 1995) \\
\hline Icy satellite tori/neutral cloud & $\begin{array}{l}\text { To be produced by R.E. Johnson of the CAPS team (cf. } \\
\text { Johnson } \text { et al., 1989)/(Ip, 1997) }\end{array}$ \\
\hline Saturn atmosphere/ionosphere & Waite $(1981)^{*}$ \\
\hline Saturn TGCM & $\begin{array}{l}\text { To be adapted from Jupiter TGCM being developed under } \\
\text { Planetary Atmospheres NRA }\end{array}$ \\
\hline
\end{tabular}

*To be updated.

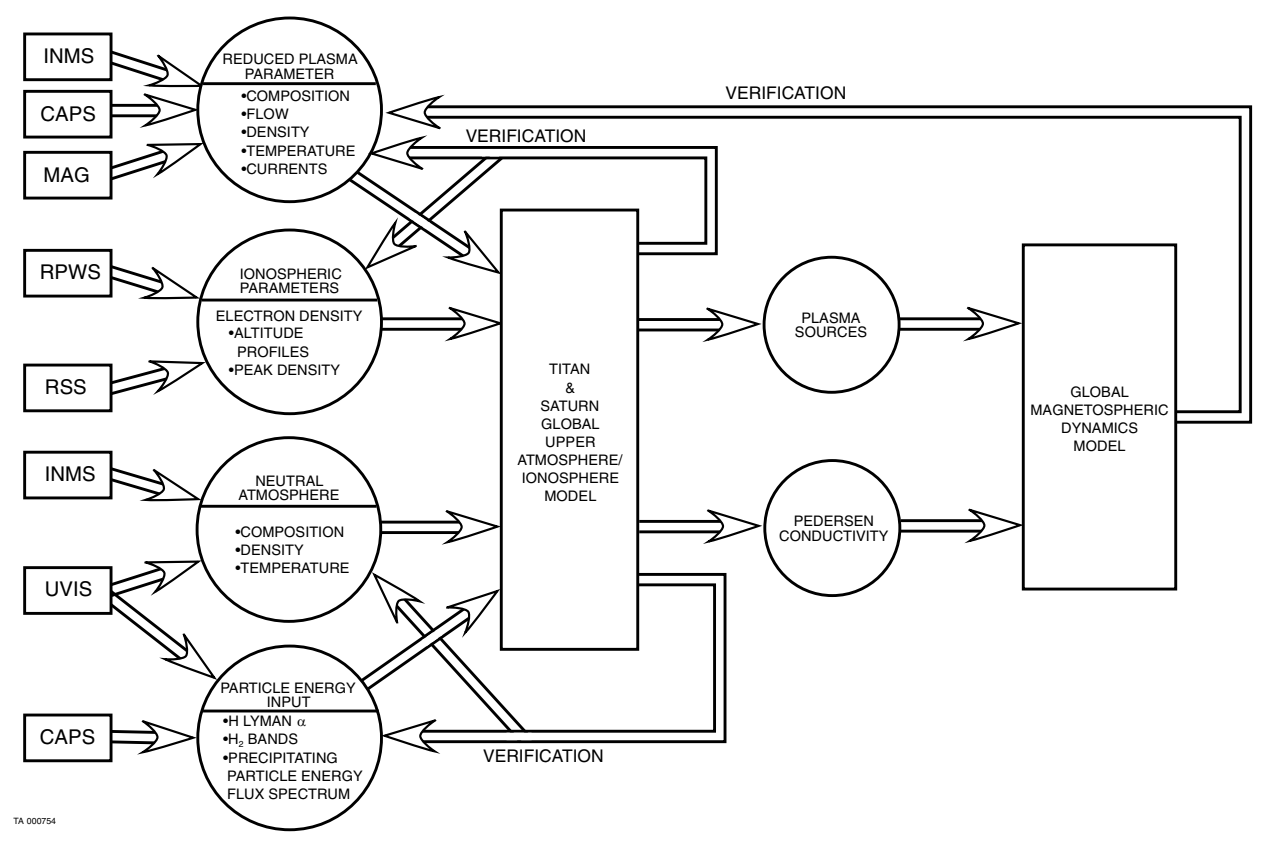

Figure 47. As illustrated in this schematic, INMS data will be integrated with the results of other Cassini experiments to address the science objectives of the Magnetosphere and Plasma Science (MAPS) working group. The working group was formed to coordinate the Cassini investigations relating to magnetospheric and plasma physical processes in the Saturn system, including two interdisciplinary theoretical investigations (Plasma Circulation and Magnetosphere-Ionosphere Coupling and Plasma Environment in Saturn's Magnetosphere). Modeling studies will play a crucial role in the interpretation of INMS data and in achieving the MAPS science goals. 
icy satellite/magnetosphere interaction regions, and in Saturn's magnetosphere; (4) reduced UVIS data on the composition and energetics of the Titan and Saturn upper atmospheres; (5) VIMS data on stratospheric structure and composition; (6) Probe data on neutral composition, aerosol formation, atmospheric dynamics, and radiative transfer in Titan's lower atmosphere; (7) MIMI images of neutral tori; and (8) MAG data. The data from other Cassini experiments will be accessed via the SOPC and will be used as inputs to models and INMS reduction routines with the agreement and collaboration of the responsible Principal Investigators.

The schematic in Figure 47 illustrates how INMS data will be used together with data from other experiments and theoretical models to address key mission science objectives - in this case, those of the Magnetosphere and Plasma Science (MAPS) Working Group.

\section{Acknowledgements}

The INMS investigation is a collaborative effort involving many talented and dedicated individuals. The authors of this paper would like to express their deep appreciation to the following people in particular for their contributions to the project: David Anderson, Dana Burket, Butch Carruth, Kristie Frick, Morgan Orcyere, Eddie Weigle, Charles Zinsmeyer (Southwest Research Institute); Robert Abell, Robert Arvey, Steven Cagiano, Dan Harpold (NASA Goddard Space Flight Center); Bette Bilodeau and Florence Tan (IDEA, Inc.); Michael Paulkovich (Jackson \& Tull); Mirl Bendt, Christina Carlson, Paul Cursey, Sharad Dixit, Edward Patrick, Eric Raaen, John Westberg (NYMA); Mark McQuaid, Doug Hawk, Rick Bitzell, Anthony Melak, Michael Barciniak (Swales \& Associates); Kenneth Arnett, Steven Battel, Bruce Block, John Maurer, Ryan Miller, John Parejko, Steve Sheppard, Erin Walter, Julia Xu (University of Michigan).

\section{References}

Anicich, V. G., and McEwan, M. J.: 1997, 'Ion-molecule chemistry in Titan's ionosphere', Planet. Space. Sci. 45, 897.

Banaszkiewicz, M., Lara, L. M., Rodrigo, R., López-Moreno, J. J., and Molina-Cuberos, G. J.: 2000, 'A coupled model of Titan's atmosphere and ionosphere', Icarus 147, 386.

Barbosa, D. D.: 1987, 'Titan's atomic nitrogen torus: Inferred properties and consequences for the Saturnian aurora', Icarus 72, 53.

Barbosa, D. D.: 1990, 'Radial diffusion in Saturn's magnetosphere', J. Geophys. Res. 95, 17167.

Bird, M. K., et al.: 1997, 'Detection of Titan's ionosphere from Voyager 1 radio occultation observations,' Icarus 130, 426.

Brecht, S. H., Luhmann, J. G., and Larson, D. J.: 2000, 'Simulation of the Saturnian magnetospheric interaction with Titan', J. Geophys. Res. 105, 13119. 
Bridge, H. A., et al.: 1981, 'Plasma observations near Saturn: Initial results from Voyager 1', Science 212, 217.

Bridge, H. A., et al.: 1982, 'Plasma observations near Saturn: Initial results from Voyager 2', Science 215, 563 .

Broadfoot, A. L., et al.: 1981, 'Extreme ultraviolet observations from Voyager 1 encounter with Saturn', Science 212, 206

Carlson, R. W.: 1980, 'Photo-sputtering of ice and hydrogen around Saturn's rings', Nature 283, 461.

Capone, L. A., Dubach, J., Prasad, S. S., and Whitten, R. C.: 1983, 'Galactic cosmic rays and $\mathrm{N}_{2}$ dissociation on Titan', Icarus $\mathbf{5 5}, 73$.

Chappell, C. R., Moore, T. E., and Waite, J. H., Jr.: 1987, 'The ionosphere as a fully adequate source of plasma for the Earth's magnetosphere', J. Geophys. Res. 92.

Chassefière, E., and Cabane, M.: 1995, 'Two formation regions for Titan's hazes: Indirect clues and possible synthesis mechanisms', Planet. Space Sci. 43, 91.

Clarke, J. T., Trauger, J., and Waite, J. H., Jr.: 1989, 'Doppler-shifted H Ly $\alpha$-emission from Jupiter's aurora', Geophys. Res. Lett. 16, 587.

Comas Solá, J.: 1908, 'Observations des satellites principeaux de Jupiter et de Titan', Astron. Nach. 179, 289.

Connerney, J. E. P. and Waite, J. H., Jr.: 1984, 'New model of Saturn's ionosphere with an influx of water from the rings', Nature 312, 136.

Courtin, R., Gautier, D., and McKay, C. P.: 1995, 'Titan's thermal emission spectrum: Reanalysis of the Voyager infrared measurements', Icarus 114, 144.

Coustenis, A., et al.: 1989, 'Titan's atmosphere from Voyager infrared observations', Icarus 80, 54.

Coustenis, A., et al:: 1991, 'Titan's atmosphere from Voyager infrared observations. III. Vertical distributions of hydrocarbons and nitriles near Titan's north pole', Icarus 89, 152.

Coustenis, A., et al.: 1998, 'Evidence for water vapor in Titan's atmosphere from ISO/SWS data', Astron. Astrophys. 336, L85.

Coustenis, A., et al.: 2003, 'Titan's atmosphere from ISO mid-infrared spectroscopy', Icarus 161, 383.

Cravens, T. E., Keller, C. N., and Ray, B.: 1997, 'Photochemical sources of non-thermal neutrals for the exosphere of Titan', Planet. Space Sci. 45, 889.

Cravens, T. E., Lindgren, C. J., and Ledvina, S. A.: 1998, 'A two-dimensional MHD model of Titan's plasma environment', Planet. Space Sci. 46, 1193.

Cravens, T. E., Vann, J., Clark, J., Yu, J., Keller, C. N., and Brull, C.: 2004, 'The ionosphere of Titan: An updated theoretical model, Adv. Space Res. 33, 212.

Edgington, S. G., et al.: 1998, 'On the latitude variation of ammonia, acetylene, and phosphine altitude profiles on Jupiter from HST Faint Object Spectrograph observations', Icarus 133, 192 209.

Eviatar, A. and Podolak, M.: 1983, 'Titan's gas and plasma torus', J. Geophys. Res. 88, 833.

Eviatar, A. and Richardson, J. D.: 1990, 'Water group plasma in the magnetosphere of Saturn', Ann. Geophys. 8, 725.

Eviatar, A. and Richardson, J. D.: 1992, 'Thermal plasma in the inner kronian magnetosphere', Ann. Geophys. 10, 511.

Fox, J. L. and Yelle, R. V.: 1997, 'Hydrocarbon ions in the ionosphere of Titan', Geophys. Res. Lett. 24, 2179.

Frank, L. A., et al.: 1980, 'Plasmas in Saturn's magnetosphere', J. Geophys. Res. 85, 5695.

Friedson, A. J. and Yung, Y. L.: 1984, 'The thermosphere of Titan', J. Geophys. Res. 89, 85.

Galand, M., et al.: 1999, 'The ionosphere of Titan: Ideal diurnal and nocturnal cases', Icarus 140, 92.

Gan, L., Cravens, T. E., and Keller, C. N.: 1992, 'Electrons in the ionosphere of Titan', J. Geophys. Res. 97, 12137. 
Gan-Baruch, Z., et al.: 1994, 'Plasma observations in the ring plane of saturn', J. Geophys. Res. 99, 11063.

Gautier, D. and Raulin, F.: 1997, 'Chemical composition of Titan's atmosphere', in Huygens: Science, Payload, and Mission, ESA Publication SP-1177, European Space Agency, Noordwijk, The Netherlands.

Gurnett, D. A., Kurth, W. S., and Scarf, F. L.: 1981, 'Plasma waves near Saturn: Initial results from Voyager 1', Science 212, 235.

Gurnett, D. A., Scarf, F. L., and Kurth, W. S.: 1982, 'The structure of Titan's wake from plasma wave observation', J. Geophys. Res. 87, 1395.

Hall, D. T., et al.: 1996, 'Fluorescent hydroxyl emissions from Saturn's ring atmosphere', Science 272, 516.

Hamilton, D. C. and Burns, J. A.: 1993, 'OH in Saturn's rings', Nature 365, 550.

Hamilton, D. C., et al.: 1981, 'Composition of nonthermal ions in the Jovian magnetosphere', $J$. Geophys. Res. 86, 8301.

Hamilton, D. C., et al.: 1983, 'Energetic atomic and molecular ions in Saturn's magnetosphere', J. Geophys. Res. 88, 8905.

Hanel, R., et al.: 1981, 'Infrared observations of the Saturnian system from Voyager 1', Science 212, 192.

Hartle, R. E., et al.: 1982, 'Titan's ion exosphere observed from Voyager 1', J. Geophys. Res. 87, 1383.

Hidayat, T., et al.: 1997, 'Millimeter and submillimeter heterodyne observations of Titan: Retrieval of the vertical profile of $\mathrm{HCN}$ and the ${ }^{12} \mathrm{C} /{ }^{13} \mathrm{C}$ ratio', Icarus 126, 170.

Hidayat, T., et al.: 1998, 'Millimeter and submillimeter heterodyne observations of Titan: The vertical profile of carbon monoxide in its stratosphere', Icarus 133, 109.

Hilton, D. A. and Hunten, D. M.: 1988, 'A partially collisional model of the Titan hydrogen torus', Icarus 73, 248.

Hunten, D. M.: 1972, 'The atmosphere of Titan', Comments Astrophys. Space Phys. 4, 149.

Hunten, D. M., et al.: 1984, 'Titan', in T. Gehrels and M. S. Matthews (eds.), Saturn, University of Arizona Press, Tucson, AZ, pp. 671-759.

Ip, W.-H.: 1984, 'The ring atmosphere of Saturn: Monte Carlo simulation of ring source models', $J$. Geophys. Res. 89, 8843.

Ip, W.-H.: 1990, 'Titan's upper ionosphere', Astrophys. J. 362, 354.

Ip, W.-H.: 1995, 'The exospheric systems of Saturn's rings', Icarus 115, 295.

Ip, W.-H.: 1997, 'On the neutral cloud distribution in the saturnian magnetosphere', Icarus 126, 42.

Johnson, R. E.: 1998, 'Sputtering and desorption from icy surfaces', in B. Schmitt et al. (eds.), Solar System Ices, Kluwer Academic Publishers, The Netherlands, pp. 303-334.

Johnson, R. E. and Sittler, E. C.: 1990, 'Sputter-produced plasma as a measure of satellite surface composition-The Cassini mission', Geophys. Res. Lett. 17, 1729.

Johnson, R. E., et al.: 1989, 'The neutral cloud and heavy ion inner torus at Saturn', Icarus 77, 311.

Judge, D. L., Wu, F.-M., and Carlson, R. W.: 1980, 'Ultraviolet photometer observations of the Saturnian system', Science 207, 431.

Jurac, S., Johnson, R. E., and Richardson, J. D.: 2001a, 'Saturn's E ring and the production of the neutral torus', Icarus 149, 384.

Jurac, S., Johnson, R. E., Richardson, J. D., and Paranicas, C.: 2001b, 'Satellite sputtering in Saturn's magnetosphere', Planet. Space Sci. 49, 319.

Kabin, K., et al:: 1999, 'Interaction of the Saturnian magnetosphere with Titan: Results of a threedimensional MHD simulation', J. Geophys. Res. 104, 2451.

Kasprzak, W. T., Niemann, H. B., and Mahaffy, P.: 1987, 'Observations of energetic ions on the nightside of Venus', J. Geophys. Res. 92, 291. 
Kasprzak, W. T., et al.: 1996, 'Cassini orbiter ion and neutral mass spectrometer instrument', SPIE Proc. 2803, 129.

Keller, C. N. and Cravens, T. E.: 1994, 'One-dimensional multispecies hydrodynamic models of the wakeside ionosphere of Titan', J. Geophys. Res. 99, 6527.

Keller, C. N., Cravens, T. E., and Gan, L.: 1992, 'A model of the ionosphere of Titan', J. Geophys. Res. 97, 12117.

Keller, C. N., Cravens, T. E., and Gan, L.: 1994, 'One-dimensional multispecies magnetohydrodynamic models of the ramside ionosphere of Titan', J. Geophys. Res. 99, 6511.

Keller, C. M., Anicich, V. G., and Cravens, T. E.: 1998, 'Model of Titan's ionosphere with detailed hydrocarbon chemistry', Planet. Space Sci. 46. 1157.

Khurana, K. K., Kivelson, M. G., and Russell, C. T.: 1997, 'Interaction of Io with its torus: Does Io have an internal magnetic field?', Geophys. Res. Lett. 34, 2391.

Kiser, R. W.: 1965, Introduction to Mass Spectrometry and Its Applications, Prentice-Hall, Inc., Englewood Cliffs, NJ.

Kivelson, M. G. and Russell, C. T.: 1983, 'The interaction of flowing plasmas with planetary ionospheres: A Titan-Venus comparison', J. Geophys. Res. 88, 49.

Kivelson, M. G., et al.: 1996, 'Discovery of Ganymede's magnetic field by the Galileo spacecraft', Nature 384, 537.

Kostiuk, T., et al.: 1997, 'Ethane abundance on Titan', Planet. Space Sci. 45, 931.

Kuiper, G. P.: 1944, 'Titan: A satellite with an atmosphere', Astrophys. J. 100, 378.

Kunde, V. G., et al.: 1981, ' $\mathrm{C}_{4} \mathrm{H}_{2}, \mathrm{HC}_{3} \mathrm{~N}$, and $\mathrm{C}_{2} \mathrm{~N}_{2}$ in Titan's atmosphere', Nature 292, 686.

Lammer, H. and Bauer, S. J.: 1991, 'Nonthermal atmospheric escape from Mars and Titan', J. Geophys. Res. 96, 1819.

Lammer, H. and Bauer, S. J.: 1993, 'Atmospheric mass loss from Titan by sputtering', Planet. Space Sci. 41, 657.

Lanzerotti, L. J., et al.: 1983, 'Implications of Voyager data for energetic ion erosion of the icy satellites of Saturn', J. Geophys. Res. 88, 8765.

Lara, L. M., et al.: 1996, 'Vertical distribution of Titan's atmospheric neutral constituents', J. Geophys. Res. 101, 23261.

Lazarus, A. J. and McNutt, R. L., Jr.: 1983, 'Low energy plasma ion observations in saturn's magnetosphere', J. Geophys. Res. 88, 8831 .

Ledvina, S. A. and Cravens, T. E.: 1998, 'A three-dimensional MHD model of plasma flow around Titan', Planetary and Space Sci. 46, 1175.

Lellouch, E., et al.: 1989, 'Titan's atmosphere and hypothesized ocean: A reanalysis of the Voyager 1 radio-occultation and IRIS 7.7- $\mu \mathrm{m}$ data', Icarus $\mathbf{7 9}, 328$.

Lellouch, E., et al.: 1990, 'Titan's thermosphere profile', Icarus 83, 308.

Lewis, J. S.: 1971, 'Satellites of the outer planets: Their physical and chemical nature', Icarus 15, 174.

Lindal, G. F., et al.: 1983, 'The atmosphere of Titan: An analysis of the Voyager 1 radio occultation measurements', Icarus 53, 348.

Luhmann, J. G.: 1996, 'Titan's ion exosphere wake: A natural ion mass spectrometer?', J. Geophys. Res. 101, 29387.

Luhmann, J. G. and Walker, R. J.: 1981, 'Model exospheres of the ringed planets', Geophys. Res. Lett. 8, 107.

Luhmann, J. G., et al.: 1991, 'A comparison of induced magnetotails of planetary bodies: Venus, Mars, and Titan', J. Geophys. Res. 96, 11199.

Lunine, J. I.: 1993, 'Does Titan have an ocean? A review of current understanding of Titan's surface', Rev. Geophys. 31, 133.

Lunine, J. I.: 1994, 'Does Titan have oceans?', Am. Scientist 82, 136.

Lunine, J. I., Stevenson, D. J., and Yung, Y. L.: 1983, 'Ethane ocean on Titan', Science 222, 1229. 
Lutz, B. L., deBergh, C., and Owen, T.: 1983, 'Titan: The discovery of carbon monoxide in its atmosphere', Science 220, 1374.

Maguire et al:: 1981, ' $\mathrm{C}_{3} \mathrm{H}_{8}$ and $\mathrm{C}_{3} \mathrm{H}_{4}$ in Titan's atmosphere', Nature 292, 683.

Mahaffy, P. M. and Lai, K.: 1990, 'An electrostatic quadrupole deflector for mass spectrometer applications', J. Vac. Sci. A8, 3244.

Matheson, P. L. and Shemansky, D. E.: 1996, 'Magnetospheric neutral clouds from Saturn's icy satellites' (abstract), Bull. Am. Astron. Soc., Division of Planetary Sciences meeting.

McNutt, R. L., Jr. and Richardson, J. D.: 1988, 'Constraints on Titan's ionsphere', Geophys. Res. Lett. 15, 709.

Morfill, G. E., et al.: 1983, 'Some consequences of meteoroid impacts on Saturn's rings', Icarus 55, 439.

Müller-Wodarg, I. C. F., and Yelle, R. V.: 2002, 'The effect of dynamics on the composition of Titan's upper atmosphere', Geophys. Res. Lett. 29, 54-1, doi 10.1029/2002GL016100.

Müller-Wodarg, I. C. F., Yelle, R. V., Mendillo, M., Young, L. A., and Aylward, A. D.: 2000, 'The thermosphere of Titan simulated by a global three-dimensional time-dependent model', J. Geophys. Res. 105, 20833.

Nagy, A. F. and Cravens, T. E.: 1998, 'Titan's ionosphere: A review', Planet. Space Sci. 46, 1149.

Nagy, A. F., Barakat, A. R., and Schunk, R. W.: 1986, 'Is Jupiter's ionosphere a significant plasma source for its magnetosphere?', J. Geophys. Res. 91, 351.

Ness, N. F., Acuna, M. H., Behannon, K. W., and Neubauer, F. M.: 1982, 'The induced magnetosphere of Titan', J. Geophys. Res. 87, 1369.

Neubauer, F. M., et al.: 1984, 'Titan's magnetospheric interaction', in T. Gehrels and M. S. Matthews (eds.), Saturn, University of Arizona Press, Tucson, AZ, pp. 760-787.

Niemann, H. B., et al.: 1997, 'The gas chromatograph mass spectrometer aboard Huygens', in Huygens: Science, Payload and Mission ESA SP 1177, p. 85.

Owen, T.: 1982, 'The composition and origin of Titan's atmosphere', Planet. Space Sci. 30, 833.

Pospieszalska, M. K. and Johnson, R. E.: 1989, 'Magnetospheric ion bombardment profiles of satellites-Europa and Dione', Icarus 78, 1.

Pospieszalska, M. K. and Johnson, R. E.: 1991, 'Micrometeorite erosion of the main rings as a source of plasma in the inner Saturnian plasma torus', Icarus 93, 45.

Richardson, J. D.: 1986, 'Thermal ions at Saturn: Plasma parameters and implications', J. Geophys. Res. 91, 1381.

Richardson, J. D.: 1998, 'Thermal plasma and neutral gas in Saturn's magnetosphere', Rev. Geophys. 36, 501.

Richardson, J. D. and Sittler, E. C., Jr.: 1990, 'A plasma density model for Saturn based on Voyager observations', J. Geophys. Res. 95, 12019.

Richardson, J. D., Eviatar, A., and Siscoe, G. L.: 1986, 'Satellite tori at Saturn', J. Geophys. Res. 91, 8749.

Richardson, J. D., et al.: 1998, 'OH in Saturn's magnetosphere: Observations and implications', J. Geophys. Res. 103, 20245.

Rishbeth, H., Yelle, R. V., and Mendillo, M.: 2000, 'Dynamics of Titan's thermosphere', Planet. Space Sci. 48, 51.

Roboz, A. and Nagy, A. F.: 1994, 'The energetics of Titan's ionosphere', J. Geophys. Res. 99, 2087.

Samuelson, R. E., et al:: 1981, 'Mean molecular weight and hydrogen abundance in Titan's atmosphere', Nature 292, 688.

Samuelson, R. E., et al.: 1983, 'CO 2 on Titan', J. Geophys. Res. 88, 8709.

Samuelson, R. E., Nath, N. R., and Borysow, A.: 1997, 'Gaseous abundances and methane supersaturation in Titan's atmosphere', Planet. Space. Sci. 45, 959. 
Sandel, B. R., et al.: 1982, 'Extreme ultraviolet observations from the Voyager 2 encounter with Saturn', Science 215, 548.

Schardt, A. W., et al.: 1984, 'The outer magnetosphere', in T. Gehrels and M. S. Matthews (eds.), Saturn, University of Arizona Press, Tucson, AZ, pp. 416-459.

Shemansky, D. E. and Hall, D. T.: 1992, 'The distribution of atomic hydrogen in the magnetosphere of Saturn', J. Geophys. Res. 97, 4143.

Shemansky, D. E., et al.: 1993, 'Detection of the hydroxyl radical in the Saturn magnetosphere', Nature 363, 329.

Shi, M., et al.: 1995, 'Sputtering of water ice surfaces and the production of extended neutral atmospheres', J. Geophys. Res. 100, 26387.

Smith, G. R., et al.: 1982, 'Titan's upper atmosphere: Composition and temperature from the EUV solar occultation results', J. Geophys. Res. 87, 1351.

Smyth, W. H. and Marconi, M. L.: 1993, 'The nature of the hydrogen tori of Titan and Triton', Icarus 101, 18.

Strobel, D. F. and Shemansky, D. E.: 1982, 'EUV emission from Titan's upper atmosphere: Voyager 1 encounter', J. Geophys. Res. 87, 1361.

Strobel, D. F., Meier, R. R., Summers, M. E., and Strickland, D. J.: 1991, 'Nitrogen airglow sources: Comparison of Triton, Titan, and Earth', Geophys. Res. Lett. 18, 689.

Strobel, D. F., Summers, M., and Zhu, X.: 1992, 'Titan's upper atmosphere: Structure and ultraviolet emissions', Icarus 100, 512.

Strobel, D. F., et al.: 1993, 'Upper limit on Titan's atmospheric argon abundance', Icarus 103, 333.

Swaminathan, V., Alig, R., Murray, W., and Sarnoff, D.: 1996, 'Design of an improved miniature ion neutral mass spectrometer for NASA applications', NASA Contract NAS5-32823.

Taylor, F. W. and Coustenis, A.: 1998, 'Titan in the solar system', Planet. Space Sci. 46, 1085.

Thompson, W. R., McDonald, G. D., and Sagan, C.: 1994, 'The Titan haze revisited: Magnetospheric energy sources and quantitative tholin yields', Icarus 112, 376.

Toublanc, D.: 1995, 'Photochemical modeling of Titan's atmosphere', Icarus 113, 2.

Trafton, L. M.: 1972, 'On the possible detection of $\mathrm{H}_{2}$ in Titan's atmosphere', Astrophys. J. 175, 285.

Vervack, R. J., Jr.: 1997, 'Titan's upper atmospheric structure derived from Voyager ultraviolet spectrometer observations', Ph.D. dissertation, The University of Arizona, Tucson, AZ.

Vervack, R. J., Jr., Sandel, B. R., and Strobel, D. F.: 2004, 'New perspectives on Titan's upper atmosphere from a reanalysis of the Voyager 1 uvs solar occultations by Titan', Icarus, 170, 91.

Waite, J. H., Jr.: 1981, ‘The ionosphere of Saturn', Ph.D. dissertation, University of Michigan, Ann Arbor, MI.

Weiser, H., Vitz, C., and Moos, H. W.: 1977, 'Detection of Lyman alpha emission from the Saturnian disk and from the ring system', Science 197, 755.

Wilson, E. H.: 2002, 'Investigations into the photochemistry of the current and primordial atmosphere of Titan', Ph.D. Thesis, University of Michigan, Ann Arbor, MI.

Wilson, G. R. and Waite, J. H., Jr.: 1989, 'Kinetic modeling of the Saturn ring-ionosphere plasma environment', J. Geophys. Res. 94, 17287.

Wolf, D. A. and Neubauer, F. M.: 1982, 'Titan's highly variable plasma environment', J. Geophys. Res. 87, 881.

Yelle, R. V.: 1991, 'Non-LTE models of Titan's upper atmosphere', Astrophys. J 383, 380.

Yelle, R. V., et al.: 1997, 'Engineering models for Titan's atmosphere', in Huygens: Science, Payload, and Mission, ESA Publication SP-1177, European Space Agency, Noordwijk, The Netherlands.

Yung, Y. L.: 1987, 'An update of nitrile photochemistry on Titan', Icarus 72, 468.

Yung, Y. L., Allen, M., and Pinto, J. P.: 1984, 'Photochemistry of the atmosphere of Titan: Comparison between model and observations', Astrophys. J. Suppl. 55, 465. 